\title{
Environment, Safety and Health Progress Assessment of the
}

\section{Idaho National Engineering Laboratory (INEL)}

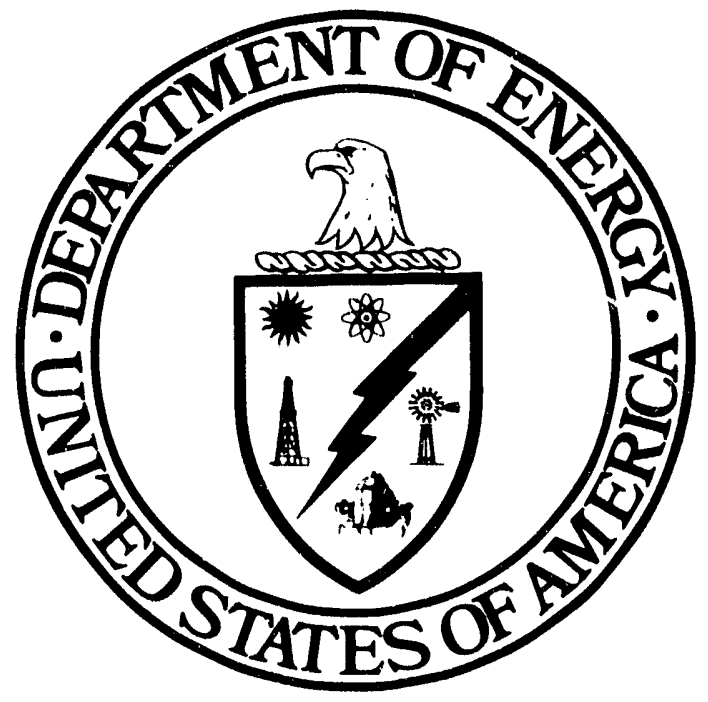

\section{U.S. Department of Energy} Washington, DC 20585 


\section{TABLE OF CONTENTS}

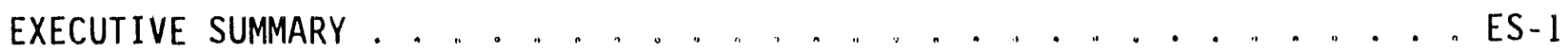

1.0 INTRODUCTION . . . . . . . . . . . . . . . . . . . 1 . 1

1.1 Environment, Safety and Health Progress Assessment Program . 1-1

1.2 Idaho National Engineering Laboratory . . . . . . . . . 1-3

1.3 Report Structure ................... $1-4$

2.0 PERFORMANCE AND PROGRESS OF INEL ES\&H PROGRAMS . . . . . . . . . . 2 -1

2.1 Overview .................... 2-1

2.1.1 Key Concern ................... 2-1

2.1 .2 Root Cause................... 2-2

2.1.3 Strengths ................... 2-3

2.2 Overview of ES\&H Management Systems Assessment . . . . . 2-3

2.2.1 Corrective Action Program ... . . . . . . . 2-6

2.2.2 Self-Assessment Program . . . . . . . . . . 2-10

2.2.3 Oversight . . . . . . . . . . . . . . . . 2-13

2.2.4 Directives, Policies, and Procedures . . . . . . . 2-17

2.2.5 Human Resources Management . . . . . . . . . . . 2-20

2.2.6 Planning, Budgeting, and Resource Allocation... . 2-23

2.3 Overview of Environmental Program Assessment . . . . . . . 2-26

2.3.1 Air Quality Management Programs . . . . . . . . 2-28

2.3.2 Surface Water Management Programs . . . . . . . . . 2-31

2.3.3 Groundwater Protection Programs . . . . . . . . 2-34

2.3.4 Environmental Radiation Programs . . . . . . . . 2-37

2.4 Overview of Safety and Health Program Assessment . . . . . 2-40

2.4.1 Construction Safety Programs . . . . . . . . . . 2-44

2.4.2 Worker Safety and OSHA Programs .. . . . . . . . 2-45

2.4.3 Maintenance Programs . . . . . . . . . . . . . . 2-50

2.4.4 Packaging and Transportation Programs . . . . . . 2-52

2.4.5 Site/Facility Safety Review Programs . . . . . . . . 2-55

2.4.6 Industrial Hygiene Programs . . . . . . . . . 2-58 


\section{LIST OF APPENDICES}

Appendix A Summary Table of Concerns, Weaknesses, and Strengths . . . A-1 Appendix B Concerns, Weaknesses, and Strengths by Discipline

B-1 Assessment Details - ES\&H Management Systems/ Concerns, Weaknesses, and Strengths........... B-1-1

B-2 Assessment Details - Environment Programs/ Concerns and Strengths .............. B-2-1

B-3 Assessment Details - Safety and Health Programs/ Concerns, Weaknesses, and Strengths ......... B-3-1

Appendix C Biographical Sketches of Team Members . . . . . . . . . . C-l Appendix D Progress Assessment Scopes . . . . . . . . . . . . . D-1 Appendix E Schedule of Onsite Activities . . . . . . . . . . . . . E-1 Appendix $F$ List of Contacts and Interviews . . . . . . . . . . . . F-1 Appendix G List of Site Documents Reviewed . . . . . . . . . . . . G-1 Appendix $\mathrm{H}$ List of Acronyms .................... . . H-1 
Executive Summary 


\section{EXECUTIVE SUMMARY}

This report documents the results of the U.S. Department of Energy's (DOE) Environment, Safety and Health (ES\&H) Progress Assessment of the Idaho National Engineering Laboratory (INEL) in Idaho Falls, Idaho. The onsite assessment, which was conducted from July 26 through August 10, 1993, included a review of selective environment, safety, and health management systems and programs of the responsible DOE Headquarters Program Office, the Office of Nuclear Energy (NE); the DOE Operations Office, Idaho (ID); the DOE Headquarters Office of Environmental Restoration and Waste Management (EM); and the site contractors EG\&G Idaho, Inc. (EG\&G Idaho), Westinghouse Idaho Nuclear Company (WINCO), Babcock \& Wilcox Idaho (B\&W), Protection Technology Idaho (PTI), and MK-Ferguson of Idaho Co. (MK-FIC).

The ES\&H Progress Assessments are part of the Department's continuous improvement process throughout DOE and its contractor organizations. The purpose of the INEL ES\&H Progress Assessment is to provide the Department with concise independent information on the following: (1) change in culture and attitude related to ES\&H activities; (2) progress and effectiveness of the ES\&H corrective actions resulting from previous Tiger Team Assessments; (3) adequacy and effectiveness of the ES\&H self-assessment programs of the DOE line organizations and the site management and operating contractor; and (4) effectiveness of DOE and contractor management structures, resources, and systems to effectively address ES\&H problems. It is not intended that this Progress Assessment be a comprehensive compliance assessments of ES\&H activities. The points of reference for assessing programs at the INEL were, for the most part, the 1991 INEL Tiger Team Assessment, the INEL Corrective Action Plan, and recent appraisals and self-assessments of INEL. Horizontal and vertical reviews of the following programmatic areas were conducted:

Management: $\quad$ corrective action program; self-assessment; oversight; directives, policies, and procedures; human resources management; and planning, budgeting, and resource allocation.

Environment: $\quad$ air quality management, surface water management, groundwater protection, and environmental radiation.

Safety construction safety, worker safety and OSHA, maintenance, and Health: packaging and transportation, site/facility safety review, and industrial hygiene.

The INEL Progress Assessment was conducted by a team of 13 professionals from various DOE offices and their support contractors, with technical and management expertise in the areas of environment, safety, and health.

Established in 1949 as the National Reactor Testing Station, INEL now contains the largest concentration of nuclear reactors in the world. Fifty-two reactors have been built, 12 of which are still operable; the others were phased out upon completion of their missions. In 1974, the site's name was changed to the Idaho National Engineering Laboratory to better characterize current projects, which now include research engineering for non-nuclear and nuclear energy programs. INEL employs approximately 11,000 people. 
The INEL mission is to provide the nation with innovations in nuclear technologies and unique scientific and engineering capabilities in non-nuclear programs that provide commercialization potential or enhance the quality of the environment.

\section{Progress in ES\&H Performance}

The Progress Assessment Team concluded that progress has been made in virtually all of the ES\&H programs that were reviewed. Especially noteworthy improvement was noted in addressing the high risk concerns, as defined by the Tiger Team Assessment, in the area of construction safety. The INEL contractor programs have displayed substantial progress and ID's effective use of the Cost Plus Award Fee (CPAF) process has been a constructive influence on the progress. Deficiencies in many of the areas reviewed had been selfidentified by ID. However, ID has not yet fully developed and implemented the management systems necessary to assure with a high degree of confidence that ES\&H risks are appropriately prioritized and effectively managed on a sitewide basis. The degree of formality with respect to ID policies, programs, procedures, and oversight is viewed by the team as insufficient to provide assurance that the aforementioned progress will be sustained and further enhanced in light of an environment of continuous change. This lack of formality may limit the ability of ID to identify higher level risks and effectively apply limited resources in the most cost-effective manner. The variety of ongoing and potential future programs at INEL introduces a complex spectrum of potential risks involving life, health, environment, property, programs, civil penalties, criminal penalties, and credibility with Federal, state, and local institutions and the media and ultimately the public at large. The task of managing this complex spectrum of risks is made all the more difficult by the extraordinary degree of change throughout the Department of Energy and the regulatory community in general, and specifically within the ID operations.

Examples of changes within DOE include: the profusion of new and revised DOE ES\&H Orders, the initiation of significant new processes in DOE such as self-assessment, the development of and increasing activities of the Defense Nuclear Facilities Safety Board, the implementation of the Office of the Assistant Secretary for Environment, Safety and Health (EH) and the Office of Nuclear Safety (NS) site representatives programs, the change in DOE Headquarters structure for Field Office interfaces, and the dramatic changes in DOE programs. Examples of change within the ID operations include: changes in the INEL mission; the change underway in the contracting arrangement for INEL; the bold reorganization of ID, which is just in the process of being implemented; and the large number of new employees in ID. Nor is it likely that this environment of change will diminish anytime in the foreseeable future. For example, it is anticipated that DOE will implement the codification of nuclear safety rules; the U.S. Congress is considering significant changes in ES\&H related law: such as the Occupational Safety and Health Act (OSHA); and there will be an ongoing effort to establish new engineering and technology programs at INEL.

The Progress Assessment Team believes that the unprecedented environment of change discussed above may have discouraged the pursuit of a formal, disciplined, documented approach to the management of ES\&H programs; an approach which serves the long range goals, but is often seen as of less benefit to the short-term or immediate concerns. 
The key concern and the associated root cause reflect the principal conclusions of the team. It is the belief of the team that an adjustment of priorities by ID to adopt a higher level of formality with respect to the ES\&H programs will enhance ID's ability to manage risk, thereby producing a substantial long-term benefit to the current and future programs at INEL. The team recognizes the fundamental principle that documentation and formality should serve as a tool, and therefore as a benefit rather than a burden. Thus, a graded approach in the application of formality is not only appropriate, but essential. With respect to ES\&H management systems, the degree of formality should be determined through judicious application of risk management principles.

The prioritization of resources based on risk and cost-effective application of resources is the essential element of an ES\&H program that has as a goal the achievement of excellence. Excellence within the context of ES\&H by definition necessitates the establishment and maintenance of a favorable risk profile. In order to achieve such a risk posture, the highest ES\&H priorities should be those that produce the greatest risk reduction per resources expended. This process necessarily requires a clear and continuously updated understanding of the risk profiles of the operations. Judicious application of risk management principles will tend to produce the most favorable risk profile for a given level of resources.

\section{Management}

The Progress Assessment Team's examination of the overall effectiveness of INEL ES\&H management systems resulted in a conclusion that INEL has made progress in improving the management systems subsequent to the 1991 Tiger Team Assessment, but that further improvements are necessary to achieve the level of excellence DOE and INEL management expect.

INEL self-assessment' and corrective action programs evidence progress. All of the INEL contractor organizations have developed and are using their own self-assessment processes as a management tool for improvement. However, taken collectively, these systems do not yet provide a sitewide system to capture ES\&H deficiencies, establish the risk-based priority of corrective actions, provide trend analyses, perform root cause analyses, and provide lessons learned. ID has not yet provided formal guidance and direction to ID organizations or INEL contractors to ensure the development of sitewide self-assessment programs that produce consistent and meaningful data. ID has initiated a management information system known as the Compliance Management System in order to resolve Tiger Team Assessment issues. In addition, ID has identified internal issues since the Tiger Team Assessment. However, ID has not accorded priority to and the resources for the aggressive resolution of the Tiger Team Assessment and self identified management issues. Most environmental and management corrective action plans involving major sitewide issues remain to be closed.

ES\&H oversight, directives, policies, and procedures programs at INEL have improved. ID improvements have been made in the areas of quality assurance $(Q A)$; the application of the CPAF process to improving contractor environmental, safety, and health performance; safety and health performance at the Radiological and Environmental Services Laboratory (RESL); the Facility 
Representatives program; and new technical area ID Supplemental Directives. Deficiencies identified included a lack of formality in documenting line oversight activities and findings; improper resolution of the Tiger Team Assessment identified stop work and restart authority issues; the lack of direction on systemic oversight related issues identified through ID independent oversight; the development, upgrading, and maintenance of "ID policies and procedures; and a non-adherence to established ID procedures. Furthermore, the team noted that the documentation associated with the newly authorized ID organization appears to reflect an overall reduction in the independence, authority, visibility, and senior management attention to ES\&H oversight.

Progress has been made in improving the ID directives and procedures system in that a directives manager has been assigned and a QA Working Group has been established. However, ID management has not dedicated the resources necessary to ensure timely and effective action to correct fundamental weaknesses in this key management system. INEL contractor organizations have made progress in establishing, improving, and implementing formal systems for directives and procedures; the number and performance of ES\&H oversight committees; and the scheduling, conduct, and formality of independent and line oversight appraisals and surveillance activities.

Substantial progress has been made in the implementation of strategic planning at INEL since the 1991 Tiger Team Assessment. ID and its contractors have adopted a strategic, sitewide planning perspective; ES\&H considerations appear to be an integral part of the INEL strategic planning; and all the INEL contractors appear to be full and active participants in the planning process. However, the mechanism is not fully defined to assure that industrial hygiene and environmental sitewide risks are captured and identified in subordinate implementation plans to meet the objectives of the strategic plan. ID is using the CPAF process effectively to influence the ES\&H performance of its contractors. However, ID subordinate implementation planning processes are virtually nonexistent and the INEL contractors' planning processes are not yet fully functional. For example, adequate implementation plans for addressing known deficiencies in the ID policy and procedure systems and for the INEL self-assessment program have not been developed or implemented to drive these issues to resolution. Furthermore, ID lacks a detailed reorganization implementation plan that specifies the essential activities that must accompany or follow a major organizational realignment.

ID has had a positive impact on INEL Human Resource Management. All INEL contractor human resources management programs evidence substantial improvement over the past 2 years, including the WINCO program which was judged to be a relatively strong program during the Tiger Team Assessment. The ID employee skill profile has experienced a dramatic improvement in the percentage of technical staff, and the percentage of engineers and scientists has increased to a level greater than 60 percent of total staff from a level of less than 30 percent 3 years earlier. While the ID program line organization's ES\&H oversight has been strengthened, the lower priority accorded independent ES\&H oversight that the Tiger Team Assessment identified still persists. 


\section{Environment}

The Progress Assessment Team's review of the environmental program resulted in a conclusion that INEL has made good progress, in the areas reviewed, in further developing the environmental compliance programs and in implementing the restoration program since the 199l Tiger Team Assessment. Also, the site has established excellent communications among ID and its contractors, and Federal and state environmental agencies.

However, several deficiencies inhibit ID's ability to achieve excellence in the environmental compliance program. In many instances, ID is implementing elements of the environmental program without fully integrating rigor and formality into program implementation and operational planning, particularly with respect to the management of sitewide INEL issues. Progress in the environmental compliance area has been largely due to the efforts of informal staff level committees that are working to address sitewide environmental issues. As such, ID management has not provided the authority, commensurate with qualifications and responsibility, to an organization(s) with responsibility for both ensuring sitewide environmental compliance and implementing the requirements of DOE 5400.1.

\section{Safety and Health}

The Progress Assessment Team's evaluation of selected safety and health programs resulted in a conclusion that INEL has made significant progress in the areas reviewed, and that an overall positive cultural change is occurring in these areas. Progress in the construction safety program of MK-FIC is especially noteworthy in light of the findings of the Tiger Team Assessment. The EG\&G Idaho industrial hygiene data management system, laser safety and training programs also evidence substantial progress. Additional contractor progress in the safety and health areas includes the development of an EG\&G Idaho maintenance management implementation program plan, development of oversight requirements, and improved job control systems. Significant progress has occurred at INEL in the closure of 1991 Tiger Team Assessment OSHA findings.

The INEL safety and health programs are not fully developed and implemented. These INEL programs vary in their formality, depth, and level of implementation. Sitewide performance indicators, self-assessments, strategic goals and plans for the INEL site safety and health programs have not been fully established within the ID and INEL contractors' organizations, and are not fully utilized for sitewide integrated planning and program management. ID has not fully determined the requirements and direction for ID and INEL organizations to set goals, prepare, and report indicators for core areas of the industrial safety and health program in support of the overall strategic goals of ID. Long range safety and health organizational implementation plans are not prepared or utilized within the ID. Current INEL sitewide implementation planning activities for safety and health are not risk based. It was also noted that the implementation of the safety and health program within ID has largely been driven by responses to external drivers rather than being based upon a clear definition of overall programmatic plans, objectives, and management of risks from a strategic organizational initiative. 


\section{Key Concern, Root Cause, and Strengths}

The INEL Progress Assessment Team evaluated the concerns, weaknesses, and strengths. No immediate concerns were identified. The team identified one key concern that is considered to be a distillation of the INEL ES\&H deficiencies.

ID has not fully scoped, developed, and implemented formal and effective management systems that will provide the framework, mechanisms, and information necessary to assure appropriate and timely, risk based, resolution of ES\&H issues and to ensure the achievement of ES\&H excellence at INEL.

The team identified one probable root cause underlying the concerns and weaknesses addressed in this report.

ID has not given sufficient emphasis to the risks that ES\&H issues pose to the successful accomplishment of the INEL mission and to the benefits to be realized by providing the management systems necessary to address these issues in a disciplined and documented manner.

The team also identified three strengths, which, as defined, are examples of exceptional performance, achievement, or excellence.

The INEL Training Advisory Council provides a number of sitewide ES\&H training benefits including: a forum for the uniform formulation and promulgation of training policy, the development of training qualifications, the consolidation of training assets, and the standardization of training programs.

The EG\&G Idaho laser safety program and industrial hygiene data management system (System 80 ) are examples of model programs.

MK-FIC has developed a model construction safety and health program to support construction activities at INEL. 
1.0

Introduction 


\section{$1.0 \quad$ INTRODUCTION}

\subsection{ENVIRONMENT, SAFETY, AND HEALTH (ES\&H) PROGRESS ASSESSMENT PROGRAM}

In June 1989, DOE announced a 10-point initiative to strengthen ES\&H programs and waste management operations within DOE. One of the initiatives involved conducting independent Tiger Team Assessments of DOE operating facilities. To date, 35 Tiger Team Assessments have been conducted. These large, comprehensive assessments established baselines for ES\&H compliance levels, evaluated ES\&H management programs, identified root causes of noncompliance, and provided for corrective action plans. As part of the continuing effurt to institutionalize line management accountability and the self-assessment process, and to evaluate the actions taken in response to Tiger Team Assessment findings, the Department directed that smal1, focused ES\&H Progress Assessments be performed. The ES\&H Progress Assessment at INEL, conducted from July 26 through August 10, 1993, is the twelfth assessment of this new program.

The point of reference for assessing programs at INEL was, for the most part, the INEL Tiger Team Assessment which was conducted from June 17 through August 2, 1991. The level of onsite effort for that assessment was approximately 750 person-weeks versus 39 person-weeks for the ES\&H Progress As ses sment.

The objectives of the INEL ES\&H Progress Assessment were to develop an updated picture of how INEL has progressed since the 1991 Tiger Team Assessment; how effectively INEL has corrected the specific Tiger Team deficiencies and the root causes of those deficiencies; and whether the current structures, resources, and systems are in place and functioning to identify weaknesses in a timely manner and effectively manage ES\&H issues.

Accomplishing these objectives involved performing evaluations of the following:

- change in culture and attitude related to ES\&H activities;

- $\quad$ progress and effectiveness of the ES\&H corrective actions resulting from the previous Tiger Team Assessment;

- adequacy and effectiveness of the ES\&H self-assessment programs of the Office of Nuclear Energy (NE) and INEL management; and

- effectiveness of DOE and contractor management structures, resources, and systems to address ES\&H problems and new ES\&H initiatives resulting from the 1991 Tiger Team Assessment.

The assessment was conducted by a team of specialists from various DOE offices and support contractors, with expertise in the areas of the environment, safety, health, and management. The Team Leader was a senior DOE manager from the Albuquerque Field Office. Team members, with their areas of responsibility and work-related experience, are identified in Appendix $C$.

The assessment process consisted of a team planning meeting, initial site visit, offsite review of documents, DOE Headquarters and onsite interviews, observations, inspections, and onsite document review. The initial site visit 
was conducted from June 28 through July 2, 1993. This activity included presentations by NE and INEL personnel; touring the site/facility; collecting documents for review; and planning the assessment. Team members reviewed documents and developed more formal assessment scopes (see Appendix D) and activity schedule lists (see Appendix E) between July 6 and July 16, 1993. Several team members conducted interviews with DOE Headquarters personnel during this period.

The onsite assessment was conducted July 26 through August 10, 1993. During this period, the team conducted interviews with INEL and contractor personnel, inspected facilities, reviewed documents and data, developed the results of the assessment, drafted the assessment report, and held a formal closeout with INEL and contractor management. Daily team meetings were held to discuss issues and assessment progress. To facilitate the full understanding of the issues and encourage involvement in the assessment process, INEL and contractor personnel were invited to attend and participate in these meetings.

The approach used by the team to perform the evaluations and achieve the objectives detailed above involved both horizontal and vertical reviews of ES\&H activities. The horizontal reviews evaluated the existence and adequacy of management structures, systems, and programs for identifying and addressing ES\&H problems and requirements. The management systems evaluated included oversight; directives, policies, and procedures; human resources management; and planning, budgeting, and resource allocation. Horizontal and vertical reviews were also performed on the self-assessment and corrective action programs. Although these two programs are integral parts of ES\&H management systems, they are addressed as separate disciplines in this report. The distinction was made because of the importance of these two programs as indicators of progress since the Tiger Team Assessment, and more importantly, because they are key elements of a sustainable ES\&H program.

The vertical reviews are used to validate conclusions reached during the horizontal reviews. The ES\&H technical areas selected for vertical reviews were environmental restoration and groundwater protection program; air quality management programs; surface water management programs; environmental radiation programs; construction safety programs; worker safety and Occupational Safety and Health Act (OSHA) programs; maintenance programs; packaging and transportation programs; site/facility safety review programs; and industrial hygiene programs. The selection of the areas for vertical review was based on the results of the 1991 Tiger Team Assessment report and Corrective Action Plan, other assessments, occurrence reports, and information obtained during the initiall site visit.

The team conducted a review of all the concerns and weaknesses to identify key concerns and root causes. The key concerns represent the essence of the weaknesses and deficiencies identified by the team, and the root causes represent the most fundamental reasons that the deficiencies occurred.

The correction of the 1991 Tiger Team findings and their root causes and INEL's self-assessment activities were subjects reviewed by all team members in both the horizontal and vertical reviews. The observations of team members related to Tiger Team Assessment corrective actions, other corrective actions, and self-assessment activities were consolidated and evaluated from a sitewide perspective. Details of the specific subjects covered by these reviews are provided in Section 2.0 and Appendix B of this report. The results of the 
team members' evaluations were categorized into three groups (there were no immediate concerns identified by the Progress Assessment Team):

- Concern. Any situation or adverse condition that does not meet the requirements of an applicable law, agreement, DOE riule or Order, DOE procedure, or constitutes a significantly deficient practice not covered by procedure, and is not classified as an immediate concern.

- Weakness. Any situation that indicates less than optimal performance and could be an indication of more serious problems, and is not classified as an immediate concern or concern. The term is also used for any series of situations or adverse conditions related to findings that indicate a degradation in the performance of a program or management system.

- Strength. A strength is an example of exceptional performance or achievement of excellence. A strength may be a noteworthy practice, activity, or program that clearly exceeds the acceptable level of performance and that warrants documents supported by findings of fact. Strengths may have general application at other DOE programs or operations. The purpose for documenting the strength is for communicating the strength within DOE. General application of a strength, either by its design or execution, results in more effective and improved management or operation performance.

\subsection{IDAHO NATIONAL ENGINEERING LABORATORY (INEL)}

The INEL site is located on 890 square miles in the southeastern Idaho desert. The site is 39 miles long from north to south and 36 miles wide at its broadest point. Within this perimeter are nine nuclear research and development facilities.

The Federal government selected the INEL site in the late 1940s, when the Atomic Energy Commission needed a location for conducting nuclear research and development and nuclear-related defense work. Established in 1949 as the National Reactor Testing Station, INEL now contains the largest concentration of nuclear reactors in the world. Fifty-two reactors have been built here, 12 of which are still operable; the others were phased out upon completion of their missions. In 1.974, the site's name was changed to the Idaho National Engineering Laboratory to better characterize current projects, which now include research engineering for non-nuclear and nuclear energy programs. INEL employs approximately 11,000 people.

The INEL mission is to provide the nation with innovations in nuclear technologies and unique scientific and engineering capabilities in non-nuclear programs that provide commercialization potential or enhance the quality of the environment.

The management of INEL is assigned to ID. The major DOE program office with programmatic responsibility at INEL is the Office of Nuclear Energy (NE). Five private contractors operate INEL for ID, including EG\&G Idaho, WINCO, $B \& W$, PTI, and MK-FIC. 


\subsection{REPORT STRUCTURE}

The results of the assessment are addressed in two main sections of this report. Section 2.0 presents the team's overall evaluation of the results of the Progress Assessment. This includes an identification of the key concerns and root causes of the assessment, a listing of strengths, and overview sections for each area of responsibility. Each overview section provides a summary of the assessment conclusions for each area assessed. Appendix B includes the individual concerns, weaknesses, and strengths. A summary of concerns, weaknesses, and strengths is presented in Appendix A.

Each evaluation item is given a number that identifies its category. The disciplines are identified by the following designations: $M=$ ES\&H Management Systems, $E=$ Environmental Programs, and $S=$ Safety and Health Programs. The categories are represented by: $C=$ concern, $W=$ weakness, and $S=$ strength . These letters are followed by a sequential number assigned to each evaluation item within a given category. As an example, the first management concern would be written as $M / C-1$. These identifiers are used in both the body of the report and in Appendix $B$.

Where appropriate, discussions are supported by references to specific interviews and documents. These references are associated with the reference numbers on the interviews and documents 1 isted in Appendices $F$ and $G$ respectively. In the report, the references are shown by placing the reference number in parentheses. The first letter in the reference number is either I or D, indicating whether the reference is an interview or document. The second letter is a team member identifier used for internal document control. The alphabetic designation is followed by a sequential number. As an example, the sixth interview reference by team member "A" would be I-A-6. 
2.0

\section{Performance and Progress of INEL ES\&H Programs}




\section{$2.1 \quad$ OVERVIEW}

The Progress Assessment Team concluded that considerable progress has been made in virtually all ES\&H programs that were reviewed. Many INEL contractor programs evidenced substantial progress and ID's effective use of the cost Plus Award Fee (CPAF) process has had a positive influence on that progress. Many of the deficiencies identified by the 1991 Tiger Team Assessment have been addressed, but systemic deficiencies persist in ES\&H management systems and functional programs. Areas where deficiencies were particularly evident included formality of and adherence to ID policies and procedures; corrective action and self-assessment programs; implementation planning; and the sitewide environmental compliance program.

Specific strengths were identified in the areas of the MK-FIC construction safety program, the EG\&G Idaho laser safety program and the industrial hygiene data management system, and the INEL Training Advisory Council. The key concern and its underlying probable root cause reflect the team's observations that ID has not defined and developed the necessary management systems that provide the framework for effective ES\&H performance and has not given sufficient consideration to the impacts of ES\&H risks on the INEL mission.

\subsubsection{Key Concern}

The INEL Progress Assessment Team evaluated the concerns, weaknesses, and strengths. No immediate concerns were identified. The team identified one key concern that is considered to be a distillation of the INEL ES\&H deficiencies.

ID has not fully scoped, developed, and implemented formal and effective management systems that will provide the framework, mechanisms, and information necessary to assure appropriate and timely, risk based, resolution of ES\&H issues and to ensure the achievament of ES\&H excellence at INEL.

In addition to an appropriately staffed organizational structure, an effective ES\&H program requires certain management systems that identify issues, assigns proper priorities based on risk, and effects complete and timely resolution of those issues. While progress has clearly been achieved in the INEL ES\&H programs, the current policies, programs, and procedures may not be sufficient to sustain this progress, address new issues using appropriate risk management, and continue towards the DOE goal of ES\&H excellence.

While ID has initiated development of some ES\&H management systems, ID has not accorded sufficient priority and committed resources to the development and effective implementation of essential management systems such as the self-assessment, corrective action, and oversight programs; to human resource management; to implementation planning; to the clear definition of roles, responsibilities, and authorities; and to the development of appropriate policies and procedures. The inadequacies of these ID management systems have resulted in incomplete direction to the INEL contractors and have hindered the focusing of attention on the management and resolution of issues on a sitewide basis. An ID or INEL self-assessment program plan has not been developed and issued to ensure consistent, compatible data to provide clear overall self-assessments of ID and INEL as a site. The absence of an established, 
implemented, and effective sitewide issues management system, which is based on the assessment of risk, has resulted in a number of important ES\&H issues being inadequately addressed.

These inadequacies in management systems, direction to the contractors, and a sitewide management approach, were identified by the Tiger Team in 1991, but have yet to be comprehensively addressed. These management system inadequacies can be attributed, at least in part, to the lack of clearly defined roles, responsibilities, and authorities; the absence of formal implementation planning; and the lack of accountability for the resolution of identified issues. The absence of formal, updated ES\&H policies, programs, and procedures creates an environment where ES\&H activities are not based on an assessment of risks and vulnerabilities, and are not performed with appropriate rigor and formality; conditions that inhibit the achievement of ES\&H excellence.

\subsubsection{Root Cause}

The Progress Assessment Team identified the following probable root cause underlying the concerns and weaknesses addressed in this report.

I0 has not recognized the benefits to be realized by developing disciplined and documented risk management systems necessary for the identification, evaluation, prioritization and cost-effective disposition of risks that ES\&H issues pose to the successful accomplishment of the INEL mission.

INEL has a distinguished history of engineering and scientific accomplishments in support of the missions of DOE and its predecessor agencies. INEL's successes have been founded on its technical assets and ID management's ability to serve its client's needs. A legacy of these factors is an organization with a product orientation, able to manage effectively as the INEL product 1 ine evolves and changes, as it often has in the past. However, another factor has been introduced into the INEL mission over the past few years that has profound implications on INEL's ability to successfully carry out its mission. Unlike its other product lines, ES\&H performance is a less tangible, but equally demanding, product that requires its own management systems and attention. ID has not given sufficient consideration to the fact that ES\&H performance is an essential INEL co-product that requires formal, rigorous management systems to drive and support an ES\&H program that identifies issues, assigns proper priorities based on risk, and effects complete and timely resolution of those issues. These systems include planning to focus activities towards the product; clear definition of roles, responsibilities, and authorities; self-assessment and corrective action programs to ensure product quality remains high and continually improves; appropriate policies and procedures; oversight programs to ensure that the organization's goals and objectives are achieved, and policies and procedures are pursued and followed with formality and rigor; and human resource management to ensure that sufficient, qualified staff are available to supply the product. These management systems have been successfully applied to INEL's traditional product lines over the years. The fact that these systems remain to be developed or completed, and applied to the ID ES\&H product line suggests that ID has not yet given sufficient consideration to the impartance of these management systems to the INEL mission. Full development and implementation management of systems that recognize and address the ES\&H risks 
associated with other aspects of the INEL mission will be necessary for the INEL to maintain viability as a national asset.

\subsubsection{Strengths}

The Progress Assessment Team identified the following strengths:

The INEL Training Advisory Council provides a number of sitewide ES\&H training benefits including: a forum for the uniform formulation and promulgation of training policy, the development of training qualifications, the consolidation of training assets, and the standardization of training programs.

The EG\&G Idaho laser safety program and industrial hygiene data management system (System 80 ) are examples of model programs.

MK-FIC has developed a model construction safety and health program to support construction activities at INEL.

\subsection{OVERVIEW OF ES\&H MANAGEMENT SYSTEMS ASSESSMENT}

The Progress Assessment Team evaluated the overall effectiveness of INEL ES\&H management systems. The assessment was conducted through a combination of interviews; review of key documents; and, where appropriate, field inspection of activities and processes. Specific management disciplines were selected for review based on the 1991 Tiger Team Assessment areas of concern, or because those disciplines were believed to be highly characteristic of ES\&H program performance. The management disciplines assessed at INEL were corrective action program; self-assessment program; oversight; directives, policies, and procedures; human resource management; and planning, budgeting, and resource allocation.

Based on the review of these areas, the Progress Assessment Team concluded that INEL has made progress in improving the management systems subsequent to the 1991 Tiger Team Assessment. However, notwithstanding this progress, the team identified several areas where little progress is evident and other areas where further progress is necessary. A summary of progress as well as persisting deficiencies at INEL includes the following:

- Progress has been made at INEL in implementing a corrective action program to address deficiencies identified by the 1991 Tiger Team Assessment and internal and external assessments. The elements of an effective corrective action program that are in place at INEL are not fully developed and do not yet constitute a comprehensive program that provides management with the information needed to capture ES\&H deficiencies, ensure appropriate and timely corrective actions, judge overall performance, and resolve ES\&H programmatic issues. The existing ID corrective action program is based on a process that was established for the Tiger Team Action Plan Project (TTAPP). ID does not yet have a sitewide comprehensive program that relies on its own ability to identify deficiencies, set priorities for corrective actions, follow corrective actions to closure, and verify appropriate actions. The progress to date with respect to a comprehensive corrective action program includes: the identification of the essential elements of the corrective action plan process such as systems for 
risk-based prioritization, root cause analyses, trend analyses, lessons learned, and verification of the effectiveness of corrective actions. The vital elements are in various early stages of development, some have been implemented to a limited extent while others remain to be defined and developed. This system is designed to provide the necessary information for management decision making in the implementation of a risk-based issues management system. However, the utility of this management system may be limited by concerns regarding the use of individual unrelated information management systems throughout INEL, the perceived complexity of the Compliance Management System (CMS) by users, the closure and validation of environmental-related corrective action plans, and the lack of some important program elements noted above. The priority and resources necessary to aggressively resolve these issues have not been provided.

- INEL self-assessment programs evidence progress since the 1991 Tiger Team Assessment, all of the INEL contractor organizations have developed and are using their self-assessment processes as a management tool for improvement. ID, though the CPAF process, has provided incentives for the INEL contractors to complete their Tiger Team self-assessment related corrective action program plans. However, ID has not provided formal guidance and direction to ID organizations or INEL contractors to ensure the development of sitewide self-assessment programs that produce consistent, meaningful, and timely data. As stated above, there is not an INEL-wide system to establish the priority of corrective actions, establish performance indicators, perform root cause analyses, and provide lessons learned. Sitewide ES\&H issues cannot be readily identified because the various self-assessment processes throughout INEL yield incompatible information that makes integration difficult. The fragmentation and independence of the various INEL self-assessment processes, within, between, and among contractor organizations, and within ID, inhibits ID's ability to effectively determine sitewide ES\&H performance, correct ES\&H deficiencies, and manage ES\&H risks.

- ES\&H oversight programs at INEL show improvement since the 1991 Tiger Team Assessment. ID improvements have been made in the areas of Quality Assurance (QA), the application of the CPAF process to improving contractor ES\&H performance, ES\&H performance at RESL, the Facility Representatives program, and some technical area ID Supplemental Directives. INEL contractor improvements were noted in the scheduling, conduct, and formality of independent and line oversight organization appraisals and surveillance. ES\&H oversight staffing of the contractors has increased. MK-FIC has developed a solid, proactive construction safety oversight program. All INEL contractors have established numerous ES\&H oversight committees providing management involvement and oversight, independent reviews, and instilling line ownership and input in the identification and resolution of ES\&H issues. ID progress can be described as inconsistent and less than aggressive: many of the 1991 Tiger Team Management 
findings and key findings have not been corrected or closed; and ID has not demonstrated a clear commitment to and has not identified the necessary resources for aggressively resolving known ES\&H oversight related programmatic deficiencies. ID has not assured that stop work and restart authorities and processes are consistently and clearly defined and understood at INEL. The team noted deficiencies in the content and substance of the formal and informal documentation associated $w$, th the newly authorized ID organization with respect to its organizational structure, missions, and functions. This documentation portrays an overall reduction in the independence, authority, visibility, and senior management attention to ES\&H oversight.

- INEL contractor organizations have made progress in establishing, improving, and implementing formal systems for directives and procedures since the 1991 Tiger Team Assessment. However, many ID Tiger Team Corrective Action Plan commitments to update and upgrade policies have not been completed, no changes have been made to the ID Policy Manual, many ID procedures have not been developed or updated, and numerous ID implementation procedures are not being followed. In general, INEL contractors have established formal and comprehensive directives, policies, and procedures systems with formal processes for development, maintenance, and control of these documents. Formal hierarchies for directives, policies, manuals, procedures, instructions, etc., have been established and contractors have formal directives systems in place.

- ID has had a positive impact on INEL human resource management programs, all INEL contractors have substantially improved their programs since the Tiger Team Assessment. There was evidence during the assessment that iD recognizes and supports the importance of qualified contractor staff to the successful execution of the INEL mission. ID has emphasized enhancements in the mechanics and uniformity of the ID individual performance review. All INEL contractor human resources management programs evidence substantial improvement over the past 2 years including the WINCO program which was judged to be a relatively strong program during the Tiger Team Assessment. INEL contractor Employee Concerns Programs (ECPs) have been substantially strengthened in response to deficiencies identified by the Tiger Team Assessment. While ID program line organization's ES\&H oversight has been strengthened, the lower priority accorded independent ES\&H oversight that the Tiger Team Assessment identified still persists.

- Implementation of strategic planning processes at INEL have made substantial progress since the 1991 Tiger Team Assessment. ID and its contractors have adopted a strategic, sitewide planning perspective; ES\&H considerations appear to be an integral part of the INEL planning; and all the INEL contractors appear to be full and active participants in the planning process. A draft INEL Institutional $\mathrm{Plan}$ integrates strategic, programmatic, crosscutting, and sitewide issues. ID is using the CPAF process effectively to influence the ES\&H performance of its contractors. 
The INEL contractors have made progress on a broad front in improving their planning processes. ID subordinate implementation planning processes are virtually nonexistent and the INEL contractors' are not yet fully functional. Lacking formal, risk-based implementation plans that would set priorities for and guide ID ES\&H activities on a cost-effective basis, the ID and the INEL contractor's ES\&H activities are reactive and may, not be addressing the most important issues in a disciplined fashion. ID lacks a detailed reorganization implementation plan that specifies the essential activities that must accompany or follow a major organizational realignment.

\subsubsection{Corrective Action Program}

In the corrective action program area, the Progress Assessment Team evaluated the adequacy of the ID and INEL site programs to address deficiencies identified by the 1991 Tiger Team Assessment, as well as ES\&H deficiencies identified by other oversight and self-assessment activities. In conducting this assessment, the Progress Assessment Team looked specifically at the management systems and programs for identifying and tracking corrective actions, prioritization, root cause analysis, trending, and lessons learned. The responsibilities and delegated authorities regarding implementation and closure of corrective action activities was also evaluated.

The corrective action program is an essential ES\&H management system that provides management with information needed to judge overall performance and resolve ES\&H issues. The Tiger Team Assessment identified the following three findings related to the INEL corrective action programs:

- ID and INEL contractors have not implemented effective ES\&H oversight programs consistent with DOE. Orders and best management practices (see Tiger Team Assessment Finding MF-1).

- INEL contractors (with the exception of WINCO and EG\&G Idaho) do not have an effective and integrated ES\&H management information system (see Tiger Team Assessment Finding MF-9).

- ID and INEL contractors have been ineffective in identifying significant ES\&H issues, determining the root causes, and implementing timely and effective corrective action (see Tiger Team Assessment Finding MF-16).

One of the root causes identified by the Tiger Team Assessment was that management (at DOE-HQ, ID, and INEL contractors) had not provided the vision, direction, and oversight needed to achieve compliance with current ES\&H requirements and to move towards excellence. This was further delineated in another root cause which stated that adequate management systems were not in place either in ID, DOE-HQ, or contractors to fully implement and monitor DOE ES\&H policies. This root cause was determined to be the result of a lack of management information systems to provide status reports and inconsistent guidance from DOE-HQ.

The corrective action program at ID and INEL was assessed following the Performance Objectives and Criteria for Progress Assessments (Progress Assessment Manual, Appendix B-1, December 1992), Performance Criteria 2.5.6 
(ID) and 4.5 .6 (Contractors). These criteria require a determination of whether DOE and its contractors have formal and effective corrective action programs. The assessment was conducted by reviewing selected documentation including policies, procedures, assessments, correspondence, corrective action tracking reports, etc,, and by interviewing selected DOE-HQ, ID, and INEL contractor personnel.

The elements of an effective corrective action program are in place at INEL; however, these elements do not yet constitute a program that provides management with the information needed to judge overall performance and resolve ES\&H programatic issues. The priority and resources to aggressively resolve the Tiger Team management issues have not been fully provided (see Concern $M / C-1)$.

The ID corrective action program is presently based on a process that was established for the Tiger Team Action Plan Project (TTAPP). The policy statement of the TTAPP states that this process shall coordinate the development and provide for the issuance of action plans that identify corrective actions to address all Tiger Team findings and concerns, including root causes. The essential elements of the corrective action plan (CAP) process were identified by $I D$ as: issue identification, issue capture, responsibility assignment, CAP development, CAP approval, CAP execution, verification of completion, and closure. Once the essential elements are in place and are being implemented, "supplementary" elements would be added. ID has identified these supplementary elements as: risk-based prioritization, root cause analysis, trend analysis, lessons learned program, and effectiveness assessments. These essential elements are not yet fully developed within the corrective action program or for the application to the full spectrum of issues mariagement at INEL.

An INEL management information system known as the Compliance Management System (CMS) has been initiated to implement the policy of the TTAPP. This system could, when fully developed and implemented, provide the necessary information for management decision making in the implementation of a risk-based issues management system. This system will have the ability to provide prioritization, tracking, trending, root cause analys is, lessons learned information, and closure for both external and internal identified ES\&H deficiencies. However, the team has identified problems regarding this system which involve the use of individual systems, the perceived complexity of the CMS by users, closure and validation of corrective action plans, and the lack of some vital elements (see Concern $M / C-1$ ).

Program execution cross-cut direction is being developed by ID to require contractors to track their identified ES\&H deficiencies in the CMS by October 1, 1993. This is accomplished by the use of a document for contracting action known as Program Execution Guidance (PEG). In addition, a Program Management Plan for the transition from a pilot project to a working program is being prepared. These initiatives will be important steps to resolve the issues from Tiger Team concerns; however, the schedule for implementation has slipped significantly since the Tiger Team Assessment.

The corrective action systems for internally identified deficiencies are not implemented with the degree of formality as that for Tiger Team findings. A recent ID Office of Environmental Safety and Health Oversight (OES\&HO) assessment report concluded that most ID line organizations were not 
evaluating, tracking, performing lessons learned evaluations, trending, or adequately closing ES\&H deficiencies that had been identified by OES\&HO. Contractor self-assessment identified deficiencies are not consistently prioritized, trended, or evaluated for lessons learned at this time; however, the full development and implementation of the CMS as described in the TTAPP may resolve these issues (see Concern $M / C-1$ ).

One element for an effective issues management program is a risk-based prioritization system. Without such a system, limited resources may be inappropriately used with no commensurate reduction in risk. The guidance provided by an effective risk-based prioritization system would be valuable for an ES\&H program that strives for excellence. The basic elements of such a system have been developed and implemented by WINCO and this system has been selected as the preliminary model for the ID and INEL sitewide program. This is an area in which concentrated efforts could provide effective and immediate benefits.

Another important element of an effective issues management program is a lessons learned program that assures the dissemination of information to appropriate managers and workers at the workplace. In order to provide the necessary information to appropriate personnel, the training program must be flexible and comprehensive enough to quickly adapt to new information. Both WINCO and EG\&G Idaho have lessons learned programs that feed into training programs for their individual activities. Such programs could provide the basis for an integrated, sitewide lessons learned program.

ID and INEL have made significant progress in closing Tiger Team CAPs. For the major categories of Tiger Team concerns, 32 percent of environmental CAPs, 45 percent of all management and organization CAPs, 99 percent of 0ccupational Safety and Health Act (OSHA) CAPs, and 60 percent of safety and health CAPs have been closed. About 68 percent of the total 1,858 CAPs have been closed as of July 30, 1993. This does not provide the complete picture, however, because most of the environmental and management CAPs remaining to be closed involve major, sitewide issues. ID and INEL have stated that present budgetary constraints and the complexity of integrating major management systems sitewide have resulted in many of the scheduled completion dates to slip and some actions to be overdue. This is illustrated in the 22 percent of scheduled completion dates overdue for environmental CAPs and 19 percent for management and organization CAPs. Adequate priority and resources to aggressively resolve these issues have not been fully provided.

The following five Tiger Team key findings addressed significant management issues that adversely impacted ID and INEL's ES\&H performance:

- Management within ID and the site contractors is not adequately performing its ES\&H oversight responsibilities (KF-041).

- Activities at the INEL are not being performed with the formality and rigor consistent with DOE policies and requirements for the attainment of ES\&H excellence (KF-042).

- ID and the majority of INEL contractors do not place strategic importance on ES\&H in their planning, budgeting, and resource allocation processes (KF-043). 
- ID has failed to provide the sitewide direction and guidance necessary to ensure an effective and sustainable ES\&H program at INEL (KF-044).

- The ID and site contractors are not managing their human resources with sufficient emphasis on ES\&H responsibilities (KF-045).

At this time, ID has closed only one of these key findings; the one relating to strategic planning (KF-043). For the CAPs regarding ES\&H oversight and the formality and rigor of operations, none of the milestones have been completed. In addition, all four milestones for the ES\&H oversight CAP are presently overdue and two of the four milestones for the formality and rigor of operations CAP are presently overdue. Furthermore, all milestones in the self-assessment CAP (see Tiger Team Assessment Finding SAF-1) are presently overdue. The priority, resources, and guidance that are necessary to resolve these key findings have not been effectively provided (see Concern $M / C-7$ ).

Another important set of management findings include the 24 Tiger Team issues relating to management deficiencies at ID and INEL (see Tiger Team Assessment Findings MF-1 through MF-24). These findings cover the spectrum of concerns from broad ES\&H programs to focussed specific issues. At this time, only five of the 24 CAPs are closed. Significant issues that remain open include: ES\&H oversight, OES\&HO roles and responsibilities, sitewide leadership, ES\&H management in iormation system, the Cost Plus Award Fee (CPAF) system, construction ES\&H oversight, INEL quality assurance program, training, and the INEL stop-work authority. At this time, 8 percent of those CAPs scheduled for closure are overdue. Again, the management priority and direction to aggressively resolve the issues are lacking as addressed in Management Concern $M / C-7$.

Tiger Team Management Finding MF-5 addressed deficiencies in the INEL strategic and subordinate implementation planning process. However, the action plan for MF-5 (Strategic Planning) had two milestones that culminated in the implementation of an INEL-wide strategic planning process. When the INEL strategic planning process was implemented this action item was closed. The failure of this Tiger Team Assessment corrective action to drive the development of INEL implementation planning processes is the result of a flawed action plan rather than a deficiency in the closure process. However, the net effect was the same; ID implementation planning has not received management attention and the lack of implementation plans represents a potential vulnerability for ID (see Concern $M / C-7$ ).

ID and INEL contracturs need to make the priorities, provide the necessary resources, and issue the guidance to ensure that the systems discussed above are fully developed and effectively implemented into a comprehensive INEL Corrective Action Program.

The Progress Assessment Team identified one concern related to the corrective action program area, which is identified in Appendix B-1 (see Concern $M / C-1$, Corrective Action Program). 


\subsubsection{Self-Assessment Programs}

The Progress Assessment Team assessed the development and implementation status of the ID, B\&W, EG\&G Idaho, MK-FIC, PTI, and WINCO self-assessment programs. The team evaluated each programs' conformance with the July 31, 1990, DOE-HQ Guidance on ES\&H Self-Assessment and the DOE Self-Assessment Guidance Document (December 1992), as well as the status of program implementation. Self-assessment elements including program plans, assessment processes, related management systems, and assessment reports and documentation were reviewed to determine if self-assessment activities are regularly conducted to evaluate and report the status and quality of all aspects of ES\&H performance. Processes to determine root causes for deficiencies and to complete corrective actions were also reviewed. The key standards used in this assessment were the ES\&H Management Performance Objectives and Criteria for Progress Assessments (Progress Assessment Manual, Appendix B-1, December 1992), Performance Objectives 2.5 and 4.5.

The assessment approach used by the Progress Assessment Team included interviews with INEL personnel responsible for developing and implementing self-assessment programs as well as interviews with line personnel who perform self-assessment activities. The approach also included the review of INEL procedures, guidance documents, status of corrective action plans, and products of the INEL self-assessment process; and self-assessment reports, action plans, root cause analysis, trending information, and lessons learned.

The Management Subteam for the 1991 Tiger Team Assessment identified 17 findings and one key finding related to self-assessment. The key finding stated that ID and each of the INEL contractors reviewed had initiated self-assessment effort, but the implementation process was incomplete; the programs and reports did not meet all the applicable criteria of the Secretary's Guidance; and the portions of the self-assessment programs that were developed had not been institutionalized.

After the 1991 Tiger Team Assessment, ID sponsored a self-assessment workshop on August 26, 1991, for ID and INEL contractor representatives to present the DOE-HQ self-assessment policy as contained in the July $1990 \mathrm{HQ}$ guidance. The Tiger Team Corrective Action Plan for self-assessments required ID to revise the existing ID Self-Assessment Program Plan and to issue an ID Supplemental Directive to provide guidance to INEL contractors. Pending issuance of those documents, ID organizational elements continued to perform self-assessments in accordance with the pre-Tiger Team Program Plan and later followed a draft Self-Assessment Program and Implementing Procedures issued to ID Principal Staff by the ID Deputy Manager of Operations. Quarterly self-assessment were conducted within most ID organizations starting in late 1991. Several quarterly horizontal cross-cut evaluations were performed to identify issues common to ID organizations. The Office of Environment, Safety and Health Oversight (OES\&HO) has performed independent routine surveillance and functional and management appraisals as directed by DOE 5482.1B and has provided an analys is of their independent oversight in an annual report. The INEL contractors, using the formally transmitted July $1990 \mathrm{HQ}$ guidance and the informal guidance from OES\&HO, began to develop and implemented the ir self-assessment programs.

Two years after the 1991 Tiger Team Assessment, revisions to the ID Self-Assessment Program Plan and the ID Supplemental Directive that 
incorporates the DOE Guidance on ES\&H Self-Assessments have still not been issued. ID has struggled with reconciling and incorporating the various $H Q$ Program Secretarial Officer (PSO) guidance documents into a single coherent self-assessment program. ID has not completed any of the six milestones on the Tiger Team Corrective Action Plan related to ID's self-assessment program. In April 1993, a proposed ID Self-Assessment Program Plan was presented to and rejected by the INEL Management Board. Subsequently, ID has issued a self-assessment program "White Paper" (dated May 14, 1993) to present a less "rigorous" program. However, this "White Paper" is merely a suggested course of action and does not describe a comprehensive self-assessment program nor provides the details to implement one. As a result, some of the ID organizations have suspended conducting their formal quarterly self-assessments. ID management has not fulfilled its commitment to the revise and issue the ID Self-Assessment Program PIan and the ID Supplemental Directive that incorporates the DOE Guidance on ES\&H Self-Assessments. These delays in issuing this guidance has hindered the performance of effective self-assessments within ID and have resulted in inconsistent self-assessment data from INEL contractors making an overall assessment of the INEL difficult.

Even without formal guidance from ID, the Progress Assessment Team noted that the INEL contractors have made progress in the area of self-assessment since the 1991 Tiger Team Assessment. Over the last 2 years, all of the INEL contractor organizations have developed to varying degrees and are using their self-assessment processes as a management tool for improvement. In addition, ID, through the Cost Plus Award Fee (CPAF) process, has provided incentive for the INEL contractors to complete their Tiger Team Corrective Actions Plans related to self-assessment. All INEL contractors have identified that their self-assessment program corrective actions are complete and are ready for review for closure by ID. However, not all of the essential elements of an effective self-assessment program (e.g., prioritization of corrective actions, performance indicators, root cause analysis, and lessons learned) have been developed anci implemented by all of the contractors. The following are summaries of the progress and status of the various INEL contractor self-assessment programs.

B\&W has initiated an integrated and formal self-assessment program. Progress since the INEL Tiger Team Assessment includes developing formal self-assessment procedures, training all managers to perform management walkdowns, identifying assessment areas, and conducting management and independent assessments on a scheduled basis. B\&W uses its self-assessment process as a mechanism to familiarize managers with their facilities, identify deficiencies and track corrective actions, and process the information for management decisions. Individual assessments are rolled up into quarterly, semi-annual, and annual reports. B\&W has been providing periodic status reports for internal findings and external findings, concerns, and observations with supporting analysis to the staff and General Manager.

B\&W has an effective management walkdown process. The results of the management walkdown activity are compared to other audit/assessment findings including internal audits, Tiger Team Assessments, and external audits. Risk assessment and root cause analysis are performed on all findings. B\&W has identified areas for improvement in its self-assessment process and has developed corrertive actions to fully establish formal processes to identify key ES\&H perforinance indicators, and perform trend analys is and risk vulnerability based on prioritization. In addition, B\&W plans to improve the 
interface between its own assessment data system and the INEL Compliance Management System (CMS). Self-assessment related corrective actions that resulted from the INEL Tiger Team are identified by B\&W as complete for review for closure by ID.

EG\&G Idaho has improved its self-assessment processes since the INEL Tiger Team Assessment. EG\&G Idaho has developed an aggressive self-assessment surveillance program, but has had difficulty institutionalizing it throughout all departments. As a result, the EG\&G Idaho self-assessment process was found to be inconsistent across two of its major departments. The Progress Assessment Team noted that the level of maturity was inconsistent between the Facilities \& Maintenance Department and the Power Reactor Programs Department. Each of the programs were working towards EG\&G Company Procedure 1.7, "Self-Assessment Surveillances." EG\&G Idaho has recognized its self-assessment process can be improved. The Progress Assessment Team was informed through interviews by several EG\&G Idaho representatives that EG\&G Company Procedure 1.7 (issued December 24, 1992) was about to be updated along with other company procedures and programs to clarify schedules, documentation, corrective actions, tracking and trending, and verification. Self-assessment related corrective actions and milestones resulting from the INEL Tiger Team Assessment have been identified by EG\&G Idaho as complete and are pending review for closure by $I D$.

There have been some substantial events that represent a cultural change at MK-FIC since the INEL Tiger Team A'ssessment with respect to self-assessments propagated by the General Manager. The General Manager has issued a self-assessment policy statement to be carried out by all employees. A formal program plan for conducting self-assessment was developed and issued. In addition, a Performance Assurance Office was created and has developed a self-assessment activity schedule. MK-FIC has changed the language of its construction subcontracts to require subcontractors to develop, submit for review, and conduct ES\&H self-assessment activities. In addition, subcontracts include the requirements for subcontractors to have qual ified ES\&H representatives to conduct the assessments. Subcontractors are also required to conduct daily inspections. Results from the daily inspections are compared with the MK-FIC Targeted Surveillance Program as a means of assessing the quality of both programs. Self-assessment related corrective actians and milestones resulting from the INEL Tiger Team Assessment have been identified by MK-FIC as complete and are pending review and closure by ID.

PTI progress with regard to self-assessment since the INEL Tiger Team Assessment includes the development of a formal Self-Assessment Program Plan. This plan includes development of inspection modules to cover disciplines including conduct of operations, firearm safety, and aviation safety. In addition, PTI management has begun to conduct self-assessments using these inspection draft modules that were derived from baseline criteria from DOE orders and other guidance documents. The modules are finalized for issuance as the topic comes up on PTI's 3-year self-assessment schedule.

Self-assessment related corrective actions and milestones resulting from the INEL Tiger Team have been identified by PTI as complete and are pending review and closure by ID.

WINCO has made progress towards the implementation of its self-assessment program. WINCO's commitment to institutionalize the program is evident in its June 1993 Self-Assessment Program Implementation Plan. The WINCO 
self-assessment process includes elements to identify deficiencies including procedures, personnel, and systems. In addition, assessment data from internal and external appraisals are processed and prioritized for use as a management tool. WINCO has committed, through its procedures and its implementation plan, to train personnel to have a demonstrated knowledge and proficiency to conduct self-assessments. In addition, WINCO has developed 34 areas of inquiry in environmental protection, safety and health, business management, and safeguards and security. The areas of inquiry are matrixed against 36 assessable units (facilities, functions, and programs) and are scheduled for routine evaluation. Performance objectives and criteria to evaluate the assessable units are selected from DOE Orders, Federal and state requirements, and good management practices.

WINCO has performed an annual root cause analysis for the last 3 years. Results from this analysis and the Annual Self-Assessment of WINCO Operations are reviewed and company-wide actions have been initiated by the Management Root Cause Committee, which is chaired by the Executive Vice President. The key finding from the WINCO June 1993 Annual Self-Assessment identified that the WINCO self-assessments program is not fully developed. The assessment also identified that the self-assessment program for line management self-assessments is not fully implemented at WINCO. The June 1993 WINCO Self-Assessment Implementation Plan appears to address the measures necessary to institutionalize the self-assessment program. Self-assessment related corrective actions that resulted from the INEL Tiger Team are identified by WINCO as complete and are pending review and closure by ID.

In summary, ID has not taken the lead to provide guidance and direction to INEL contractors to assure consistent and meaningful self-assessment data that will support a sitewide self-assessment. The Progress Assessment Team found each of the INEL contractors used different methods to determine the priority of corrective actions, performance indicators, root cause analysis, and lessons learned. The varying INEL self-assessment processes developed by INEL yields information that cannot be readily integrated to identify sitewide issues. The fragmented and independent self-assessment processes that exist at INEL and within ID does not provide ID a method to determine, with a high degree of confidence, sitewide ES\&H performance to correct programmatic deficiencies.

The Progress Assessment Team identified one concern related to the ID self-assessment program, which is presented in Appendix B-1 (see Concern $M / C-2$, ID Self-Assessment Program).

\subsubsection{Oversight}

In the area of oversight, the Progress Assessment Team evaluated the adequacy and effectiveness of the ID and INEL contractor programs for oversight of ES\&H activities at INEL and the progress made in this area since the 1991 Tiger Team Assessment. This portion of the assessment focussed primarily on the assessment and review element of oversight. Other key elements of ES\&H oversight and related management systems such as self-assessment, corrective action, management information systems, and directives systems were addressed to a limited extent, but are detailed in other sections of this report. In conducting the assessment, the Progress Assessment Team reviewed the policies, plans, and procedures detailing how oversight activities are performed by 1 ine and independent oversight organizations of ID and INEL contractors. The Team 
also reviewed samples of documentation that reflects the adequacy of implementation of these oversight policies, plans and procedures. Assessment in this area focused primarily on the ID oversight program and activities and only on a small sampling of oversight program elements for the contractors including ES\&H committees, independent assessment, and stop-work/restart.

The assessment approach taken by the Progress Assessment Team was to interview ID and INEL contractor personnel responsible for line and independent , oversight and to review pertinent documentation to determine the overall adequacy of the program; both structure and implementation. The key standards used for this assessment include the ES\&H Management Performance Objectives and Criteria for Progress Assessments (Progress Assessment Manual, Appendix B-1, December 1992), Performance Criteria 2.4.2, 2.4.3, 4.4.2, and 4.4.3.

Oversight is an essential management system which provides assurance that all activities related to INEL are performed in accordance with ES\&H related requirements. Oversight is also a management system that drives individual and organizational performance towards excellence in ES\&H. An effective ES\&H oversight involves many systems that provide decision making information and assure management that the ES\&H program at INEL is being fully and effectively implemented. These systems include line and independent assessment (DOE and regulatory body mandated management, functional and internal appraisals, audits, surveillances, Operational Readiness Reviews (ORRs), Operational Readiness Evaluations (OREs)) and review (committees, councils, documents), including integral or supporting subsystems that provide management and staff with information on performance (issues management, corrective action, commitment tracking, performance indicators/trend analysis, root cause analysis, and lessons learned).

Inadequate oversight was identified as one of the root cause elements for the one overall key finding in the 1991 Tiger Team Assessment and was identified as a Management Subteam key finding. In addition, inadequate oversight was noted by the Environmental Assessment Subteam as a key finding and the key findings of all three Safety \& Health Subteams indicated significant oversight deficiencies for ID and the various contractors. Management Finding MF-1 identified the failure of ID and INEL contractors to implement effective ES\&H oversight programs. Management Finding MF-11 identified deficiencies in the definition, communication, and understanding of roles, responsibilities, and authorities with regard to stop work and restart actions. Section 3 of the 1991 Tiger Team Corrective Action Plan describes numerous actions that ID and the contractors had taken or were taking which included increasing the onsite presence of INEL management, and better defining management roles, responsibilities, and accountability. The action plans for the above listed key findings and MF-1 delineated additional planned corrective actions related to oversight.

Improvements have been made in ES\&H oversight in the areas of Quality Assurance $(Q A)$, the application of the Cost Plus Award Fee (CPAF) process to improving contractor ES\&H performance, safety and health performance at RESL, the Facility Representatives program, the development of some and technical area ID Supplemental Directives. Thorough, well documented independent oversight appraisals and surveillances are being performed by the ID office of Environmental Safety and Health Oversight (OES\&HO). In general, the progress ID has made has been inconsistent and less than aggressive especially with 
regard to the prompt and effective resolution of identified ES\&H issues. Many of the 1991 Tiger Team Management findings and key findings have not been corrected or closed. ID has not accorded sufficient priority, nor allocated the necessary resources to aggressively resolve known ES\&H oversight related programmatic deficiencies, including those identified by ID internal oversight and self-assessment activities. Certain elements of the ES\&H oversight program are not being performed and documented in a manner that provides ID management with all needed information and the assurance of adequacy of the ES\&H program at INEL. ID has not assured that stop work and restart authorities and processes are consistently and clearly defined and understood at INEL. Contractors have inadequately addressed the Tiger Team Management finding related to stop work and ID has performed inadequate verifications of the corrective actions and incorrectly closed these issues.

In addition to these existing ID oversight program deficiencies, the team is further concerned with the content and substance of the formal and informal documentation associated with the newly authorized ID organization with respect to its organizational structure, missions, and functions. This documentation portrays an overall reduction in the independence, authority, visibility, and senior management attention to ES\&H oversight. The Progress Assessment Team is making no judgement of the adequacy or benefits of the new organization. However, it is not clear that this approved organization, as presently defined, embodies an appropriate management commitment to ES\&H.

ID progress in addressing ES\&H oversight issues include the following examples:

- Although not evaluated in depth, interviews with numerous INEL personnel, evidence of improved contractor ES\&H performance in many areas, and evidence in the cover letters of various Performance Evaluation Reports, indicate that ID has significantly improved the use of the CPAF process to improve ES\&H performance. (See also Section 2.2.6 of this report for a further discussion of progress in this area.)

- Significant progress was apparent at RESL since the 1991 Tiger Team Assessment; primarily in the last year. ES\&H specialist have been added to the RESL staff. An initiative to perform "no-fault" team assistance assessment of individual laboratories is identifying and correcting ES\&H and physical condition problems and achieving a greater sense of ownership in the laboratory personnel. The RESL Safety Committee is an active organization with planned reviews and walkthrough inspections. RESL managers are conducting "Management by Walkdown" surveillances and documenting these activities and the results. RESL is identifying ES\&H issues formally on Discrepancy Reports and tracking these to closure through their own issue tracking system. This system includes all identified ES\&H issues, both external and internal, and issues from assessment documents for the past 2 years are being reviewed for adequate closure and entered into the tracking system if actions are incomplete.

- ID has demonstrated progress in the proactive development of strong and effective Supplemental Directives for the Safety 
Analysis and Review System (ID 5481.1B), Aviation Safety (ID 5480.13), and for Vehicle Safety (see Section 2.2.6).

- ID has made progress in hiring and placing additional Facility Representatives (FRs) into the field. The Facility Representatives are experienced, trained, and knowledgeable and are performing a strong role in the day-to-day ES\&H oversight of contractor activities. Facility Representatives in the ER\&WM and Nuclear Programs are especially effective at identifying programmatic ES\&H issues. The NP Facility Representatives program has implemented special training, qualification, and certification processes. ID is currently expanding this program into an ID-wide Facility Representative Program.

Examples of inconsistent or sporadic progress, and oversight program deficiencies identified by the team are summarized as follows:

- The QA function is now included in the ID OES\&HO organization and independent ES\&H and QA audits/appraisals are being performed on a scheduled basis. An ID QA PIan was issued in August 1992, to implement DOE $5700.6 \mathrm{C}$, but the ID QA Implementation Plan (QAPP) and subordinate $A M$ level $1 \mathrm{mplementing} \mathrm{plans}$ and procedures have not been issued (the ID and ER\&WM QAPPs are in draft form). Actions to develop and implement these plans and procedures were initiated in 0ctober 1992, but have not been aggressively pursued.

- The OES\&HO has issued several thorough oversight documents issued in 1993 that identified significant, programmatic, ES\&H management deficiencies within ID inciuding the OES\&HO Assessment of ID Line Management Systems for Managing OES\&HO Findings issued March 10, 1993, and the First Annual Office of Oversight Report issued March 9, 1993. In addition, the internal "Progress Assessment" issued on March 18, 1993, ident ified systemic ES\&H program deficiencies in a number of areas within ID. However, ID management has not taken a formal, proactive response to these self-critical and thorough oversight reports. To date, there has been no formal response to any of these reports and no management directed corrective action plans developed to address the issues raised by these oversight efforts.

- There are numerous ID policies and policy implementing procedures that are not being adhered to, especially in the areas of the issuance of surveillance schedules; the conduct and/or documentation of line staff survelllances/monitoring activities and management walkthroughs; the documentation deficiencies; the development of corrective action plans; and the tracking and closure of corrective actions.

- Additional weaknesses in ID oversight in the areas of industrial hygiene and the INEL environmental protection program are discussed in Sections 2.4 .3 and 2.3 of this report.

The INEL contractors have demonstrated progress in the areas of ES\&H oversight evaluated by the Progress Assessment Team. Many of the Tiger Team Assessment Finding Corrective Action Plan milestones have been completed and either 
closed by ID or are ready for verification and closure. Independent and line oversight organizations are performing formal appraisals and surveillances in accordance with issued schedules and the processes are described in written procedures. ES\&H oversight staffing of the contractors has increased. MK-FIC has developed a solid, proactive ES\&H oversight program.

All of the INEL contractors have established numerous ES\&H oversight committees which provide management involvement and oversight, independent reviews, and have instilled line ownership and input to the identification and resolution of ES\&H issues.

The Progress Assessment Team identified continued weaknesses in the communication and formalization of stop work/restart actions. Procedures are still inadequate and corrective actions to the Tiger Team Finding were incomplete and improperly verified and closed by both the contractors and ID. The team also identified weaknesses related to the activities of EG\&G Idaho ES\&H oversight committees in that not all are clearly defined, documented, or performed at the minimum frequencies specified in policies, procedures, and committee charters. The team notes that although these deficiencies were noted, EG\&G Idaho committees as a whole appeared to address numerous ES\&H functional areas, were involved in the review and resolution of key issues, and involved senior management at EG\&G Idaho.

The Progress Assessment Team identified two concerns and one weakness associated with the INEL oversight programs, which are presented in Appendix B-1 (see Concerns $M / C-3$, ID Oversight, and $M / C-4$, INEL Stop Work/Restart Processes; and Weakness M/W-1, EG\&G Idaho ES\&H Oversight Committees).

\subsubsection{Directives, Policies, and Procedures}

In the area of directives, policies, and procedures the Progress Assessment Team evaluated the adequacy and effectiveness of these systems within ID and selected INEL contractors to provide rigorous and formal vehicles to assure that ES\&H requirements are met at INEL. The team also evaluated the progress made in this area since the 1991 Tiger Team Assessment. In conducting this assessment, the Progress Assessment Team looked at the procedures for identifying and implementing the ES\&H requirements of applicable standards; translating these requirements into formal policies, plans, procedures, and instructions; controlling the changes to the requirements and these implementing documents; and applying these documents in practice. Tiger Team Management Finding MF- 7 described the ID directives system as being ineffective in communicating directive expectations and requirements, and in assuring adequate implementation.

The assessment approach taken by the Progress Assessment Team was to review pertinent policies, plans, and procedures; to interview ID and contractor personnel responsible for these programs; and to determine the existence and adequacy of ES\&H related procedures for a sampling of INEL programs to determine the overall adequacy of thi directives, policies, and procedures program; both its structure and implementation. The key standards used for this assessment include the ES\&H Management Performance Objectives and Criteria for Progress Assessments (Progress Assessment Manual, Appendix B-1, December 1992), Performance Criteria 2.4.1, 2.4.2, 4.4.1, and 4.4.2. 
INEL organizations have made progress in establishing, improving, and implementing formal systems for directives and procedures since the 1991 Tiger Team Assessment. The ID directives and procedures program is defined in the ID Policy Manual; ID Notice ID N 1321.001, "Idaho Operations Office Directives System Policy"; and ID Supplemental Directive ID 1321.1E, "Idaho Field Office Directives system." These documents outline a basic system for processing DOE Orders and SEN Notices; define the hierarchy of ID directives, policies, and procedures; and establish a policy of adherence to policies and procedures.

Progress has been made since the Tiger Team Assessment in improving the ID directives and procedures system. A Directives Manager has been assigned in the Office of the Assistant Manager for Administration (AMA), responsible for the ID directives system. A Quality Assurance (QA) Working Group, formed to develop the ID QA Plan to implement DOE $5700.6 \mathrm{C}$, was extended by the ID Manager in December 1992, with the tasks of coordinating new ID procedures and developing three office-level procedures including a writer's guide, a document control system, and a new organization and functions directive. However, none of the newly formatted ID Office-wide procedures, nor any of the newly identified cross-cutting issue ID Supplemental Directives have been issued to date. Many commitments to update and upgrade ID policies, made in various Tiger Team Corrective Action Plans, have not been completed; no rhanges have been made to the ID Policy Manual since the Tiger Team Assessment. ID has not been successful in developing and issuing a functional self-assessment program plan and implementing procedures.

ID management has recently determined that ID policies will now be delineated in ID Supplemental Directives and the Policy Manual will be canceled. The responsibility to coordinate, develop, and upgrade ID policies, directives, and procedure development duties have been collateral duties. Management has not dedicated the resources necessary to ensure timely and effective action to correct the known weaknesses in this key management system. As a result, progress has been slow and the situation is frustrating to many staff where activities, roles, responsibilities, and authorities (RRAs) have not been clearly defined, and existing procedures do not reflect current conditions, requirements, or performance. The lack of clear, up-to-date ID Office-wide procedures for cross cutting activities leads to inconsistency and uncertainty in RRAs across the organization. These delays in developing ID policies, directives and procedures discourages the development of effective operating procedures in subordinate organizations.

In addition to the deficiencies where procedures have not been developed or updated, there are numerous ID implementation procedures for ES\&H matters that are not being followed. This is especially evident in the areas of the issuance of surveillance schedules; the conduct and/or documentation of 1 ine staff surveillances/monitoring activities and management walkthroughs; the documentation deficiencies; the development of corrective action plans; and the tracking and closure of corrective actions. The failure to periodically review and promptly update procedures fosters an attitude of acceptance that some procedures don' $t$ need to be followed because they are outdated or wrong. Thus, the decision to adhere to procedures must be judged on the circumstances in each case. The resulting lack of control, accountability, and consistency is contrary to good management practice and the directions contained in DOE 5700.6C, "Quality Assurance," and DOE 5480.19, "Conduct of Operations." The large number of outdated procedures and lack of adherence to procedures' is especially serious when considering the important role of clear policies and 
procedures in providing guidance and direction to new employees. Nearly 60 percent of the ID staff have less than 5 years of service and over 100 people have been at ID for less than 2 years.

Although improvements have been made recently in the ID system for processing DOE Orders within ID and transmittal to the INEL contractors, a deficiency in providing clear and documented communication of expectations to the contractors was noted by the team which indicates the need for additional system improvement. ID did not formally respond to a September 1992 contractor letter specifying that all or parts of various ES\&H related DOE Orders would not be implemented due to lack of budgeted resources. No implementation plans or schedules were formally required of the contractor as a result of this letter, nor was formal approval/disapproval of the contractor's deferral of implementation documented (see Concern $M / C-4$ ).

Performance data throughout DOE operations demonstrates that among the highest risks are aircraft operations and motor vehicles. DOE-HQ has pubi ished an aviation safety Order, but not a motor vehicle safety Order for all DOE vehicles operations. Furthermore, for operations involving hazards that are not "routine" DOE-HQ has published Orders for the analysis and disposition of such hazards. The Progress Assessment Team examined the ID Supplemental Directives and programs in these areas.

A Supplemental Directive, ID 5480.13 dated August 12, 1.91 addresses Aviation Safety. In addition to the establishment of roles and responsibilities, stringent safety criteria are specified such as pilot Airline Transport Pilot (ATP) certification, 14 CFR 43 maintenance specifications for aircraft, and 14 CFR 135 standards for charter aircraft operations. A brief onsite review of the PTI aircraft operations was performed by the Progress Assessment Team Leader. The pilots are ATP certified, and the flight operations are conducted in accordance with 14 CFR 135 standards except when precluded by specific security program requirements. The ID line manager, the PTI General Manager, and the two PTI aircraft pilots interviewed by the team demonstrated knowledge of the safety standards and appeared to have a genuine commitment to safety as the first priority. The pilots demonstrated an in-depth knowledge of every aviation incident mentioned by the Progress Assessment Team Leader, and they understood the lessons learned from said incidents. In addition to DOE safet.y oversight, the PTI aviation program is inspected quarterly by the Federal Aviation Administration. It appears that PTI has an exemplary aviation safety program.

It was noted that ID has issued a Motor Vehicle Safety Program Supplemental Directive dated August 12, 1991. This was done in the absence of a DOE Order in recognition of the hazardous nature of vehicle operations. This Supplemental Directive appears to have the potential to influence the reduction of risk in this area, and ID is to be commended for this initiative.

The ID Supplemental Directive ID 5481.1B dated Octaber 18, 1991 has merits which are discussed in the Site/Facility Safety Review section of this report. An example of a safety analysis process conducted under the prescriptions of ID $5481.1 \mathrm{~B}$ is also discussed in that section.

In general, INEL contractors have established formal directives, policies, and procedures systems with formal processes for development, maintenance, and control of these documents. Formal hierarchies for directives, policies, 
manuals, procedures, irstructions, etc., have been established. Contractors have formal directives' systems to describe the processing of DOE Orders, identifying applicability and requirements, determining the level of compliance, and developing action plans to implement the requirements.

EG\&G Idaho has an established and formal hierarchal system of requirements, policies, and procedures. This four level system is defined in a EG\&G Idaho Company Policy and Requirements manual titled the "Resource Manual." The processing of DOE and ID directives is detailed in Company Procedures Manual implementing Procedure 1.9, "DOE and ID Directives Implementation." The development, revision, and control of EG\&G Idaho policies and procedures are formally controlled by procedure and there is evidence that these documents receive timely and periodic review and upgrading.

WINCO has an established system of Policy Directives and implementing procedures, including extensive functional procedures manuals and operating procedures. Policy and procedure development and control is addressed by formal procedures in the WINCO Standard Operating Procedures Manual. Processing of DOE directives is addressed in Standard Operating Procedure $W A-20$. There is evidence that these documents receive timely and periodic review and upgrading.

MK-FIC ES\&H policies and procedures are contained in their Construction Management Services Manual. MK-FIC procedure CMSM 2A-2-01 detalls the processing of DOE directives. There is evidence that these documents receive timely and periodic review and upgrading.

The Progress Assessment Team identified two concerns related to the directives and procedures systems, which are presented in Appendix B-1 (see Concerns $M / C-3$, ID Oversight, and $M / C-5, I D$ Directives, Policies, and Procedures).

\subsubsection{Human Resources Management}

In the human resources management area, the Progress Assessment Team evaluated the ID and the INEL contractors' human resource management (HRM) systems to assess their effectiveness in ensuring the availability of sufficient qualified human resources for full implementation of INEL ES\&H requirements. Specific issues included HRM plans that define and set priorities for addressing the requirements for full implementation of ES\&H programs; programs for staff development, training, and certification; and staff recruitment programs that ensure the availability of sufficient qualified ES\&H staff. This assessment area was selected because the INEL Tiger Team Assessment identified numerous deficiencies that were directly or indirectly related to the lack of effective HRM programs. All Tiger Team Assessment subteams noted inadequate training; the lack of sufficient, qualified staff; and in some cases the failure to accord suffictent resources to training. A number of key concerns and root causes could be traced to the lack of effective training programs. The key standards used to assess the progress in addressing these deficiencies were the ES\&H Management Performance Objectives and Criteria for Progress Assessments (Progress Assessment Manual, Appendix B-1, December 1992), Performance Objectives 1.3, 2.3, and 4.3: The two primary performance measures used to evaluate $I^{\prime}$ 's progress in establishing effective ES\&H HRM programs throughout INEL were the status of ID ES\&H-related HRM management. systems and the status of its contractors' systems. 
The approach of this assessment was to exainine the HRM programs of ID and the INEL contractors by conducting vertical reviews through several of these organizations. The primary emphasis of the review was on the ability of DOE and its contractors to effectively define their ES\&H s.taffing needs and ensure that these needs are satisfled. Specifically, vertical reviews through ID. EG\&G Idaho, WINCO, B\&W, MK-FIC, and PTI focused on their respective operations, ES\&H oversight, and human resource development organizations. In addition to the vertical reviews through these organizations, a horizontal review of these organizations was taken to examine the degree to which the various interrelated human resource requirements are coordinated and integrated across each organization on a sitewide basis.

Based on the performance measures described above, it is evident that ID has had a positive impact on INEL HRM as it relates to the INEL contractors. All INEL contractor's have substantially improved the ir HRM programs since the Tiger Team Assessment. By contrast, limited improvements in the ID program, particularly with respect to ES\&H-related training, have only recently occurred. There was evidence during this assessment that 10 supports the importance of qualified contractor staff to the successful execution of the INEL mission. However, ID's less than aggressive approach in addressing its own HRM defictenctes, coupled with the fact that ID continues to provide less than the minimum resources necessary to the Office of Environmental Safety and Health Oversight (OES\&HO) staff as identified by the Tiger Team Assessment. suggests that 10 management has not yet accepted the central importance of fully qualified and trained ID ES\&H staff to the successful conduct of the INEL mission.

ID has failed to effectively address the Tiger Team Assessment finding that it had not given sufficient priority to acquiring the necessary professional ES\&H staff required to carry out its ES\&H oversight responsibilities. OES\&HO staffing levels increased by approximately a third following the Tiger Team Assessment and have since decreased by a third to approximately the Tiger Team Assessment staffing levels, while ID staffing levels have increased from 424 people to approximately 520 people (adjusted for the defederalization of INEL firefighters). Over this 2-year period of intense hiring to compensate for a large staff turnover and to satisfy ID management's desire to further enhance its technical human resources, 10 hired 71 scientist and engineers, while failing to maintain even the minimum resources necessary for an effective independent ES\&H oversight organization.

The status of the ID ES\&H training and staff development program has not progressed as much as the INEL contractors' programs, primarily because of a slow start in establishing a centralized program. ID responded to the Tiger Team Assessment training-related findings by centralizing ES\&H training in the Training and Development Branch (TDB) and increasing the staffing level from a single training officer to an organization staffed with seven individuals by November 1991. This oryanization experienced a rapid decline to three staff members by January 1992, primarlly because ID did not formally translate its concept for this new organization into formally defined and communicated roles, responsibilities, and authorities (RRAs). This resulted in employee frustration followed by their migration to other positions within ID. Following an ID self-assessment in February 1992 that identified these problems, ID management took corrective actions to revitalize the TDB. The $T O B^{\prime}$ s accompiishments since that time were evident during this assessment and the ID Assistant Manager for Administration (AMA) management expressed a 
reilistic understanding of what needs to be accomplished to achieve an effective ES\&H training program. ES\&H-related training conducted by the ID Program Offices such as the Ass istant Manager for Nuclear Programs (AM/NP) and Assistant Manager/Energy Programs (AM/EP) shows recent improvement after receiving little attention for over a year following the Tiger Team Assessment. The ID Office of Nuclear Programs Facility Representative (FR) Program received 1ittle attention between the Tiger Team Assessment and October 1992. The program now appears to be receiving management attention: ID is implementing the NE VErsion of the DOE FR Program; a training program for ID-AMP is in place: and about half the Facility Representatives have undergone basic qualification. Generic Factlity Representative cards have been prepared and oral boards are now being conducted for Facility Representatives: however, the facility-specific qualification program has not progressed to the point where individuals are completing the program.

The emphasis 10 has placed on the enhancement of the mechanics and uniformity of the ID individual performance review process was evident. By February 1992, 98 percent of the Individual Development Plans (IDPs) of all 10 employees were completed; an IDP user guide has been prepared; and an IDP workshop training program has been developed. However, the quality of the individual performance appraisals has not yet been appreciably improved with respect to specific, measurable ES\&H performance expectations. ID management recognizes this deficiency persists, in part, because effective 1 ine and independent oversiglit of the IDP process has not yet been implemented.

A second measure of ID progress in establishing effective ES\&H HRM systems that will serve the INEL mission today and in the future, is the progress of the INEL contractors. In this respect, substantial progress has been noted in the INEL-wide HRM programs. While each contractor's HRM program reflects the character of that organization, overall there is little to distinguish one program from another. All INEL contractor HRM programs evidence substantial improvement over the past 2 years including the WINCO program which was judged to be a relatively strong program during the Tiger Team Assessment. Furthermore, all contractor programs contain elements that require their continued attention either because they are not yet fully implemented or have not yet satisfied the increased performance expectations of contractor management. INEL contractor Employee Concerns Programs (ECPs) have been substantially strengthened in response to deficiencies identified by the Tiger Team Assessment. There appears to be wide-spread acceptance of and enthusiasm for ES\&H training among the contractor employees. White the INEL contractors have made progress on a broad front in improving their ES\&H HRM systems, specific achievements include the following:

- B\&W's corporate parent, McDermott International, has transferred several ES\&H training- or safety awareness-related programs to INEL including the B\&W Total Quality Management, Safety Training Observation, and "Target Zero" Injury Reduction Programs.

- EG\&G Idaho has substantially increased its ES\&H professional staff since the Tiger Team Assessment. In 1991, 7 of 14 industrial safety staff were certified compared to 33 of 37 today. Other increases in ES\&H staff over 1991 levels include a nearly 4 -fold increase in certified fire protection professionals; a 2 -fold increase in certified radiation professionals; and a 10 -fold increase in environmental protection professionals. 
- MK-FIC has increased tts ES\&H staff from 3 to 13 ES\&H professionals; established and communicated ES\&H goals to all employees; imposed ES\&H training requirements on their construction supervisors; and established a strong, job-related, performance based training program. The dividends of the MK-FIC training program include a six-fold reduction in the recordable incidence rate and a nearly three-fold reduction in the lost day incldence rate since the Tiger Team Assessment.

- PTI has increased the number of ES\&H professlonals from 7 to 13 since the Tiger Team Assessment including a full time industrial hygiene professional, an aviation safety officer, Special Response Team safety officers, and an ES\&H training specialist.

- WINCO, in addition to enhancing an already strong HRM program, developed the Westinghouse/DOE 6-week environmental school that is specifically focused on professional training in environmental laws for DOE facilities. To date, 32 WINCO employees and 4 ID individuals have attended the school.

The Progress Assessment Team ident ifled one concern and one strength related to the human resources management area, which are presented in Appendix B-1 (see Concern M/C-6, Human Resource Management, and Strength $M / S-1$, INEL Training Advisory Counct1).

\subsubsection{Planning, Budgeting, and Resource Allocation}

In the planning, budgeting, and resource allocation area, the Progress Assessment Team evaluated the ID and the INEL contractors' management systems used to define and set priorities for sitewide resource requirements, allocate resources appropriately, and monitor the accomplishment of environment, safety, and health (ES\&H) objectives. This assessment area was selected because the 1991 INEL Tiger Team Assessment identified numerous deficiencies that were traced directly or indirectly to the lack of strategic and subordinate implementation planning throughout INEL. The Tiger Team Assessment root cause addressed a fundamental planning deficiency at INEL and each subteam noted the lack of sitewide near- and long-term goals and objectives. One Management Subteam key finding related directly to INEL planning deficiencies: "ID and the majority of INEL contractors do not place strategic importance on ES\&H in their planning, budgeting, and resource allocation processes." In addition to this key finding and root cause, the INEL Tiger Team report is replete with deficiencies that can be related directly to the lack of a comprehensive sitewide planning, budgeting, and resource allocation process. The key standards used to assess the progress in addressing these deficiencies were Secretary of Energy Notice (SEN) $-25-A$ and the ES\&H Management Performance Objectives and Criteria for Progress Assessments (Progress Assessment Manual, Appendix B-1, December 1992), Performance Objectives 1.1,2.1, and 4.1.

The approach of this assessment was to examine the planning, budgeting, and resource allocation process of ID and the INEL contractors by taking vertical reviews down through these organizations. Primary emphas is was placed on ID's effectiveness in formally articulating its vision of the present and future INEL mission, communicating its vision to its contractors, and ID's ability to hold its contractors accountable for defining and executing their missions in 
a planned and disciplined fashion. The strategic and subordinate implementation planning process of the contractors was examined to evaluate their planning processes and to evaluate the effectiveness of DOE's planning, budgeting, and resource allocation process. Specifically, vertical reviews through ID, EG\&G Idaho, WINCO, B\&W, MK-FIC, and PTI focus on their respective operations divisions, ES\&H oversight organizations, and the ES\&H performance assurance organizations. In addition to these vertical reviews, a horizontal review across these organizations was conducted to examine the degree to which various interrelated subordinate implementation planning processes are coordinated and integrated on a sitewide basis.

The two primary performance measures used to evaluate ID's progress in establishing effective strategic and subordinate implementation planning process at INEL are the status of ID planning systems and the status of its contractors systems. Based on these performance measures, it is evident that ID has made a positive impact on INEL planning as it relates to the INEL contractors. While the INEL strategic planning processes have matured and are functioning, the subordinate implementation planning processes of ID are neither defined nor developed and the INEL contractors' are not yet fully functiona1. As a result, in the absence of formal, risk-based implementation plans, which would set priorities and guide ID ES\&H activities on a cost-effective basis, the ID and the INEL contractor's ES\&H activities are reactive and may not be addressing the most important issues in a disciplined fashion. Furthermore, the lack of such ID implementation plans may represent a substantial vulnerability for ID.

Since the Tiger Team Assessment, ID and its contractors have adopted a strategic, sitewide planning perspective; ES\&H considerations appear to be an integral part of the INEL planning; and all the INEL contractors appear to be full and active participants in the planning process. An INEL Strategic Plan issued 6 months after the Tiger Team Assessment provided clear INEL mission and vision statements that defined ES\&H considerations as an important element of planning, considered ES\&H considerations in a sitewide crosscutting manner, and established strategic objectives and strategies. A draft INEL

Institutional Plan incorporates and blends the best of the earlier INEL Strategic Plan and a more recent draft strategic or business plan into a single coherent plan that clearly integrates strategic, programmatic, crosscutting, and sitewide issues. These plans serve as the foundation of the INEL planning processes.

ID is currently pursuing a bold management approach for INEL that is designed to provide enhanced oversight of its INEL contractor activities and the INEL facilities. However, ID lacks a reorganization implementation plan that specifically details the essential activities that must accompany or follow a major organizational realignment. An important element of the ID management strategy is the shift of its management resources from its main offices to field locations throughout the INEL. This will involve a major reorganization that ID management has been carefully considering over the past 2 years and that has recently been approved by DOE-HQ. Since the ID reorganization will result in a major change in organizational structure, reporting relationships, and operating philosophy, the current ID management systems will be require revision. Examples of management systems that will have to be revised to reflect the new organizational and individual roles, responsibilities, and authorities include: the mission and function statements of ID organizational units, ID organizational interface agreements, the ID directive system, 
quality plans, program plans, oversight plans, and individual position descriptions and performance plans. The fact that ID is still modifying its management systems to correct the deficiencies identified 2 years ago by the Tiger Team Assessment serves as compelling testimony of the challenge that ID management faces in fully implementing its new management approach. ID has not yet prepared a comprehensive plan that assigns responsibility for developing or modifying the necessary management systems, provides a schedule with interim milestones and deliverables, and identifies the necessary resources to fully implement the ID reorganization.

The lack of a reorganization implementation plan is not a singular planning deficiency within ID. In general, ID implementation plans are cutdated, incomplete, or in draft form. ID implementation plans generally consist of a loosely related group of formal and informal documents that include outdated office program manuals; draft Quality Program Plans; groups of procedures, many outdated or in draft form; formal and informal surveillance schedules; memoranda detailing organizational goals and objectives; and performance indicator reports that take a number of formal and informal forms.

Recent improvements that have been noted in ID's planning, budgeting, and resource allocation process include enhancements in formulating the ES\&H crosscutting aspects of the INEL budget, the preparation of a Supplemental Directive to define planning authorities and responsibilities, and ID's use of the Cost Plus Award Fee (CPAF) process to influence the ES\&H performance of its contractors. While the ID CPAF process was not intensively examined during this assessment, there is substantial evidence that ID now uses this important management tool to influence the ES\&H performance of the INEL contractors by rewarding or penalizing them for their ES\&H performance.

Substantial progress has been noted in the INEL-wide planning processes. The INEL contractors' strategic plans are directly linked to the INEL Mission Statement; accord priority to ES\&H; and address environment, safety, health, and quality (ESH\&Q) as a key area of strategic importance to the contractor and INEL. These strategic plans serve as important examples of the disciplined, unified, sitewide approach ID and its contractors have taken towards defining the INEL mission over the past 2 years. Comprehensive operational and ES\&H-related multi-year plans flow from the contractor strategic $p l a n s$. In general, contractor operational plans flow from the strategic plan down through each organization to the lowest operational unit in the form of work packages. In general, INEL contractor implementation plans lack sufficient details below the work package level. Contractor implementation plans generally lack those working level plans that define and guide the specific work approach and activities of employees, identify the necessary resources, establish management performance expectations including deliverables with attendant schedules and interim milestone are in various stages of development, provide for performance variance tracking, and define the interrelationship between work packages (see Concern $E / C-1$ ).

Notwithstanding the planning weaknesses at the sub-work breakdown structure (WBS) level, the INEL contractors have made progress on a broad front in improving their planning processes. Specific achievements include the following:

- $\quad B \& W$ ensures that INEL goals and objectives are integrated into B\&W corporate strategic planning through the B\&W Idaho General 
Manager's active participation in B\&W's corporate planning process.

- EG\&G Idaho initiatives aimed at enhancing its ES\&H management systems include: a business systems self-assessment, an ES\&H checklist for preparing work authorization documents, priority for ES\&H in its overhead account budget calls, and the identification of ES\&H professionals for and assignment to specific ES\&H crosscutting budget guidance issues.

- MK-FIC has identified for the first time all DOE requirements related to their activities, and defined the level of compliance established and the resources required to satisfy these requirements.

- PTI planning and budgeting is a zero-based process based on ID program execution guidance that is distributed into work packages that address DOE requirements. A formal change control process is used to approve and document all requirement revisions.

- WINCO continues to enhance its planning processes by integrating all departmental activities with the WINCO mission and the Total Quality Plan, Roadmapping, the INEL vision, and the Environmental Restoration and Waste Management (ER\&WM) Five-Year Plan. Nearand long-term cost account activities are prioritized.

The Progress Assessment Team identified one concern related to the planning, budgeting, and resource allocation area, which is presented in Appendix B-l (see Concern M/C-7, Planning, Budgeting, and Resource Allocation).

\subsection{OVERVIEW OF ENVIRONMENTAL PROGRAM ASSESSMENT}

The Progress Assessment Team evaluated the overall effectiveness of the Idaho National Engineering Laboratory (INEL) environmental program. The assessment was conducted through a combination of interviews with key personnel, field investigations, and a review of documents. Specific components of the environmental program were selected for review based on previous Tiger Team Assessment areas of concern and as indicators of current ES\&H program performance. The environmental components assessed at INEL were air quality management, surface water management, groundwater protection, and environmental radiation.

Based on the review conducted by the Progress Assessment Team, INEL has made progress in further developing their environmental program and in implementing their restoration program since the 1991 Tiger Team Assessment. However, the resolution of several deficiencies is necessary in order to progress towards excellence. In many instances, ID is implementing environmental activities without fully integrating rigor and formality into program implementation and operational planning, including preparation of program plans and procedures. In addition, ID management has not provided authority, commensurate with qualifications and responsibility, to an organization(s) with responsibility for ensuring sitewide environmental compliance. This authority need not infringe on the project offices' line authority and responsibility for day-to-day compliance, but should provide the ID with a mechanism for more effective maragement of crosscutting issues and significant progress towards 
improved environmental performance. ID has also not placed a high priority on or shown a commitment to implementing the requirements of DOE 5400.1. especially in the area of environmental monitoring, to ensure the site as a whole achieves environmental compliance and progresses towards excellence.

With respect to the specific environmental components reviewed, the Progress Assessment Team reached the following conclusions:

- In the area of air quality management, progress has been made by ID and its contractors in achieving compliance with existing air pollution control regulations and in addressing state and Federal air permitting requirements. These achievements have been made possible in large part due to improvement in communications between ID and contractors, and between ID and the Idaho Air Quality Board (IDAQB). However, ID has not made adequate progress relative to the air portions of the key findings of the 1991 Tiger Team Assessment. These deficiencies involve the delineation of authority for the coordination of significant air issues and the compliance assurance/oversight program and ambient air monitoring program, which retain the same weaknesses that were identified by the 1991 Tiger Team. These deficiencies have restricted the INEL air quality management program to only manage issues where there are explicit state or Federal regulations. Actions must be taken to improve the air quality management program through the assignment of real authority for sitewide issues and the implementation of a formal prioritization process with the responsibility and corresponding authority for ensuring sitewide environmental compliance.

- In the area of surface water management, ID has begun to increase the priority given to surface water issues and to recognize their responsibility to develop a sitewide Surface Water Management

Program. Progress in this area includes: defining "waters of the United States," preparing water discharge permit applications for state and Federal requirements, and performing a site liquid discharge survey. While ID has shown improvement in several areas of surface water management, no formal comprehensive Surface Water Management Program has been developed to ensure consistent implementation of environmental surface water regulations and requirements across the site. A road block to consistent implementation is the lack of an ID organization(s) with the responsibility and corresponding authority for manaing sitewide surface water programs.

- In the area of the groundwater protection program, progress since the 1991 Tiger Team Assessment includes establishing a Groundwater Committee at INEL to coordinate and exchange lessons learned on groundwater issues; assigning a groundwater technical specialist position to coordinated sitewide groundwater monitoring and protection actions; preparing a Groundwater Protection Plan and the INEL Groundwater Monitoring Plan to assist in defining roles and responsibilities for groundwater monitoring and protection activities; signing a Federal Facilities Agreement/Consent Order (FFA $/ C O)$ that establishes a procedural framework and schedule for restoration actions at the INEL; improving working relationships 
with Federal and State of Idaho environmental agencies; and establishing the Environmental Restoration Management Office to perform remediation actions and manage the INEL restoration program. However, improvements are needed in the overall management and implementation process for the groundwater protection and environmental restoration programs. ID's ability to attain excellence in these programs will be inhibited by not having: provided sufficient and appropriate authority to the organization(s) responsible for sitewide groundwater issues; formalized roles and responsibilities through the documents used to manage the restoration program; and integrated actions for environmental compliance and environmental restoration.

- In the area of environmental radiation, progress since the 1991 Tiger Team Assessment has been good in managing the data quality process, including the completion of an environmental monitoring baseline document, the improvement of radionuclide air effluent data quality for EPA National Emission Standards for Hazardous Air Pollutants (NESHAPs) compliance and, the performance, by some contractors, of thorough evaluations of their effluent air monitoring for conformance with ANSI 13.1-1969. However, without an organization with the responsibility and authority to develop and require uniform sitewide environmental monitoring and surveillance practices including documented rationale and objectives in a comprehensive Environmental Monitoring Plan; the achievement of excellence will be inhibited. The issue of a comprehensive Environmental Monitoring Plan was a key finding of the 1991 Tiger Team Environmental Subteam. Finally, the inappropriate closure of several ambient air monitoring program milestones indicates the need to obtain independent and appropriate technical reviews on the closure of Tiger Team Corrective Action Plan milestones and findings.

The Progress Assessment Team identified one concern associated with ID's $^{\prime}$ Environmental Program. This concern is presented in Appendix B-2 (see Concern E/C-1, Sitewide Environmental Management Program).

\subsubsection{Air Quality Management}

In the air quality management area, the Progress Assessment Team evaluated the adequacy of current programs developed to protect, monitor, and characterize effluent and ambient air quality. Specifically, progress was assessed with regard to the management of INEL sitewide key issues as identified in the 1991 Tiger Team Assessment. The key environmental issues included problems identified with DOE Coordination and Oversight of sitewide (crosscutting issues) air pollution control issues and the ambient monitoring program. These air pollution control issues are largely defined by the following elements: (1) laws, including the Clean Air Act Amendments of 1990 regulations promulgated by the United States Environmental Protection Agency (EPA) under the Clean Air Act (CAA) and by the Idaho Air Quality Bureau (IDAQB), and permits issued pursuant to these regulations; (2) DOE Orders; (3) ID and contractor policies and procedures; and (4) best management practices.

The general approach of the air portion of the environmental assessment was a programmatic review related to the air pollution control management program 
and its progress towards excellence. The activities performed in this review consisted of interviews with ID, EG\&G Idaho, B\&W, and WINCO management; review of documents related to the management of the programs; and tours or field verification activities. The key standards used to assess the site include Performance Objectives and Criteria for Conducting DOE Environmental Audits (Progress Assessment Manual, Appendix B-3, December 1992); Protocols for Conducting Environmental Management Assessments (DOE/EH-0326); ES\&H Management Performance Objectives and Criteria for Progress Assessment (Progress Assessment Manual, Appendix B-1, December 1992); and DOE 5400.1, "General Environmental Protection Program."

Adequate progress has occurred in the air pollution control management program since the 1991 Tiger Team Assessment. To date, resources have been committed by ID and its contractors to perform the necessary technical tasks to comply with specific regulatory requirements that are mostly incorporated in the State's Construction Permit requirements. However, improvements are needed in the overall management, planning, and implementation process, particularly with respect to the management of sitewide INEL issues. ID's ability to attain excellence in their air pollution control program will be inhibited by not having authority, commensurate with qualifications and responsibility assigned, to a group responsible for sitewide air issues. This authority need not infringe on the project office's line authority and responsibility for day-to-day compliance, but should provide INEL with a mechanism for more effective management of crosscutting issues and significant progress towards improved environmental performance.

Two air quality management findings from the Tiger Team Assessment were identified as key' findings for the overall environmental assessment. One of these findings has been closed out (see Tiger Team Assessment Finding A/CF-1). Review of $A / C F-l^{\prime}$ s action plan indicates that the finding should not have been closed, because the required first step (i.e., "The first subject to be addressed will be a formal delineation of authority... ") identified in the action plan's discussion was never reflected in the plan's milestones. In practice, the lack of appropriate authority has restricted the INEL air quality management program to only manage air quality issues where there are explicit state or Federal regulations. This is because the ID prioritization process excludes formal involvement of the Environmental Support Division (ESD) and requires clear and specific regulatory drivers to be judged high priority. The INEL organization (i.e., ESD) responsible for sitewide air issues has very limited formal authority, and, therefore the management of INEL air regulatory issues is actually by consensus.

The second key air finding's (see Tiger Team Assessment Finding A/CF-2) action plan has only one milestone that was required to be finished by the date of the Progress Assessment. This milestone was indicated as closed on the same date as was scheduled (i.e., January 10, 1992). The closure process for milestones does not require independent verification of technical closeout packages. Review of the information used to close out this milestone indicates that improper technical review resulted in this milestone being closed out (see Concern E/C-1). Specifically, this milestone was closed with a baseline document that should have been a monitoring plan. In summary, relative to the Tiger Team's key findings inadequate progress has been made since the Tiger Team Assessment. This observation also raises concerns as to the adequacy of the action plan development process and action plan closure process (see Concern $M / C-1$ ). 
INEL is operated by ID, with $\mathrm{CH}$ and the Pittsburgh Naval Reactor office having programmatic authority. ID has primary responsibilities for the INEL sitewide air pollution control program including authority to be the point of contact with the State of Idaho and EPA Region X, except for point of contact responsibility. The State of Idaho considers the entire INEL to be a single major stationary source as it applies to the enforcement of state air pollution control regulations. This presents peculiar problems for the INEL, especially when considering the fact that ID has no authority over the Naval Reactor Facility (NRF) and only permitting responsibility for ANL-W, but the NRF's and ANL-W's air emissions are viewed as part of the single INEL stationary source. For example, earlier this year NRF petitioned the state for an operating permit separate from the other sources on the INEL without notice to ID or evaluation of the impact this action might have on the overall INEL air emissions operating permit. IDAQB rejected this request on the basis that a separate NRF operating permit would require a different regulatory interpretation for the entire site that would likely result in a major modification for all the INEL existing air permits and emission limitations.

INEL has four main operating contractors, EG\&G Idaho, WINCO, ANL-W', and B\&W, performing research, development, and manufacturing on the INEL. In addition, two other contractors MK-FIC and PTI, supply construction and security services, respectively, onsite. The National Oceanic and Atmc spheric Administration (NOAA) and the United States Geological Survey (USGS) also provide technical support for the INEL environmental monitoring program.

The INEL site ambient air monitoring program is operated by RESL with meteorological support services provided by NOAA. By the end of August, the responsibility for the Environmental Monitoring Plan and implementation will be transferred to ID's Environmental Support Division (ESD). This transfer of responsibilities is complicated by the fact that ESD's position, ultimate responsibility, and authority are currently not defined in the new ID organization.

There are over 10,000 emission points distributed over 1,100 buildings and structures on the INEL with more than 600 emission points identified as sources for the emissions of criteria pollutants according to "Air Emissions Inventory for the INEL." Radionuclide air emissions of concern on the INEL are noble gases, gaseous and particulate fission products, and transuranics. Non-radionuclide air pollutants emitted are nitrogen oxides, sulfur dioxide, carbon monoxide, volatile organic compounds, particulate, lead, and fluorides. In addition, sources of potential air toxics emissions, some of which are the same physical sources identified in the criteria pollutant emissions inventory, have been recently quantified as part of the draft INEL air toxics inventory.

The site has made substantial progress in establishing communications between ID and contractors, and between ID and the IDAQB. This progress has been achieved largely through the informal efforts of ID and its contractors in setting up monthly meetings to discuss important air pollution control issues. These meetings and the rapport that has been developed across the contractor and ID reporting lines has resulted in a staff-level group, within the personnel responsible for sitewide environmental compliance, that possess little direct authority, but are dealing quite effectively with IDAQB air permit requirements and specific regulations. This group is not adequately addressing complex and subjective requirements because it is difficult to come 
to a consensus on the requirements and approval that is tied to demonstrating to upper-level management a clear and strong regulatory driver. Upper level management's lack of response to less than clear and strong regulatory drivers prevents the INEL air quality management program from making progress towards excellence. A major challenge is ahead for the staff-level group during the next 2 years as the Clean Air Act Amendments of 1990's Operating Permit Program attempts to develop and enforce a single air operating permit, and the impending ID reorganization re-assigns INEL's staff (see Concern $M / C-7$ ).

It is important to point out that while the permitting requirements are currently well understood, the compliance assurance/oversight program for air pollution control issues is still very much in the condition it was during the 1991 Tiger Team Assessment.

In summary, INEL is performing adequately relative to the existing EPA and state air pollution control regulations. However, the site is still not being adequately managed to ensure compliance with DOE Orders, as was found in the Tiger Team Assessment. EPA and state air pollution control regulations are currently being enforced at the INEL site boundaries; however, DOE Orders affect both on and offsite impacts. The INEL is comprised of approximately 890 square miles. Therefore, air emissions are typically present in much lower concentrations at the site boundaries and offsite than they are onsite. ID management has not implemented the requirements of DOE 5400.1 relative to onsite ambient air quality. Both radionuclide and nonradiological (i.e., $\mathrm{NO}_{\mathrm{x}}$ ) air effluents could have long-term impact on local soil and terrestrial environs.

The future issues that are potentially the most critical to INEL are the promulgation of more stringent air regulations such as the Operating Permit requirements, and the lack of authority in a single technically qualified body to administer and represent INEL air pollution control activities. These new regulations will be significantly more stringent and more complex than the current air pollution control regulations. ID does not appear to be posturing itself to deal with the broader issue of air quality management represented by changing regulations and DOE Orders (see Concern $E / C-1$ ).

\subsubsection{Surface Water Management}

In the area of surface water management, the Progress Assessment Team evaluated the adequacy and effectiveness of the INEL program to assure that surface water discharges are characterized and managed according to DOE requirements and Federal and state regulations. During the 1991 Tiger Team Assessment, a key finding was written on the lack of characterization and monitoring of wastewater streams and the disposal of waste streams through discharge to the surface rather than treatment. This key finding represented the issues contained in four compliance findings and six best management practice findings in the Tiger Team Assessment report. All of these findings are still open, al though progress has been made on individual milestones. The key standards against which the site was assessed include: Performance Objectives and Criteria for Conducting DOE Environmental Audits (Progress Assessment Manual, Appendix B-3, December 1992) relating to surface water programs; Protocols for Conducting Environmental Management Audits of DOE Organizations (DOE/EH-0326); ES\&H Management Performance Objectives and Criteria for Progress Assessments (Progress Assessment Manual, Appendix B-1, 
December 1992); the Clean Water Act (CWA); regulations promulgated by the EPA under CWA; regulations promulgated by the Idaho Department of Health and Welfare (IDHW); and DOE 5400.1, "General Environmental Protection Program."

The general approach taken by the team was a programmatic review related to surface water management activities and included conduct of interviews with individuals at both ID and operating contractors (EG\&G Idaho, WINCO, and B\&W) that are responsible for the monitoring and management of wastewater at INEL. In addition, interviews were conducted with personnel within the ID office of Environmental Safety and Health Oversight (OES\&HO) to evaluate DOE's oversight of this area. To support the interviews, the following principle documents were reviewed:

- The Phase I liquid effluent inventory;

- The plan for the characterization of the liquid effluents;

- The Environmental Monitoring Plan: baseline document;

- The Groundwater Protection Plan; and

- The Draft INEL Water Resources Program Plan.

Also, selected site visits were performed to determine how the plans are being implemented in the field.

Significant progress has occurred in the surface water management program since the 1991 Tiger Team Assessment. To date, resources have been committed by ID and its contractors to perform specific state and Federal regulatory requirements for the discharge of wastewaters to the land and stormwater permits. However, improvements are needed in the overall management, planning, and implementation process, particularly with respect to the management of sitewide INEL issues. Currently, the line organizations have been given the responsibility and authority for day-to-day compliance at their facilities; however, ensuring compliance at the individual facility does not ensure compliance on a sitewide basis. Therefore, ID's ability to ensure compliance and attain excellence in their surface water management program will be inhibited by not having a formalized surface water program and not having assigned the responsibility and corresponding authority to an ID organization(s) for sitewide surface water issues. This authority need not infringe on the project office's line authority and responsibility for day-to-day compliance, but should provide the INEL with a mechanism for more effective management of crosscutting issues and significant progress towards improved environmental performance.

Wastewater discharges from INEL go to the onsite sewage treatment plants, septic tanks, evaporative treatment systems, percolation ponds ( 1 and appli_-tion), drainfields or drainage patterns, and to publicly owned treatment works for the Idaho Falls facilities only. New municipal treatment systems are being designed for the RWMC, CFA, SMC, and TRA; the ICPP system is being upgraded. The process and sanitary wastewater treatment system at SMC is being upgraded, from a percolation system to an evaporative treatment system and an evaporative treatment system has been constructed for the warm waste at TRA. In addition to the treatment of municipal and industrial wastewater, examples of pretreatment of wastewaters at the INEL include the use of silver 
recovery canisters assoclated with photography laboratories, lead removal filters associated with the PTI gun range, ofl/water separators, and neutralization of demineralization regenerant water. Wastewater at the IRC is neutralized only as needed. Additional small discharges from various processes at the site are discharged to the land surface.

During the 1991 Tiger Team Assessment, the surface water management program was found to be "non-existent." Most wastewater streams were not fully characterized or monitored, and waste streams were managed primarily through disposal rather than through treatment. The wastewater monitoring programs were limited in scope relative to parameters analyzed for sample type, frequency, and location. Standard operating procedures were found to be inadequate or non-existent for radiological and non-radiological sewage treatment plant monitoring programs; however, the caltber of the field sampling in the EG\&G Idaho nonradiological program was excellent. Wastewater treatment at INEL at the time of the Tiger Team in many instances consisted of only the removal of the liquid to a system that conveyed the wastewater into the ground. The general lack of regulatory controls at the site had fostered an attitude of complacency toward optimizing treatment of the liquid wastes.

Sirce the 1991 Tiger Team Assessment, INEL has begun to change their priority with regard to surface water issues and recognize their responsibility to develop a sitewide Surface Water Management Program; however, in most cases this change in priority has been from the level of the technical specialist up, rather than in coordination with a prioritized strategic vision from INEL management. ID technical specialists have begun to develop sitewide policies and programs that are essential to an effective program, including: defining the "waters of the United States" on the site; preparing and submitting a National Pollutant Discharge Elimination System (NPDES) permit application for a process water discharge at the ICPP; submitting Wastewater Land Application permit applications to the State of Idaho for the Percolation Ponds and Sewse Treatment Plant Infiltration Trenches at ICPP and initiating the Wastewater Land Application permit applications at CFA, TRA, and TAN; the conduct of Phase I of the Site Liquid Effluent Inventory; and the current effort to implement the INEL Surface Water Management Program Plans (SWPPPs) in compliance with the sitewide NPDES General Stormwater Permits. Each of these examples have been performed or are being performed on a coordinated sitewide basis. The major driver is an informal INEL Surface Water Committee which includes: ID, EG\&G Idaho, WINCO, B\&W, ANL-W, and the Naval Reactor Facility (NRF). The participation of both ANL-W and NRF is particularly noteworthy based on the pastidifficulties ID has had coordinating sitewide environmental issues with respect to ANL-W and NRF operations.

While INEL has shown improvement in several areas of surface water management, no formal comprehensive Surface Water Management Program has been developed to ensure consistent implementation of environmental surface water regulations and requirements across the site (see Concern $E / C-1$ ). The lack of this program has allowed contractors to set their own priorities for wastewater management, which may conflict with sitewide priorities and has led to coordination difficulties between various organizations within ID. In addition to the lack of a sitewide program, there has been no formal sitewide prioritization of surface water related projects, which can lead to critical sitewide projects being passed over for projects with more specific interest to a given program organization. 
An additional concern, in the area of surface water management, has been the lack of authority of an ID organization(s) with the responsibility for ensuring envirunmental compliance on a sitewide basis (see Concern $E / C-1$ ). Currentiy, the Environmental Support Division (ESD), which has the responsibility for sitewide surface water management, does not have formal input in to the planning and prioritization process or the development of project implementation plans. This lack of authority, at the technical level. has caused a significant delay in the development of the Environmental Monitoring Plan and the low prioritization of the development of flood plain maps. In addition, the lack of authority has allowed the selection of the Technical Area North (TAN) percolation pond area for the discharge of remediated groundwater without consideration for how this will effect the ability of the site to obtain a Wastewater Land Application Permit.

\subsubsection{Groundwater Protection Programs}

In the groundwater protection area, the Progress Assessment Team evaluated the adequacy of prograins developed to protect, monitor, and characterize groundwater resources, and to identify, evaluate, and restore contaminated groundwater sites. In conducting these assessments, the team looked specifically at the groundwater portion of the Environmental Restoration Program and the Groundwater Protection Management Program. The Groundwater Protection Management Program was assessed to determine how effectively it integrated a variety of groundwater actions including the manney in which the environmental restoration program groundwater portion was being planned, managed, and coordinated with the sitewide monitoring programs administered by the ID Environmental Support Division. The Groundwater Protection Management Program was selected because groundwater was an integral part in the key findings for the Environmental Monitoring and Survelilance Program; DOE Direction, Coordination, and Oversight of INEL Activities; and Wastewater Characterization and Management in the 1991 Tiger Team Assessment. The groundwater portion of the Environmental Restoration Program was selected because the identification, evaluation, and restoration of contaminated groundwater is a major part of the INEL's Environmental Restoration Program.

The approach taken by the team was a programmatic review related to these groundwater protection activities and included interviews of ID, operating contractors (EG\&G Idaho, WINCO, MK-FIC Environmental Services, and B\&W), support contractors (MK-FIC Environmental Services and GEOTECH), and EM management; selected visits were made to groundwater monitoring and/or restoration sites.

To support the interviews, the following principle docuinents were reviewed:

- Federal Facility Agreement and Consent Order;

- Guidance for Assessing Low Probability Hazard Sites at INEL;

- INEL Environmental Restoration MSA Project Management Plan;

- The Groundwater Protection Plan; and

- INEL Groundwater Monitoring Plan. 
Additional documents relating to the management of the Environmental Restoration Program and the Groundwater Protection Management Program were also reviewed. The key standards used to assess the site include Performance Objectives and Criteria for Conducting DOE Environmental Audits (Progress Assessment Manual, Appendix B-3, December 1992) relating to Groundwater Programs and Inactive Site Program Planning; Protocols for Conducting Environmental Management Audits of DOE Organizations (DOE/EH-0326): and ES\&H Management Performance Objectives and Criteria for Progress Assessinents (Progress Assessment Manual, Appendix B-1. December 1992).

Progress has occurred in the groundwater protection program since the 1991 Tiger Team Assessment. This progress includes establishing a Groundwater Committee at INEL; updating the Groundwater Protection Management Program Plan; implementing a Groundwater Monitoring Program; conducting a Well Fitness Evaluation Survey; signing a Federal Facilitites Agreement/Consent Order (FFA/CO) that establishes a procedural framework and schedule for restoration actions at the INEL; improving working relationships with Federal and State of Idaho environmental agencies; and establishing the INEL Environmental Restoration Management office (ERMD) to perform remediation actions and manage the INEL restoration program.

Improvements, however, are needed in the overall management and implementation process for the groundwater protection program. ID's abllity to attain excellence in their groundwater protection program will be inhibited by not having formalized roles and responsibllities; provided sufficient and appropriate authority to the organization responsibio for sitewide groundwater issues; or integrated actions for groundwater protection and environmental restoration. To date, three of the four findings from the 1991 Tiger Team Assessment remain open.

Two key organizations at ID are involved in groundwater protection and management, with overall coordination for groundwater issues assigned to the Environmental Support Division's Groundwater Program Manager. The Environmental Restoration Division has responsibility for restoration actions including remediation of groundwater under the FFA/CO.

During the Tiger Team Assessment, the implementation of the groundwater management program was found to be adequate, but "there appeared to be an overall lack of clear definition in responsibilities and the site could not consistently meet substantive schedule requirements of regulations and DOE Orders." The groundwater monitoring program was elaborate, however, the quality and representativeness of the data was questionable. Groundwater monitoring at the INEL was performed by seven different government agencies, $M \& 0$ contractors, and support contractors.

Since the 1991 Tiger Team Assessment, ID has recognized its responstbility to develop a sitewide Groundwater Management Program. ID has developed or taken several actions that are necessary for an effective program, including: assigning a groundwater technical specialist position to coordinated sitewide groundwater monitoring and protection actions; preparing a Groundwater Protection Management Plan and the INEL Groundwater Monitoring Plan to assist in defining roles and responsibilities for groundwater monitoring and protection activities; and performing a Well Fitness Evaluation Survey to ensure the quality of the groundwater monitoring data was not impacted by the condition of the well. Each of these actions has been performed on a 
coordinated sitewide basis. A major factor in the progress seen in the groundwater protection program has occurred as a result of activities of the INEL Groundwater Committee. This chartered Committee, which includes members from the ID Environmental Support Division and Environmental Restoration Division, USGS, EG\&G Idaho, WINCO, B\&W, ANL-W, M-K Environmental Services, and Naval Reactor Factlities (NRF), meets monthly to coordinate and exchange lessons learned on groundwater issues. ANL-W and NRF participation helps to ensure the coordination of groundwater issues across the INEL.

While ID has shown improvement in providing groundwater protection coordination and management, there st 111 remains a concern with the separation between the authority and responsibility for groundwater protection and the groundwater compliance technical expertise. Responsibllity for environmental compliance at each factlity has been assigned to the cognizant Line Program (Assistant Manager), with the compliance duties often performed by one person. Responsibility for developing and coordinating the sitewide environmental monitoring and protection program is assigned to the Environmental Support Division. Technical expertise for ensuring sitewide compliance exists within the Environmental Support Division. This division does not have the responsibility or authority to ensure sitewide compliance. Therefore, since the division has very limited formal authority, the management of the sitewide groundwater protection program is supporled by consensus through the INEL Groundwater Committee, rather than by a strategic viston of ID management (see Concern $E / C-1)$.

Regarding the environmental restoration program, INEL was 1isted on the National Priorities List (NPL) in November 1989. As a result, a FFA/CO between ID, the U.S. Environmental Protection Agency (EPA) Region $X$, and the State of Idaho was signed on December 9, 1991. This FFA/CO integrates the requirements of the Comprehensive Environmental Response, Compensation, and Liability Act (CERCLA); Resource Conservation and Recovery Act (RCRA); Idaho Environmental Protection and Health Act; and provides the framework and schedules for characterizing, assessing, and remediating sites at INEL. Presently, 10 Waste Area Groups (WAGs) of potential release sites have been identified for action under the FFA/CO, including sites at the NRF and at ANL -W. The WAGs at NRF and ANL-W, which are handled by $\mathrm{CH}$ and Pittsburgh Naval Reactor office, are not included in 1D's Environmental Restoration Program.

At the time of the 1991 Tiger Team Assessment, the restoration program was in the initial phase of development, and there was room for improvement in the area of sitewide program planning, coordination, and implementation. Since that time, the INEL Environmental Restoration Management office (ERMD) has been established to perform remediation actions and manage the INEL restoration program. Through the EM 5-year planning process, project plans and budgets have been developed, and activity data sheets and funding have been estabilshed for the WAGs. In addition, the INEL Environmental Restoration Major System Acquisition (MSA) Project Management PIan is used to define the process used to manage and control the restoration program at INEL. Within the ID Restoration Program, strong internal communication among management and WAG managers has been developed. Outside of INEL, excellent working relationships have been established with Federal and state environmental agencies on actions and programs involved in the FFA $/ C O$. This excellent relationship is shown by the awarding of the EPA Bronze Metal for Commendable Service to several ID personnel for their work in "exemplary team 
commitment, creativity, and expertise in finding innovative and precedent setting methods to achieve rapld cleanup dectsions."

However, several documents used to manage the restoration program have not been updated and/or approved. The ER\&WM Managing for Safety and quality Manua1, Section 2.0, "Organization. Mission, and Function Statements, "for the Environmental Restoration Division (revision 2 - June 1991) has not been updated to remove the Grand Junction Project office duties and responsibilities. Several "Management Controls Instructions" were developed and are being used by ERD, but have not been approved by the Assistant Manager/Environmental Restoration and Waste Management (AM/ER\&WM) or incorporated into Section 4.0 of the ER\&WM Managing for Safety and Quality Manual. As an example, the Admintstrative Record/Information Repository Document Incorporation Procedure is dated September 30, 1992 and is in Revision 2, but has not been approved by AM/ERWM or incorporated into Section 4.0. In addition, the INEL Environmental Restoration MSA Project Management Plan, revision 2, has not been approved by AM/ER\&WM or the Manager, ID (see Concern $M / C-2)$.

\subsubsection{Environmental Radiation}

In the area of environmental radiation, the Progress Assessment Team evaluated the progress made by INEL since the Tiger Team Assessment conducted in July 1991. During the assessment, the team reviewed management systems, activities, and documents of plans and programs generated by ID and the various site contractors in response to the Tiger Team findings. ID (including RESL) and selected site contractors (B\&W, EG\&G Idaho, and WINCO) were also assessed for their ability to implement corrective actions for closure of findings and conduct effective self-assessments. Specifically, the areas examined were those of environmental radiological monitoring and surveillance for ambient air and effluent monitoring. The ambient air and effluent monitoring program was selected because it was an integral part in one of the 1991 Tiger Team Assessment's key findings relating to the INEL Environmental Monitoring and Surveillance Program.

The approach taken by the Progress Assessment Team was a programmatic review related to these environmental radiological protection activities via document review, interviews of ID and contractor management and staff, and focused field verification of corrective actions. To support the interviews, the following key documents were reviewed:

- INEL Environmental Monitoring Baseline Document;

- 1992 INEL NESHAPs Annual Report; and

- The INEL Site Environmental Report for 1991.

This programmatic review involved a vertical slice examining the issues of DOE oversight and monitoring programs. Additional documents relating to the management of the Environmental Radiation Programs and Environmental Monitoring Programs were also reviewed. The key standards used to assess the site include Performance Objectives and Criteria for Conducting DOE Environmental Audits (Progress Assessment Manual, Appendix B-2, December 1992) relating to environmental radiation protection and air quality protection; Protocols for Conducting Environmental Management Audits of DOE Organizations 
(DOE/EH-0326); ES\&H Progress Assessment Manual (December 1992); Environmental Regulatory Guide for Radiological Effluent Monttoring and Environmental

Survell1ance (DOE/EH-0173T); and DOE 5400.1, "General Environmental Protection Program," and DOE 5400.5, "Radiation Protection of the Public and the Environment," as primary requirements.

The findings of the Tigur Team Assessment, which are relevant to the scope of this Progress Assessmerit, include the lack of a comprehensive Environmental Monitoring Plan (EMP), which was a key finding (KF-001); three findings in the air discipline, two of which described deficiencies in the ambient air monitors (see Tiger Team Assessment Finding $A / C F-3$ ) and radiological stack effluent monitoring (see Tiger Team Assessment Finding A/CF-7), while the other finding concerned data provided in the National Emission Standards for Hazardous Air Pollutants (NESHAPs) Report (see Tiger Team Assessment Finding $A / C F-9)$; and two findings in the radiation discipline, one which related to the calculation of dose to the public (see Tiger Team Assessment Finding $\mathrm{RAD} / \mathrm{CF}-1)$, and the second relating to air monitoring during emergency situations (see Tiger Team Assessment Finding RAD/CF-3). Other relevant environmental radiation findings of the 1991 Tiger Team Assessment were also evaluated for progress as they related to air issues.

ID has made good progress related to data quality with unabated radionuclide air effluent estimates. It appears that the INEL is now in compliance with EPA NESHAPs requirements. However, INEL has not made significant progress towards correcting other deficiencies noted below, all of which were identified by the Tiger Team in the area of environmental radiation and related air quality management findings. ID has not established uniform sitewide environmental monitoring objectives that RESL and the contractors at INEL would use in developing radiological monitoring and surveillance programs, and reporting of information. Part of the delay in developing the EMP may be due to a lack of oversight that should have come from the ID office of Environmental Safety and Health Oversight (OES\&HO). This group has the responsibility for sitewide oversight of environmental compliance; and to date, has not pizform any crosscutting appraisals of radiological and nonradiological environmental monitoring and surveillance programs. Furthermore, the ambient air monitoring program RESL currently maintains was found to be technically deficient with respect to all new sampier filter shrouds, and the siting of at least two locations. The comprehensive Environmental Monitoring Plan, which is the driver behind the design and implementation of the INEL radiological monitoring and surveillance programs, has not been completed. The exercise of developing a comprehensive Environmental Monitoring PI wi, per the requirements of DOE 5400.1 and $\mathrm{DOE} / \mathrm{EH}-0173 \mathrm{~T}$, should correct the shortcomings that exist in the current program and provide detailed recommendations on improvements that are necessary.

There are a number of facilities at INEL that release radioactive materials into the air via stacks, vents, and diffuse sources such as ponds and contaminated soil. Each contractor (i.e., ANL-W, B\&W, EG\&G Idaho, NRF, and WINCO) is responsible for inventorying, sampling, analyzing, and reporting radioactive air emissions from their facilities. The air emissions data reported by each contractor is entered into the Radioactive Waste Management Information system (R.WMIS). This data is used in calculating the dose to the public which is published annually in the Site Annual Environmental Report and the NESHAP Report. DOE 5400.1 requires that the design criteria and rationale 
for the radiological ambient air and effluent monitoring programs be presented in a comprehensive Environmental Monitoring Plan. Furthermore, 40 CFR Part 61 outlines criteria and EPA acceptable methods for continuous air effluent monitoring, and states periodic confirmatory measurements be made to confirm regulatory compliance.

The 1991 Tiger Team Assessment identified the lack of a comprehensive EMP for the INEL (see KF-001). The INEL developed an action plan to create a comprehensive Environmental Monitoring Plan, and committed to complete this action by February 1, 1993. The Progress Assessment Team found that INEL had developed an environmental monitoring basel ine document in June 1992 that provided a description of the current responsibilities and approaches of the contractors for radiological monitoring. This document is not a comprehensive Environmental Monitoring $\mathrm{Plan}$ with respect to the requirements of DOE 5400.1 because it lacks the criteria outlined in DOE/EH-0173T.

ID has failed to ensure that radiological stack monitoring programs have been developed consistently across the INEL, and contractors have not been provided sufficient guidance to review and upgrade their sir monitoring programs.

Radiological stack monitoring programs for the INEL contractors were identified during the Tiger Team Assessment as possessing numerous design deficiencies in stack sample collection and monitoring equipment, and analytical procedures (see Tiger Team Assessment Finding A/CF-7). The ID and INEL site action plan requires a review of stack sampling systems and associated procedures, but individual contractor action plans do not uniformly address this issue with respect to required action and timeline for completion of milestones. This may result in inconsistent, and of varying quality, sampling approaches across INEL. There has been some progress on this issue, and initial milestones have been met. However, some Tiger Team Assessment milestones related to air effluent sampling systems have been closed out without a thorough appraisal of applicable requirements. As a result, some stack sampling systems have been determined not to need continuous monitoring but, in fact, the systems in question are not fully characterized for accurate periodic confirmatory monitoring and thus do not meet the requirements of 40 CFR 61, Subpart H, and DOE/EH-0173T.

The dose to the public, which was the subject of Tiger Team Assessment Finding $\mathrm{RAD} / \mathrm{CF}-1$, is calculated in part from contractors' air monitoring data. The Tiger Team noted that errors in the sampling and analysis of the air monitoring (see Tiger Team Assessment Finding A/CF-7) propagate through the various airborne effluent radioactivity estimates and may eventually result in errors in the calculation of the offsite dose. The ID and INEL contractor action plan to address this finding involved evaluating and integrating the INEL contractors' radiological stack monitoring elements into the Environinental Monitoring Plan. This new information would then be integrated into any revisions of the INEL dose calculation methodology, as stated in the RAD/CF-1 action plan. The completion of milestones required in the action plans to achieve the integration of this information into the Environmental Monitoring Plan will not be met due to the delay in completion of the Environmental Monitoring Plan.

The Tiger Team Assessment identified that the NESHAPs report submitted to the EPA for compliance with 40 CFR 61 consisted of numerous errors in methodologies for estimating emissions, and discrepancies between the data supplied by the contractors and the data appearing in the report (see Tiger 
Team Assessment Finding $A / C F-9)$. ID designed an action $p 1$ an to address this finding which involved assessing each source of radioactive emissions at the INEL and randomly re-evaluating 10 percent of the data on estimated unabated release potential. There has been much progress made by ID and the site contractors on this issue. As noted above, it appears that the INEL is now in compliance with the EPA NESHAPs requirements for radionuclides.

\subsection{OVERVIEW OF SAFETY AND HEALTH PROGRAM ASSESSMENT}

The Progress Assessment Team evaluated the overall effectiveness of the INEL safety and health program. This assessment was conducted through a sampling of programmatic organizations and functions, including a combination of interviews; a review of key documents; and where appropriate, field inspection including a sampling of activities and processes. Specific safety and health disciplines were selected for review based upon previous Tiger Team Assessment areas of concern, or because those disciplines were believed to be characteristic of safety and health program performance, or because the area was indicative of current performance. The safety and health disciplines assessed at INEL were the construction safety programs, worker safety and OSHA programs, maintenance programs, packaging and transportation programs, site/facility safety review programs, and industrial hygiene programs.

Based on the safety and health review, the Progress Assessment Team reached the following conclusions:

- In the area of construction safety programs, progress has been made in the MK-FIC program. MK-FIC has developed and implemiented a model construction safety and health program. This turnaround since the INEL Tiger Team Assessment is a result of improvements that were established and implemented in the management systems, which have dramatically improved the injury/illness rates. There has been an increase in MK-FIC's construction safety and health professional staff since the 1991 Tiger Team Assessment which has significantly improved the construction program. Special procedural emphasis has been placed on staff training, tracking, and trend analysis, root cause analysis and correction, formal training: procedures and management accountability for construction safety performance, and the conduct of job safety analyses. MK-FIC has implemented an integrated approach to assuring the provision of industrial hygiene services for construction projects through a requirement for safety and health reviews in the project design and planning stages, which includes requirements for site safety and health plans for environmental restoration and waste management operations. In the area of hazard communication, MK-FIC has implemented requirements for subcontractor submittal of safety and health program documentation, and site standardization of training requirements to include sponsorship of National Safety Council courses for its subcontractors. MK-FIC has also implemented a training/qualification program for construction supervisors and managers to include safety and health requirements. Work control systems now include requirements for job safety analysis, plan of the day meetings, construction safe work permits, pre-bid and pre-construction safety conferences, and subcontractor daily inspections. In the area of oversight, MK-FIC has effectively developed and implemented requirements for 
construction supervisor surveillances, targeted surveillances and management assessments, and a quarterly MK-FIC corporate office assessments. ES\&H goals and performance indicators are established for safety and health activities and are presented in a monthly report to management.

In the area of the occupational safety and health programs for general industry, EG\&G Idaho has established a Compliance Management System (CMS) to track completion of the 1991 Tiger Team findings. EG\&G Idaho has corrected all of the Tiger Team Assessment Category II findings in this area. The remaining Category III findings have been assigned milestones for completion. EG\&G Idaho has developed and implemented a trending analysis system to determine root causes.

EG\&G Idaho has established a single point of contact safety person who coordinates its construction safety with MK-FIC. EG\&G Idaho has in response to a hoisting and rigging incident at the 0ak Ridge Site, effectively implemented a hoisting and rigging program, and has published a manual for hoisting and rigging operations. As a part of the lesson learned approach, EG\&G Idaho initiated a survey of the entire INEL site in January 1993 to inspect all rigging apparatuses and remove from service all of the unsatisfactory equipment. In the area of human resources, an EG\&G Idaho Safety and Health Process Improvement initiative has been implemented. The number of technical certifications of EG\&G Idaho's technical staff has increased. An EG\&G Idaho Training Advisory Council was established to coordinate. ES\&H training development across INEL. The purpose of this council is to consolidate training, reduce and resolve concerns in the areas of training at INEL. EG\&G Idaho has established a centralized data base to track ES\&H issues and milestones.

EG\&G Idaho does not have an effective lessons learned process to evaluate environment, safety, and health deficiencies at all of its ID facilities to determine whether other facilities could benefit from being advised of occurrences. Without the elements of trending and lessons learned, it is difficult not to repeat past errors or to prevent the occurrence of similar incidents at other facilities.

Several safety and health program elements were submitted by EG\&G Idaho to ID as exemplary programs and nominees for the DOE-HQ Worker Protection Pilot Initiatives. The elements include asbestos management, laser safety, employee safety assurance process, Hazard Communications, and the Requirements Awareness Programs.

Subsequent to the 1991 Tiger Team Assesiment, a Technical Safety Appraisal (TSA) was conducted at the WINCO Idaho Chemical Processing Plant (ICPP). The Health and Safety functional areas included the TSA areas in DOE/EH-135 as well as the seismic and engineering support. The TSA Team identified 99 concerns in the TSA technical areas and 194 OSHA noncompliance issues. Ninety-five of the technical area concerns involved WINCO 
performance and the remaining involved ID. A sample of corrective actions reviewed indicated that they were appropriately structured to include upgraded management systems and programs necessary with the goal of achieving health and safety excellence. The programs and systems include the Oversight and Appraisal Program, Compliance Management System, Training Program, and an upgraded Procedures Control System. The individual corrective action plans include schedules, milestones, budgetary information, and the organizations responsible for implementation. WINCO management has taken a strong leadership role in developing an action plan to respond fully to the TSA assessment.

- The worker safety and OSHA program consists of two areas; construction safety and general industry/occupational safety and health as defined by DOE prescribed U.S. Department of Labor Occupational Safety and Health standards. The ID Office of Environmental Safety and Health Oversight (OES\&HO) has developed and implemented a comprehensive program which plans, schedules, conducts, and reports inspections, surveillances, special reviews, and appraisals of contractor construction and occupational safety programs and has developed a oversight program manual. OES\&HO has conduated an acceptable number of surveillances of the construction and general industry safety programs. OES\&HO has implemented root cause and trending analys is of the construction safety and general industry programs. Areas for improvement include the development of a trend analysis capability.

- In the maintenance program area, EG\&G Idaho has made progress since the 1991 Tiger Team Assessment. EG\&G Idaho has developed and implemented maintenance management program practices, oversight requirements, and improved the job control systems. Overall safety performance indicators reviewed by the team indicate that actual injury incidence rates in the maintenance area remain unchanged from 1991. The changes to programs that were implemented by EG\&G Idaho do not appear to have affected the worker safety performance. Improvements in the area of conformance with DOE $4330.4 \mathrm{~A}$ were noted by the Progress Assessment team in the areas of savings in procurement costs, asbestos abatement, staff certifications in ES\&H, and maintenance staff training. EG\&G Idaho has issued planning documents and a maintenance management program document; however, the supplemental directive ID $4330.4 \mathrm{~A}$ does not adequately address the new requirements of DOE $4330.4 A$.

The Progress Assessment Team evaluated the packaging and transportation area of all five site contractors and RESL. The numbers of onsite and offsite shipments of hazardous and nuclear materials varies from hundreds per year by EG\&G Idaho to only a few per year by PTI, MK-FIC, and RESL. The team noted progress in this area among all five site contractors. B\&W has made progress in developing procedures, shipper interface agreements with EG\&G Idaho, and training requirements. EG\&G Idaho has made progress in closing out the 1991 Tiger Team Assessment concerns. Annual internal oversight audits by the EG\&G Idaho Performance Oversight Assessment Group and self-assessments of the EG\&G Idaho packaging 
and transportation program have been conducted. Corrective actions implemented by EG\&G Idaho to improve their packaging and transportation program have paid dividends: six 0ccurrence Reports were written against EG\&G Idaho in this area in 1992, whereas none have been issued through July 1993. WINCO has modified its policy document and revised packaging and transportation procedures to meet DOE requirements. PTI has issued a new procedure which adequately addresses the requirements for employees involved in shipment of hazardous materials. MK-FIC has added a comprehensive Hazardous Material Transportation section to their overall plant policy manual, which meets the specified DOE requirements.

In the area of site facility/safety review programs, the team assessed the method and effectiveness by which RESL addressed the Tiger Team Assessment concerns with respect to safety documentation as well as the management systems to arrive at satisfactory reviews of their facilities. An examination of the safety analysis report that was written for their laboratory facility showed that the documentation was poorly conceived, technically flawed, and of limited use to management in permitting a judgement as to facility operation safety requirements. RESL management did not follow the formal ID system for safety analys is review that was specified and as a result the product not a quality report. RESL has since corrected their policies and responsibility definitions regarding the generation and maintenance of facility safety documents so incidents of this sort should not recur. In contrast to this deficient performance, the safety documentation covering the removal of unexploded ordnance at specific INEL locations was well planned and executed. Acceptable safety reviews were completed and acceptable technical expertise was employed in areas where it did not formerly exist. Additionally, the project was found to be well managed by ID from a technical standpoint.

- Significant progress in the area of industrial hygiene has occurred at INEL in the closure of 1991 Tiger Team Assessment findings by ID and all INEL site contractors. Implementation of programmatic change has occurred in the industrial hygiene program within a relatively short period of time since the 1991 Tiger Team Assessment. This progress indicates that a positive cultural change is occurring within the industrial hygiene area. However, the development of the INEL site industrial hygiene programs currently are not fully complete and programs among the site contractors vary in their formality, depth, and level of implementation. The consolidation of the INEL contractors in 1994 adds impetus for standardization, coordination, and integration of industrial hygiene program planning and prioritization systems from a sitewide perspective. The scope, depth, and formality of the ID and INEL site contractors planning needs further improvement to sustain and further improve the INEL site industrial hygiene program post response to the Tiger Team initiative. Sitewide performance indicators, self-assessment, strategic goals, and plans for the INEL industrial hygiene program have not been fully established within the ID and INEL 
contractors' organizations, and are not utilized for sitewide integrated planning and program management.

Long range industrial hygiene program plans are not prepared or utilized within ID. Surveillances of the industrial hygiene program conducted by ID are not always preformed by industrial hygienists. Staffing levels within ID OES\&HO and the Technical Support Division (TSD) are insufficient to support programmatic requirements. In general, the industrial hygiene self-assessment programs among the INEL site contractors have been limited to compliance issues and have not incorporated program management performance objectives. The implementation of the industrial hygiene program within ID has largely been driven by the initiative of the working staff levels rather than being based upon a clear definition of overall programmatic plans, objectives, and management of risks from a strategic organizational initiative within ID.

\subsubsection{Construction Safety Program}

In the area of construction safety, the Progress Assessment Team evaluated the adequacy of INEL's site program in terms of the effectiveness of MK-FIC construction safety programs. MK-FIC provides construction management services to the INEL. Construction safety was evaluated as part of the 1991 Tiger Team Assessment with significant deficiencies noted, which included 2 Category I, 12 Category II, and numerous Category III findings. In conducting this Progress Assessment, the team looked specifically at how well MK-FIC has integrated the management of construction safety into the project management process and the use of the self-assessment process to improve program performance. This approach was selected because ID and MK-FIC project managers have the line responsibility to ensure that MK-FIC and subcontractor activities fully comply with Occupational Safety and Health (OSH) requirements. The assessment was performed by interviewing MK-FIC and ID staff responsible for construction safety, reviewing construction safety program documents, and observing site conditions and activities. The key standards used to assess the management and performance of ID and MK-FIC in the construction safety area include 29 CFR 1926 and 1910 OSHA regulations, DOE 5480.9 and 4700.1 , and the ES\&H Performance Objectives and Criteria for Technical Safety Appraisals (Progress Assessment Manual, Appendix B-4, December 1992).

Overall, MK-FIC has a model construction safety program. This turnaround since the Tiger Team Assessment is a result of improvements in management systems, which have dramatically improved the injury/illness rates. One area of improvement that has significantly helped the program was an increase in construction safety staff. Another area of improvement has been development of special training procedures and training courses that address tracking and trending analysis,' root cause analys is and correction, management accountability for construction safety performance, and the conduct of job safety analyses. These procedures have been put in place within the past year and have provided effective measures to improve performance in deficient areas of construction safety.

The Progress Assessment Team did not identify any concerns related to the Construction Safety Program. 


\subsubsection{Worker Safety and OSHA Programs}

In the worker safety and Occupational Safety and Health Act (OSHA) program area, the Progress Assessment Team evaluated the adequacy of the ID management system and its INEL contractors to ensure worker safety. In conducting the assessment, the Progress Assessment Team looked specifically at management systems and programs that support and ensure effective implementation and oversight of occupational safety and health programs. These areas were selected because they were identified by the INEL Tiger Team Assessment as key findings. The approach taken by the Progress Assessment Team was to conduct interviews of ID and contractor managers and employees assigned responsibilities relating to occupational safety and health activities and the review of selected safety and health documents. This effort was coupled with site visits to observe the effectiveness of the implementation of the INEL contractors safety and health programs. Site visits and interviews were used to determine the effectiveness of management systems in the adoption, implementation, and enforcement of mandated OSHA standards and regulations. The standards against which the site was assessed included 29 CFR 1910, "Occupational Safety and Health Standards," and 29 CFR 1926, "Safety and Health Regulations for Construction"; DOE Orders and directives relating to occupational safety and health programs; the Tiger Team Assessment Corrective Action Plan; and the ES\&H Performance Objectives and Criteria for Technical Safety Appraisals (Progress Assessment Manual, Appendix B-4, December 1992), specifically Performance Objectives relating to Occupational Safety (OS) and Personnel Protection (PP).

An effective occupational safety and health management program includes provisions for the systematic identification, evaluation, and prevention or control of general workplace hazards, specific job hazards, and potential hazards that may arise. It will seek to prevent injuries and illnesses, whether or not compliance is at issue. As the size of a worksite or the complexity of a' hazardous operation increases, the need for written guidance increases in order to ensure clear communication of policies and priorities, and consistent and fair application of the rules. A limited review of ID and contractor worker safety and OSHA programs indicated effectiveness except for lockout/tagout. Sitewide lockout/tagout guidelines are not being consistently followed. Some of the operating contractors are not consistently using the ID Outage Request Form. The ID oversight systems in the areas of construction and industrial safety have been developed and implemented.

The worker safety and OSHA programs at ID have made significant improvements since the 1991 Tiger Team Assessment. Approximately 99 percent of the Tiger Team Assessment OSHA-type findings have been completed. The remaining findings are being tracked and completion target dates have been established. Innovative worker safety programs have been put in place to improve the worker safety and OSHA programs and appear to be effective. Interviews with several technical and first time supervisors indicate that there is a sincere and positive attitude that involves the basic everyday safety issues.

Occupational safety and health bulletins are published and distributed to employees throughout the site to alert them to potential hazards.

In the construction area, MK-FIC has developed policies and system procedures that are well written and complete. MK-FIC has initiated a formal tracking system for closure procedure, trend analysis, and root cause for noncompliance issues. This system enables MK-FIC to determine the type of noncompliance 
issue that is being found most frequently. MK-FIC has developed several types of audits for construction inspections and surveillances. Daily walkdown inspections are performed on all of MK-FIC's work locations in the area of construction safety. MK-FIC has developed a strong construction program (see Strength $\mathrm{S} / \mathrm{S}-2)$.

In March 1992, the INEL Training Advisory Council was established to coordinate ES\&H training development across INEL. The purpose of this council is to provide uniform sitewide training, and the consolidation of training into one training area (see Strength $\mathrm{M} / \mathrm{S}-1$ ).

EG\&G Idaho

The Environment, Safety and Quality Department of EG\&G Idaho is using and supporting ID in developing the Compliance Management System (CMS) to track completion of the 1991 Tiger Team Assessment findings. EG\&G Idaho has completed all of the Tiger Team Assessment Category II milestones on schedule. EG\&G Idaho did not have any Category I findings. Of four Category II corrective action plans, three are closed. One remains open with one milestone remaining open, which is scheduled for closure on October 1, 1994, and is reported to be on schedule. The remaining Category 111 findings have been assigned milestones for completion. EG\&G Idaho has assigned the Performance Oversight and Assessment Unit and a process assessment team to ensure that the previous Tiger Team Assessment OSHA findings have been completed and that the milestones are met. EG\&G Idaho has established a root cause analysis process used for performance oversight and assessment activities that is used to determine basic occupational safety and health problems.

Since the previous Tiger Team Assessment, EG\&G Idaho has implemented improvements in their formalized safety training program. This program is made largely from the Occupational Safety and Health Regulations 29 CFR 1910 and 29 CFR 1926. The training modules include tracking and trending of employee performance and other performance indicators.

EG\&G Idaho has a single point of contact safety person who coordinates the construction safety issues at the site for construction safety issues with MK-FIC, who does all of the site construction work. EG\&G Idaho has implemented Conduct of Operations under the guidelines of DOE 5480.19 and has a manual that is specifically used for that purpose. Vertical slice interviews were conducted with EG\&G Idaho employees about the Conduct of Operations Manual and several craft workers stated that they were asked for input into development of this manual, especially in the electrical field.

EG\&G Idaho has implemented a hoisting and rigging program and has published a manual for hoisting and rigging operations. In January 1993, INEL initiated a survey of the entire INEL site for the purpose of inspecting all rigging apparatus and removing from service all of the unsatisfactory equipment.

In the area of human resources since the 1991 Tiger Team Assessment, an EG\&G Idaho Safety and Health Process Improvement initiative has been implemented. This initiative focuses on supporting safe work attitudes. Active participation by all levels of employees is supported for the identification of physical hazards and incorrect work habits. A back care program has been developed and an electrical safety committee has been established. 
The number of technical certifications of EG\&G Idaho's technical staff have improved. In the area of industrial safety, the staff certification has increased from 14 in 1991 to 33 certifications in 1993. In the fire protection area, staff certifications have increased from 7 in 1991 to 11 certifications in 1993.

At EG\&G Idaho, safety issues identified by the Performance Oversight and Assessment Organization and respective corrective actions are tracked in their centralized data base. From their data base, a monthly report is generated and distributed to management. The responsible managers take such actions as is necessary to ensure the implementation and timely completion of corrective actions warranted by these reports. If a responsible manager expects that corrective action milestones may be missed he or she is required to report to appropriate management, describing the inability to meet commitments and issuing a revised action plan.

EG\&G Idaho does not have an effective lessons learned process to evaluate environment, safety, and health deficiencies at all its ID facilities for determining whether other facilities could benefit from being advised of occurrences (EG\&G Idaho and the Environment, Safety and Quality Department circulate safety bulletins on major DOE issues.) Without the elements of trending and lessons learned, it is difficult not to repeat past errors or to prevent the occurrence of similar incidents at other facilities.

Several safety and health program elements were submitted by EG\&G Idaho to INEL as exemplary programs and nominees for the DOE-HQ Worker Protection Pilot Initiatives. The elements included asbestos management, laser safety, Employee Safety Assurance Process, Hazard Communications Program, and the Requirements Awareness Programs. The Hazard Communications Program was selected by DOE-HQ as one of four pilot programs for all DOE laboratories. The program is currently being plloted with Argonne National Laboratory-East. Since the last Tiger Team Assessment, EG\&G Idaho has reduced its departments from 13 to 6 . This initiative has significantly improved communications within the EG\&G Idaho operations.

ID

The Progress Assessment Team found that ID has made a significant effort in developing a single sitewide safety issues management program, but many improvements are yet to be made before the program can function as an effective and comprehensive safety issues management system. Specifically, ID has neither provided implementation guidance to the ID line management nor required the contractor to develop or submit an integrated, sitewide implementation plan, both of which have inhibited the full development of the program (see Section 2.2.1).

In the absence of a sitewide safety issues management system, ID and its operating contractors rely on a number of diverse processes that are not integrated to manage safety issues. As a result, the status of ES\&H issues cannot be easily or readily determined; the performance of contractors in implementing appropriate actions to correct identified safety issues cannot always be promptly or correctly ascertained; and essential information from trending or the lessons learned process is not available for use in the development of proactive corrective actions. ID does not look at the formal 
process to review the effectiveness of the corrective actions process for safety issues management.

Safety issues management encompasses activities that include identifying safety issue deficiencies and communtcating those defictencies at all levels of management. Effective safety issues management ensures that mangers have the information necessary to make effective decisions toward the resolution of safety issues and generate improvements in the oversight and management of ES\&H operations.

Safety issues management is the process by which findings are identified, tracked, and appropriately resolved to prevent recurrence. The key elements of an effective safety issues management program are:

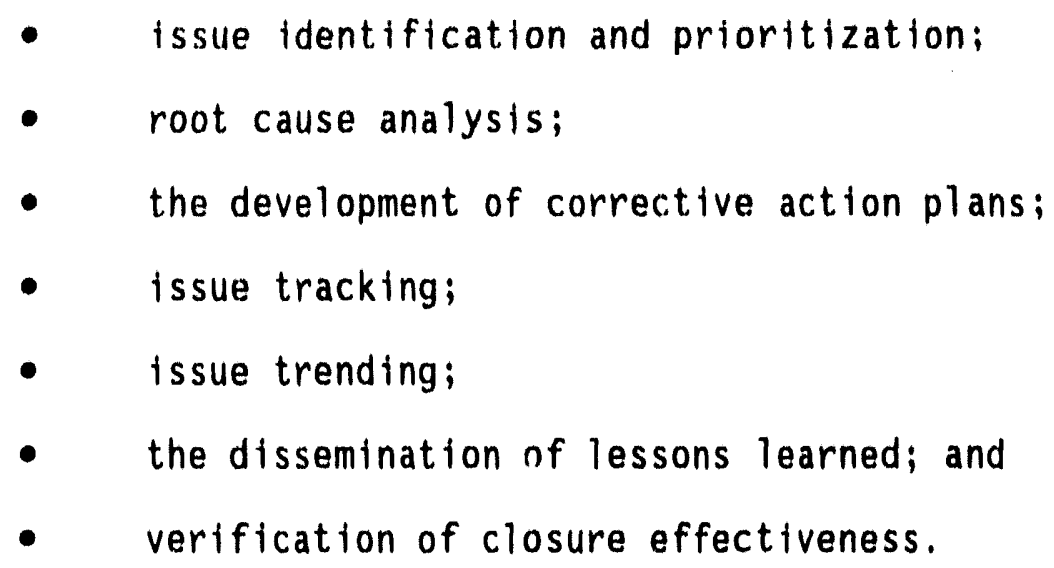

DOE 5482.18 requires determination of the adequacy of trend and $r$ isk analysis, including follow-up on accidents, incidents, and occurrences. Management is required by DOE $5700.6 \mathrm{C}$ (which involves ANSI/ASME NQA-1) to ident ify problems that hinder compliance by the organizations with its quality, safety, and environmental requirements. Assessment results should be tracked and resolved by those managers having responsibility in the area assessed with followup review of deficient areas initiated as necessary.

In response to the 1991 Tiger Team Assessment, ID committed to developing and implementing a sitewide safety issues management system - the Compliance Management System (CMS) - which is currently in "pilot stage." It is $10^{\prime} s$ contention that when the CMS is fully functional, it will resolve the Tiger Team Assessment finding regarding inadequate ES\&H issue management. CMS will contain the key elements of an effective safety issue management program, including issue identification and prioritization, development of corrective action plans, root cause determination, issue tracking, trending, lessons learned, and verification of the effectiveness of corrective actions before closure. As the CMS system is currently set up, it does not use a standard root cause analys is methodology, that applies appropriate rigor based on significance. CMS was developed as a sitewide safety issues management system for the use of DOE and contractors alike. However, contractors have not implemented CMS to any significant degree; instead, they currently rely on multiple systems that are localized to specific contractors. While ID has made a significant effort to develop and implement a single sitewide safety issues management program, many improvements are yet required before the program can function as an effective and comprehensive safety issues management system. Factors that may affect the overall success of this 
single, sitewide program are the lack of formal processes for prioritization, cause determination, trending, and lessons learned. ID has neither provided implementation guidance to ID 1 ine management or the contractor nor required the contractor to develop or submit an integrated, sitewide implementation plan for approval.

The Office of ES\&H Oversight has developed and Implemented a comprehensive program which plans, schedules, conducts and reports inspection, surveillance, spectal reviews, and appraisals of contractor construction and occupational safety programs. Since the Tiger Team Assessment, an Office of Oversight Manual has been instituted which codified these programs. The execution of these management systems has resulted in the performance of 12 major appraisals and about 300 inspections/surveillance of occupational/construction safety programs and activities. The development and issuance of the CY 92 Annual OES\&HO Report contains an analysis of 269 inspection findings pertaining to industrial/construction safety, which presents underiying causal factors and work place distribution of these defictencies. Presentiy, OES\&HO staff conducts root cause and trending analysis in the industrial and construction safety areas to support the annual report. Refinement's are being developed in the OES\&HO program to provide the formal development of a trend analysis capability that can be used for ongoing oversight activities in the construction and industrial safety area to identify potential safety hazards. However, ID has not aggressively pursued correction of the issues identified in this report (see Concern $M / C-3$ ).

WINCO

The 1991 Tiger Team Assessment covered all ES\&H aspects of the INEL facilities and activities with the exception of the health and safety (H\&S) functional areas of the Idaho Chemical Processing Plan (ICPP). Subsequent to the 1991 Tiger Team Assessment, a Technical Safety Appraisal (TSA) was conducted at ICPP. The H\&S functional areas included the TSA areas in the ES\&H Performance Objectives and Criteria for Technical Safety Appraisals (DOE/EH-135) as well as the seismic and engineering support areas. A formal written response to the Tiger Team Assessment findings, concerns, and root causes was submitted in the INEL Tiger Team Corrective Action Plan.

The TSA Team identifled 99 concerns in the TSA technical areas and 194 Occupational Safety and Health Act (OSHA) noncompliance issues. Ninety-five of the technical area concerns were addressed to WINCO.

The DOE Assistant Manager for Nuclear Programs has program responsibility for corrective action $\mathrm{plan}$ development and oversight of plan implementation by WINCO and others.

The TSA Action Plan was modelled after the INEL Tiger Team Corrective Action Plan. All appropriate corrective actions are structured to include upgraded management systems and programs necessary with the goal of achieving H\&S excellence. The programs and systems include the Oversight and Appraisal Program, Compliance Management System, Training, and an upgraded Procedures Control system.

The actions to correct each of the 99 TSA concerns, 2 key concerns, and 194 OSHA findings are addressed in the TSA Action Plan. The individual corrective action plans include schedules, milestones, budgetary information, and the 
organizations responsible for implementation. Since the two key concerns identified in the assessment were formulated based on their potential impact on the safety of activities conducted at ICPP. WINCO elected to prepare individual corrective action plans for these issues. The corrective action plans for these key concerns and the management and organization findings from the INEL Tiger Team Corrective Action Plan form the bridge between the major, underlying root causes and the individual TSA concerns.

WINCO's professional safety staff has increased with the addition of two safety engineers, four industrial hygienists, and one fire protection engineer. The professional certifications obtained during the period include two Certified Safety Professionals through the Board uf National Safety Professionals, two Certified Industrial Hyglenists and one Certified Industrial Hygienist-in-Training through the American Board of Industrial Hygiene.

WINCO submitted its Heat Stress Management Program which involves radiological anticontamination clothing and respirator issues to ID for nomination to the DOE Headquarters Worker Protection Pilot Initiative.

WINCO has received two National Safety Council awards - the Award of Merit and the Award of Honor. WINCO has also achleved a high degree of direct employee involvement in Safety and Health programs as evidenced by: (1) the Safety Counc 11 where bargaining unit and management representatives initiate safety improvements; (2) the Safety Observer Program where over 400 trained employees routinely inspect facilities and activities; (3) the WINCO/011, Chemical and Atomic Workers (OCAW) Safety Exchange Program where union employees are temporarily assigned to work with Industrial Safety and Health professionals on special assignments; and (4) the use of Core Teams where multi-disciplined personnel from different organizations provide safety-related work support to major operating facilities.

The WINCO Safety Management Steering Committee has proven to be a tool for promoting safety ownership throughout the company. Twice a year all WINCO Supervisors and their employees meet with the committee to report their safety performance and safety initiatives. Successful programs are promoted as lessons learned throughout the company.

The Progress Assessment Team identified one weakness related to the worker safety and OSHA program, which is presented in Appendix B-3 (see Weakness S/W-1, IO Lockout/Tagout System).

\subsubsection{Maintenance Programs}

In the maintenance programs area, the Progress Assessment Team evaluated EG\&G Idaho's Central Facilities Area (CFA) maintenance organization. This segment of INEL was chosen because the EG\&G Idaho maintenance function was cited by the INEL Tiger Team Assessment as a major concern area (there were 20 maintenance-related concerns identified in tile 1991 report). A non-reactor area was picked by the Progress Assessment Tean to evaluate general maintenance, particularly in employee safety awareness and performance and the application of the graded approach in implementing DOE 4330.4A, "Maintenance Management Program." Virtually all of the Tiger Team concerns that were identified were for noncompliance with DOE $4330.4 \mathrm{~A}$ in a variety of areas. 
In order to assess contractor progress in addressing the Tiger Team Concerns, the Progress Assessment Team reviewed contractor inaintenance-related policies and procedures, especially those addressing the use of the graded approach; evaluated safety performance data; and interviewed EG\&G Idaho maintenance staff at three different levels to determine if safety awareness and performance was really being effected.

The CFA maintenance scope includes all EG\&G factlities on INEL (except the Test Reactor Area) as well as the Radiological and Environmental Sciences Laboratory. The facilities that CFA Maintenance is responsible for include offices, warehouses, garages, laboratories, and low- and moderate-hazard nuclear facilities.

The Tiger Team Assessment found that EG\&G Idaho's maintenance procedures lacked sufficient detail to enable work to be performed in a safe manner, that work completion was not necessarily verified, that trending and tracking was weak, and that backlog management was substandard. EG\&G Idaho has taken the following steps to correct these concerns:

- EG\&G Idaho has issued the Maintenance Management Program Requirements Manual (June 24, 1992) which supplemented the existing documents. Section 3.4.7, "Backlog Work Control," addresses the maintenance procedures problems. Both ID and the Progress Assessment Team agree that this document has addressed the Tiger Team concern in a satisfactory manner.

- The Environmental Safety and Quality (ES\&Q) Department Standard Practice 1.16, "Safety and Health Program" (October 16, 1992), defines manager, employee, health professional, and committee responsibilities.

- DRR SM-134, "Safety Review, Analysis, and Work Control" (July 1, 1992), was issued with the intent of identifying levels of maintenance work completion requirements. This directive has not yet been implemented based on the Progress Assessment Team's examination of completed Work Orders and discussions with an EG\&G Idaho planner.

- The Progress Assessment Team reviewed a number of lower tiered documents in the areas of post-job clean-up (CP 2.4), DP 15.15 "Work Request (Order) System," 1.1.5 "Maintenance Work Priority and Scheduling," WMDP 15.9 "Predictive Maintenance," and WMDP 15.13 "Equipment Repair History". These documents exhibited specific requirements on the subject matters which adequately addressed earlier identified defictencies.

With respect to DOE $4330.4 A$, EG\&G Idaho has submitted to ID their program plan to implement this Order via FM-FS\&S-93-006, "Project Management P1 an for EG\&G Idaho Maintenance Management Program Implementation," last revised in April 1993. This plan documents the process of coordinating the baseline work scope, schedule, and cost to implement the order. It details the elements down to the working levels, predicts the completion of the implementation (1998), and forecasts the cost to meet this date $(\$ 28,000,000)$. However, EG\&G Idaho is doing this without up-to-date guidance from ID; ID 4330.4A, "Real Property Maintenance Management," has not been revised to reflect the latest 
posture of DOE 4330.4A, Section 10, "Responsibilities and Authorities," and in the area of applying a graded approach to maintenance at INEL (see Concern $M /(,-5)$.

Safety awareness of the EG\&G Idaho staff has sharpened as reflected by first-1ine worker comments during interviews with the Progress Assessment Team. Overal1, safety performance indicators show improvement due to a change in the Occupational Safety and Health Act (OSHA) reporting requirements, but a review of the actual injury incidence rate shows that the worker safety performance is probably about the same over the past 3 years. The changing requirements placed on the workers have not affected the quality of the work as the incidence of Occurrence Reports due to CFA maintenance remains about constant over the past 3 years and the rework request frequency remains low at 0.8 percent. Some independent pursult toward the objectives of DOE $4330.4 \mathrm{~A}$ such as savings in procurement costs, asbestos abatement practices, staff certification in ES\&H matters, and training requirement applications to the maintenance staff were documented. Discussions with knowledgeable EG\&G Idaho staff indicates that a purging of the preventive maintenance list to get rid of $10 \mathrm{w}-\mathrm{cos}$ /non-critical and idle items should reduce resource requirements in this area. Although the graded approach to maintenance practices is a policy. it was determined during interviews that planners and first-1ine supervisors were unaware of this and the work order forms themselves did not have provisions to include this detail.

In summary, the maintenance prograifi of EG\&G Idaho has addressed or is addressing the Tiger Team concerns in a satisfactory manner. Some contractor initiatives such as assisting in establishment of the INEL Maintenance Manager's Workshop were noted. ID's leadership is lacking because ID 4330.4A was found to be out of date with respect to the delineation of responsibilities and authorities, and did not address the graded approach implementation attachment.

\subsubsection{Packaging and Transportation Programs}

The Progress Assessment Team evaluated the progress of all five site contractors plus the Radiological and Environmental Sciences Laboratory (RESL) in addressing the numerous Tiger Team Concerns and assess the existence and effectiveness of these organizations' policies and procedures in the packaging and transportation area. This technical area was selected because the Tiger Team found this function to exhibit "key," "major," and "significant" defects applicable to three of the six organizations involved in the packaging and transportation of hazardous material. The 1991 INEL Tiger Team Assessment identified deficiencies in procedures, lack of procedures, training, and adherence to applicable regulations. The progress achieved by RESL and the INEL contractors in this area was evaluated by reviewing policies, procedures, and performance indicators (0ccurrence Reports), and by interviewing the organizations' managers for Packaging and Transportation. Because all of the Tiger Team concerns cited non-compliance with regulations or not using accepted good pracitices, the implementation of the INEL groups' solutions to these common problems was the principle area of inspection. The ID packaging and transportation program was not part of the Progress Assessment Team's scope. 
The number of shipments of hazardous and nuclear materials varies from hundreds per year by EG\&G Idaho to only a few per year by PTI, MK-FIC, and RESL. These shipments include onsite as well as offsite moves.

A summary of the progress made by each of the five contractors plus RESL since the 1991 Tiger Team Assessment is discussed below:

- B\&W (Rockwe11-INEL in the Tiger Team Report) packaging and transportation issues regarding procedural documents are being satisfactorily addressed: an interface agreement with the site shipper (EG\&G Idaho) which defines responsibilities of the two organizations is in effect (BWRD-051, March 30, 1993); procedures that had been noted to be deficient have been revised, which effectively alleviates a Tiger Team concern (per BWI-1310, "Compensatory Action Plan for Packaging and Transportation of Hazardous Materials" (April 30, 1992); and a training procedure that meets 49 CFR 172.700 requirements was issued.

- EG\&G Idaho has closed out the Tiger Team concern regarding the deficiencies in their quality assurance program for packaging and transportation and the other three concerns are being addressed in a satisfactory manner, but are not scheduled to be completed until 1994. The packaging and transportation operation is audited annually by the EG\&G Idaho Performance Oversight Assessment sroup. A self-assessment of this operation in July 1992 (memorandum JCM-276-92) identified three concerns regarding minor paperwork errors and minor noncompliance with standards. A clear indicator that the corrective action taken by this contractor to improve their packaging and transportation program is effective, is that while six Occurrence Reports were written against EG\&G Idaho in this area in 1992, none have been issued through July 1993.

- WINCO has modified the plant policy document to reference the revised packaging and transportation procedures that address Technical Safety Appraisal concerns. The quality policy document issuance is scheduled for October 1993.

- PTI has issued a procedure II-4-4-A, "Transportation of Materials" (Apri1 12, 1993), which adequately identifies the requirements for employees involved in shipment of hazardous materials. Nine PTI employee have taken the hazardous materials shipping course given locally by EG\&G Idaho.

- MK-FIC has added a comprehensive "Hazardous Material Transportation" section to their overall plant policy manual that meets the requirements for this function.

- RESL has issued procedure RESL-AP-17, "Shipment of Standards and Hazardous Materials" (June 30, 1993), which contains the elements to meet appropriate requirements in packaging and shipping. Three RESL employee are certified shippers and one is a certified shipping coordinator. The audit self-assessment program is not yet in place. 
PTI and MK-FIC have further alleviated problems in the packaging and transportation area by turning this function over to EG\&G Idaho since the number of annual shipments is low from these facilities (less than five). As stated above, PTI and MK-FIC now have the personnel and procedures to idrrtify when the expertise of EG\&G Idaho is required to effect a quality job of packaging and transportation at their sites. RESL has not considered utilizing EG\&G Idaho in the same manner; their annual shipments of hazardous materials are usually less than 30 and they are of small inventory.

ID 5480.3, "Hazardous Materials Packaging and Transportation Safety Requirements," is implemented and identifies in Section 6, "Responsibilities," the roles to be played by both ID and ID contractors. The ID supplemental Directive is excessive in length and in many cases is inconsistent with the corresponding DOE Order. The ID Packaging and Transportation Engineer stated that the ID Order is scheduled for reissuance in the next few months and it will be in a more usable form, but still retain the salient program requirements. This was also a concern in the 1991 Tiger Team Assessment (see Concern $M / C-5)$.

Recognizing that there are packaging and transportation safety issues that are pervasive throughout the INEL, a group consisting of ID and some contractor staffs drafted a charter for the proposed INEL Transportatiori Safety Committee in early 1992. The Scope of Responsibility in the draft charter identifies some envisioned duties for the committee, including:

- Review and comment to appropriate ID programs on proposed or impending regulatory changes, DOE Orders, or supplemental directives affecting transportation.

- Review packaging and transportation practices, audits, incidents, occurrences, and issues relating to regulatory or productivity improvement recommendations.

- Address non-compliance issues and make appropriate recommendations.

This charter was submitted to ID management for approval after having been reviewed by lower-level groups. Four of six managers whose concurrence was requested signed off within a week, but the Operations Manager for the Office of Environmental Safety and Health Oversight (OM/OES\&HO) held up the charter for 6 months, whereupon the Deputy Manager for Operations returned the draft with nonconcurrence. This series of events has reduced the enthusiasm of the lower-level managers that generated this potentially useful process to highlight all INEL transportation problems, especially that of hazardous materials. The charter package exhibits only one action having occurred since the top-level ID rejection (one signature on the new signature block occurred on March 4, 1993).

In summary, the packaging and transportation area at the INEL has undergone improvement since the 1991 Tiger Team Assessment. Appropriate procedures have been generated or amended and personnel throughout all contractor groups involved in this function have been trained and certified. As a result of the various contractors implementing new and revised appropriate documentation to correct these deficiencies and working to establish the oversight functions to monitor the effectivity of them, this technical area is now being performed in 
a manner to meet appropriate regulations. When updated and fully implemented, ID 5480.3 has the potential to provide important direction to those at INEL involved in packaging and transportation.

\subsubsection{Site/Facility Safety Review Programs}

The Progress Assessment Team's report of the site/facility safety review programs area is divided into (1) the Radiological and Environmental Sciences Laboratory (RESL) site/facility safety review programs; and (2) Unexploded Ordinance (UXO) site/facility safety review programs. The two areas were divided to determine if there are differences in establishing safety documentation at INEL due to ID versus contractor responsibility for effecting this documentation.

A comparison of these two cases illustrates how an inferior product resulted from a segment of ID not adhering to existing ID policies and not having defined internal responsibilities and authorities, as was the case of the RESL facility CFA-690 Safety Analys is Report (SAR); whereas the use of the defined ID policy enabled the generation of an SAR that well defines the risks associated with the UXO project.

\section{RESL Site/Facility Safety Review Programs}

RESL was chosen by the Progress Assessment Team for review because the 1991 Tiger Team Assessment found that the two RESL facilities (CFA-638 and CFA-690) were without any facility safety documentation, and no controls such as periodic reviews were identified. Also, because RESL is a part of ID, the performance of an operating branch of DOE was reviewed. In addition to looking at the technical quality of the two Safety Analysis Reports (SARs), the Progress Assessment Team al so looked at how ID has addressed DOE 5480.23 , which has superseded DOE 5481.1B for nuclear facilities. The team examined one facility (CFA-690, a simple laboratory with an occupancy of about 60 persons) paying attention to the physical attributes that could affect, an accidental condition; interviewed three RESL staff members with regard to practices used by RESL to generate SARs; reviewed ID documentation that governs the issuance safety-related facility conclusions; and noted what positive changes had occurred in these variables since the 1991 Tiger Team Assessment.

In performing this assessment, the team looked at the RESL management policy and its modifications which would allow for generation and periodic review of the SAR or other facility safety documents. The team evaluated the involvement of the ID Technical Support Division (TSD), which was not employed in the initial SAR generation response, to ensure that proper technica? input was used, analyses were performed, and correct conclusions were reached. The team also evaluated TSD to ensure that top-level guidance was provided to RESL regarding facility safety documentation requirements.

The Tiger Team identified three policy problems at RESL in the independent and periodic review areas. In addition, a specific technical deficiency identified that the RESL facilities had not undergone any assessments that defined the hazards and risks of operating the facilities from safety and environmental effect standpoints. The Progress Assessment Team noted that the RESL response to not having any safety analyses for their facilities was to issue a purchase order to have such a document written, but the technical 
content and detail level of the procured analysis was not in concert with the actual hazards and physical reality. The document was referred to as a Safety Analysis Report, but there were no justifications to the probability levels that would assist management in determining what physical, administrative, or procedural safety measures, if any, the facilities would require for continued operation.

The management of RESL has specified that the responsibility for ensuring that adequate formal facility safety documentation exists and that it undergoes periodic review rests with the Director (RESL-1, "Policy Manual"). The scheduling details are identified in RESL-2, "RESL Safety Committee." These two changes to the already-existing RESL policies should act to ensure that proper attention is afforded to this operational requisite.

The recent issuance of ID 5480.23 (July 29, 1993) not only provides guidance regarding the safety documentation level, but also identifies responsibilities and authorities for ID operating organizations and operating contractors. The adherence to this top-level policy should alleviate the problem of poor technical content in safety documents, which was due in part to not using existing ID resources in the preparation and review of the procurement of the CFA-690 SAR. It should be pointed out that ID 5481.1B, "Safety Analys is and Review System," was issued on October 18, 1991 (after the Tiger Team visit) and contained much of the same guidance as ID 5480.23 regarding responsibilities and authorities of ID. The procurement of the CFA-690 SAR was underway at that time; it was issued on December 23, 1992, and approved by the ID Manager on January 5, 1993. Therefore, there was a 14-month time span when the responsibility and authority definitions could and should have been executed. The implementation of the two RESL policy changes occurred just after the ID approval of the SAR.

There is a failure of ID to follow their own policy regarding ID 5481.1B, Section 6, "Responsibilities and Authorities." Also, there is a continuing problem in the timely implementation of new DOE Orders: DOE 5481.1B was issued in 1986 with the B Revision on May 19, 1987, but ID 5481.1B was not issued unti1 October 18, 1991; and DOE 5480.23 was issued to become effective April 30, 1992, but it was not until July 29, 1993, when the Progress Assessment Team was onsite that the ID version was issued.

Both ID and RESL have exhibited progress in addressing the earlier Tiger Team findings and concerns. A person with technical qualifications is now responsible for redoing the CFA-690 safety documentation. The inclusion of RESL responsibilities at both the director and safety committee levels should preclude recurrence of problems of this sort.

\section{UXO Site/Facility Safety Review Programs}

MK-FIC, the Remedial Design/Remedial Action Contractor for the Environmental Restoration Program at the INEL, is responsible for the interim action to remediate six areas containing UXO and ordnance explosive wastes (OEW). Collectively, these six areas are known as Operable Unit (OU) 10-05.

The Federal Facility Agreement/Consent Order (FFA/CO) identifies the process and schedule to aid cleanup of the areas listed in the FFA/CO action plan. This action plan identifies two OUs pertaining to ordnance areas: 0U 10-05, 
which includes the six ordnance areas targeted for this interim action: and ou 10-03, which contains the remaining ordnance areas at INEL.

The interim action to clean up UXO in $0 U$ 10-05 is intended to reduce or eliminate the risks posed by UXO and explosive residues. Six areas were chosen for this interim action because they are near or in areas frequented by INEL personnel and offsite visitors such as linemen from the power company. Therefore, they present an unacceptable risk. These risks are primarily accidental explosion of UXO and personnel exposure to explosive residues.

The UXO project was reviewed by the Progress Assessment Team in order to evaluate the risk management processes at INEL with respect to DOE as well as DOE coritractors. Elements of the project that were reviewed included: the SAR, the safety analysis review files, the associated Supplemental Directive, the technical specifications for the subcontract, the technical credentials for both the prime contractor and the subcontractor, the interface between ID and $\mathrm{DOE}-\mathrm{HQ}$ with respect to safety considerations, the involvement of the ID project engineer in the safety aspects of the project, the Environment, Safety, and Health and Emergency Plans, the Request For Proposal, and information associated with external independent safety reviews provided for the project. Additionally, the six remediation areas were inspected and the proposed operations and associated risks were discussed with the DOE project engineer.

The general impressions resulting from the above review were highly favorable. The SAR appears to address all pertinent hazards and correlates with areas of interest identified by several explosives experts in the DOE cominunity external to INEL. The risk analyses are comprehensive and appear to be bounding. For example, the worst case accident postulates a detonation involving a 2,000 pound charge, which is the largest unit of record in the ordnance operations. However, it was determined that no air drop of this size was possible due to the capacity of the aircraft in use in those operations and the maximum charge of interest involved placement rather than an air drop. The significance of this is that the potential for an undetonated charge of this magnitude to have been lost below the surface due to a fusing failure is vanishingly small, and yet the bounding accident considers this scenario. A conservative approach to the risk analyses throughout the document appears to have been taken. All appropriate operational safety and health aspects of the project appear to have been addressed. (No attempt was made during the team's review of the project to reach a conclusion independently regarding the acceptability of risk.)

Project files reveal a substantial safety review of the project by ID. Both the line organization and the oversight organization appear to have made substantive contributions to the safety aspects of the proposed operations. Supplemental Directive ID 5481.1B, "Safety Analysis and Review System" (October 18, 1991), identifies responsibilities and authorities, establishes Hazard Classification criteria, and provides guidance for safety analysis preparation by references as well as explicit requirements. Guidance for Operational Safety Requirements is also provided. This Supplemental Directive governed the development of the SAR for the UXO project.

The procurement package for the selection of a subcontractor to perform the remediation clearly demonstrates that safety was paramount in the criteria. 
The credentials of the principal individuals suggest success in obtaining safety competency.

Project files reflect a close and continuous interface between $I D$ and the DOE-HQ program office for this project. There is some evidence that ES\&H was a consideration in these ongoing communications. A memo from EM 441 to ID in May 1993 provided a few comments on the SAR.

During the team's inspection of the six remediation sites, the proposed operations were discussed in some detail with the ID project engineer. While this graduate engineer has only 2 years of experience and no prior knowledge of ordnance, considerable knowledge of the project and a good understanding of the safety considerations was displayed. The engineer clearly recognizes line management safety responsibilities and is actively involved in the execution of the project. It was also noted that ID staff recognized their lack of expertise in explosives safety, and in response to that limitation, ID obtained advice and counsel from the DOE explosives safety community. This action suggests a professional attitude on the part of ID staff and provides a foundation for continuous improvement.

This non-nuclear ID Safety Analysis Report, which addressed significant hazards, received scant attention in DOE-HQ partially due to the fact that DOE has no hazard classification criteria and minimal guidance for non-nuclear hazardous operations.

It appears that INEL organizations have dealt appropriately with the hazards inherent in this project. Inexplicably, during the inbriefing for this Progress Assessment Team on June 29, 1993, the MK-FIC General Manager made no mention of this project.

During the Progress Assessment Team interviews with the Program Secretarial offices, no individuals were found that had any knowledge of the existence of this project outside of the EM-40 project office, which the team views as a weakness (see Weakness $S / W-1$ in Appendix B-3). It should be noted that ID staff advised the Progress Assessment Team Leader of the existence of this project during his initial coordination visit.

\subsubsection{Industrial Hygiene Program}

In the industrial hygiene area, the Progress Assessment Team assessed the adequacy of ID and the INEL contractor programs of EG\&G Idaho, B\&W, PTI, MK-FIC, and the DOE Radiological Environmental Sciences Laboratory (RESL) to implement management systems and programs to identify, evaluate, and control physical, biological, and chemical hazards to INEL site employees.

In conducting the assessment, the team looked specifically at the adequacy of INEL oversight and surveillance activities, self-assessment programs, internal quality assurance programs, staffing, and management systems implemented by ID, EG\&G Idaho, MK-FIC, PTI, and RESL.

In addition, vertical slice reviews were conducted of the corrective actions taken to improve performance of the EG\&G Idaho laser safety and exposure monitoring programs, the RESL chemical hygiene and ventilation control programs, the MK-FIC industrial hygiene program and construction oversight program, the PTI lead and noise exposure programs, and the B\&W ergonomics, 
laser safety and respiratory protection programs. These areas were selected to look broadly at industrial hygiene management and progress at the site and to attempt to gauge the overal1 level of commitment of EG\&G Idaho, MK-FIC, PTI, RESL, and B\&W to adequately apply resources to correct program deficiencies.

The approach taken by the team was to conduct interviews of ID, EG\&G Idaho, MK-FIC, PTI, RESL, and B\&W ES\&H managers and staff responsible for industrial hygiene, and to review program documents, plans, reports, and corrective action files. The site contractors' programs were assessed, in part, through tours of RESL in the central area, PTI indoor firing range, EG\&G Idaho IRC facility, and B\&W TAN SMC facilities. As a part of these facility tours, an independent walk down of selected Tiger Team Assessment corrective actions was performed.

The key standards against which the site was assessed included DOE 5480.10, DOE 5480.4, DOE 5700.6C, DOE 5483.1A, Secretary of Energy Notices (SENs), Occupational Safety and Health Act (OSHA) 29 CFR 1910 and 1926, the INEL Tiger Team Assessment Corrective Action Plan, and the ES\&H Management Performance objectives and Criteria for Progress Assessments (Progress Assessment Manual, Appendix B-1, December 1992).

The INEL Tiger Team Assessment identified the following weaknesses in the INEL industrial hygiene program:

- Within the EG\&G Idaho industrial hygiene program, deficiencies existed in the areas of development of policies and procedures for independent appraisals and audits, development of formal industrial hygiene program plans, exposure monitoring program for laboratory employees, reviews of work permits, and implementation of a laser safety program.

- Within the MK-FIC industrial hygiene program, deficiencies existed in the areas of reduction on reliance of other site contractors for industrial hygiene support; development of an industrial hygiene program and policy; and resolution of deficiencies in respiratory protection, breathing air quality, and hazard communication.

- Within the B\&W industrial hygiene program, deficiencies existed in the areas of reducing industrial hygiene staff turnover and repetitive motion injuries, and resolution of deficiencies in the hazard work permit., laser safety, respiratory protection, hazard communication, and health monitoring programs.

- Within the ID industrial hygiene program, deficiencies existed in the areas of a general lack of scope, depch and formality of the industrial hygiene program, authorities, responsibilities, staffing and training, planning, resource management, oversight and surveillances, corrective action tracking systems, internal self-assessments, and audits and program documentation.

- Deficiencies were noted by the Tiger Team Assessment in the areas of the ability of ID to provide effective oversight of plant operations, staffing, industrial hygiene program policy, and 
guidance of the contractor programs. The INEL corrective action management system was noted by the Tiger Team Assessment to have deficiencies in the adequacy of verifications, procedures, and surveillances. Industrial hygiene program objectives and plans were found by the Tiger Team Assessment not to be utflized as a part of an integrated approach for ES\&H planning.

$\underline{\text { ID }}$

General findings from this Progress Assessment of the ID and INEL site industrial hygiene program indicated that:

- The vertical slice reviews conducted by the Progress Assessment Team of the INEL site industrial hygiene programs including field visits and interactions by the team with facility managers, employees, and program staff indicated that overall progress in the implementation of programmatic change in the industrial hygiene program has occurred within a relatively short period of time since the 1991 Tiger Team Assessment. This progress indicates to the team that a positive cultural change is occurring overall at INEL in the industrial hygiene area. However, the development of the INEL site industrial hygiene programs is not fully complete and programs among the site contractors vary in their formality, depth, and level of implementation.

- Issues regarding standardization and coordination of integrated site program planning and objectives should require consideration in anticipation of the transition from several site contractors to one prime operating contractor at INEL.

- The scope, depth, and formality of the ID and INEL site contractors' planning needs further improvement to sustain and further improve the INEL site industrial hygiene program.

- In general, the industrial hygiene self-assessment programs among the INEL site contractors have been limited to compliance issues and have not incorporated program management performance objectives (see Concerns $S / C-1$ and $M / C-2$ ).

The ID Technical Support Division (TSD)/Occupational Safety \& Health Branch (OSHB) currently has the responsibility for program management, development, and direction. Independent oversight is provided by an organization separate from the DOE line organization and TSD by the ID Office of Environment Safety and Health Oversight (OES\&HO). ID directs the management of the industrial hygiene program at INEL through contractual requirements with EG\&G Idaho (as the prime operating contractor), PTI, B\&W, and MK-FIC for compliance with DOE Orders and proscribed standards. A part of this implementation includes ID issued directives, and guidance, and both formal and informal ID staff/contractor interactions.

ID has made progress in correcting the industrial hygiene program deficiencies identified in the 1991 INEL Tiger Team Assessment by expanding and developing its capability of oversight of the INEL contractors industrial hygiene programs through the establishment of the OES\&HO and detailed procedures of oversight, including a triennial ES\&H appraisal. Oversight program schedules 
and assessment criteria have been developed by the OES\&HO. These activities are summarized in the First Annual Oversight Report (dated March 9, 1993), with progress reports to be provided on a semiannual basts to ID management. However, the surveillance activities of the INEL site contractors industrial hygiene programs performed to date by OES\&HO are not comprehensive in all industrial hygiene technical and program management areas; are not technical in the area of industrial hygiene interface with occupational medicine; and in some instances industrial hygiene assessments are conducted and reviewed by ID personnel who are not professional industrial hygienist (see Concern $S / C-1$ ).

ID has increased its staffing level within TSD to two professional industrial hygienists since the 1991 Tiger Team Assessment. However, the present staffing levels do not appear to be sufficient to support the level of oversight and guidance necessary for INEL. The OES\&HO oversight organization has been without an industrial hygienist since early 1992. This lack of an industrial hygienist for OES\&HO may impair the ID ability to provide acceptable oversight of the INEL site contractors (see Concerns $S / C-1, M / C-3$, $M / C-5$, and $M / C-7)$.

ID has made progress in establishing sitewide coordination of industrial hygiene issues through the establishment of an INEL Industrial Hygiene Coordinating Committee (see Concern $S / C-1$ ). However, this informal group has not been given a formal mandate and charter by ID.

While ID has made progress in the tracking and trending safety issues, ID has not directed its ES\&H and contractor organizations to define and implement key performance and risk indicators that are industrial hygiene related. ID has been successful in integrating industrial hygiene program requirements among the INEL site contractors into the ES\&H 5-year plan. Indications from ID are that the ES\&H 5-year plan guide will be utilized to become the basis for the ID site as an integrated planning approach for ES\&H (see Concern $M / C-7$ ). While ID has made progress in integrating industrial hygiene into the budgeting and planning process and providing crosscutting site guidance, it remains deficient in the capability to prioritize INEL industrial hygiene issues on a risk based scheme (see Concern $S / C-1$ ).

PTI

PTI has made progress in correcting the deficiencies identified in the 1991 INEL Tiger Team Assessment by developing formal industrial hygiene program requirements and documentation, internal assessment criteria, and ES\&H program plans, and conducting self-assessments of the industrial hygiene program. PTI has also made progress in the area of monitoring worker exposures to lead and noise at the PTI, indoor firing range, and implementing controls and medical surveillance.

The PTI ES\&H self-assessments have been primarily related to the "safety" areas, and could be improved by including more industrial hygiene related areas. While industrial hygiene program elements have not generally been integrated into the PTI self-assessment program, PTI does pian to complete the full integration of industrial hygiene into the PTI self-assessment program by October 1993. In May 1993, PTI completed an external independent assessment of the industrial hygiene program. 
The PTI Industrial Hygiene Manual defines the compliance requirements and the roles, responsibilities, and authorities of the PTI industrial hyglene program. The scope of this manual includes program definition in the deficient areas identified by the 1991 Tiger Team Assessment for noise, lead, and exposure to organic chemicals. In response to the Tiger Team Assessment, PTI hired one full-time professional industrial hygienist.

Planning within the PTI industrial hygiene program is currently based upon the DOE ES\&H 5-Year Plan Guide and an annual compliance operating plan. The annual compliance operating plan integrates the critical ES\&H program objectives with inputs from industrial hyglene staff, oversight surveillances, and DOE directives. Specific industrial hygiene program performance and risk indicators have not been fully established and integrated into the budgeting and planning process. PTI has implemented an ES\&H tracking system that is utilized as a trending and performance indicator tool for the PTI Safety Committee.

A review of the Tiger Team Assessment corrective actions for the PTI industrial hygiene program indicated that all findings were closed. A review of selected Tiger Team Assessment PTI closure packages supported DOE's validation that these findings were adequately closed.

\section{EG\&G Idaho}

EG\&G Idaho has made progress in correcting the deficiencies identified in the INEL Tiger Team Assessment by developing formal industrial hygiene program requirements and documentation, internal assessment criteria, ES\&H program plans, and conducting self-assessments of the industrial hygiene program.

Specific industrial hygiene program performance and risk indicators have not been fully established and integrated into the budgeting and planning process. At the senior management level, EG\&G Idaho has begun to develop an innovative approach to ES\&H program management planning or "Management Performance Assistance," which is intended to integrate ES\&H programmatic indicators such as assessments, risk indicators, impact analysis, and priority task analysis results into the ES\&H planning process. The EG\&G Idaho planning functions are described in Section 2 of the ES\&H Safety Manual.

EG\&G Idaho has made progress in updating program policy and procedures for respiratory protection and hazard communication, and in developing program policy and procedures for laser safety, asbestos management, record keeping and confined space entry. EG\&G Idaho has developed an industrial hygiene data base that is an example of excellence in integrating industrial hygiene exposure data for trending analysis and medical surveillance, maintenance of inventories of hazardous chemicals, and asbestos management (see Strength S/S-1). In an effort to improve communication within the industrial hygiene organization, EG\&G Idaho has implemented monthly discussion sessions with industrial hygiene staff and managers.

In the area of industrial hygiene staffing, EG\&G Idaho has increased the number of industrial hygienists from 24 in 1991 to 26 in 1993. In the area of professional development, EG\&G Idaho has implemented training courses for sampling techniques, laser safety, respiratory protection, and confined space hazard assessment. A company qualification program has also been improved for the industrial hygiene staff. 
EG\&G Idaho has made progress in resolving the 1991 Tiger Team Assessment laser safety findings. A comprehensive laser safety program that complies with ANSI Standards has been developed and implemented across EG\&G Idaho. This program is exceptional in its technical quality, and field verification indicates that EG\&G Idaho has been successful in implementing the program (see Strength S/S-1). EG\&G Idaho has developed an integrated industrial hygiene data management system (System 80 ) that integrates industrial hygiene exposure data and occupational medicine survelllances. This system utilizes unique and innovative tools for tracking and cross-referencing exposures and chemical inventories. A part of this system includes innovative data acquisition capabilities for computer pen pad entry of facility inspections and exposure data while the industrial hygienist is in the fleld. This system is viewed by the Progress Assessment team as an example of excellence in industrial hygiene dati management (see Strength $S / S-1$ ).

ECisG Idaho provides a Requirement Awareness Training program for line managers. EG\&G Idaho utflizes a Cognizant Professional (COGPRO) management i.proach for industrial hygiene, which provides for separation of the iversight and policy component within the ES\&H Department and dedicated industrial hygiene field support for facilities and operations.

The Progress Assessment Team was not able to determine that the ID OES\&HO had conducted an oversight assessment of the effectiveness of this approach. Potential problems could occur with the industrial hygienist being a part of the line organization and potential conflicts of interest of line management, and a fallure of the line organizations to implement policies developed by the industrial hygienists with in the ES\&Q organization.

In the area of independent oversight, policies and procedures have been established by EG\&G Idaho to include annual appraisals, management audits, and informal site inspections by the Performance Oversight and Assessment (PO\&A) organization. Assessments conducted by the PO\&A include an evaluation of the ES\&H self-assessments, exposure monitoring, personal protective equipment, and safety and health training. From July 1991 to July 1993, 21 industrial hygiene program audits and 8 appraisals have been conducted, which included respiratory protection, hazard communication, hearing conservation, and industrial hygiene sampling and record keeping.

\section{MK-FIC}

MK-FIC has made progress in correcting the deficiencies identified in the 1991 Tiger Team Assessment by developing of formal industrial hygiene program requirements and documentation, conducting oversight assessment of its subcontractors, developing contractual subcontracting requirements for industrial hygiene, and obtaining contractor interface agreements for provision of industrial hygiene services in support of construction activities, industrial hygiene program staffing, self-assessments, job safety analysis, and work controls.

MK-FIC has implemented an integrated approach to assuring the provision of industrial hygiene services for construction projects by implementing a requirement for industrial hygiene review in the project design and planning stages that includes requirements specified in the General Contract Condition Document \#7 and requirements for development for site safety and health plans for Environmental Restoration and Waste Management (ER/WM) operations. 
In the area of staffing, MK-FIC has increased its professional staff since the 1991 Tiger Team Assessment to include three industrial hygiene professionals and one industrial hyglene program manager.

In the area of hazard communication, MK-FIC has implemented requirements for subcontractor submittal of health and safety program documentation, and site standardization of training requirements to include sponsorship of National Safety Councll courses for its subcontractors. MK-FIC has also implemented a training/qualification program for construction supervisors and managers to include industrial hyglene requirements.

Work control systems now include requirements for job safety analysis, plan of the day meetings, construction safe work permits, pre-bid and pre-construction safety conferences, and subcontractor dally inspections.

In the area of oversight, IIK-FIC has effectively developed and implemented requirements for constructior, supervisor surveillances, targeted survelliances and management assessments, and a quarterly MK-FIC corporate office asses sment.

ES\&H goals and performance indicators are established for industrial hygiene activities and are presented in a monthly report to management. All industrial hygiene related Tiger Team Assessment corrective actions have been closed by MK-FIC. The technical quality, degree of development, and qualifications of the MK-FIC program and professional staff have indicated that the MK-FIC industrial hygiene program has become an overall example of excellence, as a model within DOE (see Strength $\mathrm{S} / \mathrm{S}-2$ ).

\section{B\&W}

B\&W has made progress in correcting the Tiger Team Assessment deficlencies by developing formal industrial hygiene program requirements and documentation; conducting self-assessments of the industrial hygiene program; developing internal assessment criteria and a triennial ES\&H assessment schedule and plan, and ES\&H program plans; developing program policy and procedures in the areas of ergonomics, laser safety, hazardous work permits, respiratory protection, hazard communication, and exposure monitoring.

B\&W has developed a corrective action tracking system that adequately tracks internal and external surveillances and corrective action plans. B\&W has closed all 23 of the industrial hygiene related Tiger Team Assessment corrective actions. A compliance action $p l a n$ to assure B\&W conformance with DOE Orders, ID directives, and OSHA regulations has been developed.

In the area of internal self-assessments, B\&W has developed a self-assessment plan and checklists for specific program areas. Pre-assessment meetings with ine managers are held to discuss the purpose and scope of the assessments, and self-assessment reports are distributed to senior and responsible managers.

In the area of staffing, B\&W has hired one Certified Industrial Hygienist (CIH) and two industrial hygiene technicians to provide support to the line organizations. 
B\&W has completed a baseline hazard inventory of its facilities and operations from which an exposure monitoring program plan is implemented.

In the area of planning, specific industrial hyglene program performance and risk indicators have not been fully established and integrated into the budgeting and planning process.

A review of the Tiger Team Assessment corrective actions for the B\&W industrial hyglene program indicated that all findings were closed. A review of selected Tiger Team Assessment B\&W closure packages supported DOE's validation that these findings were adequately closed.

A general weakness in the B\&W industrial hyglene program has been the inability of the B\&W industrial hyglenist to oversee all aspects of the SMC project due to restricted access requirements. This weakness is attributed to limitations imposed by the ID SMC Project Management Office (see Concern $S /(-1)$.

RESL

RESL has made progress in correcting the deficiencies identified in the 1991 INEL Tiger Team Assessment by developing formal industrial hygiene program requirements and documentation, conducting self-assessments of the industrial hygiene program, developing internal assessment criteria, developing program policy and procedures, and developing a laboratory chemical hygtene program (issued in April 1993, with training begun in June 1993) for respiratory protection, hazard communication, exposure monitoring, carcinogen control, and laboratory ventilation.

In February 1993, RESL reorganized the ES\&H program in an attempt to improve the coordination of ES\&H efforts. A part of this effort included the development of a task force for a laboratory cleanup effort to improve compllance with OSHA and Resource Conservation and Recovery Act (RCRA). This effort was established on a weekly basis to improve general housekeeping and to identify and correct industrial hygiene, Health Physics (HP), and Occupational Safety (OS) issues. This program has been effective in reducing quantities of unneeded chemicals and identifying operational safety and health deficiencies.

In the area of staffing, RESL hired one professional industrial hygienist; however, the industrial hygienist terminated employment in August 1993. RESL is currently interviewing for a replacement.

In the area of internal audits and surveillances, RESL has implemented a program to perform facility walk down inspections, surveillances, and formal assessments.

In the area of planning, specific industrial hygiene program performance and risk indicators have not been fully established and integrated into the budgeting and planning process.

In area of exposure, monitoring RESL began a program in 1991 that is integrated with the chemical hygiene plan. 
The RESL self-assessment program was viewed as effective in identifying deficiencies at RESL. RESL identified serious deficiencies in the perchloric acid laboratory hood ventilation systems. Resolution of this deficiency is planned, but capital improvement funds have as of yet not been committed by ID to correct this deficiency.

The Progress Assessment Team identified one concern and two strengths related to the INEL Site Industrial Hyglene Program, which are presented in Appendix B-3 (see Concern $S / C-1, I D$ and INEL Site Industrial Hygiene Program, and Strengths S/S-1, MK-FIC Construction Industrial Hygiene Program, and S/S-2, EG\&G Laser Safety and Industrial Hygtene Data Management System). 
Appendix A

Summary Táble of Concerns, Weaknesses, and Strengths 
SUMMARY TABLE OF

CONCERNS, WEAKNESSES, AND STRENGTHS

\begin{tabular}{|c|c|c|}
\hline Lumber & Trte & Page. \\
\hline \multicolumn{3}{|c|}{ Vanagenent Systems. } \\
\hline$M / C-1$ & Corrective Action Program & B-1-1 \\
\hline$M / C-2$ & ID Self-Assessment Program & $B-1-5$ \\
\hline$M / C-3$ & ID Oversight & B-1-6 \\
\hline$M / C-4$ & INEL Stop Work/Restart Processes & B-1-13 \\
\hline$M / C-5$ & ID Directives, Policies, and Procedures & $B-1-16$ \\
\hline$M / C-6$ & Human Resource Management & $\mathrm{B}-1-18$ \\
\hline$M / C-7$ & Planning, Budgeting, and Resource Allocation & B-1-24 \\
\hline$M / W-1$ & EG\&G Idaho ES\&H Oversight Committees & $B-1-30$ \\
\hline$M / S-1$ & INEL Training Advisory Council & $B-1-31$ \\
\hline \multicolumn{3}{|c|}{ Environinenta l. Programs } \\
\hline$E / C-1$ & Sitewide Environmental Management Program & $B-2-1$ \\
\hline \multicolumn{3}{|c|}{ Safety and heaglth Programs } \\
\hline$S / C-1$ & $\begin{array}{l}\text { ID and INEL Site Industrial Hygiene Program } \\
\text { Management }\end{array}$ & $B-3-1$ \\
\hline$S / W-1$ & INEL Lockout/Tagout System & $B-3-4$ \\
\hline$S / W-2$ & $\begin{array}{l}\text { Communication Within EM Organizations Regarding } \\
\text { Safety-Related Issues }\end{array}$ & $B-3-5$ \\
\hline$S / S-1$ & MK-FIC Construction Safety and Health Program & B-3-6 \\
\hline$S / S-2$ & $\begin{array}{l}\text { EG\&G Idaho Laser Safety and Industrial Hygiene } \\
\text { Data Management System }\end{array}$ & $B-3-8$ \\
\hline
\end{tabular}


This page intentionally left blank.

A-2 


\section{Appendix B}

Concerns, Weaknesses, and Strengths by Discipline

Enumeration:

$$
\begin{array}{lllll}
\mathbf{M} & =\text { Management Systems } & \mathbf{C} & =\text { Concern } \\
\mathbf{E}=\text { Environmental Programs } \mathbf{S}= & \text { Strength } \\
\mathbf{S}= & \text { Safety \& Health Programs } \mathbf{W}=\text { Weakness }
\end{array}
$$


Appendix B-1

\author{
Assessment Details - ES\&H Management \\ Systems/Concerns, Weakness, and Strength
}


Assessment Concern Number:

Assessment Concern Title:
$M / C-1$

\section{Corrective Action Program}

\section{Performance Objective}

ES\&H Management Performance Objectives and Criteria for Progress Assessments (Progress Assessment Manua1, Appendix B-1, December 1992), Performance Criteria 2.4.3.1 and 4.4.3.1 state that DOE Field Office and site contractors should have formal programs that capture, on a sitewide basis, ES\&H deficiencies identified in assessments, reviews and occurrence reports, and track corrective actions through verified closure.

\section{Concern}

ID and INEL contractors have not fully developed a sitewide, integrated corrective action program that captures deficiencies; prioritizes corrective actions; tracks, trends, and validates closure; determines root cause; and disseminates lessons learned information to provide management with the necessary decision making information in order to support cost-effective risk reduction.

\section{Discussion}

An integrated, comprehensive corrective action program is an essential management tool for understanding and correcting deficiencies and preventing recurrences. Such a program would provide:

- vital information to the planning process for resource allocation;

- vital information for performance-based management;

- the basis for the continuous improvement of ES\&H training programs; and

- serve as the foundation for an effective risk-based ES\&H program.

A properly implemented program would assure the identification, capture, and correction of ES\&H issues on a sitewide basis; track issues; provide periodic status reports; enable management to identify trends in corrective actions; and prioritize proposed corrective actions to ensure that limited resources are utilized to the best advantage (i.e., risk reduction). In addition, such a program would also provide for determining and correcting root causes, disseminating lessons learned information, both within and outside the affected facility, and providing management the means to systematically assess the effectiveness of completed corrective actions as well as overall ES\&H performance. The ID and INEL contractors have not yet fully developed and implemented an effective corrective action program that includes all of the appropriate elements.

A management information system known as the Compliance Management System (CMS) was initiated prior to the 1991 Tiger Team Assessment, but is still in the pilot phase of implementatior, and does not yet include all elements of an effective corrective action program. Some progress has been made towards the development and implementation of a sitewide integrated corrective action 
program and present plans are that all INEL contractors will be recjuired to implement the CMS by October 1993. A Supplemental Directive for the full use of CMS has not yet been issued by ID. This system, combined with the planned key elements of an ES\&H issues management program, could provide an effective management information system when fully developed and implemented.

Some of the deficiencies in the corrective action program are:

- INEL contractors are presently using individual tracking systems in addition to, and instead of, the CMS. There is some resistance to the full utilization of this single system because of the perceived complexity of the CMS input process and the belief that their individual systems may be more suited to their individual needs.

- WINCO and other INEL contractors have developed the key elements of risk-based prioritization processes and effective lessons learned programs. In addition, the EG\&G Idaho prioritization process is well developed for its individual needs; however, programs such as these are not yet developed on CMS.

- The CMS is perceived as complex by some users and potential users at ID and at INEL contractors. Although training has been provided for users at ID and INEL contractors, there is still confusion among some users regarding data input, use of the data fields, and the closure process. A formal, performance-based training program for the CMS has not been finalized at this time.

- The CMS indicates that a corrective action plan is closed whenever all milestones have been closed. However, a corrective action plan is not officially closed until a Completion of Corrective Action Notice has been signed by the ID responsible manager after independent verification of closure.

The premature indication of closure on the CMS has led to some confusion among INEL contractors regarding specific issues. This condition has resulted from the lack of a fully developed corrective action program and could be resolved when such a program is implemented.

- Internally identified deficiencies and corrective actions, including those from the ID Office of Environmental Safety and Health Oversight (OES\&HO), are not always captured, prioritized, formally tracked, followed up, and closed by ID line organizations. The program for internally identified deficiencies is a valuable management information system that has not been fully utilized. There are no requirements for independent reviews by OES\&HO of internal findings except for all Category I and II findings and 10 percent of Category III findings. However, it is unknown at this time whether or not independent reviews of the 10 percent of Category III findings are being performed. There are no present criteria for how the Category III findings are prioritized, tracked, or closed. There has been a lack of resources in some OES\&HO functional responsibilities (e.g., nuclear safety and industrial hygiene) to provide full independent 
reviews of internal findings or closure of corrective action issues assigned to OES\&HO personne1.

- One of the important aspects of an effective corrective action program is the validation process to assure that the completed actions were performed and that they adequately corrected the identified concern. ID and INEL have the elements of such a process (identified in the Tiger Team Action Plan Project (TTAPP)), but this process has not been effectively used in all cases. As an example, some of the environmental corrective actions from the Tiger Team Assessment were not effectively validated. ID made the deliberate decision to limit the number of milestones for each action plan to a total of six in order to make the enormous process more manageable. Some concerns, however, are too complex to force fit into the limited milestones. As a result, there was confusion in the validation process that all elements of some concerns were fully completed. There have been inconsistencies in the closure of some concerns, particularly in the environmental areas.

- Every corrective action plan from the Tiger Team Assessment was assigned to an Assistant Manager and an Issue Manager at ID who are responsible to ensure followup, closure, and validation. The Issue Manager is also responsible for approval of modifications to the corrective action plans after coordinating with the appropriate organizations. Staff within the organizations perform the reviews of completed action packages and, when corrective actions are complete, the completion of Corrective Action Notices are signed by the responsible Assistant Manager. There have been inconsistencies in the closure process, and as staff members move to new positions, some confusion has developed in the roles and responsibilities for closure. Objective evidence is required for corrective action plans prior to closure; however, the team identified some closure packages that did not have the necessary objective evidence (see Concern $\mathrm{M} / \mathrm{C}-4$ ). The program manager for projects at the site may not have control of the budget for the corrective action plans associated with those projects, and as a result, there have been inconsistent closure and validation for some corrective action plans.

- Some Tiger Team Assessment key findings, corrective action plans, and milestones in the environmental area have been closed by Issues Managers' without appropriate technical reviews. Those specific issues that were closed without appropriate technical review include $A / C F-1$ and several milestones of $A / C F-2$ and $A / C F-3$. In addition, the closure of several contractors' action plans within MF-11 (INEL Stop-Work Authority) has shown problems with the process. These involve the ES\&H organizations not' being involved with concurrence in restarts; contractor procedures do not address how to implement stop-work instructions issued by ID; contractors do not require the notification of stop-work actions to ID; and contractors do not address the specifics of how to document stop-work actions (see Concern $M / C-4$ ). 
In summary, the lack of a fully developed INEL sitewide, integrated corrective action program has led to inconsistencles in the closure and the overdue actions for Tiger Team Assessment and internally generated deficiencies. 
Assessment Concern Number:

Assessment Concern Title:
$M / C-2$

\section{ID Self-Assessment Program}

\section{Performance Objective}

ES\&H Management Performance Objectives and Criteria for Progress Assessments (Progress Assessment Manual, Appendix B-1, December 1992), Performance objective 4.5 , states that a comprehensive, institutionalized, sitewide self-assessment program, approved by the DOE Operations Office, regularly evaluates and reports the status and quality of all aspects of the ES\&H performance of all organizational levels (i.e., Program Secretarial Officer, Field office, contractor) under its cognizance; determines root causes for deficiencies; and ensures that corrective actions are taken.

\section{Concern}

ID does not have a formal, comprehensive, sitewide INEL self-assessment program. As a result, important information that would serve as a basis for continuous ES\&H performance improvement is not available to ID management.

\section{Discussion}

In 1990, DOE established a policy with respect to the role of self-assessment as an essential management tool for continuous performance and for pursuit of ES\&H excellence. In 1991, the Tiger Team Assessment verified that such a mariagement system was not in $\mathrm{place}$ at INEL. Today, 3 years after the DOE policy was promulgated and 2 years after the Tiger Team Assessment, ID has neither developed a formal comprehensive program plan nor fully implemented such a program. Some elements of a self-assessment program are being implemented within ID. The ID Office of Environmental Safety and Health Oversight (OES\&HO) have conducted independent assessment efforts through surveillances and appraisals; quarterly self-assessments have been performed by individual ID organizations; and ES\&H deficiencies are tracked and limited root cause analysis is performed. However, essential elements of the program such as a comprehensive corrective action program that captures all issues, consistent root cause analysis, trend analysis, and lessons learned have not been developed. Although informal discussions regarding self-assessments have been held with ID contractor organizations, ID has' failed to provide guidance or direction to the INEL contractors regarding the development of self-assessment programs. Self-assessment data provided to ID by the INEL contractors are inconsistent and incompatible, and inhibits the development of an overall INEL self-assessment.

Even without formal ID guidance, the Progress Assessment Team found progress by INEL contractors in the area of self-assessment since the 1991 Tiger Team Assessment. Over the last 2 years, all of the INEL contractor organizations have developed and are using their self-assessment processes as a management tool for improvement. In addition, ID, through the cost Plus Award Fee (CPAF) process, has provided incentive for the INEL contractors to complete their Tiger Team Corrective Actions Plans related to self-assessment. All INEL contractors have identified that their self-assessment program corrective actions are complete and are ready for review for closure by ID. 
Assessment Concern Number:

Assessment Concern Title:
$M / C-3$

ID Oversight

\section{Performance Objective}

ES\&H Management Performance Objectives and Criteria for Progress Assessments (Progress Assessment Manual, Appendix B-1, December 1992), Performance Criterion 2.4.2, states that staff are actively and personally involved in assessment (e.g., appraisals, audits, and survelllances) and review of Field Office/Site Office and site contractor activities to ensure that such activities are conducted with formality and rigor and that they comply fully with ES\&H requirements established by law, regulation, and DOE policy.

\section{Concern}

Certain elements of the ID program for ES\&H oversight of INEL contractors is not adequately structured or performed to adequately ensure ES\&!H compliance and the achievement of excellence.

\section{Discussion}

ID oversight of ES\&H activities at INEL consists of all activities that assure and inform ID management that the ES\&H program at INEL is being effectively implemented. ID oversight includes the review of documents, assessments of the contractors (audits, appraisals, and surveillances), evaluation of contractor ES\&H performance as a part of the Cost Plus Award Fee (CPAF) process, and self-assessment. At INEL these activities are performed both by the ID Program line organization (e.g., AM/NP and AM/ER), the support ES\&H staff (AM/SES) and the independent oversight organization (OES\&HO). ID is performing independent appraisals, audits, surveillances, and assessments as well as line surveillance of the contractors' activities as they affect ES\&H. Many deficiencies are being identified, communicated to the contractor, and corrected or scheduled for correction. However, the following conditions indicate that the oversight program is not being adequately performed in some areas, that oversight activities are not always properly documented, and that identified issues are not always properly prioritized and consistently and promptly resolved in a documented manner. Taken collectively, these deficiencies indicate that the program does not provide ID management with all the information needed to manage ES\&H issues and assure of adequacy of the ES\&H program at INEL. In addition, the current documentation that describes the structure, missions, and functions of the newly authorized ID organization does not embody an appropriate level of management commitment to ES\&H and appears to reflect an overall reduction in the independence, authority, and visibility of ES\&H oversight.

Deficiencies in the ID ES\&H oversight program and its execution include the following:

DOE has defined and addressed the important ES\&H issue regarding the shutdown of facilities for safety reasons and has formally defined the related processes and authorities including actions required for restart in DOE Orders, HQ guidance and direction, and ID/INEL contractor policies and procedures. Another aspect of that important ES\&H issue, one that directly affects each employee 
in every DOE and contractor organization as they conduct the tr day to day activities, is the authority to stop any work activities that adversely affect, or have the potential to adversely affect, the safety and health of site personnel or the public, or damage the environment. The authority for stop work action by INEL persorinel is defined in the ID Policy Manual, is generally delineated in implementing procedures, and understood by INEL personne1. However, the process for documenting the work stoppage, establishing and documenting corrective actions (including DOE 5000.3B occurrence reporting requirements), and the authority and documentation for restart are still not specified in ID policies or procedures. This issue was identified by the Tiger Team Assessment as Management Finding MF-11 and has not been corrected by ID to date and the milestones and corrective action plan for this finding have not been completed or closed. The Site Engineering and Support Manual does not have a procedure addressing stop work/restart, although they have line responsibility for construction safety, where the exercise of stop work authority is most 1ikely to occur.

In addition, ID improperly closed several contractor Tiger Team Corrective Action Plans related to stop work in that the actions taken did not fully address this issue and the closure evidence packages did not contain all of the necessary objective evidence. (See Concern M/C-4 for detalls on the issue of stop work/restart. See Concerns $E / C-1$ and $M / C-1$ for additional examples of improper closure of Tiger Team Corrective Action Plans.)

- Three self-assessment and oversight documents issued in 1993 have identified significant, programmatic, ES\&H management deficiencies within ID; the internal "Progress Assessment Report" issued on March 4, 1993 (D-C-73), the OES\&HO Assessment of ID Line Management Systems for Managing OES\&HO Findings issued March 10, 1993 (D-C-37), and the First Annual Office of Oversight Report issued March 9, 1993 (D-C-42). The report related to ID 1ine management actions relating to OES\&HO findings noted very inconsistent and poor performance by the ID line organizations in communicating issues to contractors, in responding to OES\&HO reports, in evaluating issues for root causes, and in tracking and verifying closure of contractor and ID corrective actions. The Progress. Assessment Team noted several instances where OES\&HO findings against ID line organizations, or its contractors, had never been responded to, nor had the issues been entered into any site tracking system, action plans developed, or documented actions taken (D-C-48 and D-C-66). To date, there has been no formal response to any of these reports and no management directed corrective action plans developed to address the issues raised by these oversight efforts.

- ID OES\&HO has not performed any sitewide cross-cutting appraisals of environmental program issues and lacks the appropriate staff expertise to conduct appraisals of the radiological environmental monitoring and surveillance program (see Concern $E / C-1$ ). 
ID has not performed the management appraisals of all INEL contractors mandated by DOE Order 5482.1B (all are now scheduled for future assessments). The one management appraisal performed, of WINC.O in early 1993 (D-C-74), was performed by a team that included line managers and was performed in accordance in a structures manner with formal performance objectives and criteria. However, this report evidences several weaknesses in this process that must be addressed prior to the continuation of this appraisal element if the resulting appraisal is to meet the intent and requirements of DOE 5482.18 and provide senior management with an accurate assessment of contractor management performance. The appraisal report did not specify or reflect that sufficient objective evidence was considered and evaluated to support the conclusions drawn in several assessment areas. Some conclusions appeared to be based solely on the reviewers opinion or the statements of interviewees. While this may be all that is available or necessary for some individual elements of an assessment area and a certainly a necessary part of the process, the support for the overall conclusion in any area should primarliy be based on the evaluation of objective evidence. These weaknesses indicate a need to further define and strengthen the management appraisal process, including issues such as training in assessment techniques, better scoping of subject areas and the activities/issues evaluated to draw conclusions, and more thorough in-process and final quality assurance and review of the content and conclustons of the team.

- The Tiger Team Corrective Action Plan, in numerous places (e.g., Table 3-2, Finding MF-1, Key Finding 041) referring to the lack of onsite presence of management personnel, states that policies and procedures will be updated to clarify and specify minimal expected performance related to walkdowns, surveillances and appraisals. The ID Policy Manual has not been revised in this regard, and in general, neither management nor staff are performing or documenting the walkdowns or survelllances speciffed in varlous $A M$ and subordinate level procedures. With the exception of the Facility Representatives and RESL, it was not apparent to the Progress Assessment Team that ID management is improving or achieving an appropriate level of management fleld presence or survelliance/monitoring activity as directed by ID policies and implementing procedures and the commitment statements in the Tiger Team Corrective Action Plans. In general, there is little documentation or in some cases no formal requirement for documentation of management monitoring efforts. Therefore, without objective evidence it was difficult for the team, and ID management, to clearly confirm the level of effort and progress in this area. However, interviews with ID staff indicated a continuing weakness in this area. ID staff stated that, although some organizations are performing management and staff "Management by Walkdown" monitoring efforts, their performance and results are seldom documented. Staff level ES\&H surveillances are typically not formally scheduled, planned, or performed, and when performed are not documented. However, the lack of formality in this area deprives ID management of a valuable measuring tool to evaluate the quantity, consistency, and effectiveness of this important 
oversight element, including the identification, tracking and closure of any observed defictencies.

- Although thorough oversight activities are being performed by ER\&WM Factilty Representatives, the deficlencles being identifled and the corrective actions and closure verifications are inconsistently documented. Deftciencies and inconsistencies observed by the team include the following:

- Trenching operations were stopped by the Facility Representative without documentation that the contractor had addressed the root cause or formally identified this issue into an ES\&H deficiency tracking system $(D-C-75)$.

- A visit report documented (only as an observation) that personnel were exiting a radiological area carrying food (posted as a "no eating area") and noted the actions taken as "discussed with the Shift Supervisor who told me he did not disagree with me."

- A visit report describing a portal monitor that sporadically al armed due to a known, non-radiological condition (adjacent door opening), which had not been corrected. Although the report clearly identified the risks/concerns with this observed deficiency (fallure to correct a known safety deficiency and the potential for personnel not to believe the al arm is real), there was no documentation of any final corrective action, root cause determination, or tracking on this issue to closure.

- A visit report stated (as an observation) that no improvements in regard to radiation postings had been made since the previous visit a month earlier, but the actions taken were documented as "none."

- ES\&H technical support organizations such as ESD do not have or ut li ize established formal documentation for ES\&H deficiencies identified during the course of their routine support activities. The value of good oversight and deficiency identification is significantly diminished if issues are not adequately and consistently documented, communicated, and tracked; the root causes are determined and corrected; and corrective actions and their effectiveness are not verified.

- Although an ID Quality Assurance Plan was issued in August 1992, to implement DOE 5700.6C, no ID Quality Assurance Implementation Plan (QAPP) and subordinate AM level implementing plans and procedures have been issued (the ID and ER\&WM QAPPs are in draft form).

As the above exampies show, many ID ES\&H oversight activities are not conducted with the rigor, formality, and uniformity needed to provide management with assurance that ES\&H performance is in accordance with 
requirements and that the ES\&H programs at INEL are progressing towards the Department's goal of excellence.

An additional area of concern related to independent oversight activities is that the number of technical personnel responsible for providing independent oversight in OES\&HO has actually been reduced by approximately one third since 1992 (from 25 to 17 people), to approximately the same level as at the time of the Tiger Team Assessment (16). These reductions include the transfer of four persons to other ID organizations that have not been replaced (D-D-231). This has occurred while the overall ID staffing has increased by almost 100 (see Concern $M / C-6)$.

Tiger Team Assessment Management Finding MF-4 identified several deficiencies in the organizational roles, responsibilities, and authorities for independent oversight functions at ID. Considering this Tiger Team Assessment finding and the deficiencies identified by this assessment with respect to the implementation of ES\&H oversight by ID, the team reviewed the available documents related to the recently approved major reorganization of the ID Field office and interviewed responsible ID managers regarding its potential effect on the ID ES\&H program. The ID reorganization, as detailed in the reorganization package submitted to and approved by $A D$ and $F M$ in DOE-HQ, appears to diminish the priority and attention ID has given to ES\&H matters and reduce the authority of the ID independent ES\&H oversight organization. While the Progress Assessment Team is making no judgement as to the adequacy or benefits of the new organization, it is not clear that this approved organization, as presently defined, embodies an appropriate management commitment to ES\&H.

The reorganization package for the DOE Idaho Operations office, dated July 12 , 1993, does not completely address the ES\&H missions and functions of the new ID organizational units and portrays a general de-emphasis of the importance and role of ES\&H oversight within ID. Specific examples of the two areas of weakness identified in the ID reorganization package include the following:

- The package does not include the Office of Quality Management or the Office of the Chief Counsel (both of which have ES\&H responsibilities per the mission statements) in the sections detailing the Organizational Structure, nor does it include any function statements for these organizations.

- The mission statement for the Office of Policy, Assurance and Resource Management (the independent ES\&H oversight organization) does not include any reference to its ES\&H or Assurance mission.

- The organization chart for the Office of Program Execution does not reflect any manager for the Matrix Support organization.

- It is not clear who the Facility Representatives, assigned to programs or projects out of the Matrix Support organization would report to (e.g., for Advanced Test Reactor (ATR), would they report to the Reactor Programs Test Reactor Area (TRA) Manager or the Reactors Programs Manager in the Office of Infrastructure Management. 
- The independent oversight function is no longer an independent organization reporting directly to the ID Manager. Instead, it reports through another layer of management that is responsible for various disparate, non-ES\&H functions; the Office of Policy, Assurance, and Resource Management. The functions of this office, as delineated in the function statements include, among others, safeguards and security, policy formulation (including non-ES\&H), the directives system, information technology, real property systems, site facilities and administrative support, computing resources, mail management, and printing and publishing, as well as ES\&H review.

- The function statement for the Assurance Division in the office of Policy, Assurance and Resource Management is very weak in regard to its essential ES\&H oversight role. The function statement does not even mention the ES\&H oversight role of the office, and does not clearly reflect critical elements such as independence, authority, or followup of identified issues. The oversight function is simply referred to as "reviews" of contractor and ID operations with regard to full compliance with all applicable laws and regulations. This is in significant contrast to the function statement for the Performance Assessment Division in the office of the Chief Financial officer, responsible for financial oversight (waste, fraud, and abuse). There the oversight functions related to financial matters are described clearly as "conducting totally independent and impartial reviews," and describes its duties variously as evaluations, "assures that," appraisals, audits, and independent tests, versus the "reviews" to be conducted by the independent ES\&H oversight organization. In addition, the function statement for the financial oversight details the roles of recommending corrective actions and ensuring the followup to determine that corrective action is taken.

- In addition to introducing an extra layer of management between the independent ES\&H oversight organization and the ID Manager, the function statement for the Assurance Division describes a further weakening of the level of independence within that organization. The function statement details the roles of providing input, coordination, review, and support for the writing, as well as implementation of procedures and plans. In addition, it details a role of coordination, monitoring, and implementation of ES\&H activities. Only one sentence in this function statement addresses the role of reviewing operations with regard to compliance with laws and regulations; it does not address the assessment of overall performance in the pursuit of ES\&H excellence, as opposed to mere compliance. A clear potential conflict exists between this organization's role for program development, coordination, and implementation, and that of performing "independent" reviews for compliance.

- The function statements for the Office of the Program Manager for Research and Development Programs and for the Office of the Program Manager for Reactor Programs make no mention of ES\&H or any relationship with the Office of Policy, Assurance, and Resource Management or the Office of Quality Management. In

$$
\text { B-1-11 }
$$


contrast, the function statements for the office of the Program Manager for Environmental Restoration and the Office of the Program Manager for Waste Management contain references to their responsibility for ES\&H and the quality of operations. They further describe a function of coordination with the office of Policy and Assurance (sic).

- Finally, the cover letter forwarding the reorganization package, which discusses the scope and benefits of the reorganization as a part of an ID strategic plan to achieve effectiveness and efficiency, makes no reference to its effects on, or enhancement of, the ES\&H program at INEL.

Finally, although the ID reorganization plan was submitted to and approved by the DOE headquarters offices of $A D$ and $F M$, it was not provided to $E H$ for review or concurrence. 
Assessment Concern Number:

Assessment Concern Title:
M/C-4

INEL Stop Work/Restart Processes

\section{Performance Objective}

ES\&H Management Performance Objectives and Criteria for Progress Assessments (Progress Assessment Manual, Appendix B-1, December 1992), Performance Objectives 2.2 and 4.2 , state that ES\&H roles, responsibilities, and authorities (RRAs) are clearly defined, formally documented, communicated, and understood. Performance Criteria 2.2.4 and 4.2.4 state that decision authorities, including the authority to stop and restart work are placed at the appropriate level, and are clearly defined, formally documented, communicated, and understood by all involved parties.

\section{Concern}

ID has not assured that stop work and restart authorities and processes are consistently and clearly defined, and understood by all personnel at INEL.

\section{Discussion}

DOE has defined and addressed the important ES\&H issue regarding the shutdown of facilities for safety reasons and has formally defined the related processes and authorities including actions required for restart in DOE Orders, DOE-HQ guidance and direction, and ID/INEL contractor policies and procedures. Another aspect of that important ES\&H issue, one that directly affects each employee in every DOE and contractor organization as they conduct their day-to-day activities, is the authority to stop any work activities that adversely affect, or have the potential to adversely affect, the safety and health of site personnel or the public, or damage the environment. The authority to both stop and restart work must be placed at the appropriate levels, and must clearly defined, formally documented, communicated, and understood by all involved parties. The importance of this ES\&H program element is further elevated by the extensive changes in RRAs that will occur as the INEL implements the new ID reorganization and the consolidation of its M\&0 contractors.

Tiger Team Assessment Management Finding MF-11 identified a 1ack of procedures and clear understanding of stop work and restart authorities. This finding resulted in the development of seven corrective action plans (CAPs) involving ID, AAO, and five contractors (excluding PTI). All five contractor CAPs have been completed and closed by the contractor and four have been verified and closed by ID (only MK-FIC's CAP remains open). Only one of six milestones for the ID CAP has been closed (during the Tiger Team Assessment). ID has not taken action to correct this issue within ID, or to provide guidance and direction to the INEL contractors, and has verified as closed contractor CAPs that did not fully address this issue.

Following are status summaries of the INEL stop work/restart programs at the time of the Tiger Team Assessment and the current weaknesses in the programs. 
The policy at the time of the Tiger Team Assessment was ambiguous and did not address restart, and implementing procedures were inadequate. The current status is unchanged. The formal ID policy has not been revised, only one organization has issued a revised procedure (OES\&HO), and that procedure (as we11 as those of Energy Programs and Nuclear Programs) does not address restart. Site Engineering Support (SES) does not have any procedure. Only OES\&HO's procedure addresses any required documentation of the stop work, corrective action or restart authorization and it addresses it very non-specifically. None address the process for handling a stop work initiated by a contractor. None require the involvement of ES\&H specialists in the formulation or evaluation of corrective actions or the decision to restart (ERWM procedure specifies facility representative concurrence). Only the AM/NP procedure requires consideration of DOE 5000.3B, "Occurrence Reporting," in evaluating the stop work action.

\section{WINCO}

The WINCO Policy Directive at the time of the Tiger Team Assessment did not address conditions necessary for restart or address stopping work for environmental reasons. The current status is that the Policy Directive now addresses environmental issues, but still does not address restart authority; does not require notification of ID of work stoppage; does not address any formal documentation of the stop work, corrective action or restart authorization; and does not address the handling of an ID stop work order. WINCO has procedures that address documentation and restart details for reportable occurrence issues (facility shutdown/restart) but it does not address individual activity stop work/restart.

\section{MK-FIC}

No formal policy existed at the time of the Tiger Team Assessment. The current status is that a new procedure has been issued, but it does not require notification of ID and only indirectly addresses how to handle an ID stop work order (handled by ES\&H Manager). However, this procedure was the most comprehensive stop work procedure reviewed at INEL and the only one to provide a dedicated form and requirements for documenting the details and approvals for stop work/restart actions.

\section{B\&W (Rockwel1)}

No formalized policy existed at the time of the Tiger Team Assessment. The current status is that two new procedures covering stop work and restart have been issued, but stop work authority is only granted to employees for work "within their scope of work or responsibility." ID is not required to be notified of stop work actions except as required by DOE Order 5000.3. The restart procedure applies to facility shutdown actions as described in SEN 16 and DOE Memorandum NE-1; not "stop work" actions.

\section{EG\&G Idaho}

At the time of the Tiger Team Assessment, stop work authority was not granted to workers, only supervisors, safety specialists, and oversight

representatives. Stop work policies/procedures did not address stop work for environmental considerations. The current status is that revisions to the Resource Manual and the Safety Manual to address worker authority and 
environmental conditions has been issued, but no implementing work procedures have been issued. The revised manuals do not specify any requirements to document the stop work, corrective actions or restart authorization; do not require notification of $I D$; and they do not require ES\&H specialist

involvement in the corrective action or restart decision. 
Assessment Concern Number:

Assessment Concern Title:
$M / C-5$

ID Directives, Policies, and Procedures

\section{Performance Objective}

ES\&H Management Performance Objectives and Criteria for Progress Assessments (Progress Assessment Manual, Appendix B-1, December 1992), Performance Criterion 2.4.1, states that a Directives System ensures that ES\&H 1 aws, regulations, DOE Orders, SENs, and other DOE requirements are translated into site-specific guidance and that such guidance is formally transmitted in a timely fashion to the site contractor. Performance Criterion 2.4.1.3 states that the processes and responsibilities for receipt, control, and distribution of directive materials are clearly defined, formally documented, communicated, and understood.

Performance Criterion 2.4.2.1 states that activities throughout the Field Office/Site office are to be conducted with the formality, rigor, and quality assurance mandated by DOE ES\&H requirements.

\section{Concern}

ID directives, policies, and procedures related to ES\&H have not been developed and maintained to provide the expectations and direction needed to implement and oversee an effective, proactive ES\&H program at INEL. The failure to ensure that existing procedures are adhered to or revised to reflect actual performance has resulted in inconsistent, informal identification and resolution of issues and incomplete performance data for management decision making.

\section{Discussion}

The ID directives and procedures system is detailed in the ID Policy Manual, an ID Notice, and an ID Supplemental Directive. These documents outline a basic system for processing DOE Orders and SEN Notices; defining the hierarchy of ID directives, policies, and procedures; and establishing a policy of policy and procedural adherence. These policies and directives with regard to the development and maintenance of procedures and adherence to procedures are, in general, not being implemented within the various ID organizations. ID has identified continued weaknesses in the area of directives, policies, and procedures through their self-assessment efforts and has had efforts underway for some time to update and upgrade policies and procedures. Progress has been made in the ID control and distribution of directives, but much less progress has been made since the 1991 Tiger Team Assessment in the area of developing a functioning procedures system within ID. A Directives Manager has been assigned in the Office of the Assistant Manager for Administration (AMA) and a Quality Assurance Working Group formed to develop the ID Quality Assurance Plan to implement DOE $5700.6 \mathrm{C}$ was extended in December 1992, with the tasks of coordinating new ID procedures and developing three office-level procedures including a writer's guide, a document control system, and a new organization and functions directive.

In addition, various AM organization have been making some attempts at updating their procedures manuals. However, these directive/procedure 
development assignments have been collateral duties and progress has been slow. Weaknesses related to procedural adequacy within ID include the following examples:

- Most AM-level procedures have not been revised since their issue/revision just prior to arrival of the Tiger Team Assessment in 1991. There is little evidence of any documented, formal review for adequacy except in SES. As such, procedures related to self-assessment, corrective actions, action tracking, and quality assurance program have not been revised to reflect changes in these programs.

- A number of ES\&H procedures identified as required back in 1991 have not yet been issued.

- The ID Policy Manual does not reflect current practices in a number of areas and a significant number of commitments in various Tiger Team Corrective Action Plans to update and upgrade ID policies have not been completed; no changes have been made to the ID Policy Manual since the Tiger Team Assessment.

- Policies'and procedures with ID-wide applicability have been identified, but not yet issued.

In addition to the above listed procedural inadequacies, there are numerous policy implementing procedures that are not being adhered to, especially in the areas of the issuance of surveillance schedules; the conduct and/or documentation of line staff surveillances/monitoring activities and management walkthroughs; the documentation deficiencies; the development of corrective action plans; and the tracking and closure of corrective actions. The failure to periodically review and promptly update procedures fosters an attitude of acceptance that some procedures don't need to be followed because they are outdated or wrong and thus the decision to adhere to procedures must be judged on the circumstances in each case. The resulting lack of control, accountability, and consistency is contrary to good management practice and the directions contained in DOE 5700.6C, "Quality A.ssurance," and DOE 5480.19, "Conduct of Operations."

The following example indicates that ID apparently has not fully corrected Tiger Team Assessment identified weaknesses in the area of giving appropriate guidance and direction to INEL contractors regarding DOE directives. In September 1992, MK-FIC identified in a FY 1993 Budget Deferral letter to the ID Contracting officer's Representative (COR) that they would not be able to implement all or parts of several ES\&H related DOE Orders (including DOE 5480.19, DOE 5700.6C, and D0E 5482.1B, "ES\&H Appraisa1 Program") without ID budget approval. This letter was not formally responded to by ID. In addition, specific implementation plans or revised plans to address how and when compliance with these Orders would be achieved were neither required by DOE, nor provided by the contractor. Determinations related to this letter were made through informal communications between responsible ID offices and the COR, and between the COR and the contractor. 
Assessment Concern Number:

Assessment Concern Title:
$M / C-6$

Human Resource Management

\section{Performance Objective}

ES\&H Management Performance Objectives and Criteria for Progress Assessments (Progress Assessment Manual, Appendix B-1, December 1992), Performance objectives 2.3 and 4.3 , state that the human resource requirements for full implementation of ES\&H programs are identified and prioritized; that plans ensure that these resource requirements are met; and that formal programs for staff development, training, and certification ensure that only fully qualified personnel are assigned to ES\&H programs.

\section{Concern}

ID has not yet implemented an effective ES\&H human resource management (HRM) program to ensure that sufficient ES\&H oversight personnel are available to carry out the ID mission; and that personnel at all levels of their respective organizations understand their ES\&H performance expectations and are qualified and, where required, certified to carry out their assigned duties and responsibilities.

\section{Discussion}

The two primary performance measures used to evaluate ID's progress in establishing effective ES\&H HRM programs throughout INEL are the status of ID ES\&H-related HRM management systems and the status of its contractors' systems. Based on these performance measures, it is evident that ID has had a positive impact on INEL HRM as it relates to the INEL contractors. All INEL contractors have substantially improved the ir HRM programs since the Tiger Team Assessment. By contrast, improvements in the ID program since the Tiger Team Assessment are not evident: ID continues to provide only the minimum resources necessary for an effective independent ES\&H oversight program (also see Concern M/C-3); ID ES\&H training and staff development programs remain in the formative stages; and ID's efforts to improve the individual performance appraisal process have not yet improved the quality of the individual performance appraisals.

The following summary of ID HRM systems and associated deficiencies addresses the ID management systems and the status of remaining deficiencies in the INEL contractors' HRM systems. The purpose of the following summary is twofold; to focus ID's attention on deficiencies in its HRM system and to give ID appropriate credit for the accomplishments of its contractors since the Tiger Team Assessment.

\section{$\underline{\text { ID }}$}

The INEL Tiger Team Assessment found that ID and its contractors were not managing their human resources with sufficient emphasis on ES\&H responsibilities. ID had not given sufficient priority to acquiring the necessary ES\&H professional staff required to carry out its ES\&H oversight responsibilities. While pockets of training excellence existed, overall training programs throughout INEL were fragmented, decentralized, informal, and incomplete. ID and the INEL contractors had not communicated specific, 
measurable, and personal ES\&H responsibilities and performance expectations to each employee. The central importance of individual ES\&H excellence had generally not been expressed throughout INEL in personnel position descriptions, performance expectations, and appraisals.

The status of the ID ES\&H training and staff development program has not progressed as much as the INEL contractors' programs, primarily because of a slow start in establishing a centralized program. The ID response to the Tiger Team Assessment training-related findings was to centralize ID training in a recently (before the Tiger Team Assessment) formed Training and Development Branch (TDB) and to increase the staffing level from a single training officer to an organization staffed with seven individuals by November 1991. While this organization made some progress in establishing an effective program, it declined to three staff members by January 1992. The rapid decline of TDB has been attributed to the failure of ID to formally translate its concept for this new organization into formally defined and communicated roles, responsibilities, and authorities (D-D-64). Specifically, ID has attributed this problem to ". . . the absence of a clear mission and purpose. " (D-D-64). As a result of an ID self-assessment conducted in February 1992 that identified these problems, ID management took corrective actions to revitalize the TDB. By June 1992, a permanent Branch Chief was appointed and the organization was restaffed.

Accomplishments since the revitalization of the TDB that are fundamental to an effective training program included the formulation of an ID Training Policy that defines the training roles, responsibilities, and authorities throughout ID (D-D-66). However, other vital elements of the program remain to be developed. For example, the rough draft of the revised ID Training Program Manual has an expected issue date of 0ctober 1993 (D-D-65). In addition to requiring an internal review and approval, important elements of the manual such as a final version of the General Training Matrix remain to be developed. During this assessment, Assistant Manager for Administration (AMA) management expressed a realistic understanding of what needs to be accomplished to achieve an effective ES\&H training program.

In addition to the training provided by TDB, ES\&H-reilated training is also conducted by the ID Program Offices such as the Assistant Manager for Nuclear Programs (AM/NP) and Assistant Manager/Energy Programs (AM/EP). The ID ES\&H training and certification programs provided by these offices has also only recently begun to show progress. Examples include:

- Progress in the RESL training program over the past year includes the preparation of approved quality assurance procedures for training and qualification (D-D-89), training modules (D-D-95 and D-D-96), and written examinations. A1l RESL staff who require training have not yet received the necessary training. However, since'management does not assign an individual to duties they are fully qualified to perform, this results in a situation that effects ID's ability to fully utilize its resources rather than one where activities are performed by individuals who are not fully qualified (I-D-2).

- The ID Office of Nuclear Programs Facility Representative (FR) Program received little attention between the Tiger Team Assessment (August 1991) and October 1992 (I-D-3, I-D-13, and 
I-D-27). Since last October, ID began implementing the Office of Nuclear Energy (NE) version of the DOE FR Program; a training program for ID-AMP has been initiated; and about half the Facility Representatives have undergone basic qualification (I-D-13). Generic Facility Representative cards have been prepared and oral boards are now being conducted; however, a facility-specific qualification program has not progressed to the point where individuals are completing the program (I-D-13).

It was evident that ID has emphasized the enhancement of the ID individual performance review process in response to the deficiencies identified during the Tiger Team Assessment. The increased emphasis that ID has placed on the individual performance review and development process has focused on improving the mechanics and uniformity of the Individual Development Plans process. The Individual Development Plans process has been improved to ensure that ES\&H training needs and human resource management received appropriate attention. By February 1992, 98 percent of the Individual Development Plans of all ID employees were completed (D-D-64), and by June 1992, TDB had added several employee development specialists to its staff. More recently, an Individual Development Plan User Guide (D-D-63) and a Individual Development Plan (IDP) Workshop Training program have been developed to further improve the quality and uniformity of the ID individual performance review and development process.

ID's efforts to improve the individual performance appraisal process are not yet evident in the quality of the individual performance appraisals. The Tiger Team Assessment found that most performance appraisal plans lacked the specific, measurable position responsibilities necessary to define and evaluate employee performance. Instead, common, difficult to measure performance expectations were the norm throughout the ID performance appraisals. These included, "insures that staff subordinates are engaged in conscientious efforts to implement, promote, and achieve compliance with all ES\&H goals and requirements. . ." and the equally common and vague "assures compliance with environmental regulations and statutes including EPA, RCRA. . ."

These weaknesses in the individual performance evaluation process persist. Generic rather than specific and measurable ES\&H performance expectations continue to be the norm. For example, a fully successful performance standard for ES\&H awareness and compliance states "Displays a conscientious effort to implement, promote, and insure compliance with all ES\&H requirements. . ." Unlike the ES\&H performance criteria, programmatic or technical criteria in the same performance plans are specific and measurable. The fully successful performance standard includes "At least $90 \%$ of the quality assurance results are within $\pm 3 \sigma$ of accepted values. .." (D-D-97).

ID management acknowledges that the Individual Development Plans process is not yet providing quantifiable ES\&H jerformance expectations that provide an objective basis for measuring performance while preserving the necessary flexibility to adjust performance activities to the facility risk profile. ID management also acknowledged that the performance appraisal process still lacks specific, measurable ES\&H performance expectations (I-D-3, 6, 28, and 29). Several ID employees who recieived marginal ratings complained they did not have specific performance standards to guide them (D-D-97). To date, ID 
has focused on the uniformity and the number completed rather than the quality of Individual Development Plans. ID management indicated that it expects to initiate a mechanism for overseeing the quality and effectiveness of the Individual Development Plan process as a part of $\mathrm{ID}^{\prime} \mathrm{s}$ independent oversight but this mechanism is not yet functioning (I-D-26 and I-D-28). By contrast, all of the INEL contractors appear to have systems that provide quantifiable performance expectations.

The Tiger Team Assessment found that ID had not given sufficient priority to acquiring the necessary professional ES\&H staff required to carry out its ES\&H oversight responsibilities (see INEL Tiger Team Assessment Finding MF-3). This finding was based on the fact that from 1989 through July 1991, ID full-time permanent staff increased by 71 people, to a level of 424 people; while the Office of Environmental Safety and Health Oversight (OES\&HO) and its ES\&4. companion and predecessor organizations' ability to conduct effective injependent ES\&H oversight was inhibited because OES\&HO only added 6 p ofessionals from outside hires.

Since the Tiger Team Assessment, Facility Representatives have been added to ID program line management organizations to strengthen ES\&H line oversight (I-D-6). By contrast, ID independent ES\&H oversight, which is primarily provided by OES\&HO, remains relatively unchanged during a period when ID staffing levels continued to increase. The following OES\&HO ES\&H professional staffing profiles were provided for the Progress Assessment Team: 8 in $1989-1990 ; 10$ in 1990; 16 in 1991; 25 in 1992; and 17 at the time of this assessment (D-D-231). In the last year, three OES\&HO staff took positions outside of ID, four individuals transferred to other positions within ID (D-D-231), and several staffing slots were filled with management personnel. However, notwithstanding these internal and external influences, including the addition of Facility Representatives, the fact remains that OES\&HO technical staffing levels increased by approximately a third following the Tiger Team Assessment and have since decreased by a third to approximately the Tiger Team Assessment staffing levels while ID staffing levels have increased from 424 people to approximately 520 people (adjusted for the defederalization of INEL firefighters). Over this 2-year period of intense hiring to further enhance its technical human resources, ID hired 71 scientist and engineers while providing less than the minimum resources necessary for an effective independent ES\&H oversight organization.

A second measure of ID progress in establishing effective ES\&H human resource management systems that will serve the INEL mission today and in the future, is the progress of the INEL contractors. In this respect, substantial progress has been noted in the INEL-wide HRM programs.

\section{INEL Contractors}

While each contractor's HRM program reflects the character of that organization, overall there is little to distinguish one program from another. A11 INEL contractor HRM programs evidence substantial improvement over the past 2 years including the WINCO program which was judged to be a relatively strong program during the Tiger Team Assessment. Furthermore, all contractor programs contain elements that require their continued attention either because they are not yet fully implemented or have not yet satisfied the increased performance expectations of contractor management. For example, while PTI and MK-FIC have made substantial progress in implementing effective 
ES\&H programs, both organizations continue to pursue ES\&H training aggressively. PTI ES\&H-required training has been completed and PTI is now conducting refresher training (I-D-32). MK-FIC management estimates that approximately 70 percent of the required ES\&H training has been satisfied. Some of the MK-FIC requirements have only recently been identified in the comprehensive DOE Order compliance determination (also see Concern $M / C-5$ ) contractors appear to understand the status of their programs and are committed to further enhancements. Furthermore, there appears to be wide-spread acceptance of and enthusiasm for ES\&H training among the contractor employees. The following paragraphs are a brief summary of the INEL contractor programs with examples of common deficiencies.

Contractor strategic plans accord ES\&H training programs strategic importance. Multi-year plans such as the EG\&G Idaho ES\&Q Department Five-Year Operational Plan (D-D-47) or the WINCO Human Resources Strategic Plan address training and human resource issues with related group milestones (I-D-5). Contractor annual program $\mathrm{klans}$ contain training related packages that define work package managers, estimated resource requirements, work scopes, planning assumptions, deliverables and associated milestones, and, in the case of EG\&G Idaho, a logic diagram (D-D-35 and D-D-36). The contractors have established company policies (D-D-40) for the management of company-wide training and issued procedures (D-D-41) that provide guidance and responsibility for implementing the policy.

ES\&H training deficiencies identified by the Tiger Team Assessment have received EG\&G Idaho attention over the past 2 years. The Central Training Group within the ES\&Q Department has been formed to provide a central focus for ensuring that ES\&H training requirements are met throughout the company. All line organizations have taken responsibility for identifying their training needs and ensliring they are satisfied through their respective training coordinators. EG\&G Idaho has consolidated its training needs analysis in the 1992 Training Requirements Matrix/Catalog (D-D-33), consolidated a description of its ES\&H training in a catalog (D-D-34), and developed a number of important formal ES\&H training courses designed to effect a lasting improvement of its training program including a train-the-trainer course (D-D-38). While EG\&G Idaho management has implemented important improvements, the EG\&G Idaho training program has not yet been fully integrated and unified across the company (I-D-26). As a result, duplication of some ES\&H training by several organizations persists. This duplication may result in less than optimum allocation of resources and increases the difficulty of providing uniform, high quality, company-wide training. EG\&G Idaho has recognized this problem and is addressing this issue through a company-wide process improvement team. Training redundancy al so persists in several other INEL cortractor organizations, particularly those with multi-faceted missions.

INEL contractor employee performance and appraisal processes have performance elements devoted to ES\&H issues that permit and encourage the use of specific, measurable performance criteria (D-D-43). An examination of actual performance and appraisal forms (D-D-43) verified that, in general, objective performance measures are being applied. For example, EG\&G Idaho senior managers are clearly held to specific and ever more challenging ES\&H performance measures such as frequencies of contamination occurrences, lost work day rates, and radiation exposure goals. In general, the performance appraisals of contractor employees contain less specific, but nonetheless 
measurable and objective performance criteria. However, these performance criteria are not always being applied uniformly with respect to ES\&H performance. For example, a recent overall performance rating of excellent (the highest rating) was granted to an individual even though the appraisal noted "(Name) needs to be more concerned about her personal safety than she is about the production of her work." An examination of performance appraisals also revealed that individual position descriptions may not provide employees with sufficient information with respect their job responsibilities. For example, an employee's comment on his performance appraisal form was that "Lack of job description has impacted the overall effectiveness of doing 'routine' duties." While this is not a wide-spread problem, similar deficiencies persist in the performance appraisal systems of the other contractors. The WINCO Human Resource Management system has been further enhanced since the Tiger Team Assessment. Job descriptions have been enhanced to include ES\&H; performance appraisals have been tied to job descriptions and linked to ES\&H objectives and expectations; a management supplement has been added to the performance appraisal process to emphasize training and staff development; and these elements have been integrated with one another and to the Total Quality Plan. Similar efforts on the part of PTI, B\&W, and MK-FIC to improve their individual performance management systems were evident.

INEL contractor Employee Concerns Programs (ECPs) have been substantially strengthened in response deficiencies identified by the Tiger Team Assessment. ECPs are defined and guided by company procedures that appear to describe the mechanics of well structured programs. However, in addition to a process, an effective program is founded on other less tangible attributes such as employee confidence in and acceptance of the program, as well as management commitment to the program. While time constraints during this assessment did not permit a thorough examination of these issues, a recent cost Plus Award Fee action by ID with respect to an INEL contractor employee morale suggests that this contractor's ECP may not yet be fully effective.

There was evidence during this assessment that ID understands and supports the importance of qualified contractor staff to the successful execution of the INEL mission. However, taken collectively, the ID's limited progress in addressing its own human resource management deficiencies, including the priority accorded to OES\&HO oversight staff as identified by the Tiger Team Assessment, suggests that ID management has recently recognized the central importance of fully qualified and trained ID ES\&H staff to the successful conduct of the INEL mission. 
Assessment Concern Number:

Assessment Concern Title:
$M / C-7$

Planning, Budgeting, and Resource Allocation

\section{Performance Objective}

Secretary of Energy Notice (SEN)-25A, and the ES\&H Management Performance Objectives and Criteria for Progress Assessments (Progress Assessment Manual, Appendix B-1, December 1992), Performance Objectives 2.1 and 4.1, state that ES\&H plans and programs are an integral part of the sitewide strategic and implementation planning, budgeting, and resource allocation process; all programmatic and ES\&H activities are integrated and prioritized; procedures exist for analyzing ES\&H risks and vulnerabilities of the entire site on a prioritized basis, and for making the necessary trade-off decisions between achieving programmatic objectives and ES\&H objectives; and implementation plans guide the accomplishment of ES\&H objectives.

\section{Concern}

INEL implementation planning processes that would transform DOE and INEL contractors' strategic and program plans into sitewide, integrated, working-level ES\&H implementation plans have not been formally defined, developed, and implemented. As a result, ID plans for implementing their reorganization and plans that would set risk-based, cost-effective priorities; guide ID's activities and work throughout INEL; and provide formality to ES\&H activities are, in general, lacking.

\section{Discussion}

Strategic and subordinate implementation or operational planning is the systematic process management uses to define, communicate, and transform its vision for accomplishing its mission into action. The planning process defines the organization's strategic goals and objectives, policies and procedures, resources, organizational relationships, management systems, and goals and objectives of subordinate organizations required to accomplish the mission. The goals and objectives from this planning process form the basis of a hierarchy of strategic and implementation planning processes by subordinate organizations that, when completed, serve to define, set priorities for, guide, and coordinate the programmatic and ES\&H activities of all participants.

The two primary performance measures used to evaluate ID's progress in establishing effective strategic and subordinate implementation planning process at INEL are the status of ID planning systems and the status of its contractors systems. Based on these performance measures, it is evident that ID has had a positive impact on INEL planning as it relates to the INEL contractors. While the INEL strategic planning processes have matured and are functioning, subordinate implementation planning processes at ID are virtually nonexistent and the INEL contractors' are not yet fully functional. As a result, in the absence of formal, risk-based implementation plans that would set priorities for and guide ID ES\&H activities on a cost-effective basis, the ID and the INEL contractor's ES\&H activities are unnecessarily reactive and may not be addressing the most important issues in a disciplined fashion. Furthermore, the lack of such ID implementation plans, particularly those 
plans that would guide and control the full implementation of its recently approved (by DOE-HQ) reorganization, may represent a substantial vulnerability for ID.

Consistent with the above assessment approach, the following summary of INEL planning processes and associated deficiencies address the ID management systems and the status of remaining deficiencies in the INEL contractors' planning systems. The purpose of the following summary is twofold; to focus ID's attention on its own planning deficiencies and to give ID appropriate credit for the accomplishments of its contractors since the Tiger Team Assessment.

ID

The INEL Tiger Team Assessment found that, while long range planning at INEL was a well-established management process, ID and its contractors were struggling to understand and comply with Department policy with respect to strategic planning and ES\&H. As a result, ID did not place strategic importance on ES\&H and neither ID nor the majority of its contractors had integrated sitewide strategic plans with subordinate implementation plans to define and guide the accomplishment of ES\&H and programmatic objectives. However, ID had established an INEL strategic planning process, managed by a Strateric Planning Council, that involved senior management and staff from ID and several of INEL contractors (PTI and MK-FIC were not involved). The 1991 INEL Strategic Plan fell far short of a strategic plan that integrated ES\&H into the INEL mission; it more closely resembled a strategic business plan. Subordinate implementation plans to guide the accomplishment of INEL ES\&H objectives did not exist. Other shortcomings of the INEL planning process included a short planning horizon that was more appropriate for a tactical planning process; and ID did not recognize the vital role the strategic planning process of its contractors could play in the INEL planning process. At the time of the Tiger Team Assessment, ID was in the early stages of revising and enhancing its strategic planning process to provide a process for establishing integrated INEL-wide strategic objectives.

Since the Tiger Team Assessment, ID and its contractors have adopted a strategic, sitewide planning perspective, ES\&H considerations appear to be an integral part of the INEL planning, and the INEL contractors appear to be active participants in the planning process. An INEL Strategic PIan (D-D-4) was issued 6 months after the Tiger Team Assessment provides clear INEL mission and vision statements that define ES\&H considerations as an important element of planning. The plan also considers ES\&H issues in a sitewide crosscutting manner and establishes strategic objectives and strategies for their achievement. However, a more recent INEL Strategic Plan (D-D-5) that is in draft form is more like a business plan than a strategic plan, a problem that the Tiger Team Assessment found with earlier INEL strategic plans. This draft plan, unlike the earlier INEL strategic plan, does not specifically address ES\&H performance and compliance as a strategic initiative as it does for market focus areas such as Waste Management and Minimization, Environmental Engineering and Restoration, and Nuclear Technology. The draft INEL Institutional Plan (D-D-3) incorporates and blends the best of the earlier INEL strategic plan and the more recent draft strategic or business plan into a single coherent plan that clearly integrates strategic, programmatic, crosscutting, and sitewide issues. A planning assumption of the 
plan recognizes the integral nature of ES\&H considerations: "ES\&H Will continue to develop as an issue at every stage of a project's lifecycle."

Perhaps the most important implementation plan that ID lacks is a reorganization plan that specifically details the essential activities that must accompany or follow a major organizational realignment. ID is currently pursuing a bold management approach for INEL that is designed to provide enhanced oversight of its INEL contractor activities and the INEL facilities.

The success of ID's concept for managing INEL rests on several vitally important elements. The first involves consolidating the current operating contracts under a single operating contractor. The competition for the INEL management and operating contract is currently being conducted $(D-D-121)$. An equally important element of the ID management strategy is the shift of its management resources from its main offices to field locations throughout INEL. This latter activity involves a major, recently approved, reorganization that ID management has been carefully considering over the past 2 years (I-I)-4 and I-D-22). Since the ID reorganization will result in a major change in structure, reporting relationships, and operating philosophy, the current ID management systems will be rendered obsolete by the reorganization. Examples of management systems that will have to be revised to reflect the new organizational and individual roles, responsibilities, and authorities include: the mission and function statements of ID organizational units, ID organizational interface agreements, the ID directive system, quality plans, program plans, oversight plans, and individual position descriptions and performance plans. The fact that ID is still modifying its management systems to correct the deficiencies identified 2 years ago by the Tiger Team Assessment serves as compelling testimony of the challenge that ID management faces in fully implementing its new management approach. ID has not yet prepared a comprehensive plan that assigns responsibility for developing or modifying the necessary management systems, provides a schedule with interim milestones and deliverables, and identifies the necessary resources to fully implement the ID reorganization (see Concern $E / C-1$ ).

With respect to this reorganization, an architecture and mission/function statements exists in a memorandum (D-D-88) requesting reorganization approval, the deliberations of an ID Implementation Focus Group (D-D-85) that considered organizational impacts (I-D-22), and a one page document entitled

"Implementation for ID Reorganization, 1993." This latter document is an "Event" and "Date (projected)" summary of reorganization activities that are expected to occur through March 1994 (D-D-232). Taken collectively, these documents fail to provide the vital details required to effectively implement the ID reorganization. For example, a number of critical activities remain undefined including the assignment of responsibilities for modifying the ID Directive System and procedures; the revision of position descriptions and Individual Development Plans (IDPs); the identification of resources to modify the ID management systems; a training plan to ensure that ID staff are qualified to carry out their new assignments; and a detail schedule, with interim milestones, that sequences interrelated activities. An additional problem associated with the implementation of the ID reorganization is the ambiguity surrounding the mission and function statements of the new office of Policy, Assurance and Resource Management in the recently approved reorganization memorandum (D-D-88). The mission statement does not address the ES\&H responsibilities of the office as they are expressed in the function 
statement. The lack of an ID reorganization implementation plans may represent a major vulnerability for ID.

The lack of a reorganization implementation plan is not a singular planning deficiency within ID. In general, ID implementation plans are outdated, incomplete or in draft form. For example, an ID Quality Assurance Plan issued in August 1992 to implement DOE 5700.6C has not yet been implemented with subordinate implementation plans and procedures (see Section 2.2.3, Oversight). ID implementation plans that do exist generally consist of a loosely related group of formal and informal documents that include an office program manual such as the Assistant Manager for Nuclear Programs (AM/NP) document entitled Managing for Safety and Quality Manual (D-D-100) and the ID Assistant Manager/Energy Programs (AM/EP) Draft Quality Program Plan (D-D-98), a group of procedures (D-D-99), a surveillance schedule (D-D-120 and D-D-126), memoranda detailing organizational goals and objectives (D-D-70 and D-D-124), and performance indicator reports that take a number of different forms (e.g., memos, bar graphs posted on bullet in boards) (D-D-123). The following examples highlight the types of deficiencies that are commonly found in documents that ID management considers elements of implementation plans:

- The AM/NP Managing for Safety and Quality Manual (D-D-100) is the basic document that describes the formal business policies and practices of the AM/NP. It consists 49 individual sections that address activities such as National Environmental Policy Act (NEPA) Document Review (revision date May 2, 1991), NP-Self-Assessment (revision date June 14, 1991), and Environmental Protection (August 1, 1990). Only three of these documents have been revised since the Tiger Team Assessment. As a result, this manual does not faithfully reflect current AM/NP ES\&H and programmatic practices.

- $\quad$ AM/NP procedures that ID management considers an integral element of their implementation plans are undergoing revisions to reflect current business practices. Other procedures have been identified that must be drafted and approved (D-D-31 and D-D-145).

Similar deficiencies exist in the implementation plans of the AM/EP and the ID Assistant Manager for Administration (AMA) with respect to the Training and Development Branch (TDB) training program plans and training needs analysis process. However, in the case of the TDB, recent progress is evident in the evolution of training implementation plans. Other recent improvements that have been noted in ID's planning, budgeting, and resource allocation process include enhancements in formulating the crosscutting aspects of the INEL budget, the preparation of a Supplemental Directive (D-D-107) to define planning authorities and responsibilities, and ID's use of the Cost Plus Award Fee (CPAF) process to influence ES\&H performance.

The DOE CPAF process is a vital management tool for influencing contractor performance through the selective allocation of resources. The Tiger Team Assessment identified a number of systemic deficiencies in the way ID used the CPAF process to influence and reward the ES\&H performance of its contractors. While the ID CPAF process was not intensively examined during this assessment, there was much evidence that ID now uses this important management tool to recognize the ES\&H performance of the INEL contractors. For example, in 
recent CPAF determinations (D-D-12, 101, 102, 103, 104, and 222) ID rewarded and penalized the ES\&H performance of its contractors in the following ways:

- A contractor's fee was reduced by $\$ 10,000$ because the contractor's ". . approach to safety and health oversight cont inues to provide less than the desired level of independence this function would require."

- A contractor's fee was increased by $\$ 25,000$ to recognize its ". . substantial commitment to ES\&H matters with substantial improvament in all areas." ID further recognized ". . . the contractor's outstanding safety performance."

- A recent cover letter and fee determination report specifically addressed a human resource issue that related to ES\&H performance: ". . . there are strong indications that work force morale has deteriorated significantly. This situation raises immediate concerns about safety.

- Another contractor received an award fee letter that stated: "Your performance in the areas of both waste minimization and waste avoidance are commendable. Particularly admirable are your efforts in the environment safety and health area; this is reflected in the increase of award fee over last period." A letter for subsequent award period noted "Your overall performance continues to be very strong." and ". . . provided commendable emergency services to the INEL during several instances. . . ."

As noted above, the progress of the INEL contractors is a second measure of ID progress in establishing ES\&H management systems that will serve the INEL mission, today and in the future. In this respect, substantial progress has been noted in the INEL-wide planning processes.

\section{INEL Contractors}

The INEL contractor strategic plans (D-D-32, 148, 165, and 195) are directly linked to the INEL mission statement. These plans accord priority to ES\&H and address Environment, Safety, Health, and Quality (ESH\&Q) as a key area of strategic importance to the contractor and INEL along with other key technical and institutional areas such as Public Perception, Technology Base, and Engineering Base. These strategic plans serve as important examples of the disciplined, unified, sitewide approach ID and its contractors have taken towards defining the INEL mission over the past 2 years. With the exception of the B\&W strategic plan (D-D-195), the INEL contractor plans are readily traceable to and constructed within the framework of the INEL plan. The minor departures of the B\&W plan in terms of form and approach have been attributed to the fact that B\&W is a relatively new INEL contractor and B\&W's Specific Manufacturing Capability (SMC) mission is distinctly different from aspects of the INEL mission (I-D-24 and I-D-27). Finally, these strategic plans have few readily apparent weaknesses. A minor weakness is the measurement of the Critical Success of contractor ES\&H training programs by the "number of classes held and employees trained" (D-D-32). While this is an important success factor, the plan does not address other important success factors such as the importance of the effectiveness of training. 
Comprehensive operational and ES\&H-related multi-year plans flow from the contractor strategic plans. For example, the EG\&G Idaho Five Year Operational Plans flow directly from the EG\&G Idaho strategic plan (D-D-32), and WINCO has a long-range human resource strategic plan that is directly tied to the INEL, WINCO, and Westinghouse strategic plans (I-D-5 and I-D-14). In general, contractor operational plans flow from the strategic plan down through each organization to the lowest operational unit. For example, the EG\&G Idaho ES\&Q Department Five-Year Operational Plan (D-D-47) has a mission statement that expands upon the EG\&G Idaho mission, major operational thrusts that can be traced to strategic objectives of the EG\&G Idaho strategic plan, strategic plans for the department and its subordinate organizational units, and specific performance measures.

The INEL contractors' annual planning consist of program plans composed of work packages that define a work package manager, estimated resource requirements, work scope, planning assumptions, deliverables and associated milestones, and a $10 y$ ic diagram (D-D-35 and D-D-36). In addition to operations activities, the plan includes work package for specific ES\&H activities such as safety and environmental support, project planning and environmental documentation, and implementation of the Radiation Control Manual (D-D-36). Mature or nearly mature implementation plans that exist include the individual work package plans of the EG\&G Idaho ESH\&Q, Power Reactor, and Environmental Restoration and Waste Management (ERWM) Divisions (D-D-59 and D-D-60). Similar plans for the Energy Research and Applications Division are incomplete, in part because this organization has such a multitude of loosely related programs (I-D-17). Other implementation plans such as the Quality Management Plan for the Performance Oversight and Assessment Unit (D-D-44) consists of an FY 1993 management plan with key milestones only through December 1992 and an audit schedule through 1993. Self-assessment program implementation plans that exist throughout INEL are also in various stages of development, in part because self-assessment approach are being modified to enhance their effectiveness (I-D-6 and I-D-17). The status of implementation planning by the other INEL contractors is similar to that of EG\&G Idaho.

In general, INEL contractor implementation plans lack sufficient details below the work package level. Contractor implementation plans generally lack those working level plans that define and guide the specific work approach and activities of empioyees, identify the necessary resources, establish management performance expectations including deliverables with attendant schedules and interim milestone are in various stages of development, provide for performance variance tracking, and define the interrelationship between work packages. 
Assessment Weakness Number:

Assessment Weakness Title:
M/W-1

EG\&G Idaho ES\&H Oversight Committees

\section{Performance Objective}

ES\&H Management Performance Objectives and Criteria for Progress Assessments (Progress Assessment Manual, Appendix B-1, December 1992), Performance Objective 4.2, states that ES\&H roles, responsibilities, and authorities are clearly defined, formally documented, communicated and understood.

Performance Criterion 4.4.2.1 states that site activities are conducted with the formality and rigor and quality assurance mandated by DOE ES\&H requirements.

\section{Weakness}

The activities of EG\&G Idaho ES\&H oversight committees are not all clearly defined, documented, or performed at the minimum frequencies specified in policies, procedures, and committee charters.

\section{Discussion}

There are many EG\&G ES\&H oversight committees that are meeting and exceeding the requirements and needs for independent oversight. However, the clear delineation of roles, responsibilities, authorities, and processes are not always documented. In addition, the infrequency of some key committee meetings and the incomplete documentation of action items and their resolution do not contribute to the assurance of the effectiveness of the committees or that their charters are being fulfilled. Examples of these weaknesses include the following:

- The Senior Management Review Group (SMRG), one of the top two independent review committees, meets only. infrequently (e.g., met in Anril and 0ctober 1992, but has not met since). The EG\&G Idaho Safety Manual incorrectly refers to the SMRG as the Nuclear Safety Review Group.

- It is not clear what issues are to be addressed by the SMRG or can be addressed by lower level independent committees such as the ER\&WM Independent Safety Review Committee.

- Meeting minutes for many committees, including the ER\&WM Independent Safety Review Committee (ISRC) and the Power Reactors Program (PRP) Personnel and Tenants Committee do not clearly delineate action items or address the resolution of open issues from the previous committee meetings.

- ID has concluded that this weakness involving the SMRG and the ISRC is resolved by procedure ER\&WMDP 1.8 .

- The makeup of the Environmental/OSHA Management Oversight Committee contained in the EG\&G Idaho Safety Manual has not been updated to reflect the August 1992, reorganization. 
Assessment Strength Number:

Assessment Strength Title:
M/S-1

\author{
INEL Training Advisory Council
}

\section{Strength}

The INEL Training Advisory Council provides a number of sitewide ES\&H training benefits including: a forum for the uniform formulation and promulgation of training policy, the development of training qualifications, the consolidation of training assets, and the standardization of training programs.

\section{Discussion}

In March 1992, ID and INEL contractors formed the INEL Training Advisory Council (ITAC). The council, guided by a draft charter (D-D-122), has the following objectives: to provide a forum for ID and the INEL contractors to address sitewide ES\&H training issues and concerns; initiate and support activities aimed at unifying and consolidating INEL-wide training, thus reducing unnecessary duplication; identify common training needs; and promote uniform sitewide training. The council is composed of training personnel from each of the INEL contractors with oversight by the ID Training and Development Branch (T\&DB). Recent ITAC accomplishments and initiatives include: assisting T\&DB in the development of an ID training policy; consolidation of INEL Hoisting and Rigging training; standardization of INEL access training; development of INEL-wide Instructor Staff Qualifications; and an assessment of INEL training needs that has led to increased training facilities. This council can provide INEL with important benefits by continuing the consolidation of INEL training assets even after the management and operating contract is consolidated and by providing a sitewide basis for uniform, high quality training programs. 
This page intentionally left blank.

B $-1-32$ 
Appendix B-2

Assessment Details - Environmental Programs/

Concern 
As:iessment Concern Number:

Assiessment Concern Title:
E/C-1

Sitewide Environmental Management Program

\section{Performance Objective}

DOE 5400.1, "General Environmental Protection Program," requires DOE to ensure good environmental management of all of its programs, and to anticipate and address potential environmental problems before they pose a threat to the quality of the environment or the public welfare. Chapter IV contains requirements for environmental monitoring programs designed to measure and monitor effluents from DOE operations. The Order requires an Environmental Monitoring $\mathrm{Pl}$ an be prepared which must include effluent and surveillance monitoring and contain the rationale and design criteria for the monitoring program as well as other information. The order requires that effluent monitoring be conducted at all DOE sites to:

- verify compliance with applicable Federal, state, and local effluent regulations and DOE Orders;

- determine compliance with commitments made in Environmental Impact Statements, or other official documents;

- evaluate the effectiveness of effluent treatment and control;

- identify potential environmental problems and evaluate the need for remedial actions or mitigation measures;

- $\quad$ support permit revision and/or reissuance; and

- detect, characterize, and report unplanned releases.

It also states "Effluent monitoring shall. . provide representative measurements of the quantities and concentrations of pollutants in liquid and airborne discharges."

DOE 5400.5, "Radiation Protection of the Public and the Environment," provides requirements for effluent monitoring for radioactivity.

D0E/EH-0173T, "Environmental Regulatory Guide for Radiological Effluent Monitoring and Environmental Surveillance," incorporates and expands on the requirements embodied in DOE 5400.1 and DOE 5400.5 by describing the elements of an acceptable effluent monitoring and surveillance program.

DOE 5480.19, "Conduct of Operations, "Chapter 1, states that "effective implementation and control of operating activities are primarily achieved by establishing written standards, periodically monitoring and assessing performance, and holding personnel accountable."

ES\&H Management Performance Objectives and Criteria For Progress Assessments (Progress Assessment Manual, Appendix B-1, December 1992) states that roles, responsibilities, and authorities for ES\&H implementation are clearly assigned to organizations as evidenced by mission and function statements, goals and objectives, and individual position descriptions. Performance Criterion 
2.4.2.1 states that "activities throughout the Field office/Site office and the site are conducted with the formality, rigor and quality assurance mandated by DOE ES\&H requirements."

Performance Objectives and Criteria for Conducting DOE Environmental Audits (Progress Assessment Manual, Appendix B-3, December 1992), cites the need to develop an Environmental Protection Management Program that identifies all elements, explains a site-specific environmental monitoring strategy, and defines roles and responsibilities for each element.

\section{Concern}

The INEL environmental protection program has inherent deficiencies that inhibit ID's ability to achieve full compliance with environmental requirements and progress towards environmental excellence.

\section{Discussion}

INEL does not have a sitewide environmental management program to meet DOE 5400.1 because the authority for environmental programs is incompletely divided between the line organizations. Each of the line organizations has been given the responsibility and authority for day-to-day compliance at their facilities; however, ensuring compliance at the individual facilities does not ensure compliance on a sitewide basis. Because no ID organization(s) has been assigned the responsibility and corresponding authority for sitewide environmental issues, INEL cannot ensure full compliance with environmental requirements and progress towards environmental excellence.

In addition to the requirements of DOE 5400.1, the diversity of the operations and the number of DOE program offices and contractors makes it essential to have a formal sitewide environmental management program with the authority to plan, develop, and implement sitewide programs in order to ensure environmental protection and compliance at INEL. However, in many instances, INEL is implementing environmental activities without fully integrating rigor and formality into sitewide environmental planning, program development, and program implementation. In addition, ID management has not provided authority, commensurate with qualifications and responsibility, to an ID organization(s) responsible for ensuring sitewide environmental compliance. This authority is necessary in order to provide INEL with a mechanism for effective management of crosscutting issues and significant progress towards environmental excellence $(D-F-19)$.

Authority for sitewide environmental issues has not been assigned to ensure that critical management functions (i.e., planning and prioritization, program development, and program implementation) are properly focussed to manage INEL sitewide (i.e., crosscutting) environmental issues which are inherently unclear and nonspecific. This concern is supported by the following observations:

- The authority and responsibility to $p l a n$ and prioritize environmental programs within ID rests with the line organizations. The Environmental Support Division (ESD), which is responsible for coordinating sitewide compliance issues, has no formal input into this planning process (I-F-5, I-F-11, and $I-F-22 ; I-G-6,21,23$, and 22 ; and $I-E-26)$. As a result, a low 
prioritization was given to the preparation of the flood plain maps which may affect the ability of the INEL to obtain Federal and state approval for the long-term storage of polychlorinated biphenyl (PCB) containing transuranic (TRU) waste at the

Radioactive Waste Management Complex (RWMC) (I-G-8, I-G-20, and I-G-22).

- The flood plain issue has been reviewed by ID. Based on an evaluation prepared by an EG\&G hydrologist, the RWMC is not located within a 100-year flood plain. A more recent study has estimated the effects of the 100-year and less frequent localized flooding scenarios (Flood Evaluatione Study- Idaho Falls, Idaho, Dames \& Moore, March 29, 1993). This report shows the estimated peak water elevation for the TSA is $5005.3 \mathrm{ft}$. For comparison, the lowest elevation for the area is the Certified and Segregated Waste Storage Building at. $5011 \mathrm{ft}$. Although there is no official flood map for the RWMC at this time, there is a project funded to prepare a map.

The authority to enforce sitewide environmental compliance is dispersed among all the of the line organizations and does not rest with ESD which is responsible for coordinating sitewide environmental compliance $(1-F-3,5,7$, and 22). For example, INEL is currently developing information necessary to obtain an air pollution control operating permit for the entire INEL, and while this issue is recognized as a crosscutting issue by INEL management, the site has not defined a single group with the decision authority necessary to implement and manage the program. The same concern has been identified for the surface water program where ESD did not have the authority to require a line organization to obtain their approval for the use of a percolation pond area at TAN. The use of this pond area may affect the ability of INEL to obtain a land application permit for the pond (1-G-6 a id I-G-22)

ESD has neither the authority nor the formal opportunity to review contractor implementation packages, and the line organization personnel with the authority do not always have the technical understanding or avail theinselves to staff with the technical understanding in order to ensure that the planned work is cost-effective and meets the required scope $(I-G-6,14,18$, and 22).

- ID has no organization(s) responsible for compliance with sitewide groundwater protection polices and resolution of cross-cutting groundwater issues (D-E-3; I-E-43). ESD has the responsibility for the coordination of groundwater protection polices and the development of the Groundwater Protection Management Program Plan and INEL Groundwater Monitoring PIan (D-E-3; I-E-24 and I-E-43). However, the responsibility for compliance with the groundwater protection polices reside within each Assistant Manager's Iine management (D-E-3; I-E-42). The Groundwater Committee provides the only sitewide coordination and information exchange on groundwater issues (D-E-6;I-E-35 and I-E-43). 
- ID has not formally assigned the authority and responsibility to complete the Environmental Monitoring Plan (EMP) (I-H-14), per the requirements of $\mathrm{DOE} 5400.1$. The recent environmental monitoring baseline document (D-H-2) contains a description of current environmental monitoring and surveillance activities. However, it failed to provide a comprehensive framework of an Environmental Monitoring $\mathrm{Plan}$, containing: rationale and design criteria for the monitoring program, extent and frequency of monitoring and measurements, sample minimum detection level and accuracy, procedures for laboratory analysis, quality assurance

requirements, program implementation procedures, direction for the preparation and deposition of reports, and investigation and alarm levels for radiological and nonradiological effluents from INEL. Such a document is essential for the coordination of ID and contractors (e.g., ANL-W, EG\&G Idaho, WINCO, USGS, NOAA, etc.) environmental monitoring and surveillance activities. This is especially true at a site as large and complex as INEL. The INEL Tiger Team Action Plan (D-H-4) set a milestone for the completion of a comprehensive Environmental Monitoring Plan by February 1, 1993. To date, this project has not been completed, and only recently has a contract been issued for external technical support ( $\mathrm{I}-\mathrm{H}-17$ and $\mathrm{I}-\mathrm{H}-19)$.

- ID has not ensured that independent verification for Tiger Team action plan closures is properly performed. During the 1991 Tiger Team Assessment, the Environmental Subteam noted that a number of radiological ambient air monitors maintained by RESL were not properly sited with respect to physical obstructions, and were not sampling at the required height and flow rate necessary to obtain a representative sample (see Tiger Team Assessment Finding $A / C F-3)$. The INEL Action Plan (D-H-4) set out a series of milestones to address this finding, which included evaluations of sampler sites, modifications of samplers, assessment of flow rates, and documenting these actions. ID has since closed the finding. Upon review of closure documents and the performance of field verification activities, the Progress Assessment Team noted that the shrouds around the air sampler heads had not been considered in the calculation of required particle capture velocity for the low volume ambient samplers (I-H-19).

Furthermore, it was noted the ambient samplers at TAN and ANL-W had not been relocated and were still in the middle of both parking lots completely surrounded by personnel transport buses at TAN and cars at ANL-W. Contrary to formal ID procedures for closure of Tiger Team Assessment Findings (D-H-12), no proper independent technical evaluation was performed with the closure of this finding $(\mathrm{I}-\mathrm{H}-17)$. Another example of improper independent validation of closure is the action plan milestone \#l to address Tiger Team Assessment Finding A/CF-2. This milestone required the development of an ambient air monitoring plan consistent with DOE 5400.1 , and was closed without proper technical and independent concurrence. The document utilized to close out this milestone does not meet the DOE requirements for a monitoring plan ( $I-F-3$, $I-F-18$, and D-F-20) and should not have been used to close this milestone. 
- Relative to air pollution control, Tiger Team Assessment Finding $A / C F-1$ and the related INEL action plan discussion specifically identified the need for formal delineation of authority commensurate with responsibility. Yet, ID closed out this finding without performing this task for sitewide air pollution control program or the other environmental programs (D-F-5; I-F-5).

ID has neither developed nor implemented formal programs necessary to manage day-to-day sitewide environmental compliance. Key components of such programs include: effective formal systems for identifying sitewide compliance issues, a process for priortizing resources necessary to support those sitewide compliance programs, developing and implementing programs to meet sitewide compliance goals, and a plan for conducting day-to-day management oversight to ensure sitewide compliance goals are met. The following examples illustrate the lack of formally developed and implemented programs:

- Formal guidance and procedures do not exist to identify which funding source (i.e., waste management, EM-30; restoration, EM-40; or landlord, EM-60) will support the sitewide environmental compliance programs; how budgeting for these programs will be coordinated; and who will provide oversight on the spending of these funds for sitewide compliance actions (I-E-26, I-E-29, and I-E-45).

- ID has not prepared a formal comprehensive Surface Water Management Program to ensure consistent implementation of environmental surface water regulations and requirements across the site (I-G-5 and I-G-6). The lack of this program has allowed contractors to set their own priorities for wastewater management, which in some cases is in conflict with informal sitewide priorities (I-G-14 and I-G-16). This has led to coordination difficulties between and among various organizations within ID. In addition, there has been no formal sitewide prioritization of surface water related projects, or for any other environmental media, which can lead to critical sitewide projects being passed over for projects with more specific interest to a given line organization (I-G-6 and I-G-22).

- ID has not formally communicated the specific requirements of DOE 5400.1 , so that site environmental managers can develop effective programs consistent with the intent of the Order ( I-F-10, I-F-17, and I-F-18). This lack of formality has resulted in varying opinions within INEL technical groups on the scope of the required environmental monitoring program, and the associated delay in developing an acceptable Environmental Monitoring Plan for INEL (I-H-18 and I-H-19). In addition, due to the fact that the scope for the monitoring program has not yet been formaily developed and accepted by the various INEL environmental groups, there is concern that a consultant has already been contracted by ID to assist in the development of the EMP without an INEL agreed upon scope. This raises the issue that the INEL may develop and implement a monitoring program that will not meet the requirements of DOE 5400.1, DOE 5400.5, and DOE/EH-0173T. 
- INEL contractors are currently developing required information (e.g., emissions data, control technology demonstrations) to obtain an air pollution control operating permit for the entire INEL. This is recognized and communicated to the site by ID management as a crosscutting issue (I-F-5, I-F-15, and D-F-22), but ID has not formally defined the priority, process, or authority for resolving differences and making commitments for the INEL as a whole (I-F-22).

- ID does not formally require contractors to prepare complete implementation packages for Tiger Team Corrective Actions ( I-G-6, $14,15,17,18$, and 20). A complete implementation package would include, at a minimum: a description of the concern, the approach (with a work breakdown structure), the responsible individuals, deliverable content and schedule dates, and an overall schedule. Because ID does not require the preparation of these packages, they cannot proactively manage the corrective action or determine whether the contractors actions will correct the concern in an efficient, cost-efficient manner. 
Appendix B-3

\author{
Assessment Details - Safety and Health \\ Programs/Concern, Weaknesses, and Strengths
}


Assessment Concern Nümber:

Assessment Concern Title:
S/C-1

ID and INEL Site Industrial Hygiene Program Management

\section{Performance Objective}

ES\&H Management Performance Objectives and Criteria for Progress Assessments (Progress Assessment Manual, Appendix B-1, December 1992), Performance Objective 2.1, states that ES\&H plans are an integral part of sitewide strategic and implementation planning and budgeting process. Performance Objective 2.2 states that the ES\&H roles, responsibilities, and authorities of the organization are clearly defined, formally documented, communicated and understood. Performance Criterion 2.3.1 states that the human resource requirements for full implementation of ES\&H programs are identified and prioritized, and plans ensure that these resources requirements are met. Performance Criterion 2.4.1 states that a directive system ensures that the ES\&H laws, regulations, DOE orders, SENs and other DOE requirements are translated into site specific guidance and that such guidance is formally transmitted in a timely fashion to the site contractor. Performance Criterion 2.4.2.1 states that activities through out the Field Office are conducted with formality and rigor and quality assurance mandated by DOE ES\&H requirements. Performance Criterion 2.4.3 states that a formal processes exists to identify key ES\&H performance indicators, preform trend analysis, and risk and vulnerability based prioritization.

\section{Concern}

The ID Technical Support Division (TSD) and Office of Environmental Safety and Health Oversight (OES\&HO) industrial hygiene programs are not sufficiently formal, staffed, planned, executed, and managed.

\section{Discussion}

Sitewide performance indicators, self-assessment, strategic goals, and plans for the INEL site industrial hygiene program have not been fully established within the ID and INEL contractors' organizations, and are not utilized for sitewide integrated planning and program management.

The ID Operations office Manager has not formally directed ID line organizations and INEL contractor organizations to set goals, prepare, and report indicators for core areas of the industrial hygiene program performance such as exposure levels to chemicals and key program implementation goals and milestones (I-K- $1,3,4,5,6,7$, and 8$)$.

Long range industrial hygiene program plans are not prepared or utilized within the ID TSD in support of line technical assistance, internal directives, guidance, and sitewide goals (I-K-1, 3, 4, 5, 6, 7, and 8).

Current INEL sitewide planning activities for industrial hygiene activities are not risk-based. No formal mechanism, beyond the ES\&H 5-Year Plan, could be determined within ID as to how ID establishes, manages, prioritizes, plans, budgets, and implements its internal and sitewide industrial hygiene program priorities and objectives. ID has not recognized the importance of ensuring that ID and INEL site contractors line and organizational unit plans are 
integrated and rolled up into upper level institutional plans and on a sitewide, priority level $(D-K-45,54,64,67$, and $68 ; 1-K-1,3,4,5,6,7$, and 8 ).

There is a general lack of line item task-level planning for most industrial hygiene program activities within ID and the INEL site contractor organizations (D-K-6, D-K-21, and D-K-24; I-K-6, 7, 8, 9, 10, 11, 13, and 14).

Crosscutting planning indicators such as independent assessments, self-assessments, operational baseline risk indicators, impact analysis, and priority analysis are not always utilized and rolled up into upper level organizational planning within ID and INEL site contractor organizations $(D-K-6,21,24$, and $54 ; 1-K-6,7,8,9,10,11,13$, and 14).

Staffing levels within ID OES\&HO and TSD are insufficient to support programmatic requirements (see Concern $M / C-6$ ). The OES\&HO organization has been without an industrial hygienist for approximately 1 year. This lack of an industrial hygienist impairs the abllity of ID to conduct independent oversight surveillances of the ID line organizations and INEL site contractors $(I-K-3, I-K-4$, and I-K-5).

The TSD currently has one industrial hygienist providing technical program review, project reviews, field audits, procedure development, and technical guidance to the line organizations. Present staffing levels within the TSD do not appear to be sufficient to support the level of oversight and guidance necessary for INEL. Furthermore, ID cannot determine if it is addressing the most important issues with its limited human resources because it lacks the appropriate plans and systems to prioritize activities $(I-K-3$ and $I-K-4)$.

Surveillances are being conducted by OES\&HO for industrial hygiene issues by safety engineers or health physicists. OES\&HO has obtained the services of a support services contract industrial hygienist to provide assistance. The use of a contractor to prepare DOE reports without the control and review of a DOE industrial hygienist could potenti-lly cause difficulties with DOE Acquisition Requirements (DEAR) and may violate Federal Acquisition Requirements (FAR) $(I-K-I$ and $I-K-5)$.

Prior to the INEL Tiger Team Assessment, repetitive motion injuries were occurring at Special Manufacturing Capability (SMC) which necessitated process operational changes. Access control restrictions within the ID SMC Project office have prohibited full access to the project by the B\&W industrial hygienist, and no access by the ID TSD industrial hygienist has occurred to ensure conformance with DOE Orders and DOE prescribed Occupational Safety and Health Act (OSHA) standards (I-K-3, I-K-10, and I-K-15).

The Progress Assessment Team was unable to verify that the DOE industrial hygienist had been able to review the process to validate corrective actions by the contractor. The B\&W industrial hygienist has only been given limited access to the SMC project and has been unable to review final assembly and research and development activities. Some of the activities preformed in areas that have been inaccessible to B\&W industrial hygienist and ID industrial hygienists may include risks of chemical exposures $(I-K-3, I-K-10$, and $I-K-15)$. 
Formal industrial hygiene program policies and procedures for ID TSD industrial hygiene progran management guidance are not of sufficient detail or do not exist to ensure compliance with DOE and DOE prescribed OSHA standards (I-K-3 and I-K-4). The ID TSD has recognized this issue and is in the process of developing a Environment Safety and Health Program Procedures Document and a ID Supplemental Directive.

Neither the ID Environmental Restoration/Waste Management (ER/WM) program management organization, nor ID TSD have developed internal program planning guidance, requirements, or procedures for ensuring conformance with documentation for Site Safety and Health Plans (HASPS) regarding worker health/industrial hygiene in conformance with DOE prescribed OSHA regulations 1910.120 "Hazardous Waste and Emergency Operations" (HAZWOPER). ID has not issued formal and sufficiently detailed sitewide guidance or supplemental directives to INEL contractors to ensure uniform conformance with HAZWOPER and HASP requirements. Existing program guidance within the ID ER/WM organization, Managing for Safety and Quality Manual, Revision 2, is not sufficiently clear and detailed to provide adequate guidance to ID project managers $(D-K-44 ; I-K-3$ and $I-K-4)$. 
Assessment Weakness Number:

Assessment Weakness Title:
S/W-1

ID Lockout/Tagout System

\section{Performance Objective}

ES\&H Performance Ubjectives and Criteria for Technical Safety Appraisals (Progress Assessment Manual, Appendix B-4, December 1992), Performance objective MA.2, states that maintenance should be conducted in a safe and effective manner to support each facllity condition and operation on the site.

Personnel are aware of and follow procedures for lockout and tagout to prevent accidental contact with energized electrical circuits and other hazardous energy sources as described in the occupational safety and health standards 29 CFR 1910.147 and 1910.333.

\section{Weakness}

ID's newly initiated sitewide lockout/tagout system is not being followed in a consistent manner for the protection of employees working on energized equipment.

\section{Discussion}

A lockout/tagout system is designed to identify and control sources of energy and hazardous materials. A system for lockout/tagout is of primary importance to ensuring worker safety in DOE factlities. The overall program for safety at DOE facilities is described in the occupational safety and health standards 29 CFR 1910.147 and 1910.333.

Although INEL has initiated a lockout/tagout system (January 1993) that is intended to ensure that one consistent lockout/tagout system is used throughout the INEL site, it is not being followed. During interviews with the contractors' craft employees, it was also revealed that the lockout/tagout ID Request Form Procedures are not being followed in some areas of the contractor's daily operations (I-I-2I and I-I-23).

A letter from ID entitled "Development of a Consistent INEL Lockout/Tagout System" (February 19, 1993) (AM/SES-OS\&EMB-93-40), states that the Lockout/Tagout procedures will be conducted in a consistent manner throughout the ID facilities. However, the Lockout/Tagout system inconsistencies have been identified by the ID staff and a focussed approach to the inconsistencies have been identified. 
Assessment Weakness Number:

Assessment Weakness Title:
S/W-2

Communication Within EM Organizations Regarding Safety-Related Issues

\section{Performance Objective}

ES\&H Performance Objectives and Criteria for Technical Safety Appraisals, (Progress Assessment Manual, Appendix B-4, December 1992), Performance Objective OA.1, states "Management should organize and manage the site/facility's work, programs, and resources so that safety and health are an integral part of the personnel duties and requirements are consistently implemented."

\section{Weakness}

DOE-EM does not assure that hazardous operations inherent in remediation programs are reviewed by the EM internal safety oversight organization.

\section{Discussion}

Although EM-44l provided comments to ID regarding the Safety Analysis Report (SAR) for the Unexploded Ordnance project $(D-L-4, D-L-7$, and $D-L-8)$, the Progress Assessment Team's Program Secretarial officer (PSO) interviews found no one with knowledge of this project outside of the project office (I-L-8). The manager of EM-23, the organization which is responsible for health and safety overview (inciuding SAR reviews), was unaware of this project and the SAR having been sent informally to DOE Headquarters for information (I-L-7). The procedures and policies at EM for proper review of safety-related programmatic documents is suspect. 
Assessment Strength Number:

Assessment Strength Title:

\section{$S / S-1$}

MK-FIC Construction Safety and Health Program

\section{Strength}

MK-FIC has developed a model construction safety and heal th program to support construction activities at INEL.

\section{Discussion}

In a year and a half. MK-FIC has developed and implemented a program that was not in existence prior to the 1991 Tiger Team Assessment. A significant effort has been made by MK-FIC in the development and implementation of safety and health program procedures, documentation, employee training programs, qualification requirements, performance indicators system, audit and surveillance programs $(D-I-36)$, construction supervisor training, contractor interface agreements, and expansion of the MK-FIC industrial hyglene staff from zero in 1991 to the current level of three professtonals and one industrial hyglene manager. MK-FIC has developed an approach that integrates the safety and health program activities and requirements with the work control system that supports job safety analysis, plan of the day meetings, construction safe work permits, engineering design planning, pre bid safety conferences, and an innovative targeted survelllance program (D-I-34) that tracks and monitors subcontractor (D-I-41) ES\&H performance.

Significant improvement in reducing the severity and frequency of occurrences is demonstrated by recent DOE and ID appraisals that found no Category I or II findings, and very few Category III findings as compared to 2 Category I, 12 Category II, and numerous Category III findings reported during the 1991 Tiger Team Assessment. In addition, a recent ID Office of Environmental Safety and Heal th Oversight (OES\&HO) appraisal (D-I-36 and D-I-37) report of MK-FIC's construction safety and health program noted significant improvement in construction safety compliance in the last 2 years based on a reduction in the occurrence of findings.

The improvement in the Construction Safety and Health Program (D-I-34) is also demonstrated by the significant improvement in MK-FIC and subcontractor injury/illness rates. Thie total recordable incident rate and lost workday incident rate per 200,0,00 manhours were approximately 26 and 10, respectively, during the 6-month period prior to the 1991 Tiger Team Assessment. For the period from October 1992 through May 1993, the total recordable incident rate was 3.86 and the lost workday rate was 0.39 .

MK-FIC and its subcontractors had worked over 750,000 hours without a lost workday injury or 111 ness when an injury occurred in late April 1993. This significant improvement in injury/iliness rates coincides with the simflar improvement in field safety compliance.

MK-FIC implemented an ES\&H Awareness Program (D-I-38) to heighten employee awareness of construction safety requirements. ES\&H goals were established and have been communicated to all employees. Through the use of performance indicators to track progress, MK-FIC has met the ir ES\&H goals (D-I-36 and D-I-40) thus far in fiscal year 1993. One innovative feature of MK-FIC's 
performance indicator program is the use of a "Safe Work Index" to measure the severity and frequency of safety compliance findings. The awareness program (D-I-38) utilizes a variety of media including frequent safety meetings, safety bulletins and alerts, billboards, critiques, and worker safety committees.

MK-FIC has developed a comprehensive General Contract Document Condition \#7 for contact bid awards and an award submittal review program that is highly detailed and effective. The quality, degree of development, and qualifications of the MK-FIC safety and health program (D-I-36 and (D-I-40) and professional staff have indicated that the MK-FIC safety and health program has become an overall example of a model program for others within DOE. 
Assessment Strength Number:

Assessment Strength Title:
S/S-2

EGLG Idaho Laser Safety and Industrial Hygiene Data Management System

\section{Strength}

The EG\&G Idaho laser safety program and industrial hygiene data management system (System 80) are examples of model programs.

Discussion

In response to a 1991 Tiger Team Assessment concern, EGíg Idaho developed an integrated laser safety program that exceeds the minimal guidance of the American National Standards Institute (ANSI) standard for laser safety programs. A portion of this program includes an innovative computer aided training program and tracking system for laser safety inspections and inventory. The laser safety program developed by EG\&G Idaho expands upon the minimum guidelines contained in the ANSI standard for laser safety to provide well documented program requirements with detailed actions required and procedures including work instructions to operators.

Key elements of this program include defined authorities and responsibilities, personnel qualification and training requirements, identification of laser beam hazards, identification of ancillary laser hazards, engineering and administrative controls, personnel protective equipment program, laser inventory procedure, laser inspect i on requirements, self-assessment/audit guidelines, medical survelllance and first aid program, and extensive references.

The EG\&G Idaho System 80 is a model program, this system is one of the few systems in DOE capable of providing linkage to occupational medicine surveillance and trending analysis. The EG\&G Idaho System 80 consists presently of three modules; exposure assessment/sampling, asbestos management and hazardous chemical inventory system. This system utilizes innovative tools for tracking and cross referencing exposures and chemical inventories. A portion of this system includes an innovative approach that utilizes a pen pad hand held computer to directly enter data in the field. A portion of the report generation capability of System 80 includes an over exposure report and a trigger for occurrence reporting.

The quality, degree of development, and implementation of the EG\&G Idaho Laser Safety Program and Industrial Hygiene Data Management System has indicated to the Progress Assessment Team that these programs are noteworthy as an example of model programs for others within DOE. 
Appendix C

Biographical Sketches of Team Members 
NAME:

John Schinkle

AREA OF RESP: Team Leader

ASSOCIATION: $\quad$ U.S. Department of Energy, Albuquerque Operations Office

EXPERIENCE: $\quad 7$ Years: Test Engineering

20 Years: Facility and Safety Engineering

- Space Nuclear Propulsion Office, NASA/AEC

- NASA PIUm Brook Reservation

- U.S. Department of Energy, Albuquerque, NM

- Participated in the pilot ES\&H Progress Assessment at the Fernald Environmental Management Project in the area of Facility Safety.

- Test/Facility Engineer - Space Nuclear Propulsion Office. Member of Test Review Board for several nuclear rocket proto-type test series. Reviewed and approved facility readiness and nuclear reactor test programs.

- Nuclear Engineer - Reactor and Criticality Safety overview of research reactors, critical facilities, and SNM handling of processing facilities.

- General Engineer - Facility Engineering Branch Chief. Directed facility engineering programs including utilities management, energy management, value engineering, design criteria development, and design review.

- General Engineer - Safety Programs Division Director. Manage safety oversight program for industrial safety, fire protection, high explosives safety, nuclear facility safety, reactor safety, and safety analysis.

EDUCATION: $\quad$ B.S., Electrical Engineering, Ohio University

OTHER:

Registered Professional Engineer 
NAME:

Kellie A. Turner

AREA OF RESP: Team Coordinator

ASSOCIATION: U.S. Department of Energy, Office of Special Projects

EXPERIENCE: $\quad 10$ Years

- U.S. Department of Energy, Washington, DC

- Office of Special Projects, Tiger Team Coordinator for the Naval Petroleum Reserves California, Management Subteam member on National Institute for Petroleum and Energy Research Tiger Team, Coordinator for Idaho National Engineering Laboratory.

- Naval Air Systems Command, Washington, DC

- Provided policy and program direction to the Command for environmental regulations and other Department of Defense environmental issues affecting Command industrial activities. Conducted Environmental Compliance Evaluations, member of the Joint Depot Environmental Panel, and Chairman of the Field Activities Board.

- Naval Aviation Depot, Cherry Point, NC

- Initiated and implemented a wide range of environmental programs in an aircraft Depot level maintenance facility. Authorized disposal method for all hazardous waste generated at the facility. Assisted in the start up of a \$15M plating facility.

- Facilities Engineer responsible for the design and modification of aircraft depot maintenance facilities to accommodate plant workload.

- Equipment Engineer responsible for the design and modification of jet engine test equipment to accommodate plant workload. Wrote equipment specifications.

- U.S. Air Force, OkTahoma City, OK

- Designed modifications for plant facilities, utilities, and test equipment in the accessories division of an aircraft maintenance depot.

- U.S. Corps of Engineers, Tulsa, OK

- Designed HVAC systems for historic homes at Fort Sill Army Base. Assisted in the inspection of major construction projects at Tinker Air Force Base.

EDUCATION: $\quad$ B.S., Mechanical Engineering, Oklahoma State University 
SAME:

David J. Allard

AREA OF RESP: Environmental Radiation Programs

ASSOCIATION: Arthur D. Little, Inc.

EXPERIENCE: $\quad 15$ Years

- $\quad$ Arthur D. Little, Inc.

- Senior Consultant and Certified Health Physicist providing technical support for DOE Assessments and Audits, and various other government and commercial client cases dealing with radiation protection issues, such as environmental monitoring, waste management, training, operational health physics, and radiation protection management.

- Participated in the Tiger Team Assessments of the Morgantown Energy Technology Center, Idaho National Engineering Laboratory, Los Alamos National Laboratory; the Environmental Audit of the Fossil Energy Sites in Wyoming; and the Environmental Management Assessments of the Continuous Electron Beam Accelerator Facility, Fernald Environmental Management Project, and Superconducting Super Collider.

- TGM Detectors, Inc.

- Vice President with responsibilities for facility radiation protection, gas-filled radiation detector design, testing, engineering, and business management.

- Nuclear Metals, Inc.

- Supervisor of Health Physics with responsibilities in the areas of environmental monitoring, external and internal dosimetry, shielding, radiation surveys, waste disposal, and regulatory affairs regarding various uranium and thorium manufacturing operations.

\section{- Albany Medical Center}

- Medical Health Physicist with responsibilities involving external and internal dosimetry, laboratory radiation protection, $x$-ray equipment testing, quality assurance, shielding, surveys, and waste disposal.

EDUCATION: M.S., Radiological Sciences and Protection, University of Lowell

B.S., Environmental Sciences, State University of New York at Albany

A.A.S., Environmental Health Technology, Hudson Valley Community College 
NAME: Richard Bowen

AREA OF RESP: $\quad$ Surface Water Programs

ASSOCIATION: Arthur D. Little, Inc.

EXPERIENCE: $\quad 10$ Years

- Arthur D. Little, Inc.

- Coordinated the Environmental Team efforts for the INEL Tiger Team.

- Managed a feasibility study to evaluate and select a remediation technology to be used in cleaning up soil and groundwater contaminated with fuel oil and lube oil.

- Led a program to develop, test, and evaluate treatment technologies for wastewaters generated during the manufacture of ball powder. The initial work addressed fundamental chemical and biological mechanisms affecting treatment. These mechanisms were subsequently used to design and operate a pilot facility at Badger Army Ammunition Plant.

- Assisted in the development of an environmental plan for the cleanup and closing of a major explosive manufacturing facility that produced TNT, NG, NC, and ammonium perchlorate. An additional objective was to plan to demilitarization of a stockpile of obsolete conventional munitions.

- Evaluated the current wastewater treatment practices for a major brewer and reviewed their proposed anaerobic treatment system. Interviewed State regulators as to how the new treatment systems would affect the brewer's ability to meet National Pollution Discharge Elimination System requirements.

EDUCATION: $\quad$ Graduate Work, Molecular Biology, University of Maryland B.S., Chemical Engineering, University of Virginia 
NAME:

Robert M. Compton

AREA OF RESP: Oversight and Directives, Policies, and Procedures

ASSOCIATION: Nuclear Power Consultants, Inc.

EXPERIENCE: $\quad 24$ Years

- Private Consultant

- Participated in DOE Tiger Team Assessments of Savannah' River, Hanford Site, Energy Technology Engineering Center, Morgantown Energy Technology Center, Idaho National Engineering Laboratory, Naval Petroleum Reserves-Casper, and Naval Petroleum Reserves of Cal ifornia.

- Participated in DOE Progress Assessments of the Fernald Envirorimental Management Project, $Y-12$ Plant, Hanford Site, Lawrence Livermore National Laboratory, Brookhaven National Laboratory, and the Rocky Flats Plant.

- Conducted appraisals of DOE M\&O contractor maintenance procedures at Savannah River and formality of operations at Pantex.

- Conducted appraisals of construction programs, Safety System Functional Inspections (SSFIs), Motor Operated Valve problems, regulatory issues, etc. for nuclear utilities.

- Participated in numerous individual and team assessments and problem resolution assignments at nuclear utilities for the U.S. Nuclear Regulatory Commission (USNRC) related to Safety System Quality Evaluations (SSQES), SSFIs, Safety System Outage and Modification Inspections (SSOMIs), Construction Appraisal Team (CAT) inspections, instrumentation, in-service-testing of pumps and valves, compensatory measures, restart readiness reviews, "problem plant" corrective actions, safety allegations, etc.

- U.S. Nuclear Regulatory Commission

- Senior Engineer and Reactor Inspector in the areas of civil and mechanical construction, testing, and modification.

- Mare Island Naval Shipyard (Department of Defense).

- Nuclear Fluid Systems Engineer and Supervisory Nuclear Engineer for construction, repair, and refueling of navy nuclear vessels.

EDUCATION: $\quad$ B.S., Civil Engineering, California State University at Chico

OTHER: $\quad$ Member, American Nuclear Society

Member, American Society for Quality Control

Member, American Society of Civil Engineers

Member, American Consulting Engineers Council 
NAME:

Victor 1. Crawford

AREA OF RESP: $\quad$ Groundwater Protection Programs

ASSOCIATION: $\quad$ U.S. Department of Energy, Office of Environmental Audit

EXPERIENCE: $\quad 17$ Years

- U.S. Departinent of Energy, Washington, DC

- Environmental Engineer under the direction of the Audit Team Leader/Environmental Subteam Leader, provides guidance, direction, and assistance to a multi-disciplined group of professionals performing Environmental Audits and Tiger Team Assessments at DOE facilities. Participated as the Deputy Environmental Subteam Leader for the Tiger Team Assessment of the National Institute for Petroleum and Energy Research, and as Deputy Team Leader for the Environmental Management Audit of Uranium Mill Tailing Remedial Action Project and the Superconducting Super Collider, and as the Environmental Subteam Leader on the Progress Assessment of the Brookhaven National Laboratory.

- Naval Facilities Engineering Command, Alexandria, VA

- Branch Head in the Assistant Commander's Office for Environment, Safety, and Health. Principal duties included developing and/or managing the Navy's Shoreside Environmental Programs for air compliance, asbestos abatement, radon assessments, underground storage tanks, spill response, water and wastewater compliance, and environmental auditing.

- Western Division, Naval Facilities Engineering Command, San Bruno, CA

- Section Head in charge of Shoreside Compliance Program support for naval installations in northern California.

- Southern Division, Naval Facilities Engineering Command Charleston, SC

- Environmental Engineer responsible for conducting environmental audits at and providing environmental support to naval installations located throughout the southeastern United States.

EDUCATION: $\quad$ B.S., Civil Engineering, California State University

OTHER: $\quad$ Registered Professional Engineer - South Carolina

Personnel Protection and Safety (29 CFR 1910.120)

DOE Tiger Team Training 
NAME: Lynne Day

AREA OF RESP: Administrative Support

ASSOCIATION: META, InC.

EXPERIENCE: $\quad 16$ Years

- META, Inc.

- Information Management Specialist. Provides administrative support for Environmental Audits; Environmental Management Assessments; Environment, Safety and Health (ES\&H) Progress Assessments; and the Environmental Subteam on Tiger Team Assessments at DOE sites.

- Participant in the Component Development and Integration Facility, Environmental Measurements Laboratory, Alaska Power Administration, and Coal-Fired Flow Facility Environmental Audits; the Uranium Mill Tailings Remedial Action Project Environmental Management Audit; the Continuous Electron Beam Accelerator Facility and Fernald Environmental Management Project Environmental Management Assessments; the Fernald Environmental Management Project, Hanford Site, Brookhaven National Laboratories, and Morgantown Energy Technology Center ES\&H Progress Assessments; and the Solar Energy and Research Institute, Los Alamos National Laboratories, Strategic Petroleum Reserves, and Naval Petroleum 011 Shale Reserves Tiger Team Assessments.

- Provided administrative support for production of the Environment, Safety and Health Progress Assessment Manual and attended Progress Assessment Training Program.

- Assisted in the production of the draft Administrative Support Procedures and Guidance for the Office of Environmental Audit.

- INNOVA Communications, Inc.

- Office Administrator. Provided system, office automation, project management, data base management, graphic, and documentation support for a local and wide area network integration firm.

- Sandler \& Greenblum

- Word Processing Departmental Manager. Developed and coordinated activities related to the word processing department for law firm. Responsible for supervision and staffing of word processing department and hardware and software procurement and installations.

EDUCATION: A.A., Computer Science, Strayer College 
NAME:

Kenneth E. Elliott

AREA OF RESP: Corrective Action Program

ASSOCIATION: U.S. Department of Energy, Albuquerque Operations Office

\section{EXPERIENCE: $\quad 34$ Years}

- Martin Marietta Corporation, Baltimore, MD

- Operations of nuciear critical assembly machines.

- USAEC HQ, Washington, DC

- Division of Licensing and Regulation, Research Reactors.

- USAEC, Oak Ridge Operations Office, Oak Ridge, TN

- Reactor Safety Division, Oak Ridge Research Reactors.

- Safety Division, Criticality Safety for ORNL and Y-12.

- USAEC, USERDA, U.S. Department of Energy, Albuquerque Operations Office, Albuquerque, NM

- Safety Programs Division, Chief, Nuclear Safety Branch.

Responsible for safety overview of Research Reactors, Criticality Safety, Nuclear Factlities Safety, Training, Packaging Safety for AL contractors.

EDUCATION:

OTHER :
B.S., Nuclear Engineering, North Carolina State University

Member of American Nuclear Society:

- Reactor Safety Division

- Nuclear Criticality Safety Division

Certified Accident Investigator

Instructor for UNM Nuclear Criticality Safety Course 
NAME:

Paul E. Flaherty

AREA OF RESP: Air Quality Management Programs

ASSOCIATION: Arthur D. Little, Inc.

EXPERIENCE: $\quad 10$ Years

- Arthur D. Little, Inc.

- Participated in the INEL Tiger Team Assessment evaluating air pollution control. The work included review of management systems, emissions inventories, control systems, permitting issues, compliance, meteorological data representativeness, and ambient monitoring programs.

- Participated in the SPR Tiger Team Assessment for locations in Texas and Louisiana. The work included review of management systems, emissions inventories, control systems, permitting issues, compliance, meteorological data representativeness, and ambient monitoring programs.

- Oversaw the design and implementation of a comprehensive air quality compliance $p l a n$ for a large aerospace company which involved the development of source inventories, regulatory requirements and interpretations, and a software system to manage the information.

- Managed the compliance evaluation project for a large utility's two fossil fuel-fired plants in an urban area. The work included control technology reviews, air quality dispersion modeling, ambient air monitoring, and representing client interests with state and Federal regulatory officials.

- Designed an advanced modeling technique for another utllity to address a complex dispersion environment, including development of regulatory acceptable assumptions for a fluid modeling study and the presentation of the study methods and results for state and Federal support.

- Assisted in the development of a state-of-the-art modeling methodology for coke oven emissions and ambient air toxic concentrations. The work was reviewed on both state and Federal levels and approved without comment.

- Managed the PSD air permit applications for MSW, RDF, and RCRA/TSCA incinerators for several large energy recovery corporations. The work included technology reviews, ambient impact assessments for criteria and noncriteria pollutants, ambient monitoring, and representation of clients with state and Federal regulatory personnel.

EDUCATION: $\quad$ B.S., Meteorology, Purdue University 
NAME:

Ernest W. Johnson

AREA OF RESP: Maintenance Programs, Packaging and Transportation Programs, and Site/Facility Safety Revtew Programs

ASSOCIATION: Battelle Pacific Northwest Laboratories

EXPERIENCE: $\quad 29$ Years

- Monsanto Research Corporation, Miainisburg, Ohto (Mound Plant)

- Sentor Research Specialist/Technical Lialson. Responsible for technical aspects of heat source/radioisotope thermoelectric generators at Mound, authored safety analysis reports for flight system and ground transportation, program manager for numerous plutonium-fueled terrestrial and space heat sources, supervisor of up to 44 technical staff persons, bullding manager for two nuclear facilities, and Technical Liaison for Galileo and Ulysses Missions for Mound.

- ORAU, EG\&G Idaho, Evergreen, PNL, and BNL

- Technical Consultant - Performed miscellaneous technical appraisals which included 14 TSA/Tiger Teams, Operational Readiness Reviews, Facility Safety Analys is Report reviews, Diagnostic Evaluations, and other performance assessments.

- PSDI, Bartech, and Lamb Associates, Inc.

- Senior Associate - Responsible for subcontract work in the heat source/radioisotope thermoelectric generator program, wrote safety analysis reports for two plutonium facilities, one flight system, and one shipping container, involved in heat source production activities at MMES/Y-12, LANL, and Mound, and performing risk and safety assessments for new processes and facilities at Mound.

EDUCATION: Ph.D., Physical Chemistry, University of Iowa

M.S., Physical Chemistry, Iowa State College

B.S., Chemistry/Mathematics, Wisconsin State College

OTHER: $\quad$ Member of American Chemical Society

Member of ASM International

Member of Phi Lambda Upsilion

Member of Alpha Chi Sigma

Co-Chair, Manufacturing, 1994 Space Nuclear Power Symposium 
NAME:

Richard B. Lynch

AREA OF RESP: Technical Editor

ASSOCIATION: META

EXPERIENCE: $\quad 5$ Years

- META

- Technical Editor. Provided technical writing and editing support for DOE on 13 Tiger Team Assessments, 7 ES\&H Progress Assessments, 2 Environmental Audits, and 2 Environmental Management

Assessments. Also, oversees the preparation of the final camera-ready copy of assessment and audit reports.

- Writer/Editor. Provided teclinical writing and editing support to DOE's Office of New Production Reactors (NP), including writing NP's Correspondence Manual and a vartety of technical articles for publication.

- Advanced Sctences, Inc.

- Writer/Editor. Researched, wrote, and edited fact sheets and information briefs on energy conservation and renewable energy topics for a DOE-funded energy information service.

- Response Analyst/Media Lialson. Analyzed and researched inquiries on energy topics from the general pubilic, U.S. Congress, and trade associations. Also, wrote information briefs, monthly news releases, and conducted media outreach activities.

EDUCATION:

B.A., General Studies, Louisiana State University 

NAME:
William P. Ortiz
AREA OF RESP: Self-Assessment Programs
ASSOCIATION: U.S. Department of Energy, Continuous Electrun Beam Accelerator Factlity (CEBAF) Newport News, Virginia
EXPERIENCE: 6 Years

- U.S. Department of Energy, CEBAF, Newport News, VA

- Assistant to Team Leader, INEL Tiger Team.

- Conducted assessment of M8O contractor's compliance with DOE, Federal, and state policy and ES\&H regulations. Evaluated contractor progress on technical milestones.

- New Mexico State University, Mechanical Engineering Department

- Research Assistant.

- Northern Engineering and Testing, Casper, WY

- Construction Materials Technician. Conducted and reported results of material analysis and quality control tests.

EDUCATION:

B.S., Mechanical Engineering, New Mexico State University 
NAME: David $K$. Pegram

AREA OF RESP: Industrial Hygiene Programs

ASSOCIATION: U.S. Department of Energy, Office of Health, Division of Industrial Hyglene Programs, EH-412

\section{EXPERIENCE: $\quad 16$ Years}

- U.S. Department of Energy, Germantown, MD

- Industrial Hygienist, responsible for evaluation and development of DOE policy and assessment of programs.

- Program management for the development of DOE Order on Exposure Assessment.

- Program management for Industrial Hygiene Program Assessments including; Tiger Team Progress Assessments, Oversight Assessments of Operational Readiness Evaluations and Internal Policy Assessment.

- Program management for the development of internal program assessment guidel ines.

- Program management for the DOE Centers for Exposure Assessment and Industrial Hygiene Data Management.

- EG\&G Rocky Flats

- Sentor Principal Engineer, responstble for providing engineering and technical support for $p 1$ ant factlities in the area of safety and health.

- Occusafe, Inc.

- Consultant/Industrial Hygienist, responsible for providing industrial hygiene consulting services to DOE Prime Contractors and Tiger Team Assessments.

- Rockwell International Rocky Flats Plant

- Principal Industrial Hygienist, responsible for development and management of industrial hygiene programs and support for plutonium production and waste operations.

- Missouri State Division of Health

- Compliance Officer, responsible for investigation of public health issues.

EDUCATION: $\quad$ B.S, Biology/Chemistry, University of Southern Colorado, Puebio Colorado.

OTHER:

Board Certified Industrial Hygienist (CIH) in Comprehensive Practice 
NAME:

AREA OF RESP: Planning, Budgeting, and Resource Allocation; and Human Resources Management

ASSOCIATION: Private Consultant

EXPERIENCE:

26 Years

- Private Consultant, Columbus, $\mathrm{OH}$

- Participated in the DOE ES\&H Progress Assessment of the Hanford Site and the Nevada Test Site, supported the DOE Office of Special Projects' strategic planning initiative, and participated on a DOE-HQ Task Force to develop Corrective Action Performance Objectives and Criteria for Progress Assessments.

- Battelle, Columbus, $\mathrm{OH}$

- Senior Technical Advisor. Participated in the Tiger Team Assessments of the Lawrence Livermore National Laboratory, Paducah Gaseous Diffusion Plant, Lawrence Berkeley Laboratory, Energy Technology Engineering Center, Sandia National Laboratories, Idaho National Engineering Laboratory, Pittsburgh Energy Technology Center, Stanford Linear Accelerator Center, and Naval Petroleum Reserves in Californta as a member of the Management Subteams.

- Participated on DOE-HQ Task Forces to develop ES\&H Management Performance Objectives and Criteria for use in Tiger Team Management and Organization assessments. Provided strategic planning support to the DOE-HQ Office of Security Evaluations.

- Conducted a triennial appraisal (DOE 5482.1B) of the Brookhaven National Laboratory.

- Manager of Nuclear Technology. Managed the Battelle West Jefferson, Ohio Nuclear Facility; a hot cell facility, a decommissioned reactor, a plutonium facility undergoing decontamination and decommissioning, and a radio-analytical facility. Responsible for compliance with DOE, Nuclear Regulatory Commission and other local, state, and Federal regulations related to nuclear materials storage, handling, and transportation, waste characterization and disposal, criticality safety, health physics, worker safety, and environmental protection.

- Associate Director, Corporate Technical Development. Managed corporate-wide IR\&D programs and conducted corporate-wide strategic and subordinate implementation planning.

EDUCATION: $\quad$ Ph.D., Nuclear Science and Engineering, Cornell University B.S., Chemical Engineering, Drexel Institute of Technology Senior Executive Program, The Wharton School, University of Pennsylvania

National and International Security Program, John F. Kennedy School of Government, Harvard University 
NAME:

Raymond R. Rogers

AREA OF RESP: $\quad$ Construction Safety Programs; and Worker Safety and OSHA Programs

ASSOCIATION: U.S. Department of Energy, Office of Occupational Safety, Technical Support Division

EXPERIENCE: $\quad 35$ Years

- U.S. Department of Energy, Washington, DC

- Occupational Safety and Health Manager.

- Serves as Senior 0ccupational Safety and Health (OSH) expert for DOE-wide worker and facility safety.

- Manager for the DOE Interpretations Guide to OSH Standards.

- Manager for the DOE 800 Response Line.

- Team Member for the EM-60 Rocky Flats Pre-Turnover Review.

- U.S. Department of Labor

- The 0ccupational Safety and Health Administration Supervisor/Area Director. Responsible for managing eight professionals in the areas of industrial hygiene, industrial and construction safety within the designated boundaries of the area office.

- Senior Safety and Health Compliance Officer. Directly responsible for inspecting a wide variety of complex and high risk industrial activities in diverse work places.

- United States Air Force,

- Construction and Utilities Superintendent: Responsible for managing civilian and military professionals in areas of contract management for heavy construction and the installation of utility systems at military facilities throughout the United States and overseas.

OTHER:

Certified Safety Executive in the World Safety Organization Certified Civil Engineering Technician 
This page intentionally left blank. 
Appendix D

Progress Assessment Scopes 
PROGRESS ASSESSMENT SCOPE

IDAHO NATIONAL ENGINEERING LABORATORY (INEL)

\begin{tabular}{|lll||}
\hline Name: & Kenneth E. Elliott & Date: $7 / 1 / 93 \quad$ Rev. \#: 2 \\
Telephone \#: & $505 / 845-5690$ & Fax \#: $505 / 845-6431$ \\
Discipline: & Management Programs & \\
Area of Responsibility: & Corrective Action Plan & \\
\hline
\end{tabular}

\section{IDENTIFICATION OF ISSUES:}

\section{Identification of Issues to Be Addressed:}

Issue 1: Effectiveness, adequacy, and formality of roles, responsibilities, and authorities of organizations involved in the Corrective Action Plan process for internal and external audits.

Issue 2: Adequacy, formality, and compatibility of line management systems for tracking and verifying all internal and external corrective actions.

Issue 3: Verification, validation, and certification processes in line management for closure of Corrective Action Plans.

Issue 4: Adequacy of the corrective action process to address individual concerns, root causes, trends, and lessons learned. Use of lessons learned process in the training programs.

Issue 5: Adequacy and formality of line management programs to prioritize corrective actions.

Issue 6: Roles of the ES\&H oversight programs in the Corrective Action Plan process.

\section{Related Tiger Team Findings:}

KF-010: ID oversight of EG\&G activities has been deficient in providing guidance to ensure implementation of operational safety initiatives.

KF-014: Management has not developed and implemented a system to track corrective actions and commitments related to safety and health.

KF-015: There is no document control program that ensures that: documents are up-to-date; procedures are current and reflect the most recent DOE requirements; procedures are reviewed periodically and revised when needed; controlled documents receive adequate oversight; procedures exist when needed and are followed by the person performing the activity.

KF-016: ID has been deficient in producing guidance for, and in conducting oversight of, the contractors to ensure operational safety. 


\section{Related Tiger Team Action Plan Items:}

Tiger Team Deficiencies.

Other Bases:

None.

\section{Overlapping Issues:}

All other assessment areas.

\section{ASSESSMENT APPROACH:}

\section{Performance Objectives to be Evaluated:}

Management Performance Objectives and Criteria:

- Oversight: 1.4 .3 and 1.4.4.

- Assessment and Review: 2.4.2.4, 2.4.3.1, 2.4.3.2, 2.4.3.3, and 4.4.2.4.

- Field Office and Site Self-Assessment Programs: 2.5.5, 2.5.6, 4.5.5, and 4.5.6.

- ES\&H Management Information System: 4.4.3.1, 4.4.3.2, 4.4.3.3.

Corrective Action Plan Performance Objectives and Criteria:

- There is a formal, documented plan for each DOE and DOE contractor Corrective Action Plan program.

- The form, content, and implementation procedures for the conduct of each Corrective Action $\mathrm{Pl}$ an program has received appropriate approval; DOE Field Office approval of Contractor program plans and Cognizant Secretarial Official approval of the DOE Field Office program plan.

- Corrective Action Plans address and prioritize all findings, issues, and root causes on a sitewide basis; including realistic, appropriately phased and sequenced schedules with measurable milestones for accomplishment; and provide reasonable cost estimates with identified funding sources.

- There are designated DOE and contractor organizations with overall responsibility for the conduct of their respective Correction Action Plan Programs. Each organization has a formal charter, operating procedures, and qualified staff whose roles, responsibilities, and authorities are clearly defined, documented, communicated, and understood.

- Corrective Action Plan programs provide for timely reporting and independent verification and closure of all corrective actions. 
- Formal Corrective Action Plan management information systems provide DOE and contractor management at all levels with the current status of corrective actions on a sitewide basis.

\section{Description and Rationale of Approach:}

- Review of applicable documentation.

- Interviews of ID and INEL personnel who are responsible for the various aspects of the corrective action process.

- A sampling of implemented corrective actions or closed items will be verified to determine adequacy of the process.

- Review of the process to determine: how action items are closed, how priorities are established, how the tracking system works, how management is involved, and whether the process addressed the underlying causes.

\section{Planned Interviews:}

Refer to Appendix $F$ in this report.

ADDITIONAL DOCUMENTS NEEDED:

Refer to Appendix $G$ in this report.

\begin{tabular}{|c|c|c|c|c|}
\hline \multicolumn{5}{|c|}{ TO BE COMPLETED BY DOE FIELD OFFICE AND SITE CONTRACTOR } \\
\hline \multirow[t]{2}{*}{ DOE Counterpart } & Name: & \multicolumn{3}{|l|}{ Tom Williams } \\
\hline & Telephone \#: & $208 / 526-2460$ & Fax \#: & $208 / 526-7910$ \\
\hline \multirow[t]{2}{*}{ Contractor Counterpart } & Name: & \multicolumn{3}{|l|}{ None } \\
\hline & Telephone \#: & $n / a$ & Fax \#: & $n / a$ \\
\hline
\end{tabular}


PROGRESS ASSESSMENT SCOPE

IDAHO NATIONAL ENGINEERING LABORATORY (INEL)

\begin{tabular}{|lll||}
\hline Name: & William P. Ortiz & Date: $7 / 1 / 93 \quad$ Rev. \#: 2 \\
Telephone \#: & $804 / 249-7145$ & Fax \#: $804 / 249-7146$ \\
Discipline: & Management Programs & \\
Area of Responsibility: & Self-Assessment & \\
\hline
\end{tabular}

\section{IDENTIFICATION OF ISSUES:}

\section{Identification of Issues to Be Addressed:}

Issue 1: Have DOE-HQ and ID provided clear guidance for the effective and complete implementation of the INEL self-assessment program? Is the self-assessment guidance and are self-assessment programs consistent across INEL to allow for effective monitoring and interpretation by line organizations up to DOE-HQ?

Issue 2: Is the implementation of the In self-assessment program and each of the INEL contractors self-assessment programs complete and do they meet the criteria of the DOE guidance? Does the INEL's self-assessment process include programs plans, assessment schedules, areas of inquiry, a corrective action process, trending and root cause analysis? Are the self-assessment programs effective and have they been approved?

\section{Related Tiger Team Findings:}

Key

Finding: Although ID and each of the INEL contractors have initiated selfassessment efforts, the implementation process is incomplete, and the programs and reports do not meet all of the applicable criteria of the Secretary of Energy's guidance. The portions of the self-assessment programs that are developed have not been fully institutionalized.

Specific: The INEL Tiger Team self-assessment findings SAF-1, 2, 3, 7, 8, 9, $10,11,12,13$, and 15 .

Related Tiger Team Action Plan Items:

KF-046.AP01: INEL self-assessment programs.

Plan Description: A detailed description of all corrective actions and milestones for resolving this finding is contained in the individual action plans for SAF-1 through 17.

Other Bases:

None. 


\section{Overlapping Issues:}

Overlap with other areas in the Progress Assessment will occur since many self-assessment activities take place within all INEL organizations and within multiple disciplines.

\section{ASSESSMENT APPROACH:}

\section{Performance Objectives to be Evaluated:}

- DOE's July 31, 1990, "Guidance of Environment Safety, and Health (ES\&H) Self-Assessment."

- ES\&H Management Performance Objectives and Criteria for Progress Assessments (Section 1.4.3,2.3.4, and 4.4.3).

- DOE's December 1992, "Self-Assessment Guidance Document."

\section{Description and Rationale of Approach:}

Self-assessment progress can be assessed by reviewing ID's, and each of the INEL contractor's status on key Corrective Action Plan milestones.

Specifically, progress assessments of:

- The development and delivery of self-assessment programs, policies, and procedures to meet all applicable criteria of the Secretary of Energy's guidance which were due by June 1, 1992.

- The development and implementation of the INEL Issues Management Program and System to track, trend, and provide the status of INEL issues, including self-assessment findings that were due by August $1,1992$.

- The completion of the initial round of personnel training in implementation of the revised self assessment programs, policies, and procedures which were due by March 1, 1993.

Programs will be evaluated against the objectives and criteria identified in the preceding section. The principal assessment approach will include:

- Reviewing the principal self-assessment related documents, and interviewing the principal persons responsible for self-assessment programs;

- Understanding the extent of invalvement in the self-assessment process at different levels;

- Interviewing selected staff level personnel involved in self-assessment related activities;

- Incorporating feedback from other assessment team members on selfassessment to understand the overall implementation and effectiveness INEL's self-assessment programs; and 
- Preparing and documenting an accurate and bal anced assessment of $I D^{\prime} s$ and INEL's progress in implementing self-assessment.

\section{Planned Interviews:}

The initial site visit interviews will be conducted with a individuals within 10 and each of the contractor organizations knowledgeable with the development and implementation of policies and procedures. The Progress Assessment. interviews will be conducted with INEL DOE program managers and contractor line manages responsible for conducting and acting upon the results of selfassessments. Refer to Appendix $F$ in this report.

ADDITIONAL DOCUNENTS NEEDED:

Refer to Appendix $G$ in this report.

\begin{tabular}{|c|c|c|c|c|}
\hline \multicolumn{5}{|c|}{ TO BE COMPLETED BY DOE FIELD OFFICE AND SITE CONTRACTOR } \\
\hline \multirow[t]{2}{*}{ DOE Counterpart } & Name: & Bob Stump & & \\
\hline & Telephone ": & $208 / 526-1448$ & Fax \#: & $208 / 526-7910$ \\
\hline \multirow[t]{2}{*}{ Contractor Counterpart } & Name: & None & & \\
\hline & Telephone ": & $n / a$ & Fax \#: & $\mathrm{n} / \mathrm{a}$ \\
\hline
\end{tabular}


PROGRESS ASSESSMENT SCOPE

IDAHO NATIONAL ENGINEERING LABORATORY (INEL)

\begin{tabular}{|lll||}
\hline Name: & Robert Compton & Date: $6 / 30 / 93 \quad$ Rev. $\#: 0$ \\
Telephone \#: & $916 / 894-8788$ & Fax $\#: 916 / 899-9525$ \\
Discipline: & Management Programs & \\
Area of Responsibilitty: & Oversight & \\
\hline
\end{tabular}

\section{IDENTIFICATION OF ISSUES:}

\section{Identification of Issues to Be Addressed:}

Issue 1: Are management systems in place and functioning at INEL that provide effective oversight of activities that involve or affect ES\&H? Are these systems documented, communtcated, and understood? Do all responsible parties clearly understand their respective roles, responsibilities, and authorities? Are the appropriate systems in existence and functioning for all organizations, line and independent: ID, EG\&G Idaho, MK-FIC, and WINCO?

Issue 2: The elements of oversight that may be addressed will include assessments, appraisals, audits, management walkthroughs, readiness reviews, survelllances, safety document reviews, corrective action reviews, triennial appraisals, oversight plans, facility representatives program, and environmental, safety and health oversight committees and councils.

Issue 3: Are individuals and organizations at all levels in ID, EG\&G Idaho, WINCO, and MK-FIC being held accountable by successive levels or management for achieving ES\&H compliance and the pursuit of ES\&H excellence?

\section{Related Tiger Team Findings:}

Inadequate oversight was identified as one of the root cause elements for the one overall key finding in the Tiger Team Assessment and was identified as a Management Subteam key finding. In addition, inadequate oversight was noted by the Environmental Subteam as a key finding and the key findings of all three Safety \& Health Subteams indicated significant oversight deficiencies for ID and the various contractors. Key findings, as numbered in the Action Plan, that related to deficiencies in the area of oversight included KF-002, $010,016,018,028,033,034,039$, and 041. Management Finding MF-1 identified the failure of ID and INEL contractors to implement effective ES\&H oversight programs.

\section{Related Tiger Team Action Plan Items:}

Section 3 of the 1991 Tiger Team Corrective Action Plan describes numerous actions that ID and the contractors had taken or were taking including increasing the onsite presence of INEL management and better define management roles, responsibilities, and accountability. The action plans for the above listed key findings and MF-1 detail further corrective actions related to 
oversight. This assessment will establish how effectively these corrective action have been.

\section{Other Bases:}

None.

\section{Overlapping Issues:}

Oversight elements include some aspects of self-assessment and corrective action systems and will require interfacing with these specific areas of assessment. Oversight issues are being specifically addressed by other team members in the areas of Industrial Hyglene and Construction Safety.

I w111 need input from other Progress Assessment Team members related to evidence of an effective oversight systems in various assessment areas: for example, is management visible in the field, and are they aware of and active in assessing activities at the working level?

\section{ASSESSMENT APPROACH:}

\section{Performance Objectives to be Evaluated:}

Management POCs $1.4,2.4 .2,2.4 .3,4.4 .2$, and 4.4 .3 .

\section{Description and Rationale of Approach:}

Determine the existence, completeness, and effectiveness of management oversight systems by the review of documents, interviews with personnel, and observation of work activities. Documentation reviewed will include policles, procedures, oversight plans, correspondence, meeting minutes, committee charters, appraisal/assessment/surve 111 ance reports, and associated actions. Interviews will include various levels in a cross section of organizations with oversight responsibilities and will address overall senior management policy and philosophy, as well as specific implementation and performance. Oversight organizations and activities for which these reviews may be directed include faclitity representatives, oversight committees and counclis, safety and quality representatives, the $Q A$ and ES\&H organizations, line management, and senfor management.

Input from other Progress Assessment Team members will be integrated with personal observations to reach overall conclusions.

Planned Interviews:

Refer to Appendix $F$ in this report.

ADDITIONAL DOCUMENTS NEEDED:

Refer to Appendix $G$ in this report. 


\section{TO BE COMPLETED BY DOE FIELD OFFICE AND SITE CONTRACTOR}

\begin{tabular}{|c|c|c|c|c|}
\hline \multirow[t]{2}{*}{ DOE Counterpart } & Name: & \multicolumn{3}{|l|}{ Cand is Webb } \\
\hline & Telephone \#: & $208 / 526-5111$ & Fax \#: & $208 / 526-7040$ \\
\hline \multirow[t]{2}{*}{ Contractor Counterpart } & Name: & None & & \\
\hline & Telephone \#: & $\mathrm{n} / \mathrm{a}$ & Fax \#: & $n / a$ \\
\hline
\end{tabular}


PROGRESS ASSESSMENT SCOPE

IDAHO NATIONAL ENGINEERING LABORATORY (INEL)

\begin{tabular}{||lll||}
\hline Name: & Robert Compton & Date: $6 / 30 / 93$ Rev. $: 0$ \\
Telephone \#: & $916 / 894-8788$ & Fax $\#: 916 / 899-9525$ \\
Discipline: & Management Programs & \\
Area of Responsibllity: & Directives, Policies, and Procedures \\
\hline
\end{tabular}

\section{IDENTIFICATION OF ISSUES:}

\section{Identffication of Issues to Be Addressed:}

Issue: The adequacy and implementation of directives and policy and procedures systems for ID and selected contractors.

This issue will be addressed from three aspects: (1) the improvement that has occurred since the 1991 Tiger Team Assessment; (2) whether appropriate systems are in place; and (3) whether current conditions foster continuous improvement in these areas.

Directives (e.g., laws, regulations, DOE Orders, SENs, and Secretarial memoranda, such as those related to self-assessment) are the primary instruments for DOE to communicate ESAH requirements throughout the DOE complex. Formal (written), coordinated, consistent management systems are needed at all levels in DOE to ensure that these directives are implemented in a timely and proper manner. Formal directives systems at DOE Headquarters Program Offices, Field Offices/Site Offices, and DOE contractors will ensure that all directives are disseminated in a timely manner to the appropriate organizations or personnel, that Cognizant Secretarial official/Field office/Area Office expectations are communicated down line, and that a documented process exists to track and ensure the adequacy of implementation. The procedures in these systems must clearly detail responsibilities, the process to follow, finite timeframes for issuance of directives and responses, review and approval of implementation plans and schedules, formal tracking/statistical mechanisms, and provide for timely and thorough assessment of implementation.

A solid framework of clear, up-to-date, written, directions detailing administrative, operational, and oversight activities are necessary to implement and maintain effective ESH\&QA programs. This framework consists of tiers of documents starting with requirements and directives, which are translated into site-specific policies, plans, and procedures and facility or activity-specific instructions. Coupled with this framework of procedures must be a clearly communicated and implemented management system detailing when and what kind of procedures are required; how procedures are developed, revised, and controlled; and a firm policy of procedure adherence.

\section{Related Tiger Team Findings:}

Management Finding MF-7 identified that the INEL directives systems were not being effectively used to ensure a common understanding of requirements, convey guidance, or ensure adequate implementation methodologies. Numerous 
Tiger Team findings related to the lack of or inadequate procedures in many areas, at ID, and at all INEL contractors. Key findings, as numbered in the Corrective Action $\mathrm{Pl}$ an, that related to deficiencies in the area of procedures area included KF-009, 012, 015, 024, 025, 027, 035, 036, 037, 040, and 042

\section{Related Tiger Team Action Plan Items:}

Section 3 of the 1991 Tiger Team Corrective Action Plan describes numerous actions that ID and the contractors had taken or were taking to develop policy and procedure guidance, upgrade polfcy directive distribution systems, order clarification, review and revise procedures, and disseminate and implement procedures.

The Progress Assessment Team will attempt to determine the level of success INEL has had in achieving these corrective actions.

\section{Other Bases:}

N/A

\section{Overlapping Issues:}

I will need input from other Progress Assessment Team members related to evidence of an effective policy for timely distribution of DOE directives and the clear communication of associated guidance, direction, and expectations. Do supervisors and workers understand ID and contractor policies and directives related to ES\&H, and demonstrate that understanding? Are management guidance, direction, and expectations regarding DUE orders and Notices being clearly communicated down to the working level in a timely manner?

I will also need input from other Team members related to evidence of an effective policy for procedure adherence and use, including document control system, f.e., are procedures being used (onsite and open where appropriate, are they being followed verbatim, are they up-to-date (controlled) and technically adequate, etc? Do supervisors and workers understand DOE and contractor policies and directives related to ES\&H, and demonstrate that understanding?

\section{ASSESSMENT APPROACH:}

\section{Performance Objectives to be Evaluated:}

Management POCs $1.4,2.4 .1,2.4 .2,4.4 .1$, and 4.4.2.

\section{Description and Rationale of Approach:}

Review of documents, interviews with personnel, and observation of activities to:

- Assess the existence and adequacy of formal procedures and systems for developing, disseminating, providing guidance and direction for, and implementing DOE directives (such as DOE Orders, SENs, and guidance documents) at ID, EG\&G Idaho, MK-FIC, and WINCO. 
Test personnel knowledge of and actual implementation of these processes for selected directive documents.

- Assess the existence and adequacy of formal policies and procedures that detail the need for formality in the implementation of ES\&H policies and programs; the processes for development, issue, revision, and control of procedures; and clear policies related to procedure use and adherence. Test personnel knowledge and actual implementation of these processes for ID, EG\&G Idaho, MK-FIC, and WINCO.

Planned Interviews:

Refer to Appendix $F$ in this report.

ADDITIONAL DOCUMENTS NEEDED:

Refer to Appendix $G$ in this report.

TO BE CONPLETED BY DOE FIELD OFFICE AND SITE CONTRACTOR

\begin{tabular}{||l|l|l|l|l|}
\hline \hline \multirow{2}{*}{ NOE Counterpart } & Name: & \multicolumn{3}{|l|}{ Candis Webb } \\
\cline { 2 - 5 } & Telephone *: & 208/526-5111 & Fax *: & 208/526-7040 \\
\hline \hline \multirow{2}{*}{ Contractor Counterpart } & Name: & None & Fax $*:$ & n/a \\
\cline { 2 - 5 } & Telephone *: & n/a & \\
\hline
\end{tabular}


PROGRESS ASSESSMENT SCOPE

IDAHO NATIONAL ENGINEERING LABORATORY (INEL)

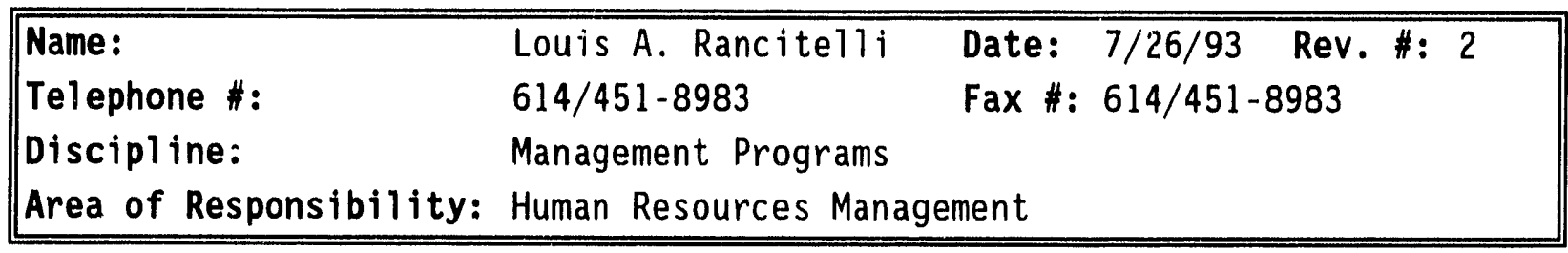

\section{IDENTIFICATION OF ISSUES:}

ID's and the INEL contractors' human resource management systems will be examined to assess their effectiveness in ensuring the availability of sufficient qualified staff for full implementation of INEL ES\&H requirements. Specific issues include management policies that define, communicate, encourage, and mandate desired individual ES\&H performance; human resource management plans that define and prioritize the requirements for full implementation of ES\&H programs; staff development, training, and certification programs; and staff recruitment programs that ensure the availability of sufficient qualified ES\&H staff.

\section{Identification of Issues to Be Addressed:}

The human resource management systems of ID and the INEL contractors will be examined to determine the progress made in correcting the systemic, wide-spread deficiencies identified during the 1991 Tiger Team Assessment. Specific issues include ID's ability to recognize and satisfy its ES\&H staffing needs and the needs of its contractors. Effective human resource management systems such as human resource management implementation plans (e.g., training program plans) are vitally important to ensuring effective ES\&H performance and maintaining an atmosphere of continuous imp:ovement. This Progress Assessment will not only examine the progress in correcting the training deficiencies identified by the Tiger Team Assessment, but will also examine the effectiveness of INEL human resource management systems in ensuring the availability of sufficient qualified ES\&H staff to carry out the INEL mission.

\section{Related Tiger Team Findings:}

The INEL Tiger Team Assessment identified numerous deficiencies that were directly or indirectly related to the lack of effective human resource management programs. All Tiger Team Assessment subteams noted inadequate training; the lack of sufficient, qualified staff; and in some cases the failure to accord sufficient resources to training. A number of key concerns and root causes could be traced to the lack of effective training programs. The INEL Tiger Team Assessment Key Finding: "The programs required to achieve full compliance. . . have not been developed and implemented at INEL." relates in part to wide-spread human resource management deficiencies throughout INEL. One Management Subteam Key Finding related directly to human resource management deficiencies: "The ID, $\mathrm{CH}$, and the site contractors are not managing their human resources with sufficient emphasis on ES\&H responsibilities." Furthermore, five Management Subteam Findings specifically addressed human resource management deficiencies: MF-3 (ES\&H Professional 
Staff); MF-19 (ES\&H Training); MF-20 (Performance Expectations and Appraisals); MF-21 (Employee Concern Programs at INEL); and MF-23 (Building Manager System). The Environmental Subteam identified lack of effective training programs as an important causal factor for the deficiencies it observed: ". . . personnel were not sufficiently trained to be aware of the environmental requirements and applicability of the requirements to their programs, and to adequately perform their responsibilities effectively." Three Safety and Health Subteams' Key Findings related to human resource management deficiencies: "EG\&G Idaho, Inc. training elements do not fully support all safety and health program activities."; "The Radiological and Environment Sciences Laboratory does not have training programs that ensure all staff members are trained and qualified to fulfill their responsibilities."; and "The Rockwell-INEL emergency protection program is not in compliance with numerous Department of Energy requirements. (e.g., training)" In addition, three Safety and Health Subteams' Probable Root Causes related to human resource management deficiencies: "Protection Technology of Idaho, Inc. is providing insufficient training and resources for some safety-related functions."; "Radiological and Environmental Sciences Laboratory is providing insufficient resources and training for some safety-related functions."; "Rockwell-INEL management has provided insufficient resources and training in some safety-related functions."

\section{Related Tiger Team Action Plan Items:}

The INEL Corrective Action Plan addresses the numerous findings, key findings, and root causes related to human resource management deficiencies in the following ways:

- the findings and key findings were addressed with specific action plan's; and

- the key findings and the root causes were also addressed in a generic fashion by identifying corrective actions for specific findings and concerns that were related to or addressed a specific key finding or root cause.

The INEL Tiger Team Assessment Corrective Action Plan included a number of activities aimed at addressing the key findings and root causes related to human resource management deficiencies throughout INEL. In the Corrective Action Plan, the ID Training and Development Branch in the Human Resources Division was assigned responsibilities to oversee and direct implementation of the training program (MF-19). There was an ID management commitment to analyze the specific Training needs in relation to ES\&H, and then determine the number and types of employees with ES\&H backgrounds needed to perform work of the organizations concerned (KF-041); establish a performance-based job task analysis for all positions in contractor ID organizations (MF-19); and develop a Management Organization and Staffing Plan and submit it to ID (KF-018). Also, an ID training records system was to be established and maintained in a training data base updated by the implementation of an automated ID training records management system (TRMS). . . (DOE3/TC.1-4), and ID was to develop and implement training policy and procedures for certifying courses and instructors (MF-19). Other important action items included "Provide ES\&H indoctrination and refresher training that includes expanded General Employee Training to ensure that priority subjects, such as emergency signals, radiation signs and boundaries, construction signs, danger tags, and 
other safety and health concerns are addressed (MK-FIC/TC.4-1)"; and "Develop a list of safety topics to be covered in bimonthly safety meetings and hold first meeting (DOE3/OA.1-6)". In addtion, improvements in INEL management position descriptions were an important element of the Corrective Action Plan. The plan included a commitment to develop specific measurable ES\&H responsibilities and performance objectives for categories of positions $(M F-20)$. This included a commitment to issue DOE policy that required DOE and its contractors to incorporate ES\&H criteria in position descriptions and performance appraisals (KF-045 and MF-20).

\section{Other Bases:}

Other bases include the NE, EM, and ID Strategic Plans, Human Resource Management Plans, Annual and Multi-Year Program Plans, and Self-Assessment Program Plans; the INEL Tiger Team Assessment Report and the INEL Tiger Team Assessment Corrective Action Plan; ID human resource management implementation plans such as ES\&H staffing plans, ES\&H training needs, identification and training program plans, and individual ES\&H performance plans; INEL contractors' strategic plans and subordinate ES\&H human resource management implementation plans such as those noted above; and DNFSB reports and recommendations (e.g., DNFSB 92-7) as they relate to INEL ES\&H training.

\section{Overlapping Issues:}

Since human resource management plans are vital subordinate implementation plans of strategic plans, the assessment of human resources management will be closely coordinated with the assessment of planning, budgeting, and resource allocation. Furthermore, the review of human resource management as related to activities such as corrective action management, self-assessment, ES\&H programs, and oversight of ES\&H functional area activities will be coordinated with INEL Progress Assessment team members who have primary responsibility for evaluating these areas. Specifically, team members examining these related areas should determine if plans exist to identify staffing needs and to ensure that sufficient qualified staff exist to carry out the duties of their assigned disciplines. Also, since a pervasive deficiency identified by the Tiger Team Assessment was the lack of training to procedures, this issue should be addresses by team members examining specific ES\&H programs.

\section{ASSESSMENT APPROACH:}

\section{Performance Objectives to be Evaluated:}

Specific performance objectives in the ES\&H Management Performance Objectives and Criteria for Progress Assessments (December 1992) will be evaluated to include 1.3 Human Resource Management (DOE-HQ), 2.3 Human Resource Management (ID), and 4.3 Human Resource Management (INEL contractors).

\section{Description and Rationale of Approach:}

The approach of this assessment will be to examine the human resource management programs of ID and the INEL contractors by taking vertical cuts down through several of these organizations. Primary emphasis will be on the DOE's and its contractor's effectiveness in defining their ES\&H staffing needs and ensuring that these needs are satisfied. In addition to the vertical cuts through these organizations, a horizontal slice across these organizations 
will be taken to examine the degree to which the various interrelated human resource requirements are coordinated and integrated across each organization on a sitewide basis. Specifically, vertical cut through ID, EG\&G, and WINCO will focus on their respective program line, ES\&H, and human resource development organizations. The human resource management programs of the other INEL contractors will be reviewed in less detail.

\section{Planned Interviews:}

Interviews of ID, DOE-EM, DOE-NE and INEL site contractor management will be conducted. Refer to Appendix $F$ in this report.

ADDITIONAL DOCUNENTS NEEDED:

Refer to Appendix $G$ in this report.

\section{TO BE CONPLETED BY DOE FIELD OFFICE AND SITE CONTRACTOR}

\begin{tabular}{|c|c|c|c|c|}
\hline \multirow[t]{2}{*}{ DOE Counterpart } & Name: & \multicolumn{3}{|l|}{ Jeff Hoyles } \\
\hline & Telephone \#: & $208 / 586-0790$ & Fax \#: & $208 / 526-7910$ \\
\hline \multirow[t]{2}{*}{ Countractor Counterpart } & Name: & \multicolumn{3}{|l|}{ None } \\
\hline & Telephone \#: & $n / a$ & Fax \#: & $n / a$ \\
\hline
\end{tabular}


PROGRESS ASSESSMENT SCOPE

IDAHO NATIONAL ENGINEERING LABORATORY (INEL)

\begin{tabular}{|lll||}
\hline Name: & Louis A. Rancitelli & Date: $7 / 27 / 93$ Rev. \#: 2 \\
Telephone \#: & $614 / 451-8983$ & Fax \#: 614/451-8983 \\
Discipline: & Management Programs & \\
Area of Responsibility: & Planning, Budgeting, and Resource Allocation \\
\hline
\end{tabular}

\section{IDENTIFICATION OF ISSUES:}

The 1991 INEL Tiger Team Assessment examined many aspects of ES\&H management performance and established a comprehensive compliance baseline. The assessment identified numerous systemic deficiencies in the INEL ES\&H management systems that profoundly influence ES\&H performance. A fundamentally important system that was found to be lacking was strategic and subordinate implementation planning, as well as the related budgeting and resource allocation processes. This Progress Assessment will not only examine the progress in correcting the planning, budgeting, and resource allocation deficiencies identified during the 1991 Assessment, but will also examine the effectiveness of these management systems in creating a climate of continuous improvement and for ensuring that such a climate will persist and prosper.

\section{Identification of Issues to Be Addressed:}

The planning, budgeting, and resource allocation processes of DOE-HQ, ID, and the INEL contractors will be examined to determine the progress made in correcting the systemic deficiencies identified during the 1991 Tiger Team Assessment. Specific issues include ID's ability to incorporate ES\&H considerations into and accord ES\&H priority in the INEL planning process and ID's ability to integrate the INEL planning, budgeting, and resource allocation process on a sitewide basis. Also each INEL organization's strategic and subordinate implementation planning process, the process by which ES\&H and programmatic activities are prioritized and integrated, the processes for allocating resources to programmatic and ES\&H activities, and the change control systems employed to ensure that important ES\&H issues receive timely management attention. Since ID plans to manage its own activities, as well as those of its contractors, it will receive emphasis in this assessment.

\section{Related Tiger Team Findings:}

The INEL Tiger Team Assessment identified numerous deficiencies that were traced directly or indirectly to the lack of strategic and subordinate implementation planning throughout INEL. The Tiger Team Assessment root cause addressed a fundamental planning deficiency at INEL: "Management at the INEL has not provided the vision. . . ." Furthermore, each subteam noted the lack of sitewide near- and long-term goals and objectives. One Management Subteam Key Finding related directly to human resource management deficiencies: "ID and the majority of INEL contractors do not place strategic importance on ES\&H in their planning, budgeting, and resource allocation processes. A Management Subteam Root Cause, "ID has failed to exercise the strong, effective leadership necessary. . .", was attributed in part to ID's failure to place 
importance on ES\&H in its planning, budgeting, and resource allocation processes. Furthermore, four Management Subteam Findings specifically addressed INEL planning, budgeting and resource allocation deficiencies: MF-3 (ES\&H Professional Staff); MF-5 (Strategic Planning); and MF-16 (Corrective Action). An Environmental Subteam Key Concern addressed the lack of planning: "ID was not effectively fulfilling its responsibility to plan. . . . A Safety and Health Subteams' Probable Root Causes related to INEL resource allocation deficiencies: "Insufficient resources have been provided to perform the safety-related functions that have been established." In addition to these key findings and root causes, many others that address deficient ES\&H programs can be traced directly to the wide-spread lack of INEL implementation plans.

\section{Related Tiger Team Action Plan Items:}

The INEL Corrective Action Plan addresses the findings, key findings and root causes in two ways. The findings and key findings were addressed with specific action plans. In addition, the key findings and the root causes were also addressed in a generic fashion by identifying corrective actions for specific findings and concerns that were related to or addressed a specific key finding or root cause. Examples from the Corrective Action Plan include: establishing an INEL ES\&H Plan and issuing an ES\&H Vision statement (policy and establishing a Deputy Manager for Operations at ID (MF-6); developing an INEL Environmental Monitoring Plan and Groundwater Monitoring Program Plan (GW/CF-1, KF-001 and KF-003); integrating ES\&H strategy and objectives into planning and issuing an ID Planning Handbook; and incorporating INEL strategies into contractor strategic plans (MF-5 and KF-043). The Corrective Action Plan also specifically addresses strategic planning aspects of the key finding and root cause related to planning. For example, the Corrective Action Plan for the Management Subteam's Key Finding related to INEL strategic and subordinate implementation planning included six important milestones:

- $\quad$ issuing a DOE-ID P1anning Handbook (12/16/91);

- $\quad$ presenting a New Strategic Planning Process, including "cause and effect fishbone" diagrams $(9 / 16 / 91)$;

- approving a Strategic Planning Council process and issuing guidance $(11 / 14 / 91)$;

- $\quad$ providing Cross-Cut Strategic Planning Unit draft plan (11/25/91);

- $\quad$ providing Contractor planning process description and resolution of specific Tiger Team findings (11/25/91); and

- incorporating INEL strategies into Contractor Strategic PIans and submit to ID.

Other Bases:

The NE, EM, and ID Strategic Plans, Annual and Multi-Year Program Plans, Safety and Health Five Year Plans, Site Development Plans, Transition Plans, and Self-Assessment Program Plans. The 1991 Tiger Team Assessment Report and the related INEL Tiger Team Assessment Corrective Action Plan. ID subordinate ES\&H implementation plans such as ES\&H program plans, ES\&H oversight plans, 
and human resource management plans. The ID contractors' strategic plans and subordinate ES\&H implementation plans such as those noted above. DOE-IG and DNFSB reports of INEL assessments conducted over the past year; and recent EH assessment reports.

\section{Overlapping Issues:}

The review of subordinate implementation planning, budgeting, and resource allocation, for activities such as corrective action management, human resource management, self-assessment, ES\&H programs, and oversight of ES\&H functional area activities will be coordinated with INEL Progress Assessment team members who have primary responsibility for evaluating these areas.

\section{ASSESSNENT APPROACH:}

\section{Performance Objectives to be Evaluated:}

Department policy with respect to planning such as SEN-25A-91 and E.P-60 Strategic Planning guidance. Specific performance objectives in the ES\&H Management Performance Objectives and Criteria for Progress Assessments (December 1992) that will be evaluated include 1.1 Planning (DOE-HQ), 1.3.1 Human Resource Planning (DOE-HQ), 1.5.1 Program-Wide Self-Assessment Program plans (NE), 2.1 Planning (ID), 2.3.1 Human Resource Planning (ID), 2.5 Field Office-wide Self-Assessment Program Planning (ID), 3.0 Corporate Parent (Corporate-wide strategic planning), 4.1 Planning (INEL Contractors), 4.3.1 Human Resource Planning (INEL Contractors), and 4.5 Site-wide Self-Assessment Program Plans (INEL Contractors).

\section{Description and Rationale of Approach:}

The 1991 INEL Tiger Team Assessment was conducted at a time when the Department's emphas is on Department-wide strategic and subordinate implementation planning was not yet completely formulated, defined, communicated, and implemented. As a result, the INEL Tiger Team Assessment found the site in the early stages of defining and implementing a comprehensive planning process. The INEL Tiger Team not only found wide-spread deficiencies related to the INEL planning, budgeting, and resource allocation processes, but also found that ES\&H had not been accorded priority within the processes. As a result, the INEL Tiger Team Assessment report is replete with deficiencies that can be related directly to the lack of a comprehensive sitewide planning, budgeting, and resource allocation process. This Progress Assessment will examine the INEL ES\&H management systems related to planning to determine the progress ID and its contractors have made in addressing the deficiencies in these vitally important management systems.

The approach of this assessment will be to examine the planning, budgeting, and resource allocation process of DOE-HQ, ID, and the INEL contractors by taking vertical cuts down through several of these organizations. Primary emphasis will be on DOE's effectiveness in formally articulating its vision of the present and future INEL mission, communicating its vision to its contractors, and ID's ability to hold its contractors accountable for defining and executing their missions in a planned and disciplined fashion. The strategic and subordinate implementation planning process of the contractors will be examined to evaluate their planning processes and to evaluate the effectiveness of DOE's planning, budgeting, and resource allocation process. 
In addition to the vertical cuts through these organizations, a horizontal slice across these organizations will be taken to examine the degree to which varlous interrelated subordinate implementation planning processes are coordinated and integrated on a sitewide basis. Specifically, vertical cuts through ID, ECi\&G, and possibly WINCO, B\&W, MK-FIC, and PTI will focus on their respective program divisions, ES\&H oversight organizations, and the ES\&H performance assurance organizations. The planning process of other INEL contractors as they relate to these vertical cuts will be assessed in less detail.

\section{Planned Interviews:}

Interviews of DOE (ID, NE, and EM) and INEL contractors' senior management will focus on the INEL planning, budgeting, and resource allocation processes. Interviews will be conducted with individuals in small groups. Refer to Appendix $F$ in this report.

ADDITIONAL DOCUMENTS NEEDED:

Refer to Appendix $G$ in this report.

\begin{tabular}{|c|c|c|c|c|}
\hline \multicolumn{5}{|c|}{ TO BE COMPLETED BY DOE FIELD OFFICE AND SITE CONTRACTOR } \\
\hline \multirow[t]{2}{*}{ DOE Counterpart } & Name: & Jeff Hoyles & & \\
\hline & Telephone ": & $208 / 526-0790$ & Fax : & $208 / 526-7910$ \\
\hline \multirow[t]{2}{*}{ Countractor Counterpart } & Name: & None & & \\
\hline & Telephone \#: & $n / a$ & Fax \#: & $n / a$ \\
\hline
\end{tabular}


PROGRESS ASSESSMENT SCOPE

IDAHO NATIONAL ENGINEERING LABORATORY (INEL)

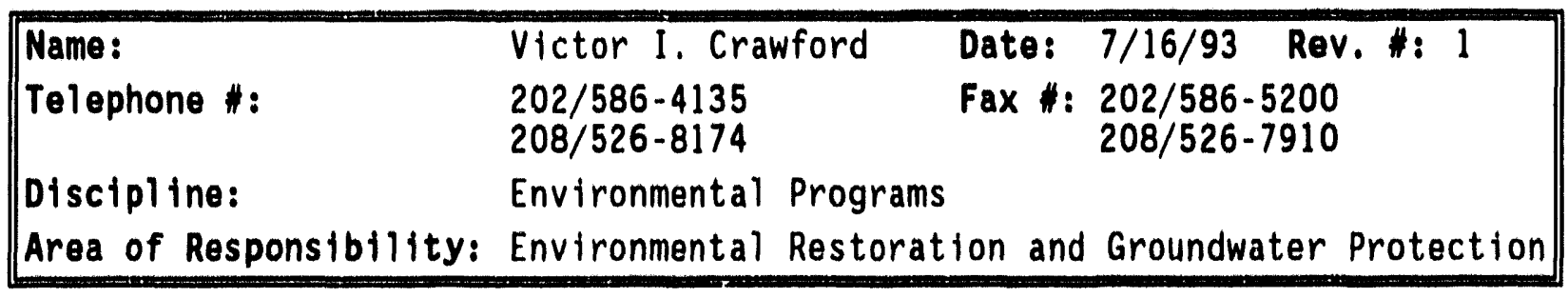

\section{IDENTIFICATION OF ISSUES:}

\section{Identification of Issues to Be Addressed:}

Issue 1: Adequacy, formality, and effectiveness of INEL groundwater protection systems, roles and responsibilities, organizational structures, and procedures for both current projects and inactive waste site cleanup actions, necessary to assure groundwater protection as required by both Federal and state environmental regulations, and DOE 5400.1.

Issue 2: Adequacy, formality, and effectiveness of the Groundwater Monitoring Program, including roles and responsibilities, organizational structures, development and implementation, and resource allocation in order to assure that complete groundwater characterization is accomplished at INEL.

Isiue 3: Adequacy, formality, and effectiveness of the planning, development, implementation, resource allocation, organizational structure, project coordination and communication, and oversight of the Environmental Restoration Program for Groundwater to assure that sufficient complete groundwater cleanup is accomplished at INEL.

\section{Related Tiger Team Findings:}

The following Tiger Team findings pertain to groundwater protection issues:

- $\quad$ SW/CF-2, SW/CF -6, SW/CF-7, SW/BMP-1, SW/BMP-3, SW/BMP-4, SW/BMP-9, GW/CF-1, GW/CF-2, GW/CF-3, GW/CF-4, GW/BMP-1, GW/BMP-2, WM/CF-3, $\mathrm{TCM} / \mathrm{CF}-7, \mathrm{QA} / \mathrm{CF}-2, \mathrm{QA} / \mathrm{CF}-9, \mathrm{RAD} / \mathrm{CF}-4, \mathrm{IWS} / \mathrm{CF}-5$, and IWS/BMPF-1

Related Tiger Team Action Plan Items:

of interest in this portion of the assessment are corrective actions dealing with the following:

- Contaminant plumes from historical injection we11, surface impoundment and landf 111 activities.

- The IAG between DOE, EPA, and the State of Idaho. 
Also of interest in this portion of the assessment are actions dealing with the following:

- Groundwater monitoring activities, with focus on well construction, abandonment of inactive wells, screen placement in the wells, protective caps, disposal of purge water, and accurate sitewide mapping of well locations.

- The characterizatiol of various effluent streams and onsite solls for radionuclides.

\section{Other Bases:}

Other bases include the following:

- INEL has been on EPA's National Priority List since 1989, however, the Federal Facility Agreement and Consent Order was not signed unt 11 December 1991, which was after the Tiger Team Assessment.

- Since the Tiger Team, INEL has received a Notice of Violation (NOV) for 23 alleged hazardous waste violations from the state and a Notice of Noncompliance (NON) for 28 alleged violations from EPA.

- Since the Tiger Team, INEL has received an NOV from the state for an alleged violation of water quality standards.

\section{Overlapping Issues:}

Coordination with the Environmental Monitoring and Survelllance Program, hazardous waste management, and wastewater management specialists will be required to ensure that components of these areas are incorporated into groundwater protection planning and that groundwater elements required by environmental permits and DOE environmental protection programs are integrated into groundwater protection planning. Coordination with the Corrective Actions Program specialist to provide the results of a field verification on at least one "reported" completed finding from the Tiger Team. Coordination with the management specialists on organizational structure issues, roles and responsibilities, and formality of programs at both the Chicago and Idaho Operations offices and among the many organizations at INEL.

\section{ASSESSMENT APPROACH:}

\section{Performance Objectives to be Evaluated:}

The following performance objectives (and associated criteria) will be used for both the functional compliance issues (vertical cut) and management issues (horizonal) issues:

Compliance Issues

GW.1: $\quad$ A formal groundwater protection managenent program should be in place to ensure compliance with Federal, state, and local groundwater laws, regulations, and requirements. 
GW. 4: Actions should be in progress for hydrogeologic characterization of solid waste management units and inactive wastes sites identifled either through a RCRA Facility Assessment (RFA) or a CERCLA Preliminary Assessment/Site Inspection (PA/SI).

\section{Management 1ssues:}

EM.1: An organizational structure should be established for a groundwater protection management program in such a manner that functions, responsibilities, and authorities are clearly defined and formally documented.

EM. 4: Groundwater monitoring activities should be conducted in accordance with formal programs supported by controlled documentation.

EM. 5: A policy and program exists for communication and involvement of external parties such as regulatory agencies, environmental groups, and the local community.

EM.6: Sufficient staffing and resources should be committed to ensure compliance with groundwater regulatory requirements.

\section{Description and Rationale of Approach:}

Many related groundwater protection activities at INEL reside with contractors, Federal agencies, other national laboratories as well as the Chicago and Idaho Operations Offices. There are several programs and projects that are underway at INEL that could impact groundwater and, therefore, should be integrated into a groundwater protection management program. This assessment will look at the incorporation of these programs and projects into a groundwater protection management program to assure effective groundwater protection.

Information necessary to conduct this assessment will include program plans related to groundwater protection and groundwater monitoring, quality assurance plans related to groundwater activities and strategy documents related to integration of groundwater protection activities. This assessment will focus on DOE and the site contractors management of groundwater protection activities for INEL, determining the assignment of roles and responsibilities and the development of policies and implementation procedures.

As part of this assessment, the INEL self-assessment process and the Tiger Team findings closure process will be evaluated to determine the current status of groundwater protection, environmental program implementation, and the waste management program.

Planned Interviews:

Refer to Appendix $F$ in this report.

ADDITIONAL DOCUMENTS NEEDED:

Refer to Appendix $G$ in this report. 


\begin{tabular}{|c|c|c|c|c|}
\hline \multicolumn{5}{|c|}{ TO BE COMPLETED BY DOE FIELD OFFICE AND SITE CONTRACTOR } \\
\hline \multirow[t]{2}{*}{ DOE Counterpart } & Name: & Lisa A. Green & & \\
\hline & Telephone & $208 / 526-0417$ & Fax \#: & $208 / 526-0160$ \\
\hline \multirow{2}{*}{ Countractor Counterpart } & Name: & None & & \\
\hline & Telephone : : & $n / a$ & Fax \#: & $n / a$ \\
\hline
\end{tabular}


PROGRESS ASSESSMENT SCOPE

IDAHO NATIONAL ENGINEERING LABORATORY (INEL)

\begin{tabular}{|lll||}
\hline Name: & Paul E. Flaherty & Date: $7 / 1 / 93 \quad$ Rev. \#: 2 \\
Telephone \#: & $617 / 498-6192$ & Fax $\#: 617 / 498-7019$ \\
Discipline: & Environmental Programs & \\
Area of Responsibility: & Air Pollution & \\
\hline
\end{tabular}

\section{IDENTIFICATION OF ISSUES:}

\section{Identification of Issues to Be Addressed:}

Issue 1: Adequacy, formality, and effectiveness of the INEL Air Pollution Protection systems, roles and responsibilities, organizational structures, and procedures to assure compliance with Idaho and EPA air pollution control permitting requirements.

Issue 2: Adequacy, formality, and effectiveness of the planning, development, implementation, resource allocation, organizational structure, project coordination and communication of the INEL Compliance Oversight Program to assure compliance with Idaho and National Ambient Air Quality Standards, regulations, and DOE 5400.1 .

Issue 3: Adequacy, formality, and effectiveness of the planning, development, implementation, resource allocation, organizational structure, project coordination and communication, and oversight of the INEL Ambient Air Monttoring Program to assure compliance with Idaho and National Ambient Air Quality Standards and DOE 5400.1 .

\section{Related Tiger Team Findings:}

The following Tiger Team findings pertain to air issues:

- $\quad A / C F-1, A / C F-2, A / C F-3, A / C F-5, A / C F-6, A / C F-9, A / C F-11, A / C F-12$, $A / C F-14, A / B M P F-1$, and $A / B M P F-2$.

Related Tiger Team Action Plan Items:

Same as above.

Other Bases:

None.

\section{Overlapping Issues:}

During the conduct of the assessment, coordination will be required with the self-assessinent specialist, groundwater specialist, surface water specialist, and radiation specialist to ensure that all aspects of the environmental monitoring program are covered. This will include chronic emissions and 
unplanned releases to the environment. In addition, coordination will be needed with the management team to ensure that ID is providing adequate oversight of the environmental monitoring program.

\section{ASSESSMENT APPROACH:}

\section{Performance Objectives to be Evaluated:}

\section{Compliance Issues}

- DOE 5400.1, "General Environmental Protection Program," will be the primary performance objective.

- State and Federal Air Pollution Control Regulations and Standards.

\section{Management Issues}

- An organizational structure should be established in such a manner that functions, responsibilities and authorities for an air pollution control program are clearly defined and formally documented.

- Air monitoring activities should be conducted in accordance with formal programs supported by controlled documentation.

- A policy and program exists for communication and involvement of external parties such as regulatory agencies and other local groups as may be required.

- Sufficient staffing and resources should be committed to ensure compliance with air pollution control requirements.

\section{Description and Rationale of Approach:}

The approach to the Air Pollution Control Monitoring and Management portion of the Progress Assessment is to conduct interviews with individuals at both ID and operating contractors (EG\&G, WINCO, and B\&W) that are responsible for the monitoring and management of air emissions and ambient concentrations at INEL. In addition, interviews will be conducted with personnel within the ID office of Environment and Safety to evaluate DOE's oversight of this area. To support the interviews, the following plans will be reviewed:

- $\quad$ plans for the development of an emissions inventory;

- plans for the characterization of air emission physical characteristics;

- Environmental Monitoring Plan; and

- Air Permitting and Compliance fissurance Management Plan.

Also, selected site visits will be performed to determine how the plans are being implemented in the field and to verify that sound management is resulting in the appropriate application of emissions measurements and ambient 
monitoring. This information will be used to assess the adequacy of the Air Permits Compliance Plan.

$\mathrm{Pl}$ anned Interviews:

Refer to Appendix $F$ in this report.

ADDITIONAL DOCUMENTS NEEDED:

Refer to Appendix $G$ in this report.

\begin{tabular}{|c|c|c|c|c|}
\hline \multicolumn{5}{|c|}{ TO BE COMPLETED BY DOE FIELD OFFICE AND SITE CONTRACTOR } \\
\hline \multirow[t]{2}{*}{ DOE Counterpart } & Name: & & & \\
\hline & Telephone \#: & & Fax \#: & $208 / 526-0160$ \\
\hline \multirow[t]{2}{*}{ Countractor Counterpart } & Name: & None & & \\
\hline & Telephone \#: & $n / a$ & Fax \#: & $n / a$ \\
\hline
\end{tabular}


PROGRESS ASSESSMENT SCOPE

IDAHO NATIONAL ENGINEERING LABORATORY (INEL)

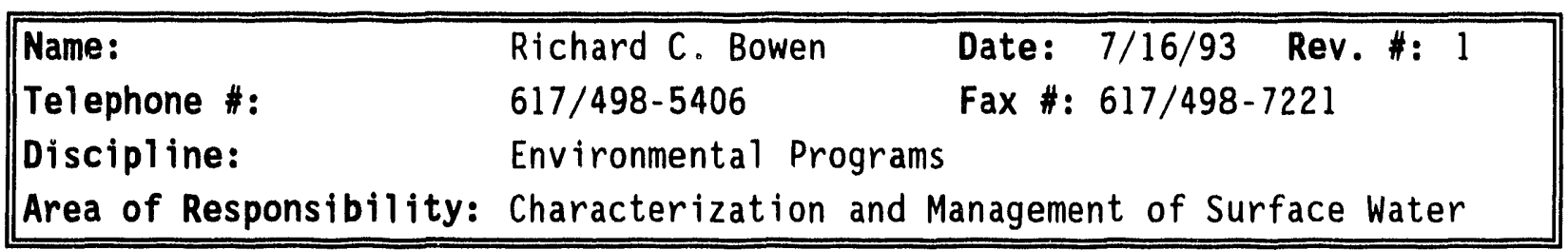

IDENTIFICATION OF ISSUES:

\section{Identification of Issues to Be Addressed:}

Issue 1: Adequacy, formality, and effectiveness of the Surface Water Characterization and Management Program, including roles and responsibilities, organizational structures, development and implementation, resource allocation, in order to assure that surface water discharges are characterized and managed according to DOE requirements and Federal and state regulations.

Issue 2: Adequacy, formality, and effectiveness of the planning, development, implementation, resource allocation, organizational structure, project coordination and communication, and oversight of the ID Environmental Support Division to assure that sufficient complete process wastewater and stormwater are managed effectively.

\section{Related Tiger Team Findings:}

The followirg Tiger Team findings pertain to surface water issues:

- $\quad S W / C F-1, S W / C F-2, S W / C F-6, S W / C F-7$, SW/BMPF-1, SW/BMPF-2, SW/BMPF-3, SW/BMPF-4, SW/BMPF-6, and SW/BMPF-7.

\section{Related Tiger Team Action Plan Items:}

Same as above.

\section{Other Bases:}

other bases include:

- INEL has been on EPA's National Priority List since 1989, however, the Federal Facility Agreement and Consent Order were not signed until December 1991, which was afier the Tiger Team Assessment.

- Since the Tiger Team, INEL has received an Notice of Violation (NOV) for 23 alleged hazardous waste violations from the state and an Notice of Noncompliance (ivON) for 28 alleged violations from EPA.

- Since the Tiger Team, INEL has received an NOV from the state for an alleged violation of water quality standards. 


\section{Overlapping Issues:}

During the conduct of the assessment, coordination will be required with the groundwater, air and radiation specialists to ensure that all aspects of the environmental monitoring program are covered. This will include normal discharges and unplanned releases to the environment. In addition, coordination will be needed with the Management Specialists to ensure that ID is providing adequate oversight and INEL-wide coordination of the environmental monitoring program.

Coordination with the Corrective Actions Program specialist will also be included to provide the results of a field verification on at least one

"reported". completed finding from the Tiger Team. Coordination with the management specialists on organizational structure issues, roles and responsibilities, and formality of programs at both the Idaho Operations Offices and among the many organizations at INEL.

\section{ASSESSMENT APPROACH:}

\section{Performance Objectives to be Evaluated:}

The following performance objectives (and associated criteria) will be used for both the functional compliance issues (vertical cut) and management issues (horizonal) issues:

\section{Compliance Issues}

SW.1: A formal surface water management program should be in place to ensure compliance with federal, state and local groundwater laws, regulations and requirements.

SW.4: Actions should be in progress for surface water characterization of all liquid discharges identified through a liquid discharge inventory.

Actions should be taken to prevent damage to the environment form any DOE operation located in a floodplain or adjacent to any wetlands.

\section{Management Issues}

EM.1: $\quad$ An organizational structure should be established in such a manner that functions, responsibilities, and authorities for a groundwater protection management program are clearly defined and fornially documented.

EM.4: Groundwater monitoring activities should be conducted in accordance with formal programs supported by controlled documentation.

EM.5: A policy and program exists for communication and involvement of external parties such as regulatory agencies, environmental groups, and the local community. 
EM.6: Sufficient staffing and resources should be committed to ensure compliance with groundwater regulatory requirements.

\section{Description and Rationale of Approach:}

The approach to the surface water characterization and Management portion of the Progress Assessment is to conduct interviews with individuals at both ID and operating contractors (EG\&G, WINCO, and B\&W) that are responsible for the monitoring and management of wastewater at INEL. In addition, interviews will be conducted with personnel within the ID Office of Environment and Safety to evaluate DOE's oversight of this area. To support the interviews, the following plans will be reviewed:

- the liquid effluent inventory;

- the plan for the characterization of the liquid effluents;

- the Environmental Monitoring Plan; and

- The Groundwater Protection Plan.

Also, selected site visits will be performed to determine how the plans are being implemented in the field and to observe a surface water sampling event.

As part of this assessment, the INEL self-assessment process and the Tiger Team findings closure process will be evaluated to determine the current status of environmental concerns previously identified involving surface water management, environmental program implementation, and the environmental monitoring program.

Planned Interviews:

Refer to Appendix $F$ in this report.

ADDITIONAL DOCUMENTS NEEDED:

Refer to Appendix $G$ in this report.

\begin{tabular}{||l|l|l|l|l||}
\hline \multicolumn{4}{|c|}{ TO BE COMPLETED BY DOE FIELD OFFICE AND SITE CONTRACTOR } \\
\hline \hline DOE Counterpart & Name: & Lisa A. Green \\
\cline { 2 - 5 } & Telephone $\#:$ & $208 / 526-0417$ & Fax \#: & 208/526-0160 \\
\hline \hline Countractor Counterpart & Name: & None & Fax $\#:$ & $\mathrm{n} / \mathrm{a}$ \\
\cline { 2 - 5 } & Telephone $\#:$ & $\mathrm{n} / \mathrm{a}$ & \\
\hline
\end{tabular}


PROGRESS ASSESSMENT SCOPE

IDAHO NATIONAL ENGINEERING LABORATORY (INEL)

\begin{tabular}{|c|c|c|}
\hline $\begin{array}{l}\text { Name: } \\
\text { Telephone \#: } \\
\text { Discipline: } \\
\text { Area of Responsibility: }\end{array}$ & $\begin{array}{l}\text { David J. Allard } \\
617 / 498-6101 \\
\text { Environmental Programs } \\
\text { Environmental Radiation }\end{array}$ & $\begin{array}{l}\text { Date: } 7 / 6 / 93 \quad \text { Rev. \#: } 1 \\
\text { Fax \#: } 617 / 498-7161 \\
\end{array}$ \\
\hline
\end{tabular}

\section{IDENTIFICATION OF ISSUES:}

\section{Identification of Issues to Be Addressed:}

The environmental radiation portion of the assessment will focus on airborne Radiological Monitoring Programs. The radiological effluents resulting from operations and activities at DOE facilities must be monitored to ensure that they are as low as practicable and offsite dose to the public meet specific EPA and DOE limits. That is, the calculation of dose to the public is an amalgam of monitoring results and data obtained from computer models. Currently, the Radiological Environmental Sciences Laboratory (RESL) is responsible for offsite monitoring, modeling, and calculating the dose to the public from operations and activities at the INEL. Individual contractors are responsible for area stack and unabated release inventories. The 1991 Tiger Team Assessment identified several issues related to the adequacy of the airborne radiological monitoring programs in place at the INEL, which ultimately provide information for the subsequent calculation of the dose to the public.

Issue 1: DOE Oversight of the Contractor Airborne Radiological Monitoring Programs. The extent to which ID programs ensure the quality and effectiveness of contractor airborne radiological monitoring programs will be examined including: plans; organizational lines of responsibility; qualifications of oversight personnel; formality of operations with respect to oversight of contractor airborne radiological monitoring programs and data quality objectives for information used in calculating dose to the public; and field verification activities by ID oversight personnel. In developing this issue, assessments of training programs, procedures, Corrective Action Plan implementation and selfassessment will be conducted. In addition, ID is responsible for preparing the Annual NESHAP Report. The Tiger Team identified numerous errors in the 1991 submission of this report. Since much of this data is also used for calculating dose to the public, the thoroughness and quality of the information provided to this report will be reviewed. Specifically, this review will include oversight of contractors' procedures, data collection, and quality verification methods, and the documented bases for any assumptions used in the calculations.

Issue 2: Radiological Monitoring Programs. The extent to which INEL contractors have identified and corrected the hardware aspects of their radiological monitoring networks to meet EPA and DOE requirements and guidelines will be reviewed. The Tiger Team 
Assessment identified numerous hardware components used in airborne radiological monitoring that required repair in order to meet requirements, including improvements in the overall quality of the data collected. Problems included inadequate stack sampling and monitoring systems for radiological emissions, and insufficient procedures regarding monitoring equipment use and maintenance. Improvements made since the Tiger Team Assessment will be evaluated along with: quality assurance; responses to changes in regulations and operations; deficiency identification, corrective action, implementation, and trending; and administration and recordkeeping.

\section{Related Tiger Team Findings:}

\section{Key Finding}

KF-001: RESL is not effectively fulfilling its responsibility to $p 1$ an and direct the INEL environmental monitoring and surveillance program.

\section{Compliance Issues}

A/CF-002: Ambient air monitors at the INEL have not been sited according to appropriate criteria.

A/CF-003: The ambient air monitors at INEL (maintained by RESL) are not properly sited with respect to physical obstructions and are not sampling at the height or flow rate necessary to obtain a representative sample.

A/CF-006: The INEL does not have a complete representative air meteorological data base to support environmental monitoring and permitting activities.

A/CF-007: Effluent monitoring of airborne radioactive emissions from some stacks at the INEL do not accurately collect aild measure particulates, and thus, do not provide representative measurements of the quantities and concentrations of pollutants in airborne discharges.

A/CF-009: The source term characterization of radioactive releases for the INEL contractors is inadequate to comply with the NESHAPs waiver letter submitted to ID by EPA Region $X$, and does not meet the requirements of the DOE.

RAD/CF-001: The calculated dose to the members of the public as a result of radiological releases during routine operations at the INEL may not be as accurate as practicable. Doses calculated to members of the public as a result of unplanned releases may not be accurate.

RAD/CF-003: RESL has not developed the procedures necessary to fulfill their environmental monitoring responsibilities during an actual emergency situation. 


\section{Related Tiger Team Action Plan Items:}

KF-001.AP01, A/CF-002.AP01, A/CF-003.AP01, A/CF-006.AP01, A/CF-007.AP01, A/CF009. AP01, RAD/CF-001.AP01, RAD/CF-003.AP01.

\section{Other Bases:}

Self-assessments, DOE Orders, and compliance assessments.

\section{Overlapping Issues:}

Overlapping issues occur primarily with the core management areas of oversight, self-assessment, corrective action planning, training, formality of operations, and the air specialists.

\section{ASSESSMENT APPROACH:}

\section{Performance Objectives to be Evaluated:}

Performance objectives and criteria that will be used in this assessment pertain to the DOE Orders in the 5400 series, in particular, DOE 5400.1 and 5400.5. The guidance document DOE/EH-0173T, "Environmental Regulatory Guide for Radiological Effluent Monitoring and Environmental Surveillance," will also be used. Federal regulations which pertain to environmental surveillance," will al so be used. Federal regulations that pertain to environmental surveillance and monitoring include the 40 CFR 60 and 61 , which address the NESHAP requirements; and invoke documents such as ANSI N13.1-169, which addresses the design and operation of stack sampling systems for radiological monitoring.

\section{Description and Rationale of Approach:}

The basic methodology consists of: understanding management systems; interviewing responsible line management personnel; inspecting facilities; reviewing appropriate plans, procedures, and analyses; and observing aspects of program implementation. Particular attention will be given to root cause issues. The assessment of the environmental radiation issues will be performed as a "vertical" examination of management systems within ID and the contractors that enable compliance with the performance objectives and criteria.

In addition to reviewing the management systems with respect to correcting the deficiencies identified in this area by the Tiger Team, we will also review the progress made in developing and sustaining a self-assessment program for those activities and programs in the environmental radiation area. This will involve a review of programs, plans, and procedures as well as interviewing personnel that implement the self-assessment process. Of particular interest will be the manner in which any deficiencies identified by the Tiger Team or as part of the self-assesiment process are closed out and verified by the contractors and by ID.

The progress that INEL and ID have made in the area of correcting and improving the data and methods used to calculate dose to the public will be reviewed. This review will involve interviews with ID and contractor staff and reviewing records. It will also include an inspection of facilities and 
systems identified by the Tiger Team as possessing deficiencies that have since been corrected and closed out by the contractors and ID. The condition of corrected items will be reviewed for compliance with DOE Orders, Federal regulations, and guidance documentation.

Planned Interviews:

Refer to Appendix $F$ in this report.

ADDITIONAL DOCUMENTS NEEDED:

Refer to Appendix $G$ in this report.

\begin{tabular}{|c|c|c|c|c|}
\hline \multicolumn{5}{|c|}{ TO BE CONPLETED BY DOE FIELD OFFICE AND SITE CONTRACTOR } \\
\hline \multirow[t]{2}{*}{ DOE Counterpart } & \multirow{2}{*}{$\begin{array}{l}\text { Name: } \\
\text { Telephone \#: }\end{array}$} & \multicolumn{3}{|l|}{ Lisa Green } \\
\hline & & $208 / 526-0417$ & Fax \#: & $208 / 526-7910$ \\
\hline \multirow[t]{2}{*}{ Contractor Counterpart } & Name: & \multicolumn{3}{|l|}{ None } \\
\hline & Telephone \#: & $n / a$ & Fax \#: & $n / a$ \\
\hline
\end{tabular}


PROGRESS ASSESSMENT SCOPE

IDAHO NATIONAL ENGINEERING LABORATORY (INEL)

\begin{tabular}{|lll||}
\hline Name: & Raymond R. Rogers & Date: $6 / 21 / 93$ ReV. \#: 1 \\
Telephone *: & $301 / 903-7331$ & Fax \#: $301 / 903-2582$ \\
Discipline: & Safety and Health Programs \\
Area of Responsibility: & Construction and OSH & Programs \\
\hline
\end{tabular}

\section{IDENTIFICATION OF ISSUES:}

\section{Identification of Issues to Be Addressed:}

Issue 1: Examine adequacy of the Construction Safety Management Program, including resources.

Issue 2: Verify adequacy of effectiveness of DOE and EG\&G oversight in construction safety.

Issue 3: Verify the adequacy of the contractors (EG\&G, WINCO, and MK-FIC) management systems that implement occupational safety standards and requirements. The following safety and health management systems will be evaluated: (1) management commitment/einployee involvement; (2) worksite analysis; (3) hazard prevention and control; and (4) safety and health training.

Issue 4: Examine and determine that corrective actions will solve the identified "root causes."

Related Tiger Team Findings:

Occupational safety and other OSHA related programs (e.g., training and certification), worker safety, Safety and Health Subteam key findings, and Management Subteam findings.

\section{Related Tiger Team Action Plan Items:}

Corrective Action Plan items covering construction and occupational worker safety (same numbering system as Tiger Team findings above).

\section{Other Bases:}

Not applicable.

Overlapping Issues:

Management, industrial hygiene, oversight, self-assessment, and multiple program office responsibilities.

\section{ASSESSMENT APPROACH:}

The effectiveness of the implementation of the elements described above will be evaluated through observations and interviews with 1 ine management and 
craft workers. Key elements will be reviewed, key safety managers will be interviewed, and site visitations involving construction and demolition activities will be made. Relevant documents will be reviewed and analyzed including daily reports from the 0ccurrence and Reporting System (ORPS).

\section{Performance Objectives to be Evaluated:}

The issues described above.

\section{Description and Rationale of Approach:}

Selected site management and programmatic findings identified by the 1991 Tiger Team for EG\&G, WINCO, and MK-FIC will receive horizontal reviews. Selected technical issues will receive vertical silce reviews to determine the effectiveness of the implementation of management actions.

\section{Overall Observation for Walkdowns:}

Housekeeping; means of egress; fire safety;a nd demolition plans to place on construction projects.

\section{Planned Interviews:}

Topics of discussion will include the four issues identified above. A questionnaire focused towards the four elements will be used during the interviews. Refer to Appendix $F$ in this report.

\section{ADDITIONAL DOCUMENTS NEEDED:}

Refer to Appendix $G$ in this report.

\begin{tabular}{|c|c|c|c|c|}
\hline \multicolumn{5}{|c|}{ TO BE COMPLETED BY DOE FIELD OFFICE AND SITE CONTRACTOR } \\
\hline \multirow[t]{2}{*}{ DOE Counterpart } & Name: & Jack Heier & & \\
\hline & Telephone \#: & $208 / 526-0662$ & Fax \#: & $208 / 526-7910$ \\
\hline \multirow[t]{2}{*}{ Contractor Counterpart } & Name: & None & & \\
\hline & Telephone *: & $n / a$ & Fax \#: & $n / a$ \\
\hline
\end{tabular}


PROGRESS ASSESSMENT SCOPE

IDAHO NATIONAL ENGINEERING LABORATORY (INEL)

\begin{tabular}{|ll||}
\hline Name: & Ernest W. Johnson Date: $6 / 29 / 93$ Rev. \#: 1 \\
Telephone \#: & $513 / 435-2971 \quad$ Fax \#: $513 / 848-4454$ \\
Discipline: & Safety and Health Programs \\
Area of Responsibility: & Maintenance, Packaging and Transportation, and \\
& Facility Review (Safety)
\end{tabular}

\section{IDENTIFICATION OF ISSUES:}

\section{Identification of Issues to Be Addressed:}

Issue 1: Thirty-six packaging and transportation (PT) concerns were identified in the INEL Tiger Team Assessment Report. All were identified as $\mathrm{H} 2$ or $\mathrm{H} 3 / \mathrm{Cl}$ or $\mathrm{C} 2$ (mainly compliance versus demonstrated safety/health/environmental problems). All six contractors plus ID were cited. ES\&H Performance Objectives and Criteria for Technical Safety Appraisals (December 1992), Performance Objective PT.1, states "Management should develop and implement a system of policies and directives that will provide for effective implementation... in operations involving packaging and transportation of hazardous materials."

- Have management practices been instituted to effectively alleviate these deficiencies? What oversight functions were put into operation to independently verify implementation?

- Have these corrective actions resulted in a quality P.T effort at the INEL?

Issue 2: EG\&G exhibited a large number (20) of concerns in the maintenance (MA) area. The performance objectives relevant to this issue are found in the ES\&H Management Performance Objectives and Criteria for Progress Assessments (December 1992), 4.2 Organization and 4.4 Oversight. Interviews of various levels of personnel, visits to the EG\&G maintenance shops, examination of records and policies, and the condition of material will be performed in order to assess the progress in this area.

Issue 3: RESL received concerns regarding FR periodic reviews. Interviews with personnel and policy reviews with subsequent results will determine progress in this area.

Issue 4: MK-FIC's artillery range remediation work will be assessed from a Facility Review (FR) (Safety Analys is Report (SAR)) standpoint. The draft SAR will be evaluated to determine that completeness of addressing issues is being performed. MK-FIC's contractual responsibility in accountability for subcontractor personnel safety will be noted. 
Related Tigor Team Findings:

PT.1, MA.1 and MA.2, and FR.

Related Tiger Team Action Plan Items:

See relevant sections of plans.

Other Bases:

None.

Overlapping Issues:

None.

\section{ASSESSMENT APPROACH:}

The information obtained by conducting interviews and examining documents of MA (EG\&G only), PT (all), FR (RESL and MK-FIC), and ID personnel to evaluate the programs they have devised/Implemented and how these programs are working at the sites.

\section{Performance Objectives to be Evaluated:}

MA.2 and MA.8 (EGrG only) and all PT and FR (if time permits).

Description and Rationale of Approach:

The above will ensure that policy changes to address the Concerns are in place, that personnel are knowledgeable of them, and that these changes are effective in the actual workplace.

Planned Interviews:

Refer to Appendix $F$ in this report.

ADDITIOHAL DOCUMENTS NEEDED;

Refer to Appendix $G$ in this report.

\begin{tabular}{|c|c|c|c|c|}
\hline \multicolumn{5}{|c|}{ TO BE COMPLETED BY DOE FIEL } \\
\hline \multirow[t]{2}{*}{ DOE Counterpart } & Name: & Mark Howard & & \\
\hline & Telephone \#: & $208 / 526-1864$ & Fax \#: & $208 / 526-7910$ \\
\hline \multirow[t]{2}{*}{ Contractor Counterpart } & Name: & None & & \\
\hline & Telephone \#: & $n / a$ & Fax \#: & $n / a$ \\
\hline
\end{tabular}


PROGRESS ASSESSMENT SCOPE

IDAHO NATIONAL ENGINEERING LABORATORY (INEL)

\begin{tabular}{|lll||}
\hline Name: & David K. Pegram & Date: $7 / 1 / 93$ Rev. \#: 1 \\
Telephone \#: & $301 / 903-9840$ & Fax \#: $301 / 903-7773$ \\
Disctpline: & Safety and Health Programs \\
Area of Responsibility: & Industrial Hyglene \\
\hline
\end{tabular}

IDENTIFICATION OF ISSUES:

\section{Identification of Issues to Be Addressed:}

Contractor Programs:

\section{General Issues (All contractors):}

- What is the scope, depth, and formality of industrial hygiene program; authorities, responsibllities, staffing and training, planning, resource management, corrective action tracking systems, internal self-assessments, and audits and program documentation?

- What is the status of closure of Tiger Team Corrective Actions?

Specific Issues:

\section{EG\&G Idaho}

- What progress has been made by EG\&G Idaho in the areas of: development of policies and procedures for independent appraisals and audits, development of formal IH program plans, exposure monitoring program for laboratory employees, reviews of work permits, and implementation of a laser safety program?

MK-F

- What progress has been made by MK-FIC in the areas of: reduction on reliance of other site contractors for IH support, development of an IH program and policy, resolution of deficiencies in respiratory protection, breathing air quality, and hazard communication?

\section{$\mathrm{RW}-\mathrm{ID}(\mathrm{B} \& W)$}

- What progress has been made by Rockwell Idaho in the areas of:

reducing staff turnover and repetitive motion injuries, resolution of deficiencies in the hazard work permit, laser safety, respiratory protection, hazard communication, and health monitoring programs? 
$\underline{\text { ID }}$

- What is the scope, depth, and formality of the industrial hygiene program; authorities, responsibilities, staffing and training, planning, resource management, contractor oversight and survelliances, corrective action tracking systems, internal self assessments and audits, and program documentation?

- What is the status of Tiger Team Corrective Actions and ID validations of closure and documentation?

PTI

- What progress has been made by PTI in the areas of hearing conservation, ventilation control systems for solvent vapors, exposure assessment and medical surveillance of employees exposed to lead, respiratory protection, and ventilation systems at the indoor firing range.

$\underline{\text { RESL }}$

- What progress has been made by the RESL in the areas of monitoring chemical exposures, control of perchloric acid in duct work, carcinogen control and laboratory chemical hygiene plan.

\section{Related Tiger Team Findings:}

ID:

\section{Key Findings}

KF-010: ID oversight of EG\&G activities has been deficient in providing guidance to ensure implementation of operational safety requirements.

KF-041: Management within ID, CH, and the site contractors are not adequately preforming their ES\&H oversight responsibilities.

KF-043: ID and the majority of INEL contractors do not place strategic importance on ES\&H in their planning, budgeting, and resource allocation process.

KF-044: ID has failed to provide the sitewide direction and guidance necessary to ensure an effective and sustainable ES\&H program at INEL.

KF-045: The ID, $\mathrm{CH}$, and the site contractors are not managing their human resources with sufficient emphasis on ES\&H responsibilities.

Specific Findings

PP. 4-6. 


\section{EG\&G ID}

\section{Key Findings}

KF-005: EG\&G industrial safety and industrial hygiene programs have serious deficiencies.

KF-007: EG\&G training elements do not fully support all safety and health program activities.

\section{Specific Findings}

PP.1-1, 1-2, 2-2, 2-4, 3-1, 3-2, 3-3, 4-1, 4-2, 5-1, and '1S.4-4, 6-1, 3-1.

\section{MK-FIC}

\section{Key Findings}

KF-017: Formal safety programs that meet DOE requirements have not been established by MK-FIC management.

\section{Specific Findings}

PP.1-1, 1-2, 1-3, 1-4, 4-9, 3-1, 5-1, and WS.5-5, 5-6, 5-7.

$\underline{R W}-\mathrm{ID}(B \& W)$

Key Findings

KF-039: B\&W does not effectively monitor health and safety activities.

\section{Specific Findings}

PP. 3-3, 4-7, 4-8, 4-9, 4-10, 5-3, 5-4, and WS.4-7.

PTI

\section{Specific Findings}

WS.3, PP.1-2, 4-3.

RESL

Specific Findings

PP. 3-2, 4-4, 5-2.

Related Tiger Team Action Plan Items:

Same as above. 


\section{Other Bases:}

A review will be conducted of the progress on the Tiger Team Corrective Action Plan for the Idaho National Engineering Laboratory and other recent selfassessments and audits performed by ID.

DOE Orders, OSHA Regulations 29 CFR 1910 and 1926, the Progress Assessment Manual Performance Objectives, Secretary of Energy Notices, and CSO directives will also be used.

\section{Overlapping Issues:}

Issues identified as industrial hygiene based including self-assessment, resources, procedures, staffing and training, Corrective Actions Plans, procedures and quality assurance also covered by other team members. The objective of the industrial hygiene review will be more narrowly focused on identified deficiencies from the Personal Protection Disciplines from the Idaho National Engineering Laboratory Tiger Team Assessment.

\section{ASSESSMENT APPROACH:}

Determine the existence of management control systems to ensure that the industrial hygienz programs are being up graded in a systematic manner including technical and programmatic issues. This assessment will also attempt to determine the effectiveness of line management to implement key objectives and resolve identified deficiencies as well as to conduct self-assessments and evaluations of the industrial hygiene programs.

Interviews of INEL site contractors and DOE ID industrial hygiene, ES\&H management, and operational personnel. A variety of ES\&H industrial hygiene procedures will be reviewed. Limited visits of selected facilities/operations will be performed to assess the effectiveness of the industrial hygiene program upgrades identified in the action plan. Limited vertical sice audits of selected areas of the contractors industrial hygiene program will be performed to assess the level of commitment of resources and cultural change.

\section{Performance Objectives to be Evaluated:}

- DOE 5483.1A, 5480.10,5480.4, and Occupational Safety and Health Administration (OSHA) Regulations 29 CFR 1910 and 1926 as they apply to industrial hygiene.

- Technical Safety Appraisal and Progress Assessment Manual performance objectives, and Secretary of Energy Notices, and Cognizant Secretarial official directives will be utilized. The Progress Assessment objectives to be evaluated against inciude: Management Performance Objectives; DOE-HQ 1.1 through 1.5, DOE ID 2.1 through 2.6 and INEL site contractors 4.1 through 4.6 and the Environmental Safety and Health Technical Safety Appraisal Performance Objectives; TC.1. TC.10, EA.1, EA.3, PP.1 through PP.6, WS.1 through WS.6, IH.1 through IH.6. Evaluation of the self-assessment program will be conducted against the DOE Self Assessment Guidance Document dated June 1992. 
Description and Rationale of Approach:

The Tiger Team Assessment findings, key findings, and root causes identified issues related to the industrial hygiene program will be reviewed. Selected technical issues will receive vertical review to determine the effectiveness of the program development and implementation in hazard communication and chemical hygiene areas. This assessment will review selected program elements, i.e., facility baseline hazard surveys/analysis, and exposure monitoring programs to determine effectiveness of the overall industrial hygiene program.

Plarıned Interviews:

Refer to Appendix $F$ in this report.

ADDITIONAL DOCUMENTS NEEDED:

Refer to Appendix $G$ in this report.

\begin{tabular}{|l|l|l|l|l|}
\hline \multicolumn{4}{|c|}{ TO BE COMPLETED BY DOE FIELD OFFICE AND SITE CONTRACTOR } \\
\hline DOE Counterpart & Name: & Don Mickelson & \\
\cline { 2 - 5 } & Telephone \#: & $208 / 526-5325$ & Fax \#: & 208/526-1184 \\
\hline \hline \multirow{3}{*}{ Countractor Counterpart } & Name: & None & Fax \#: & n/a \\
\cline { 2 - 5 } & Telephone \#: & $\mathrm{n} / \mathrm{a}$ & $\mathrm{a}$ \\
\hline
\end{tabular}


This page intentionally left blank. 
Appendix E

Schedule of Onsite Activities 


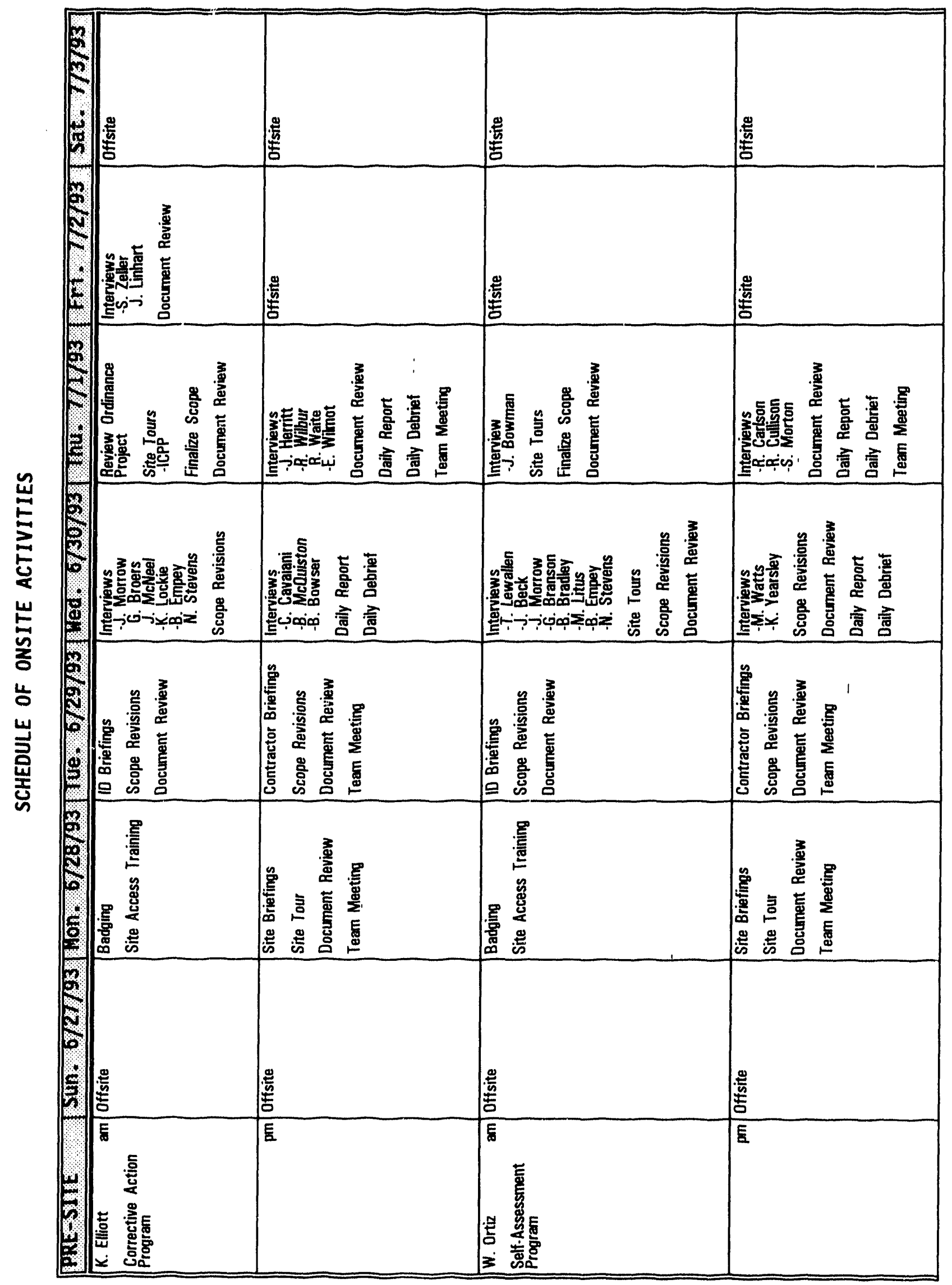

E-1 


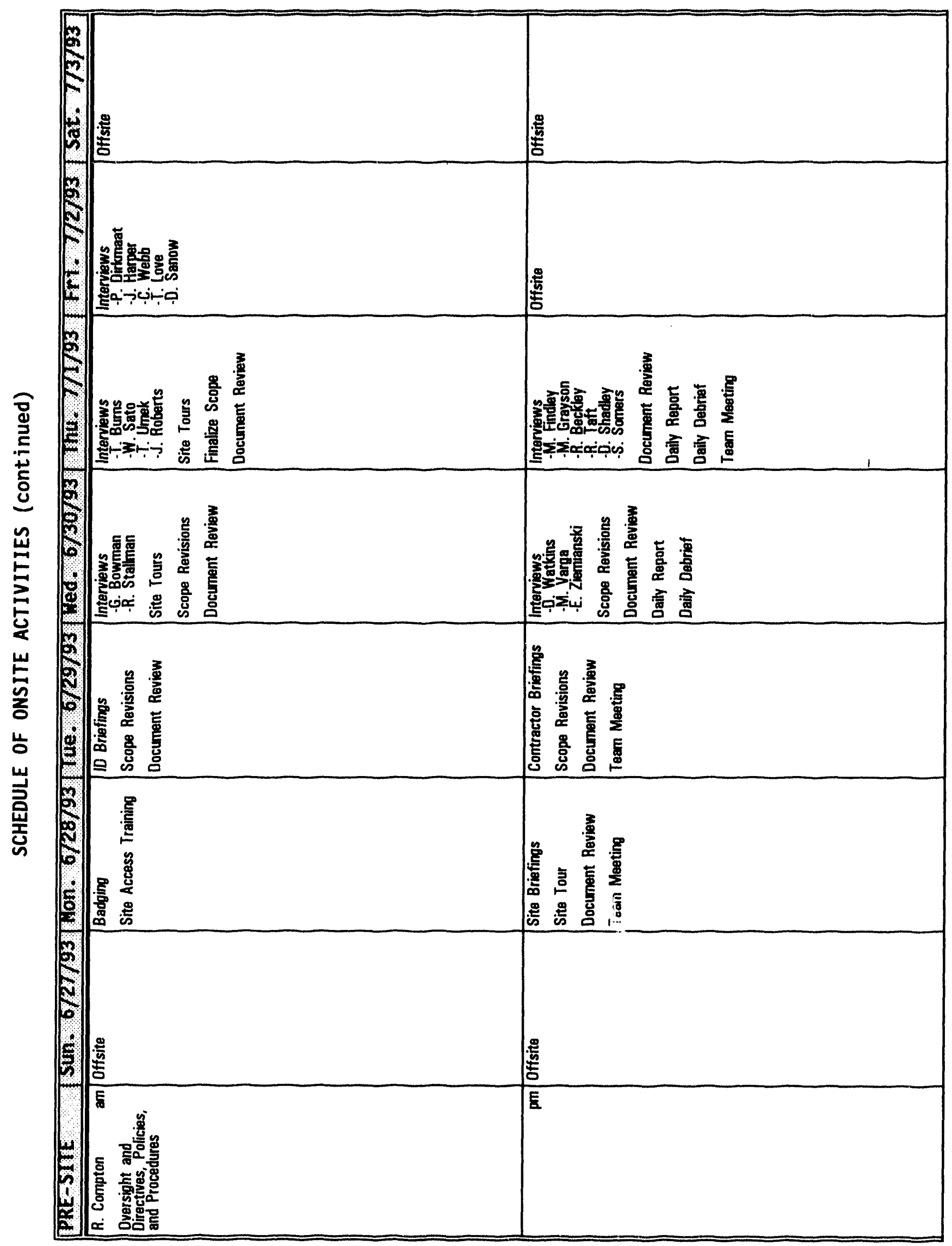

E-2 


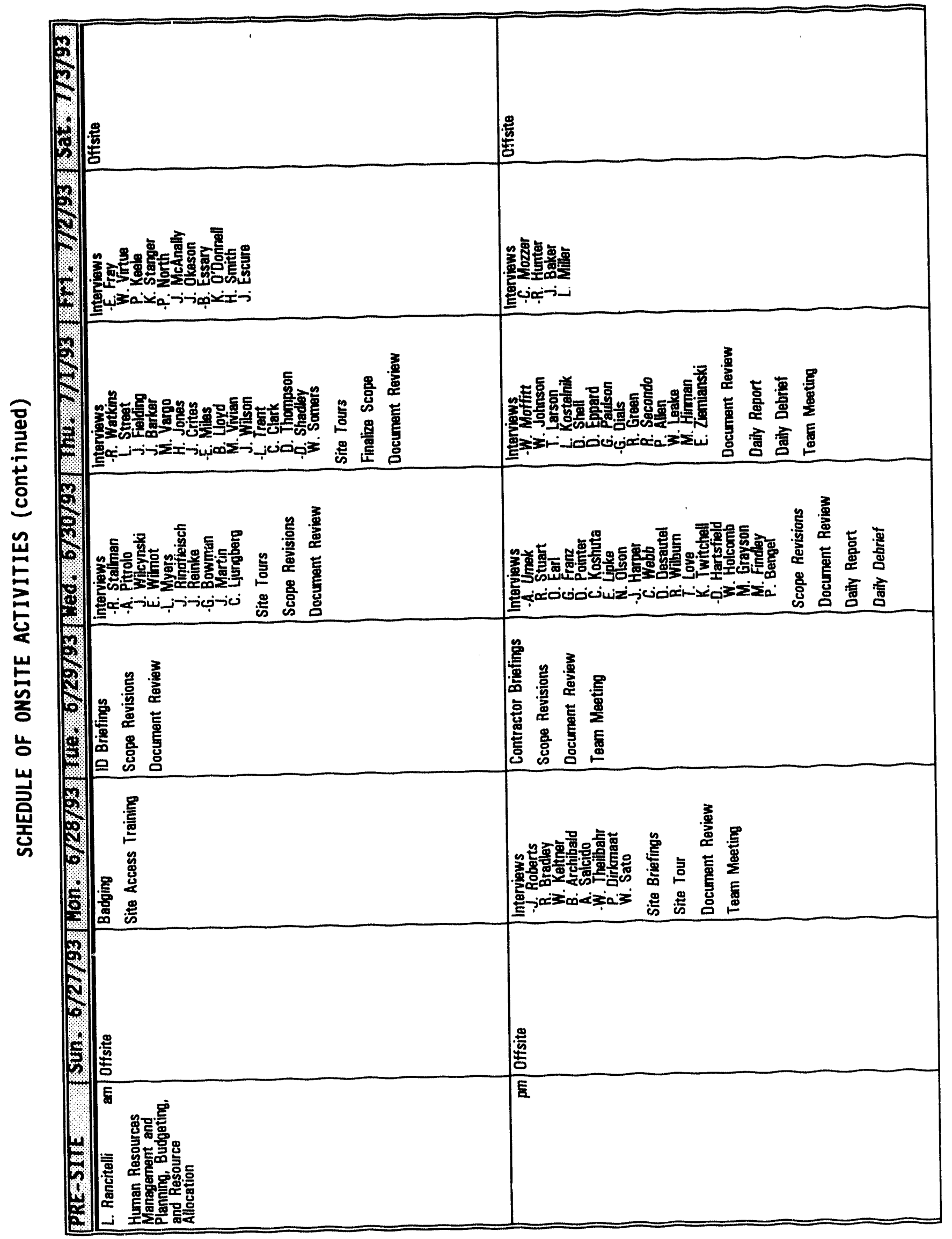




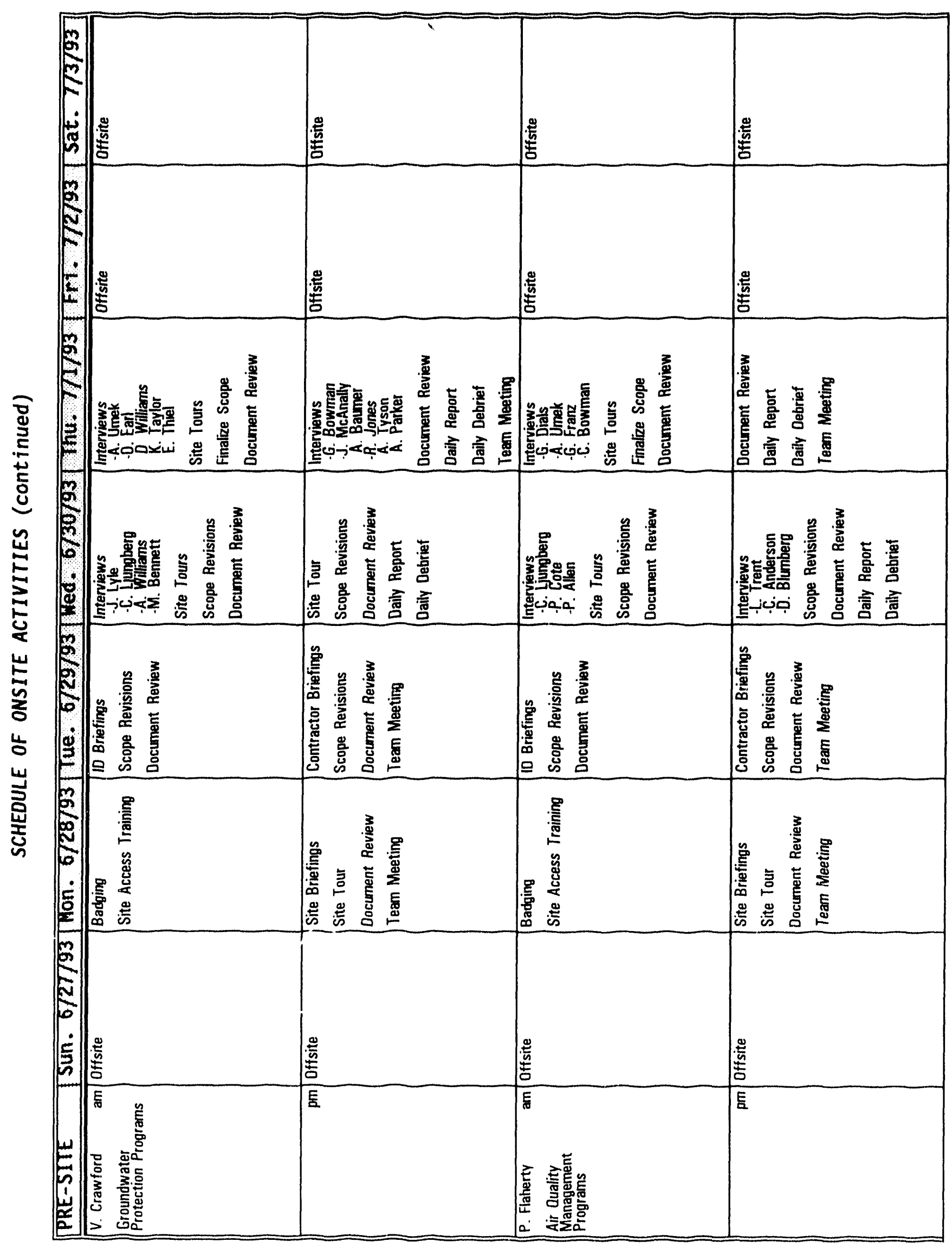




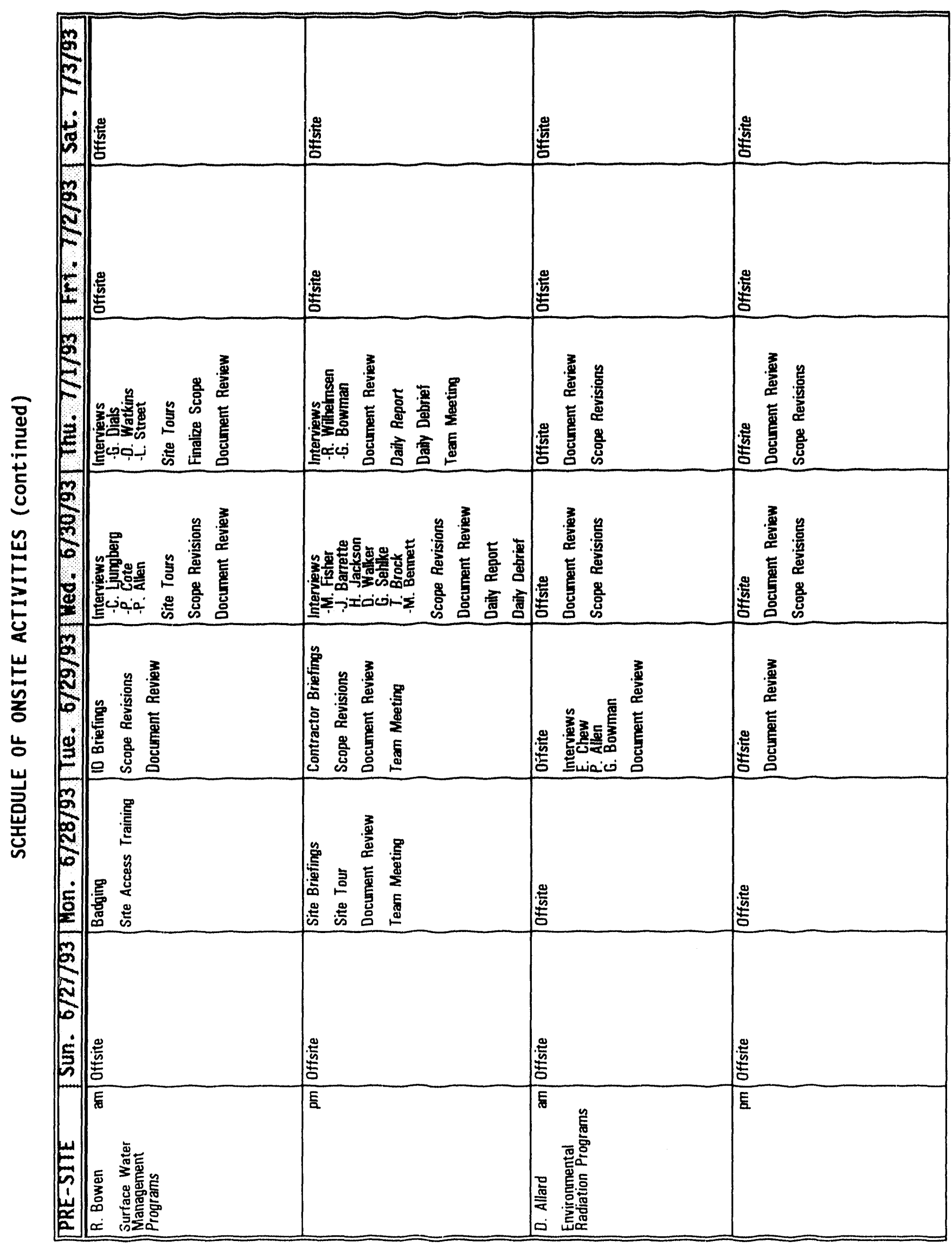




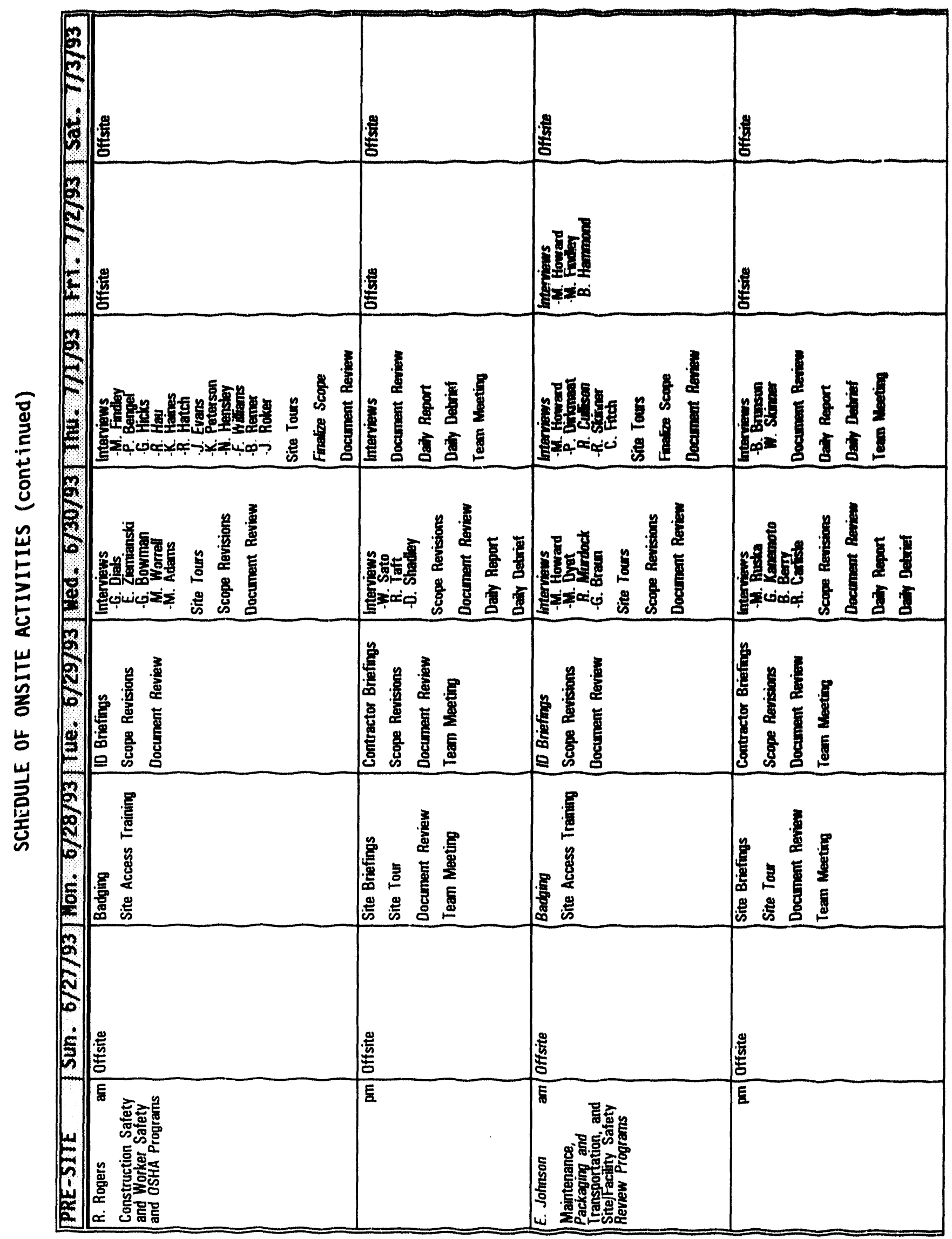




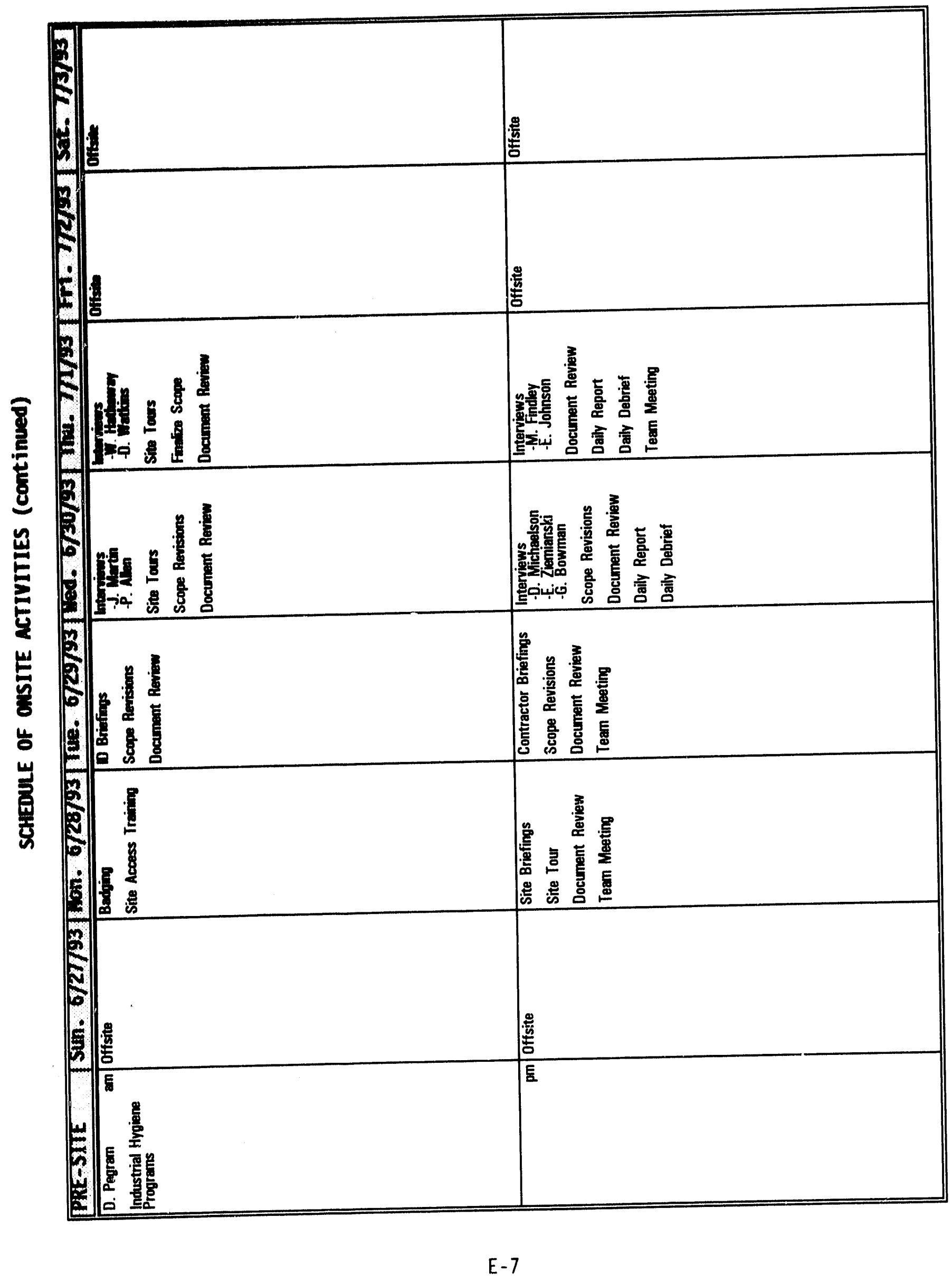




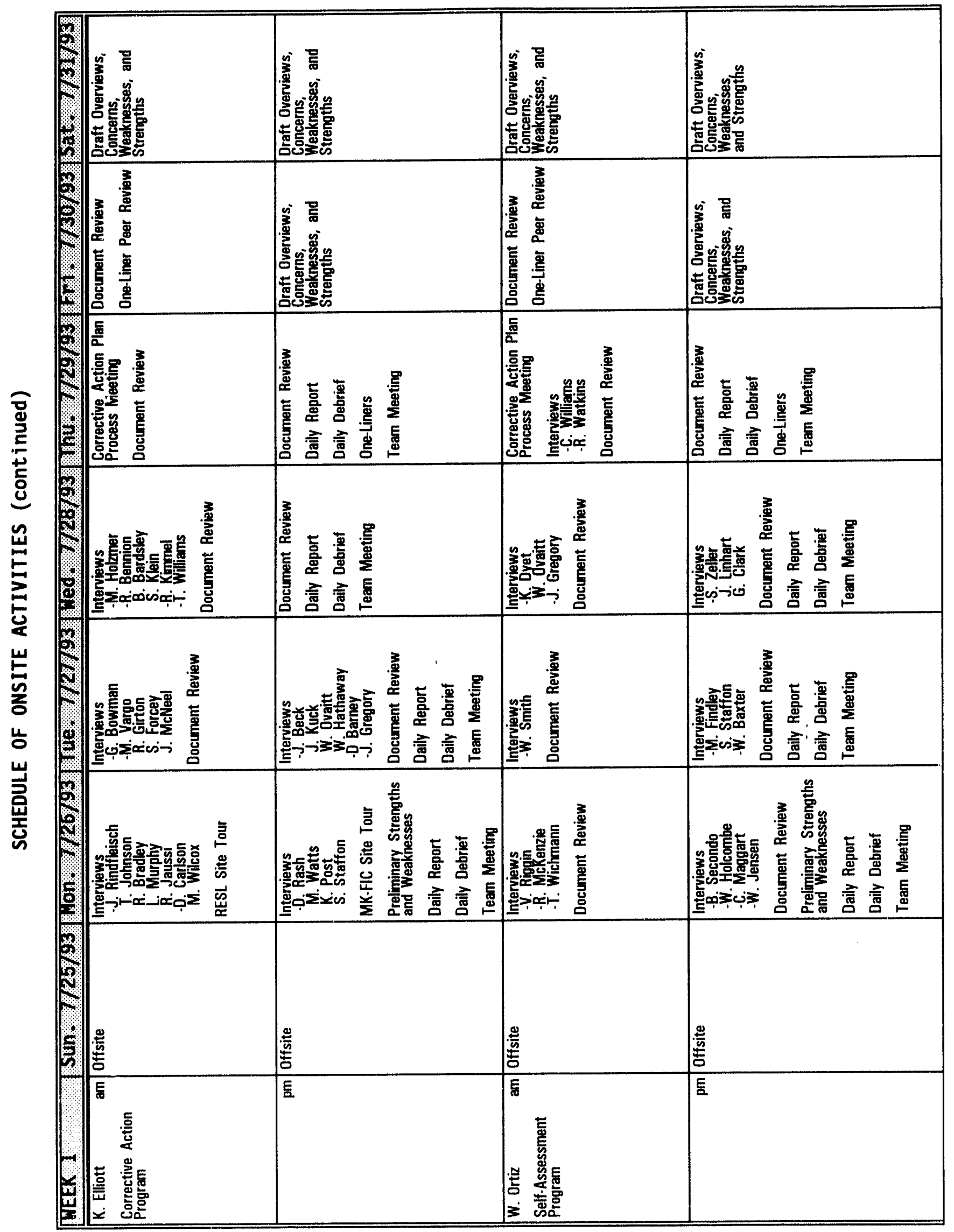




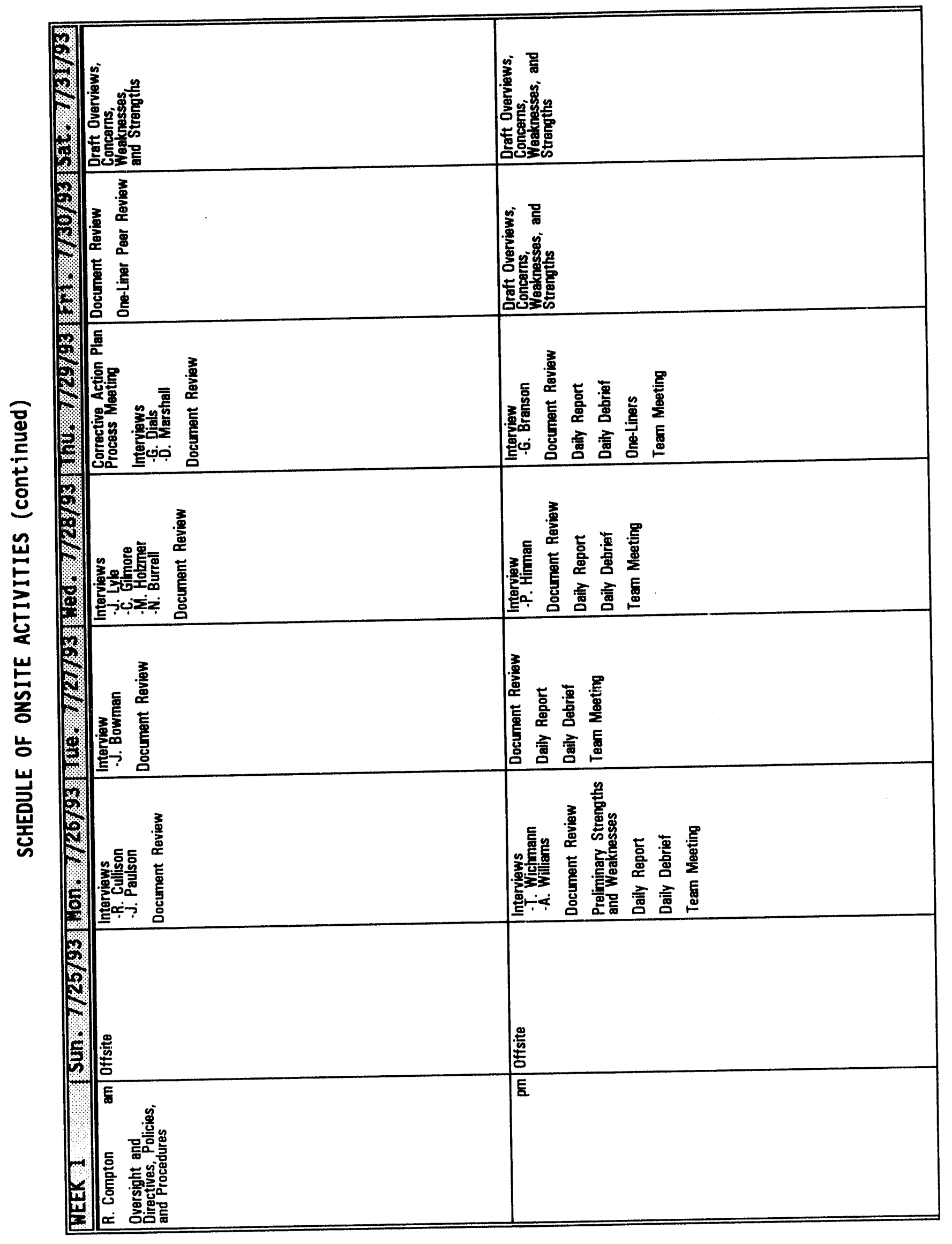

E-9 


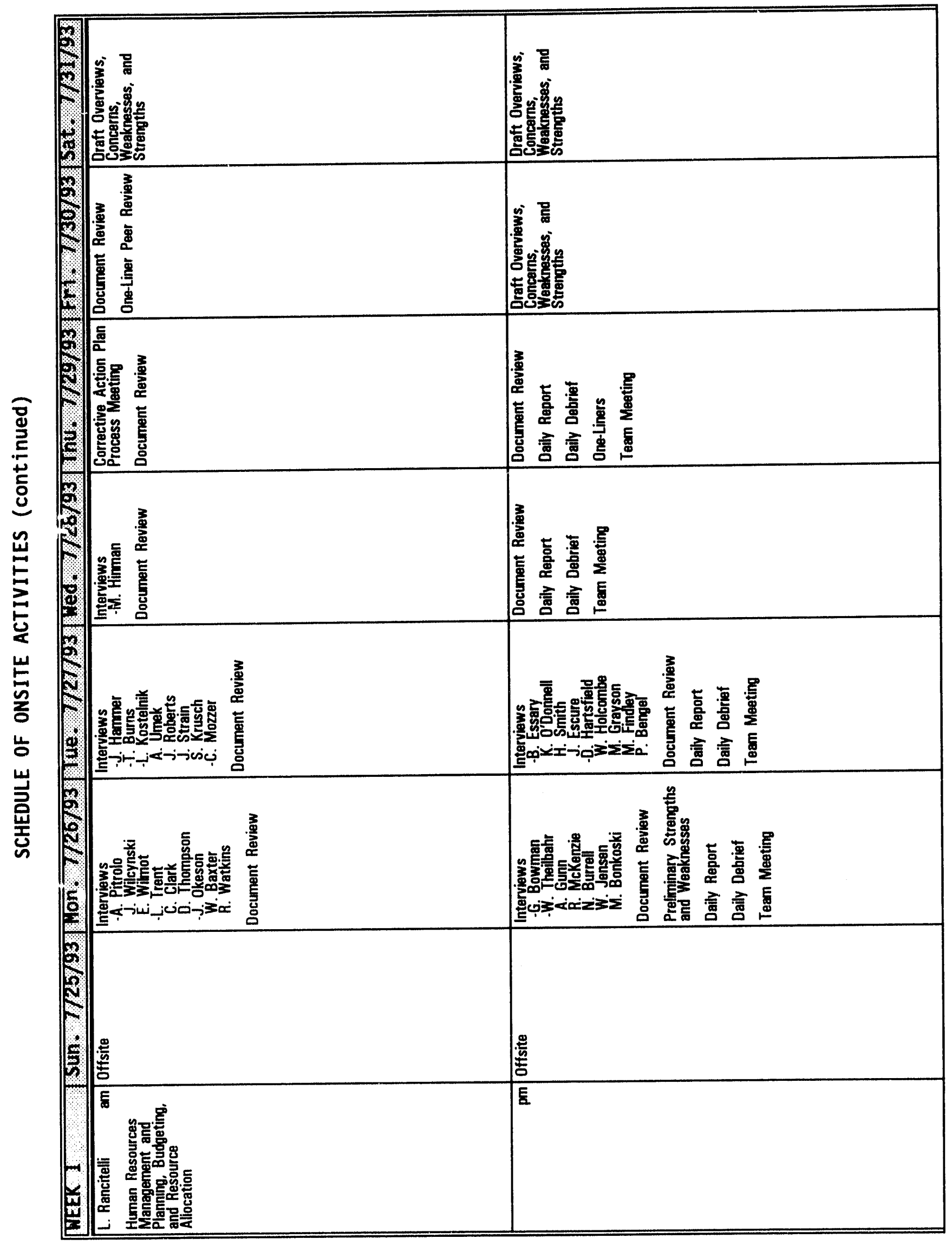

E-10 


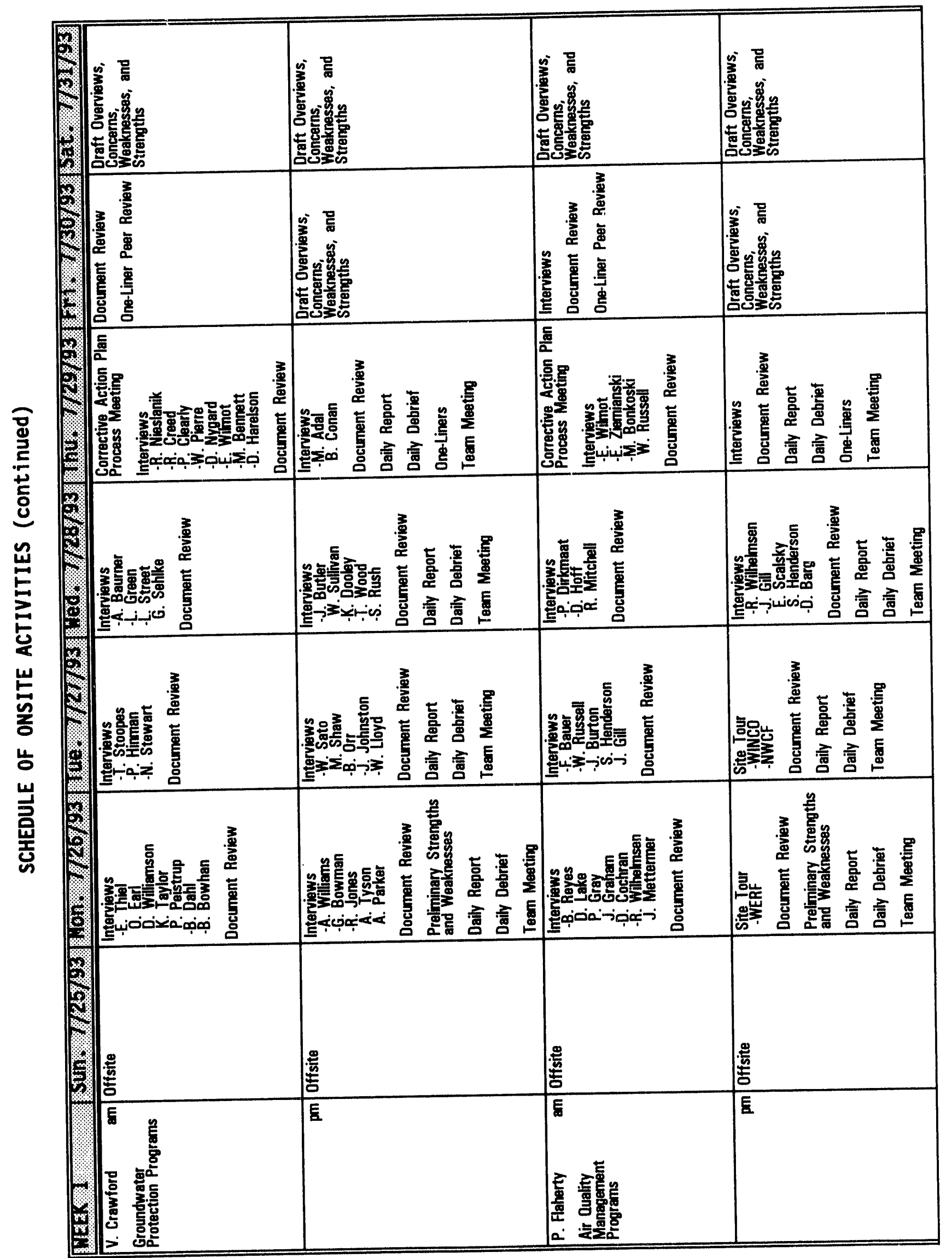




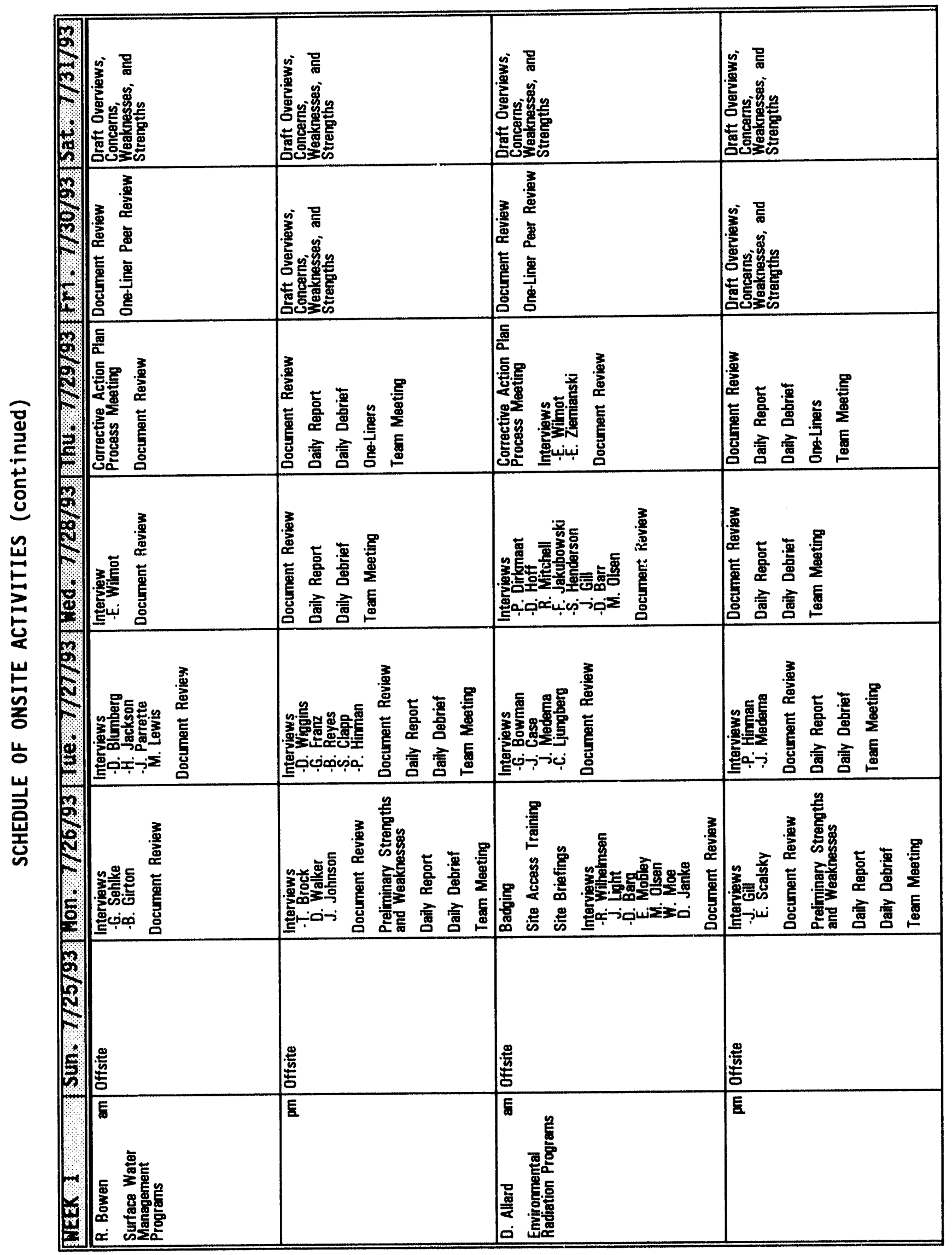




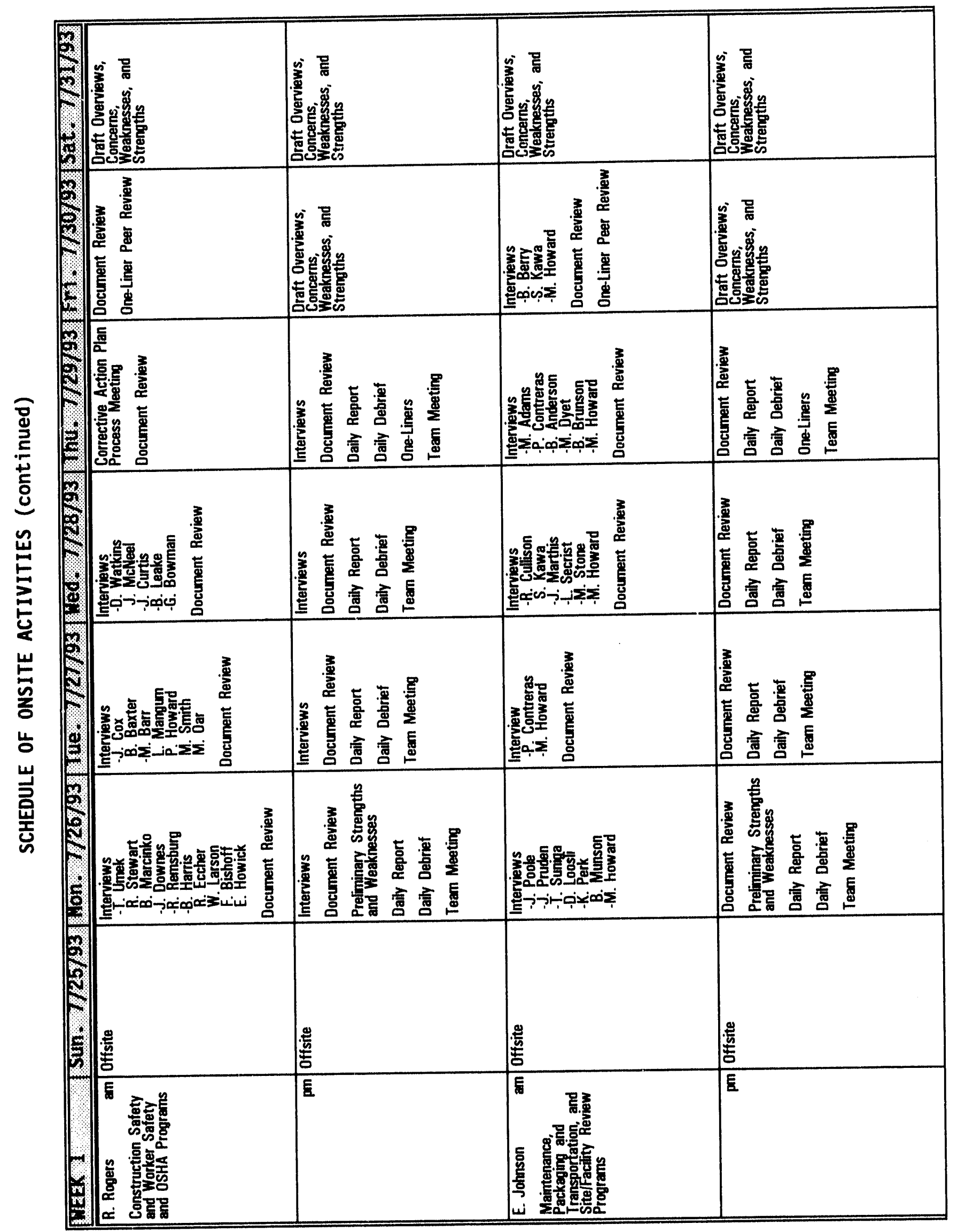




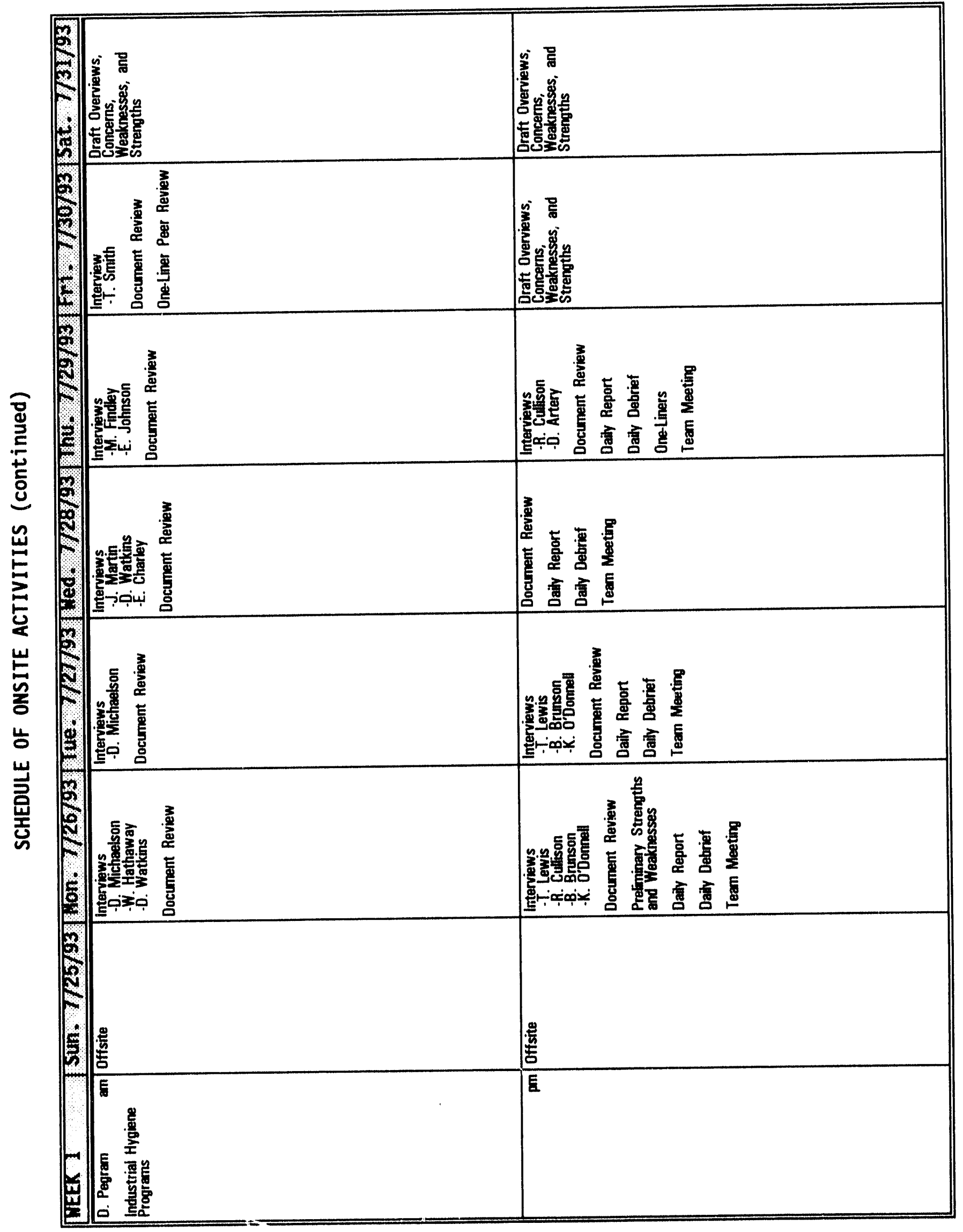




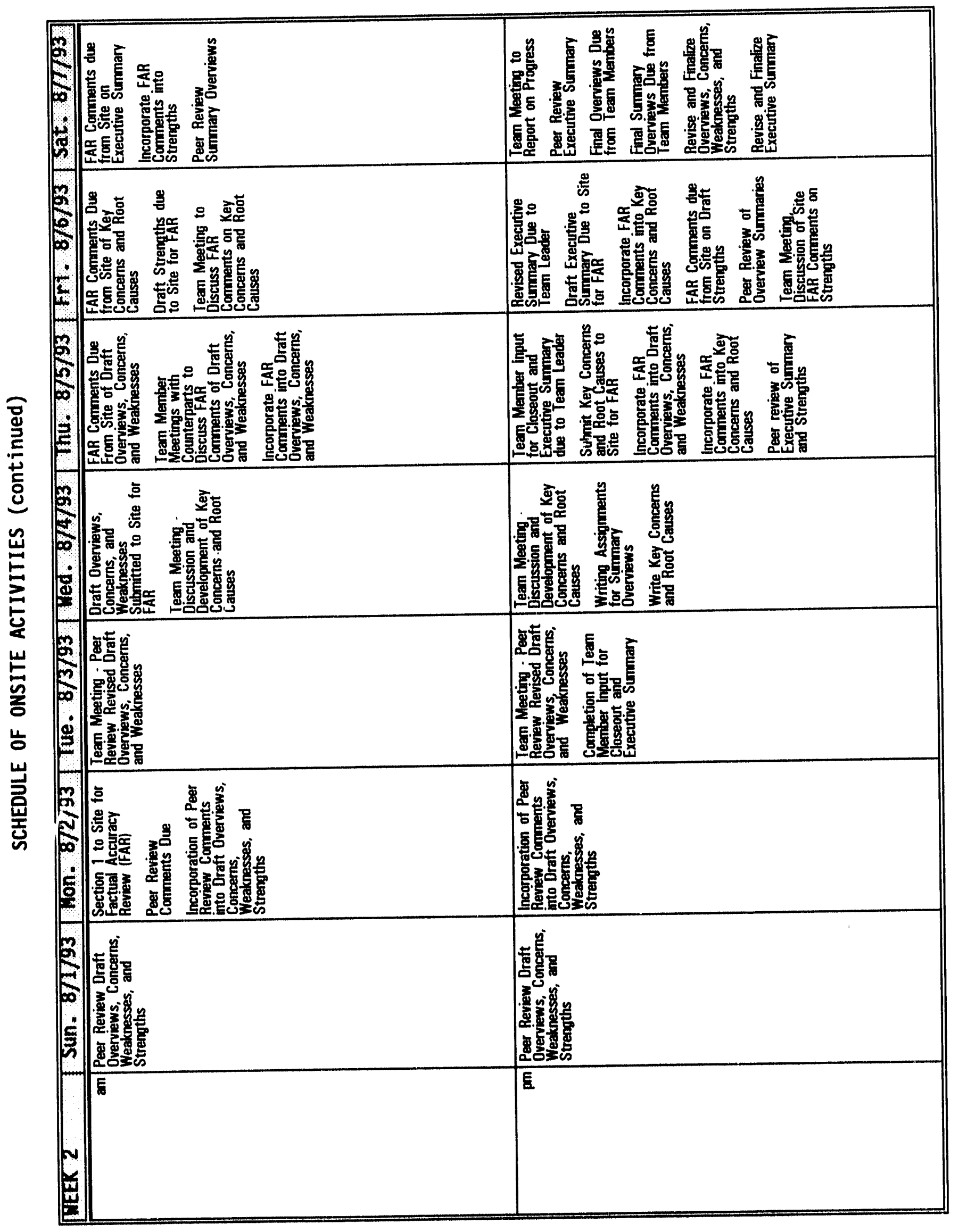




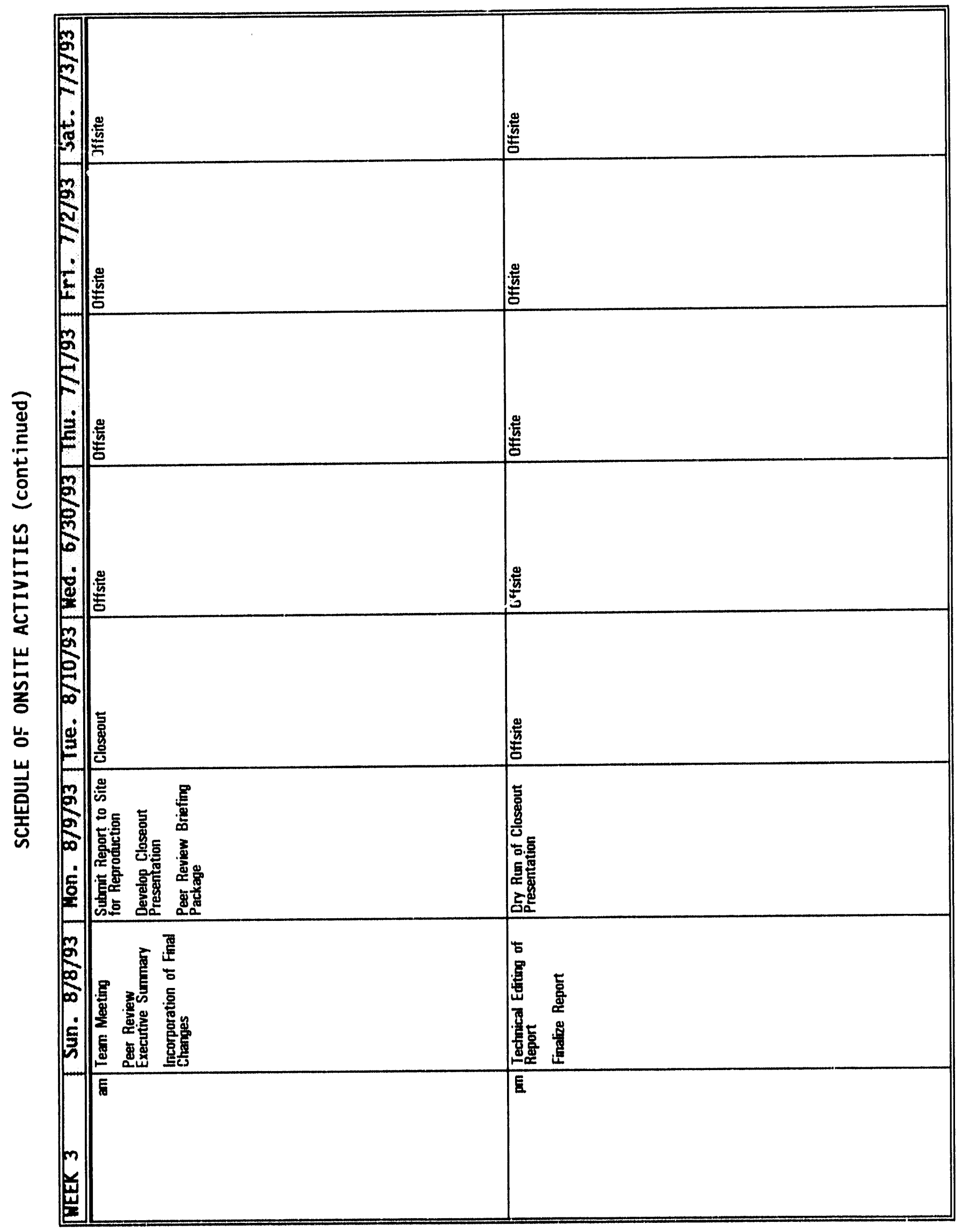

E-16 
Appendix $F$

List of Contacts and Interviews

Conducted by the Progress Assessment Team 


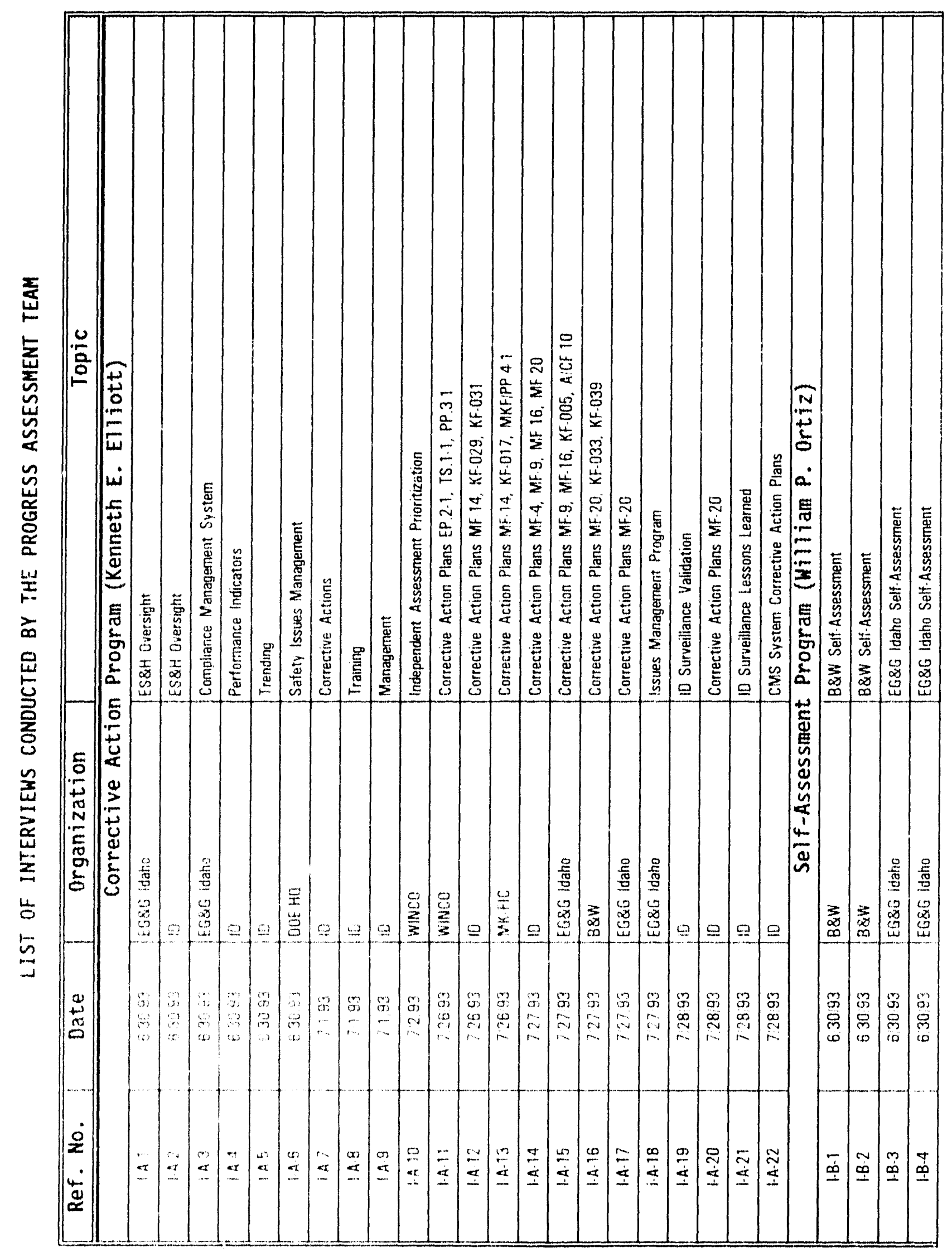




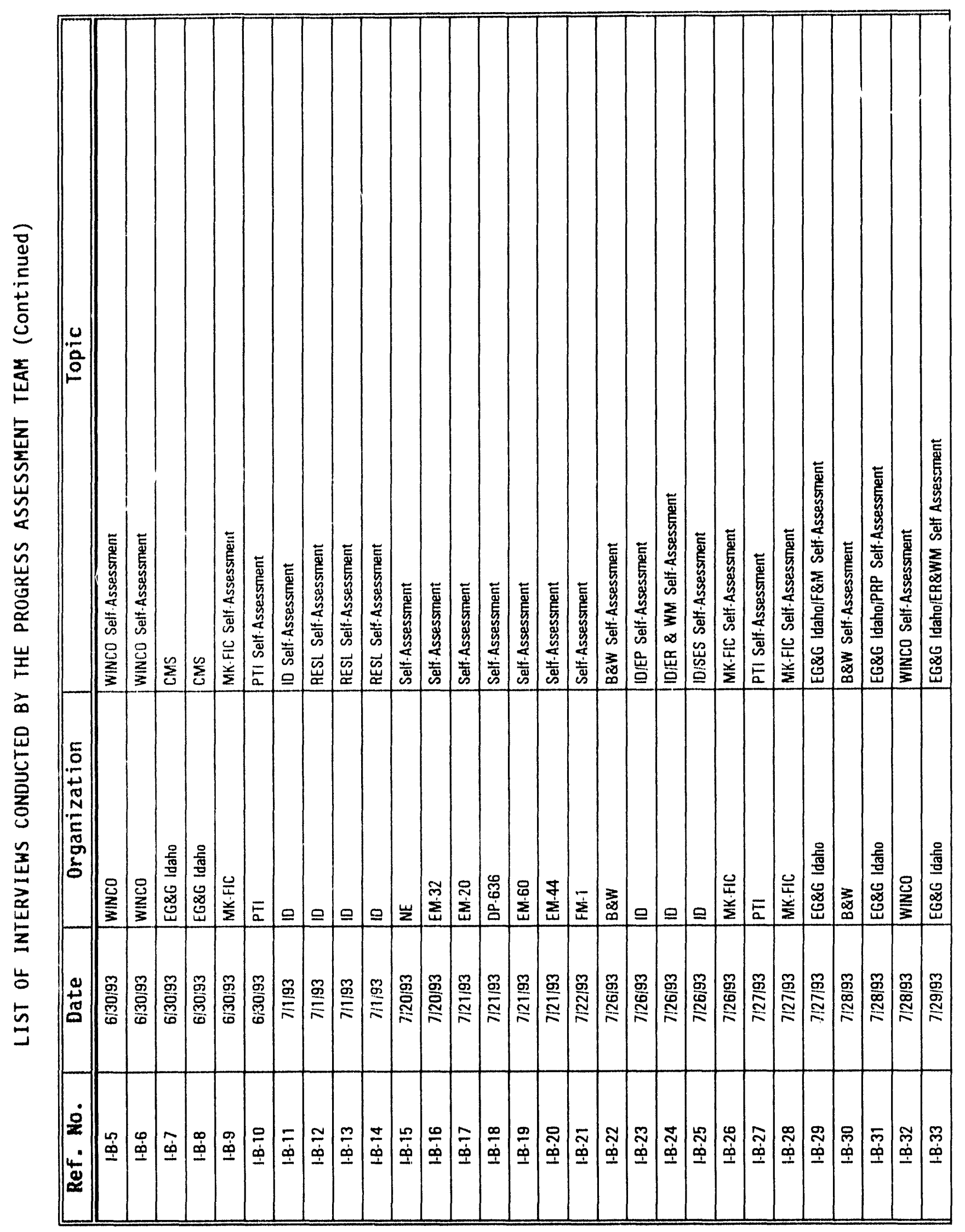




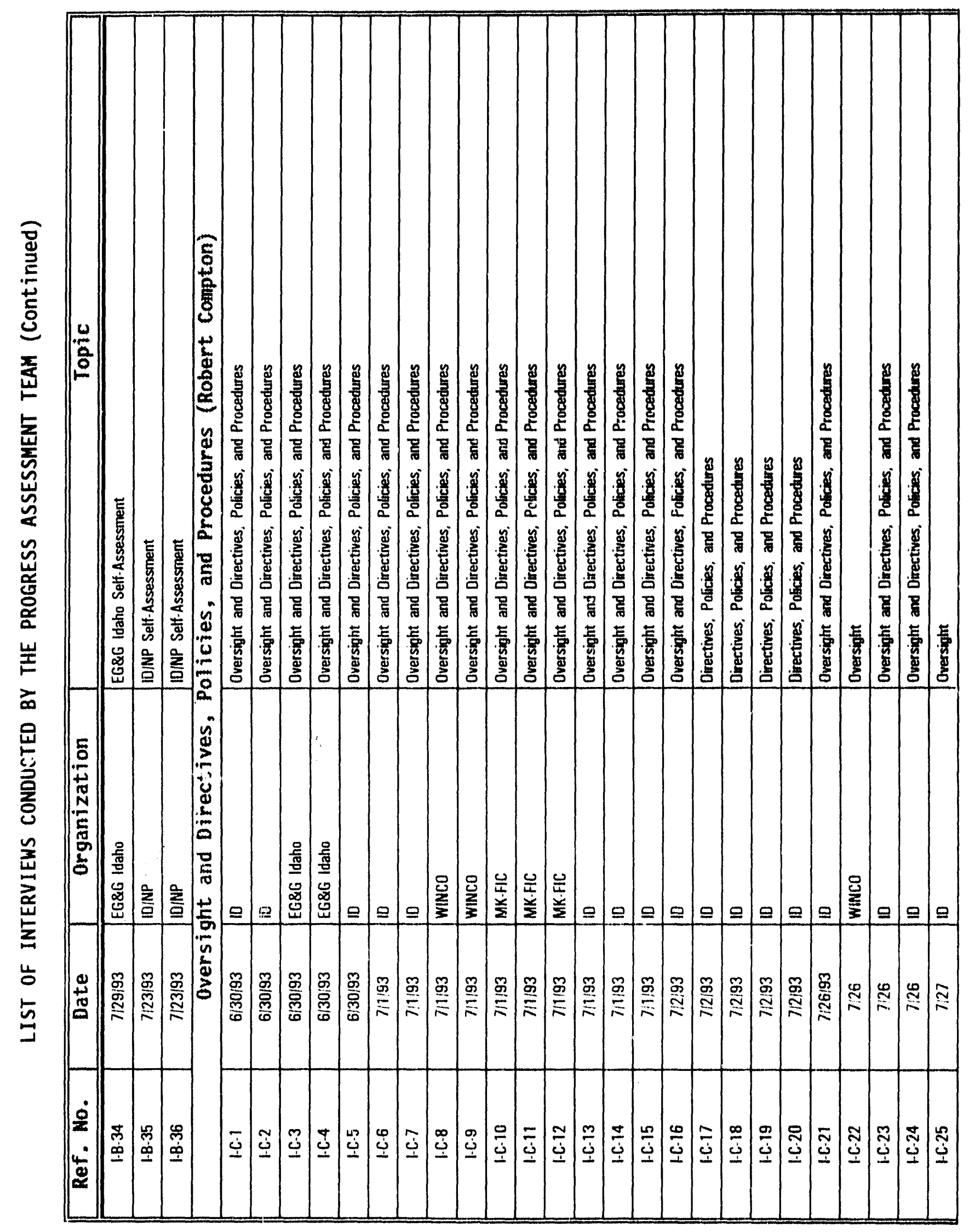




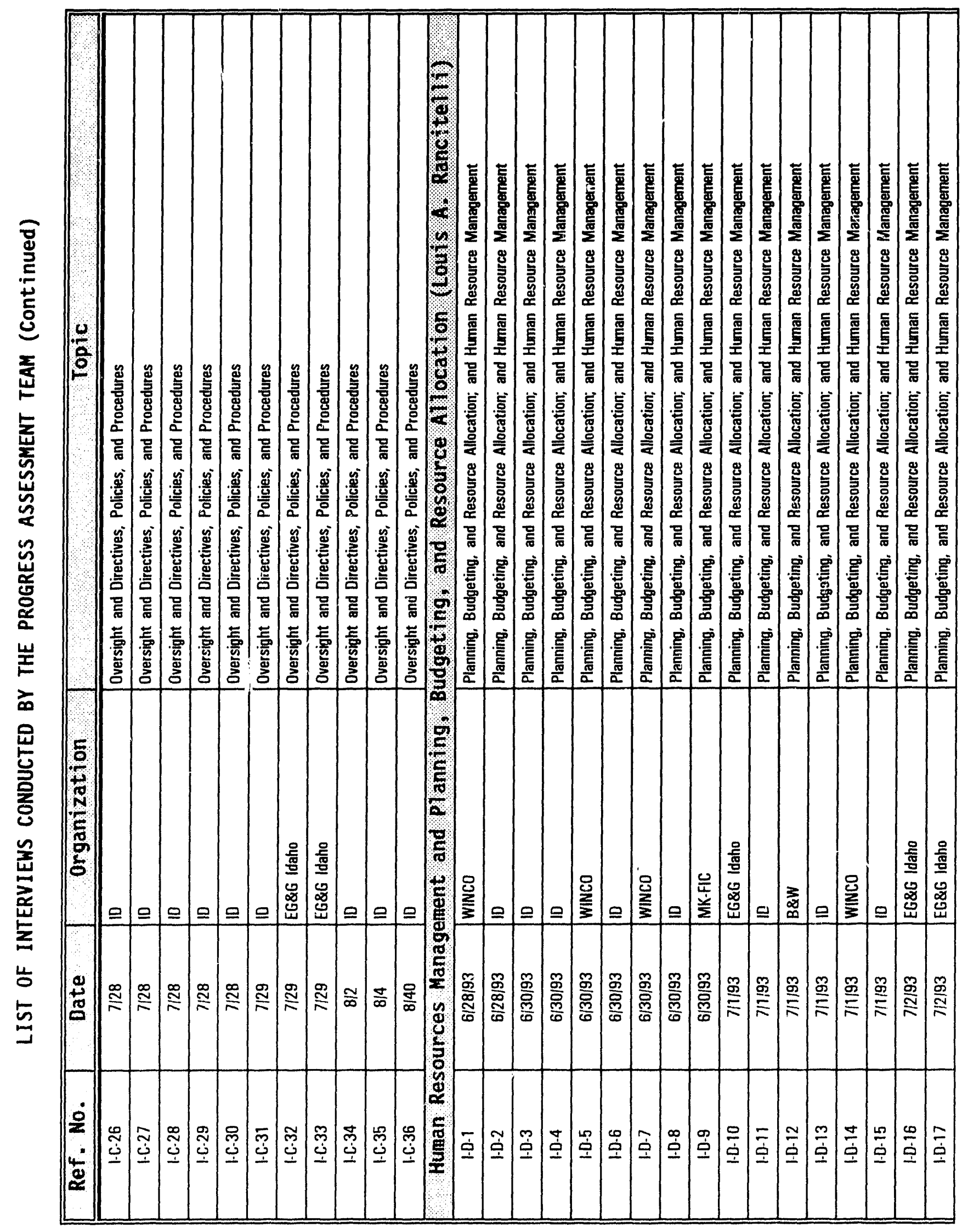




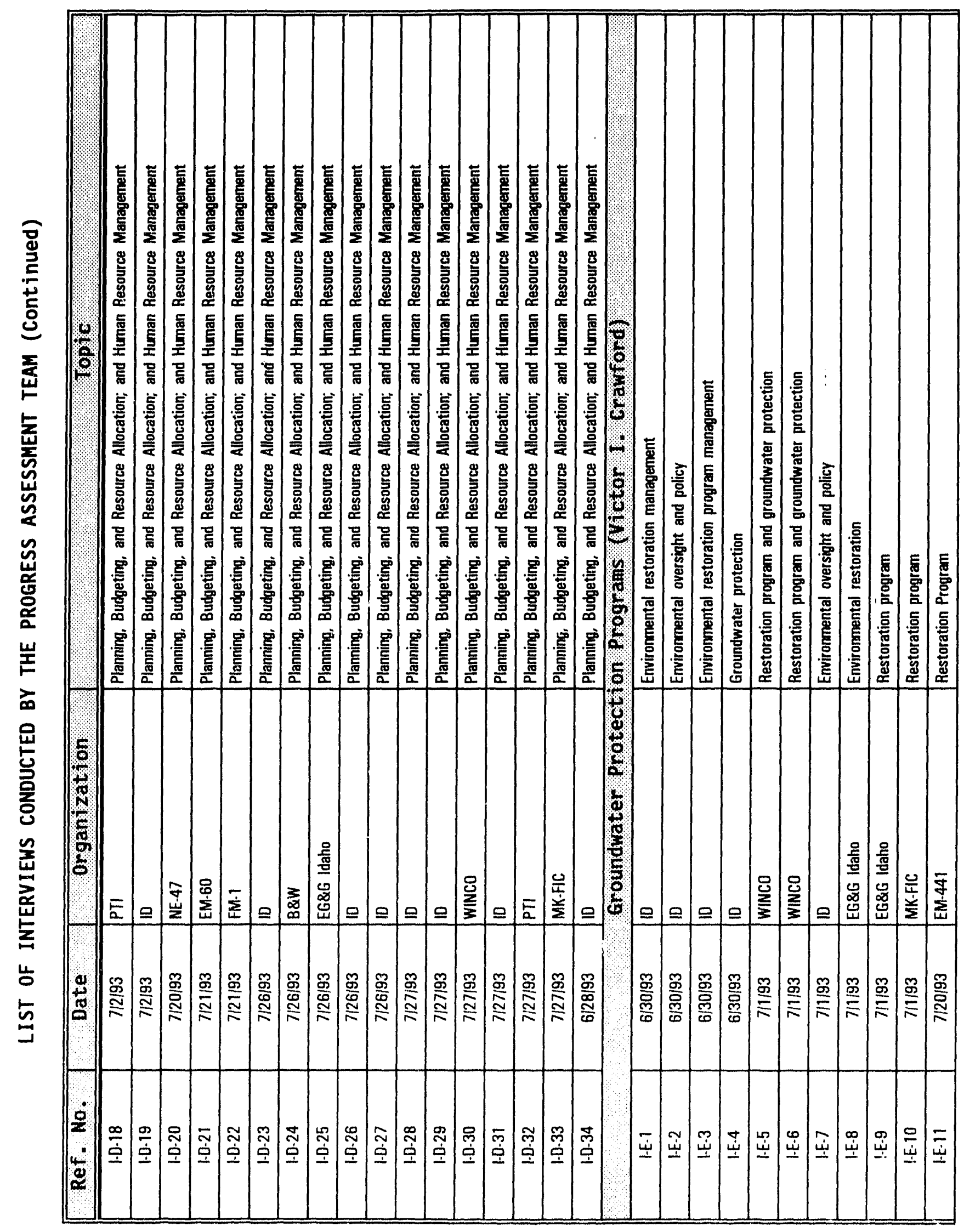




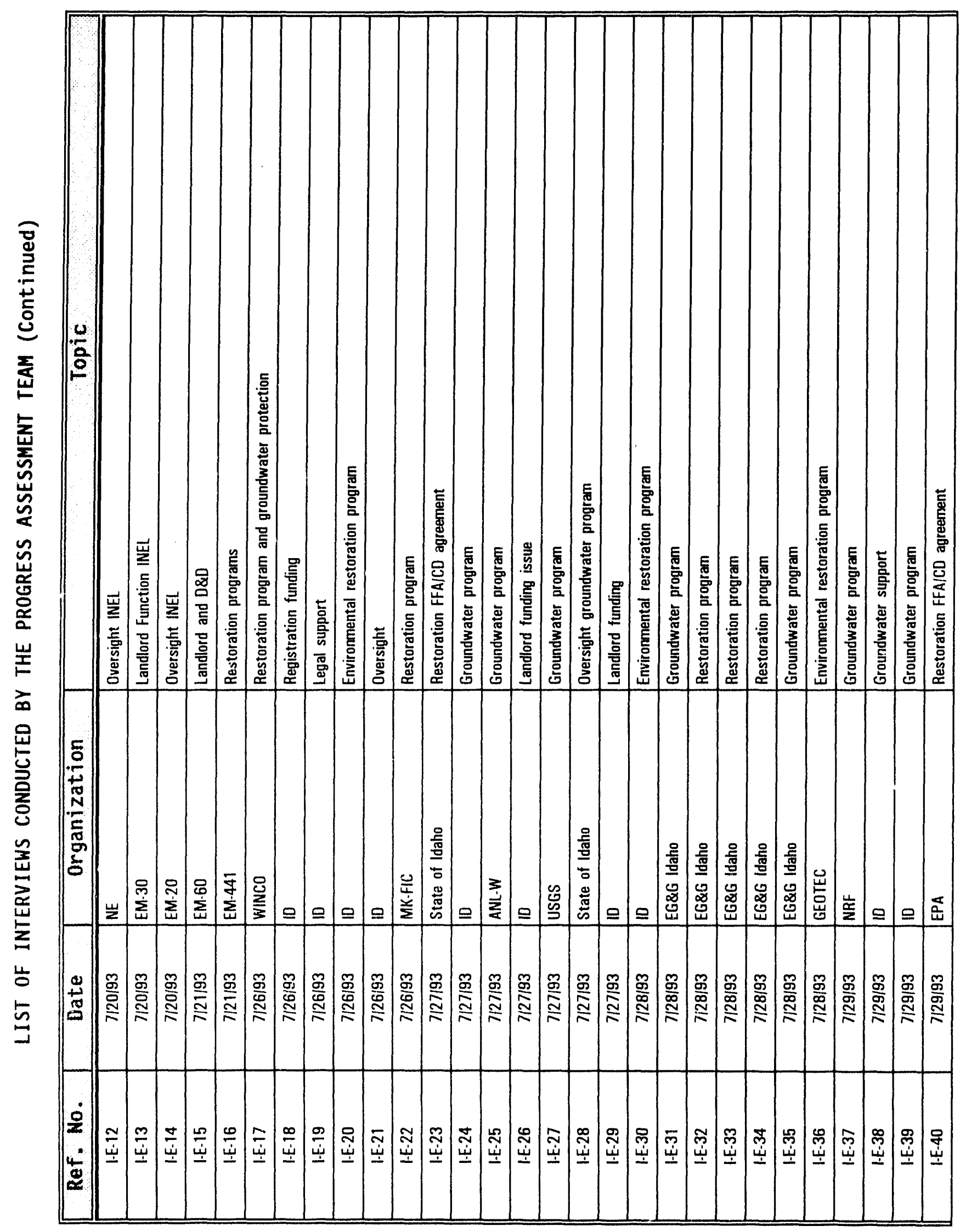




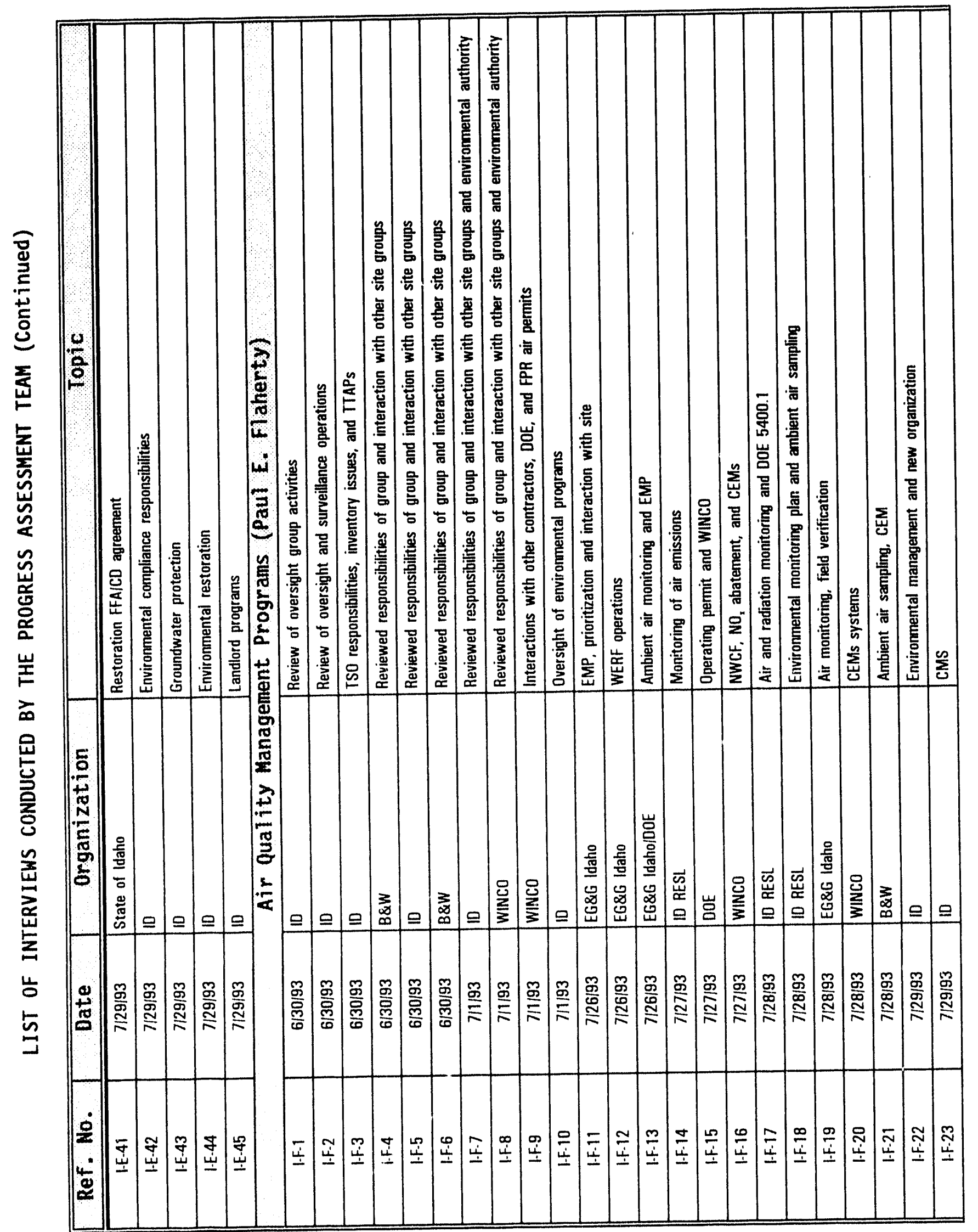




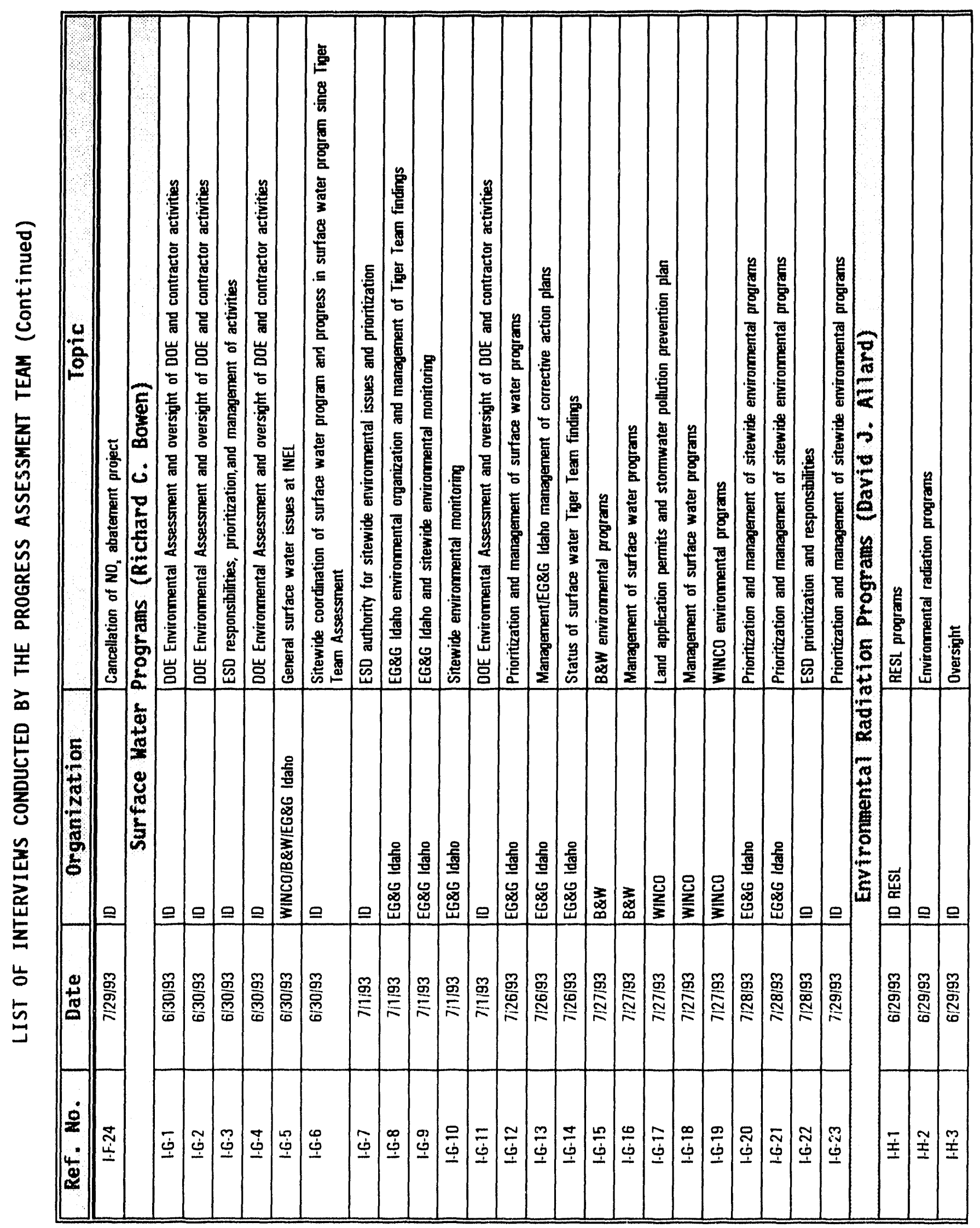




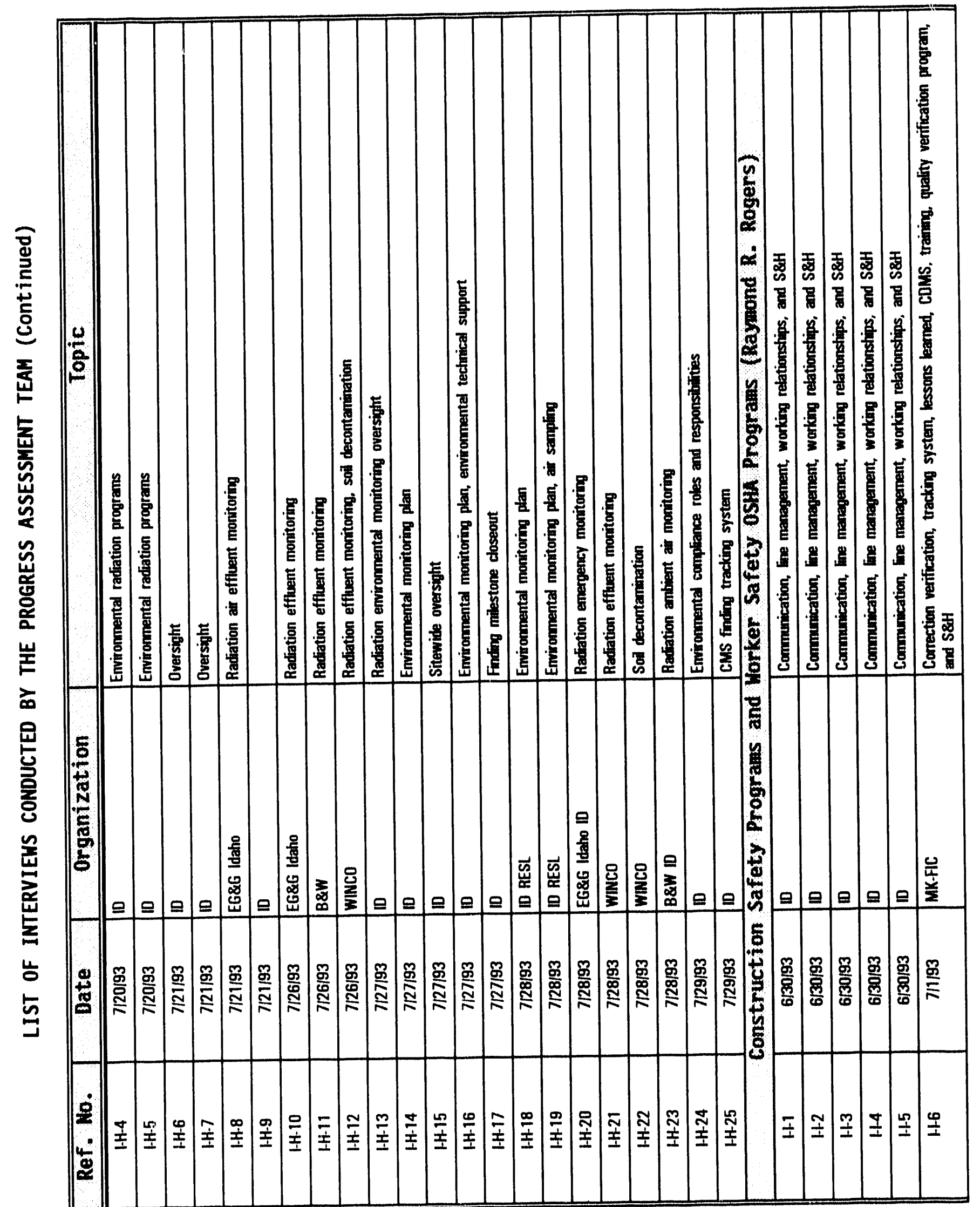









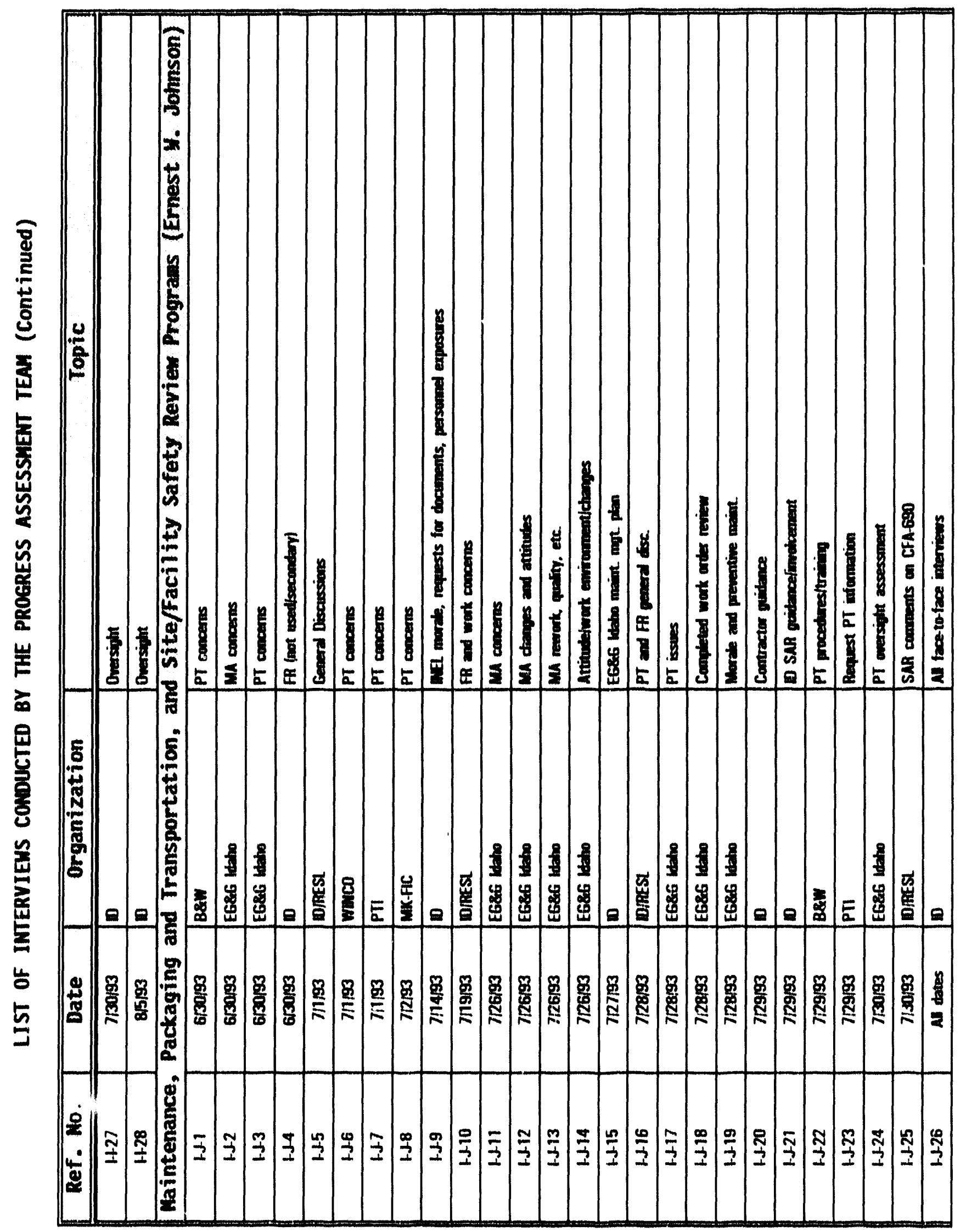




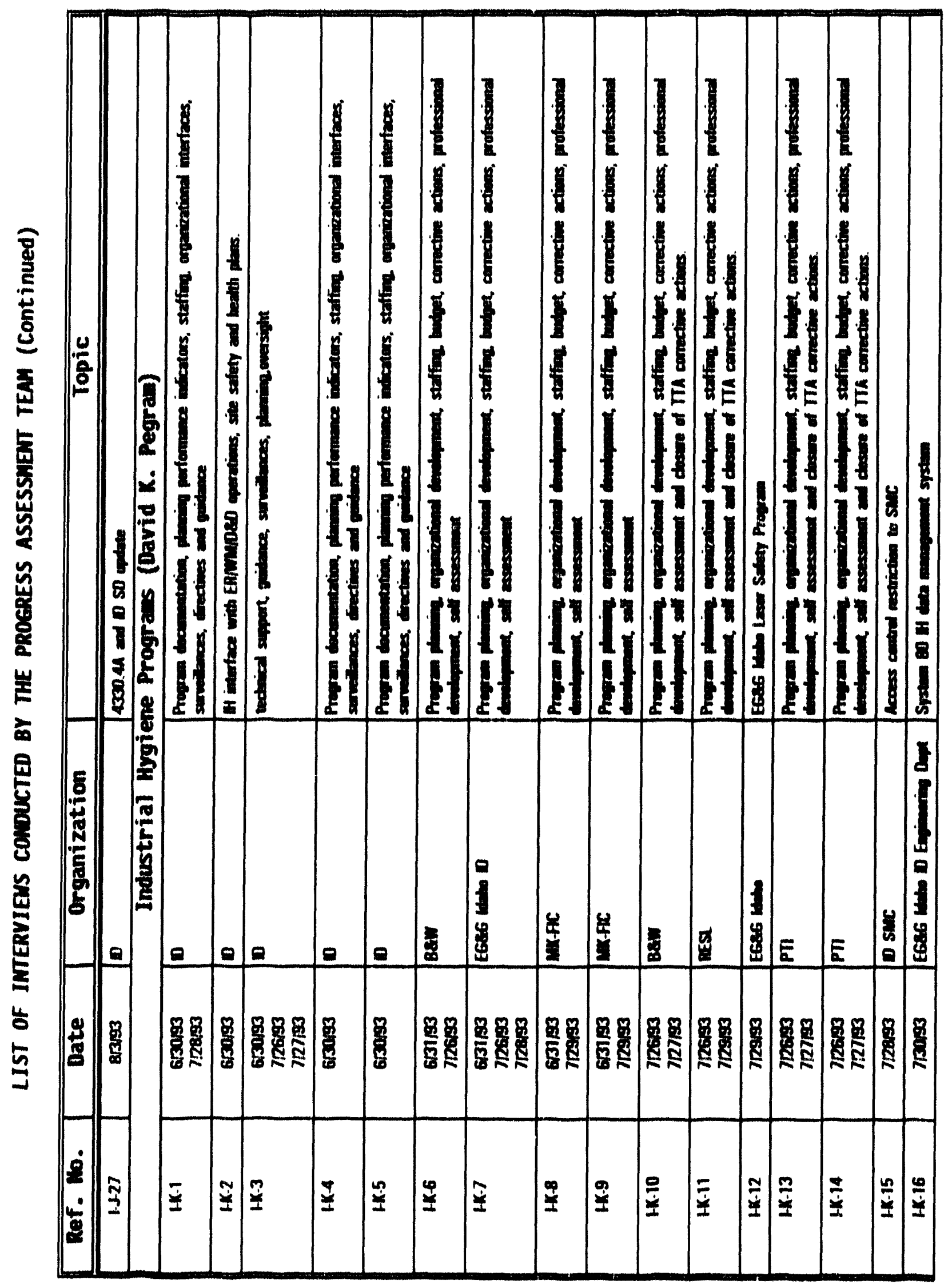




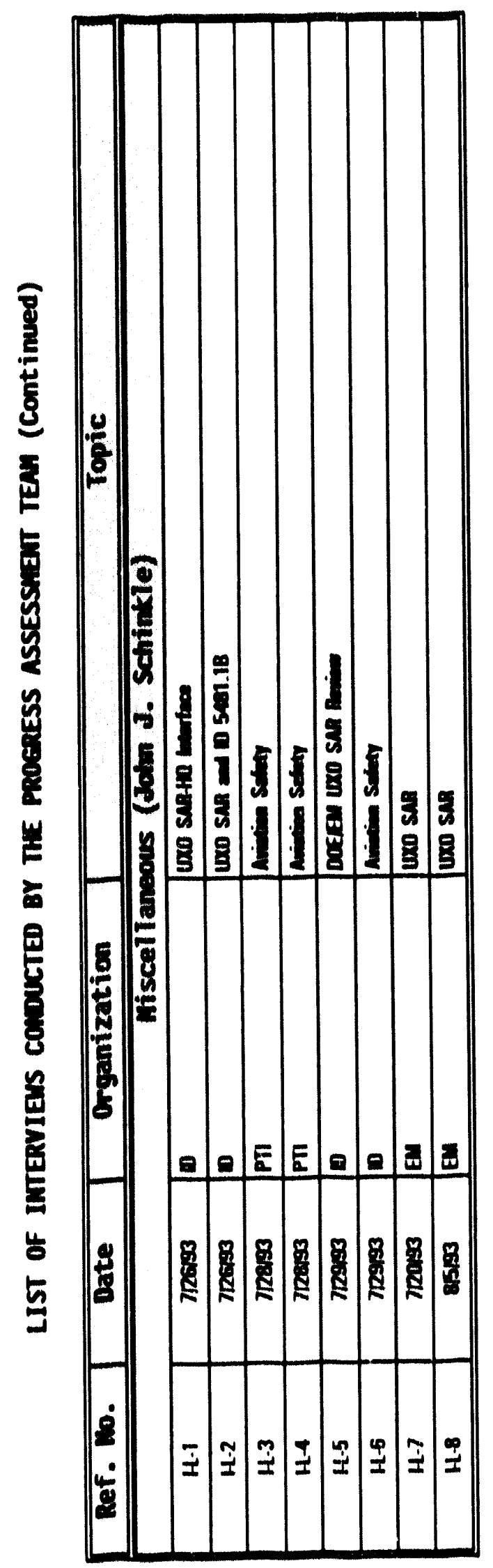


Thlo page Lntontlonally loft blank.

F-14 
Appondix G

\section{List of Site Documents Reviewed by the Progress Assessment Team}




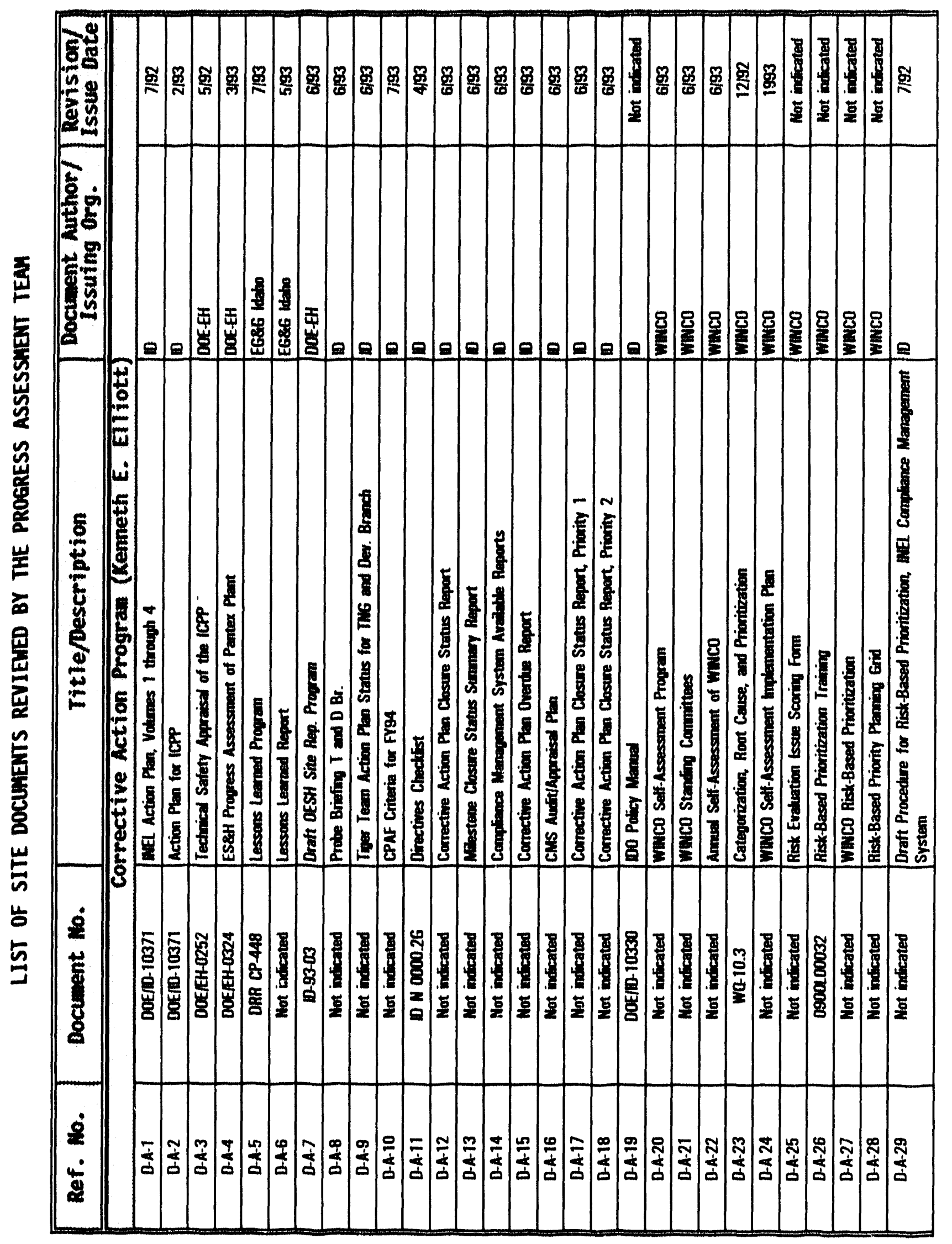




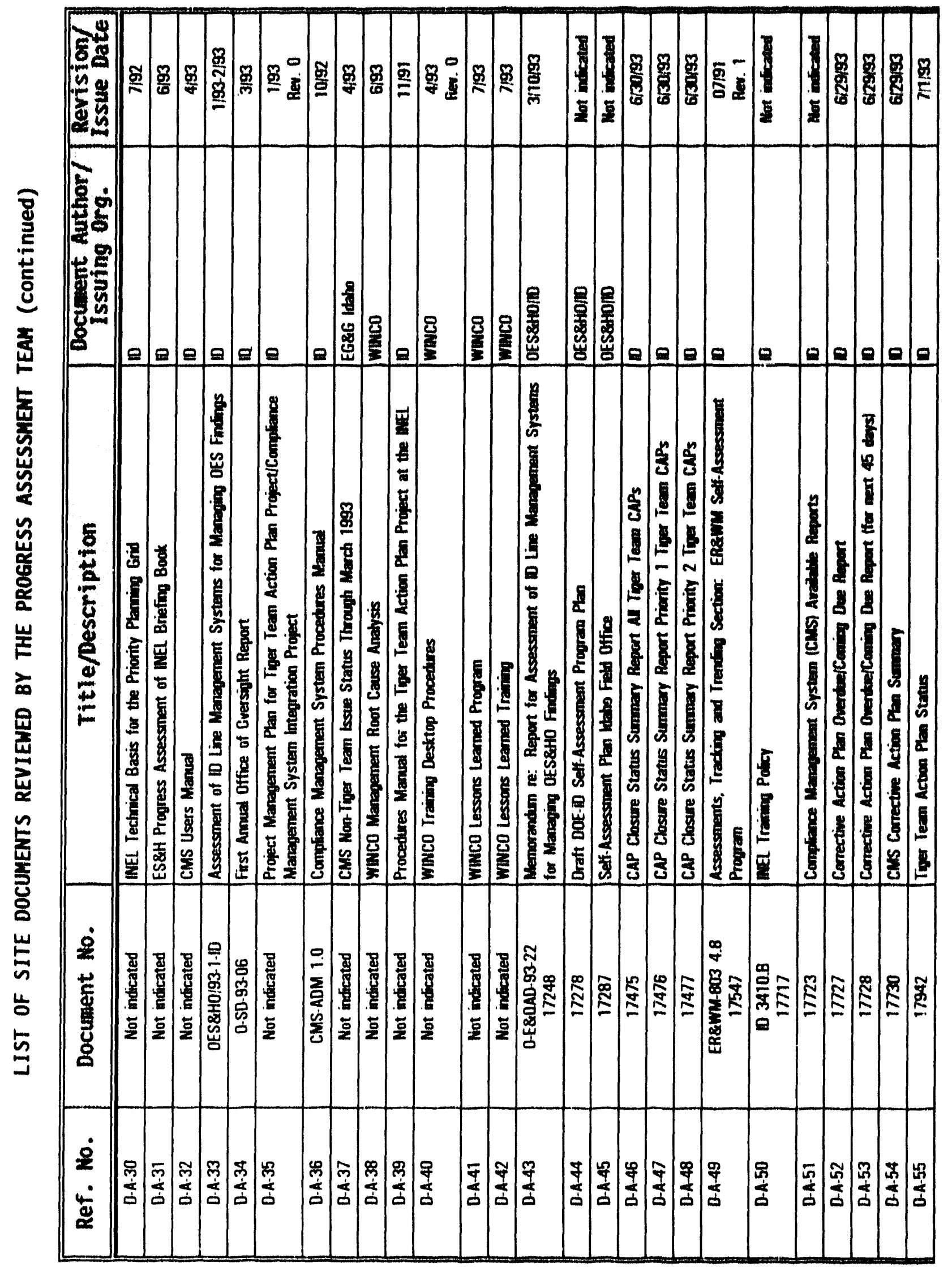




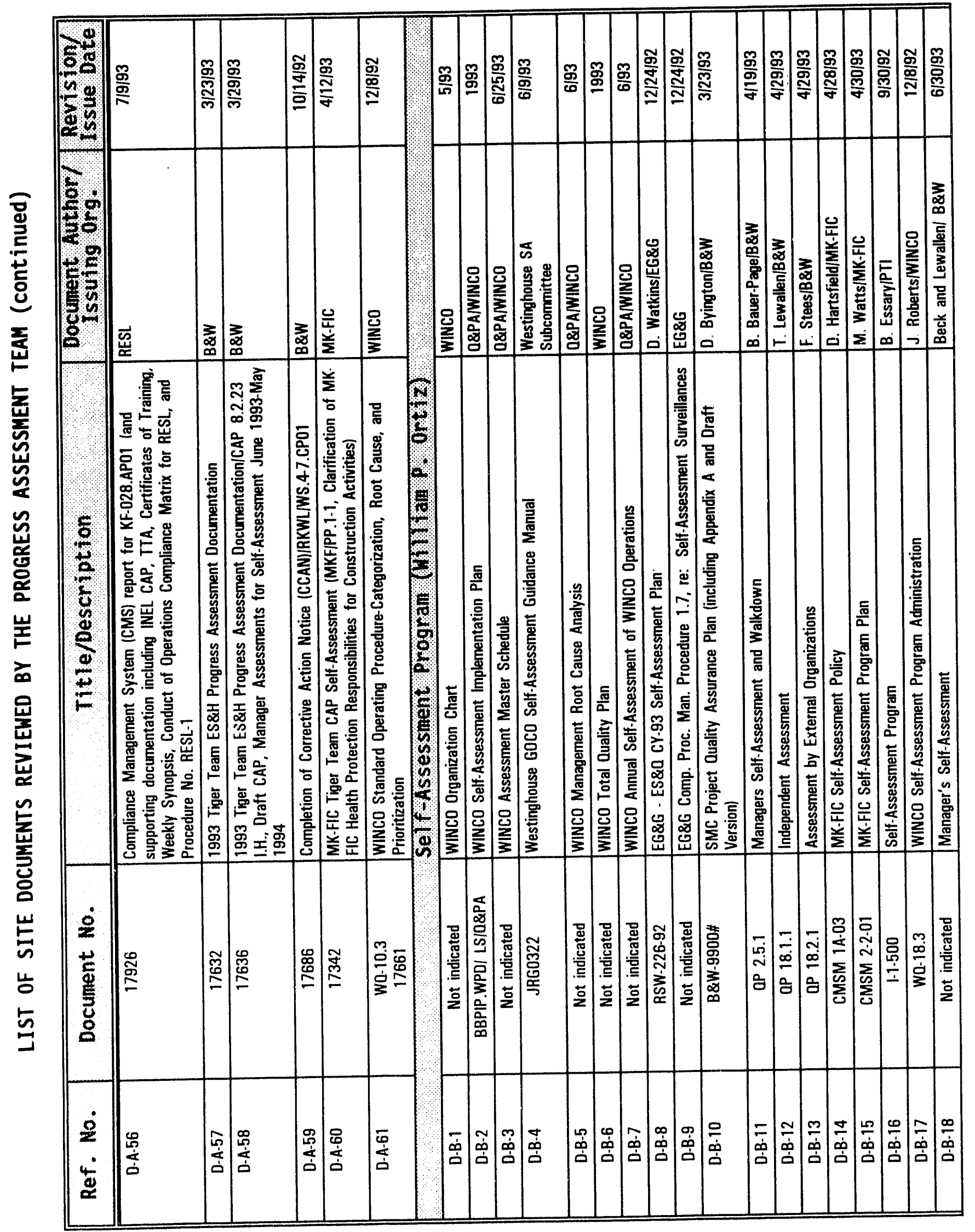




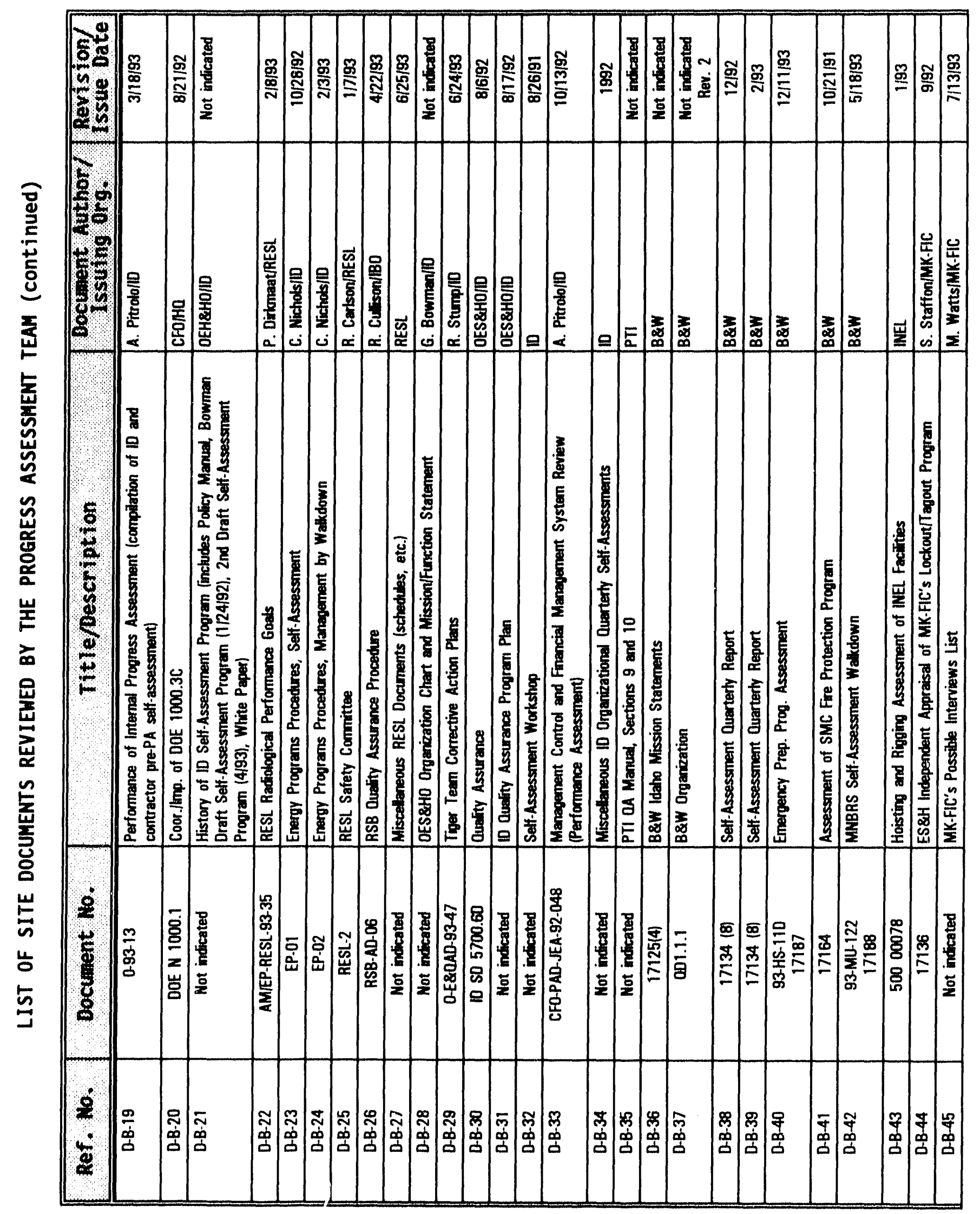




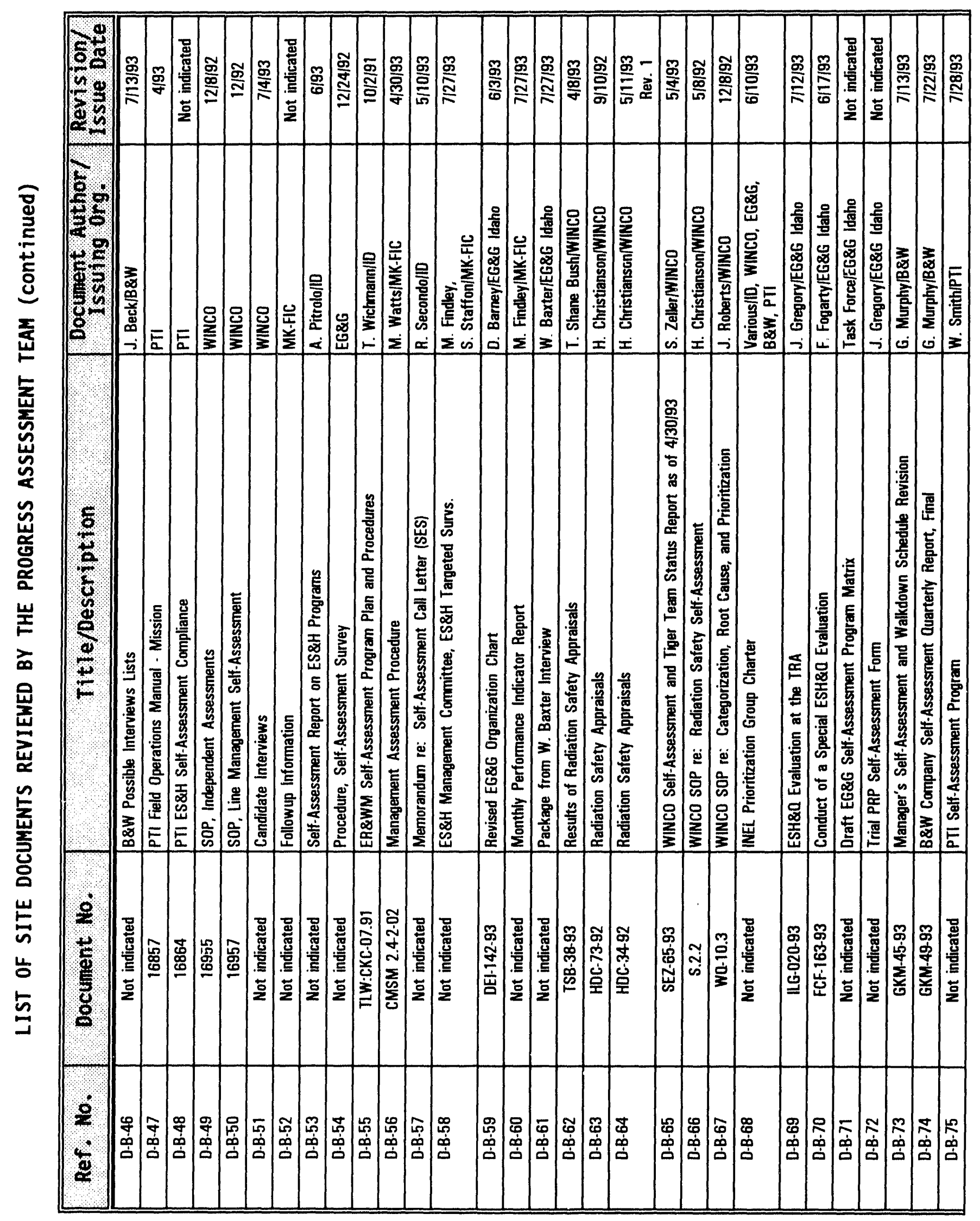




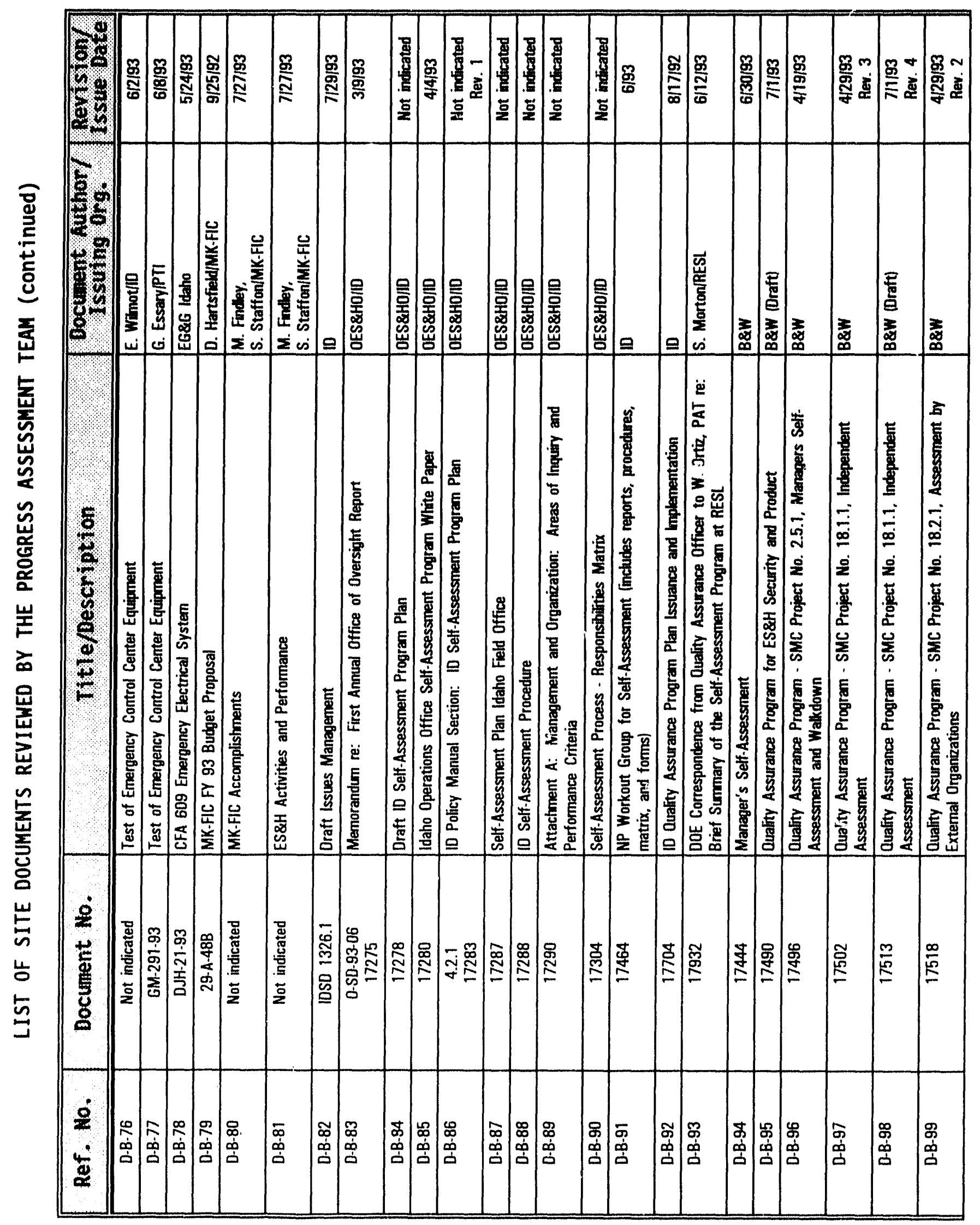




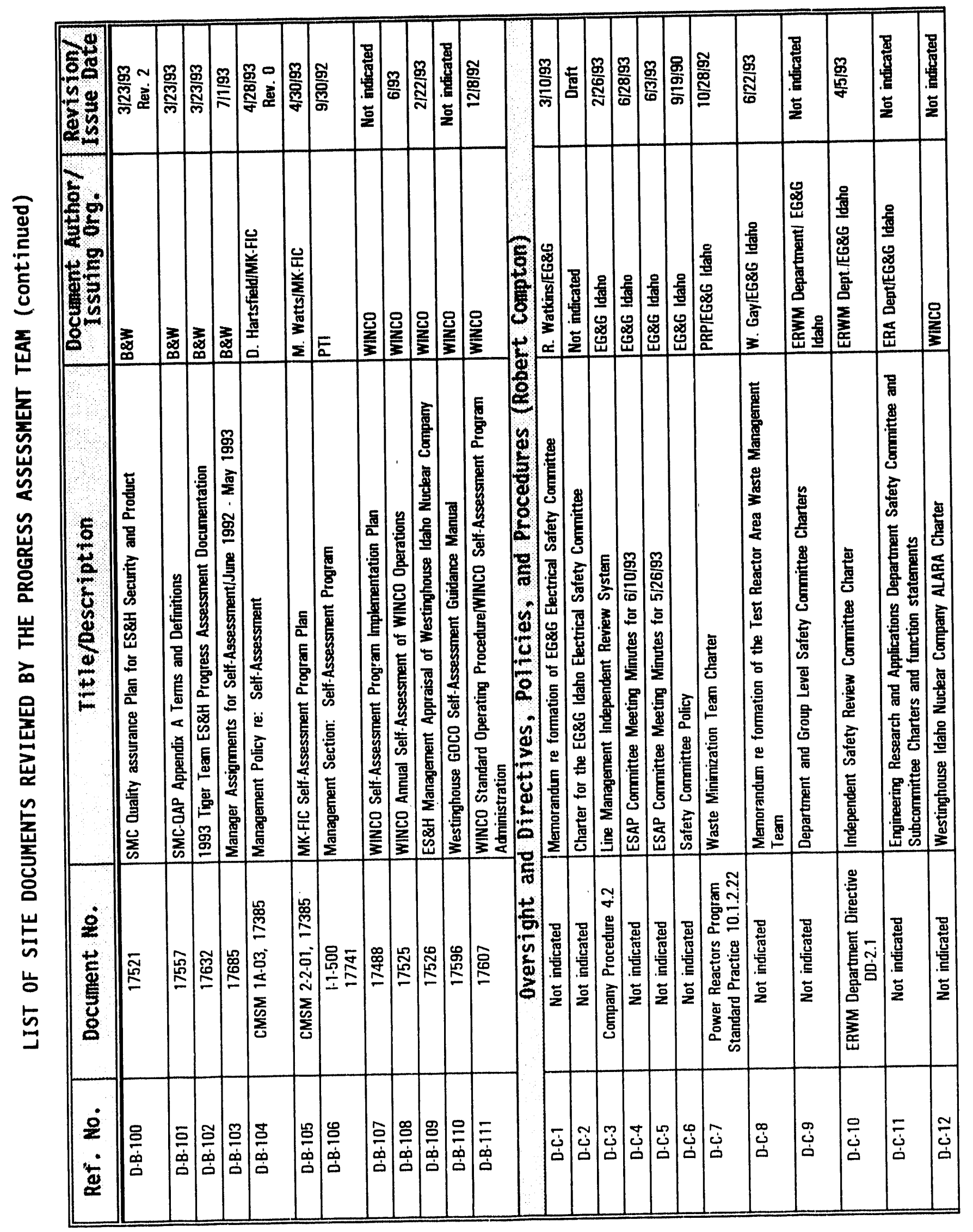




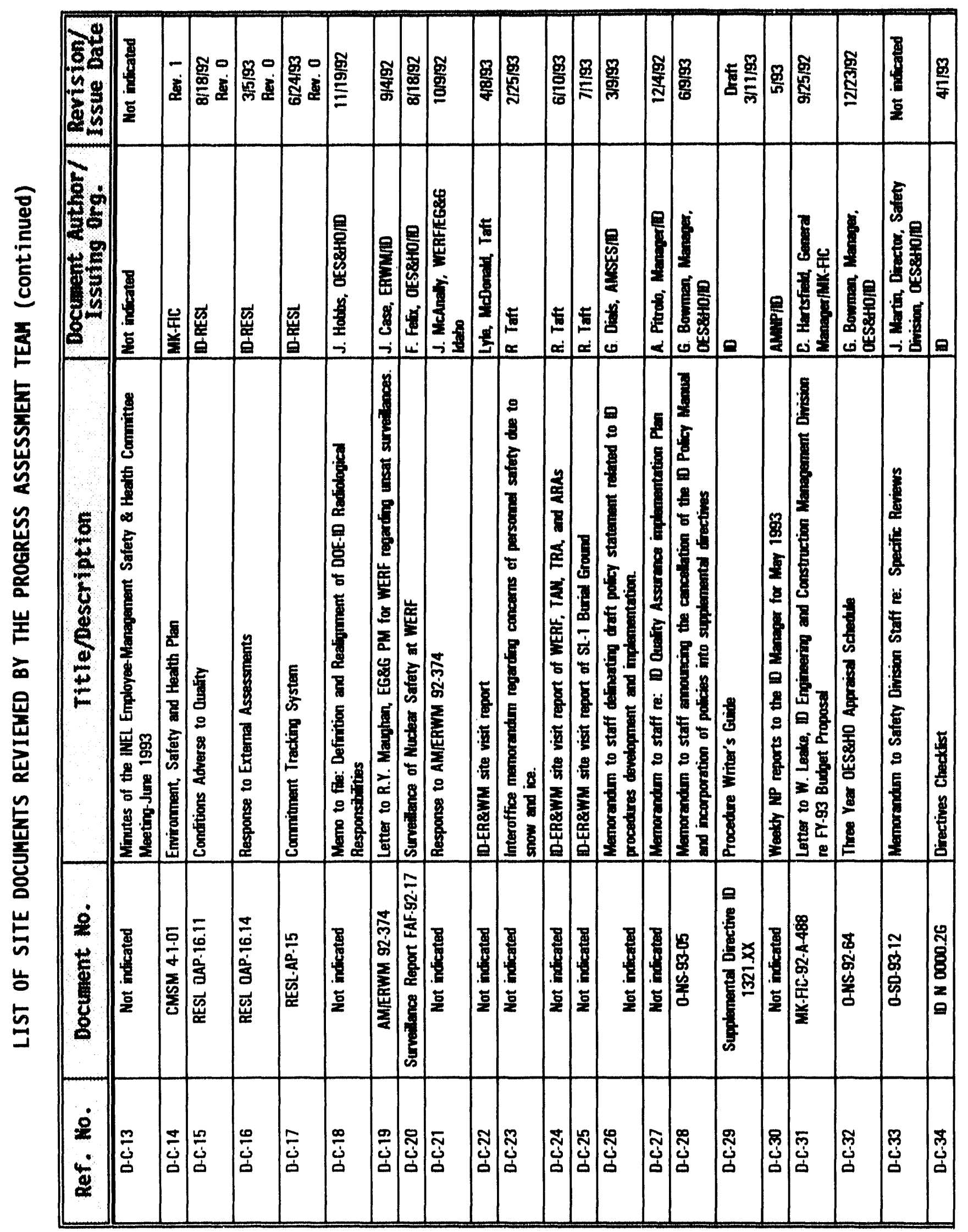




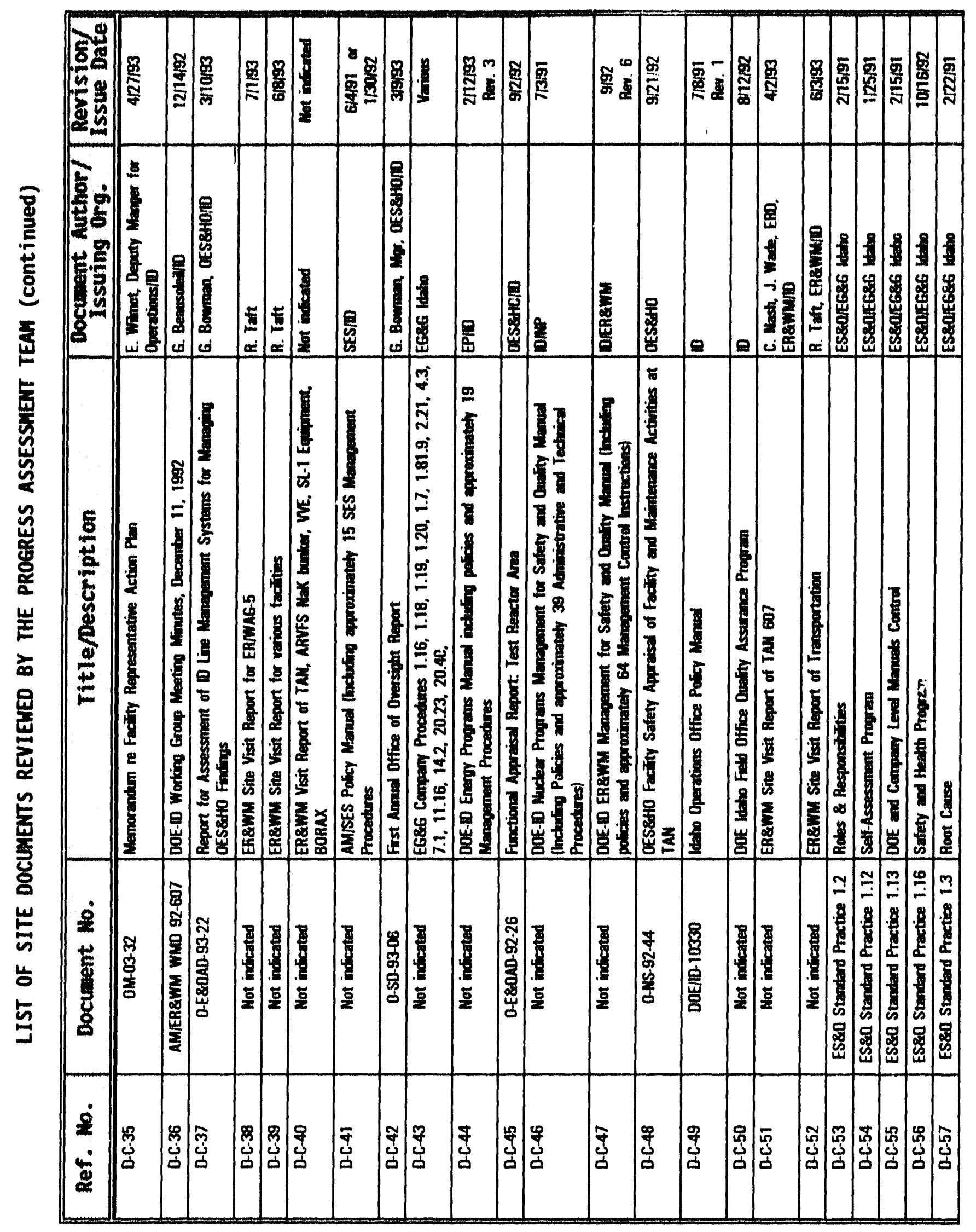




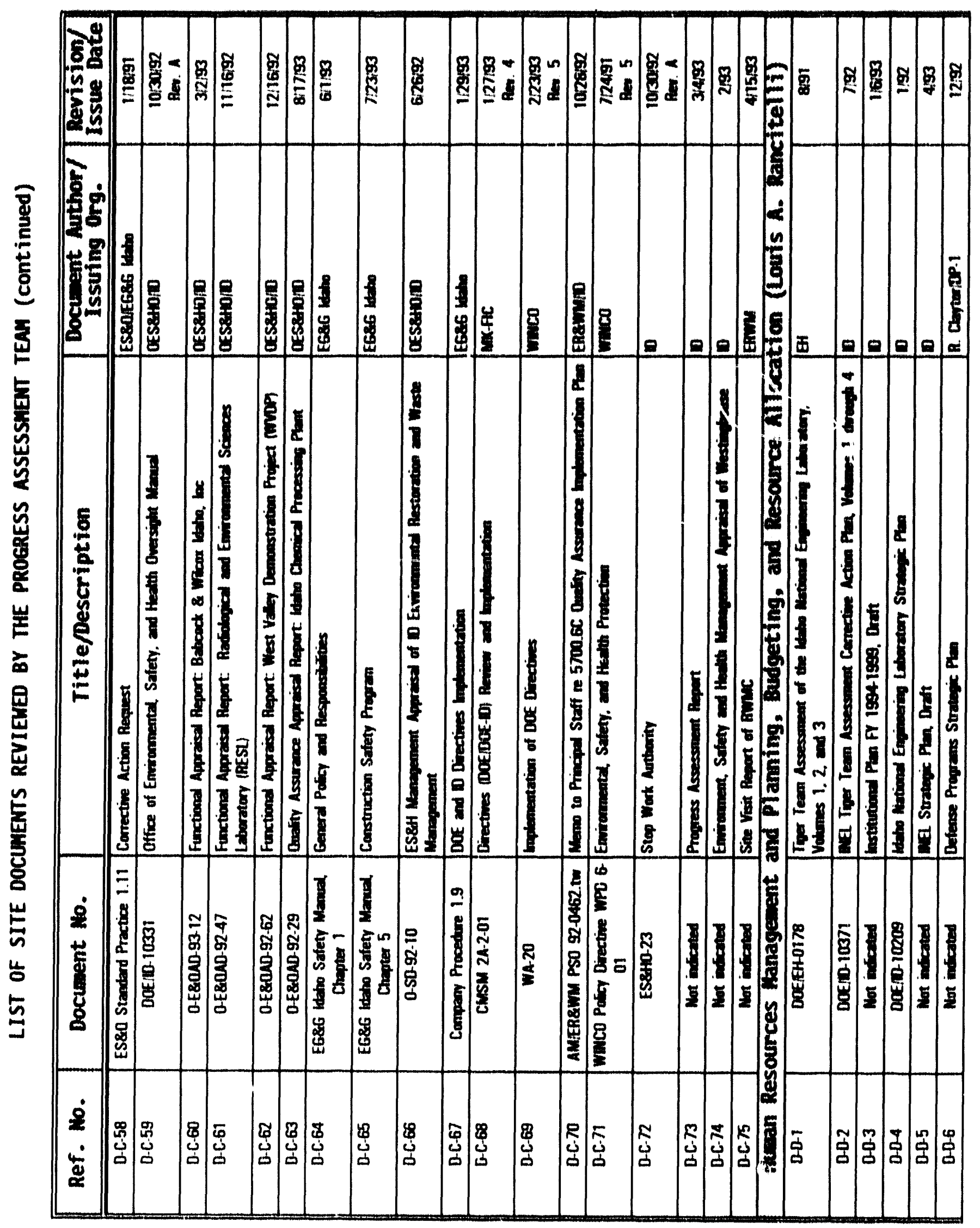




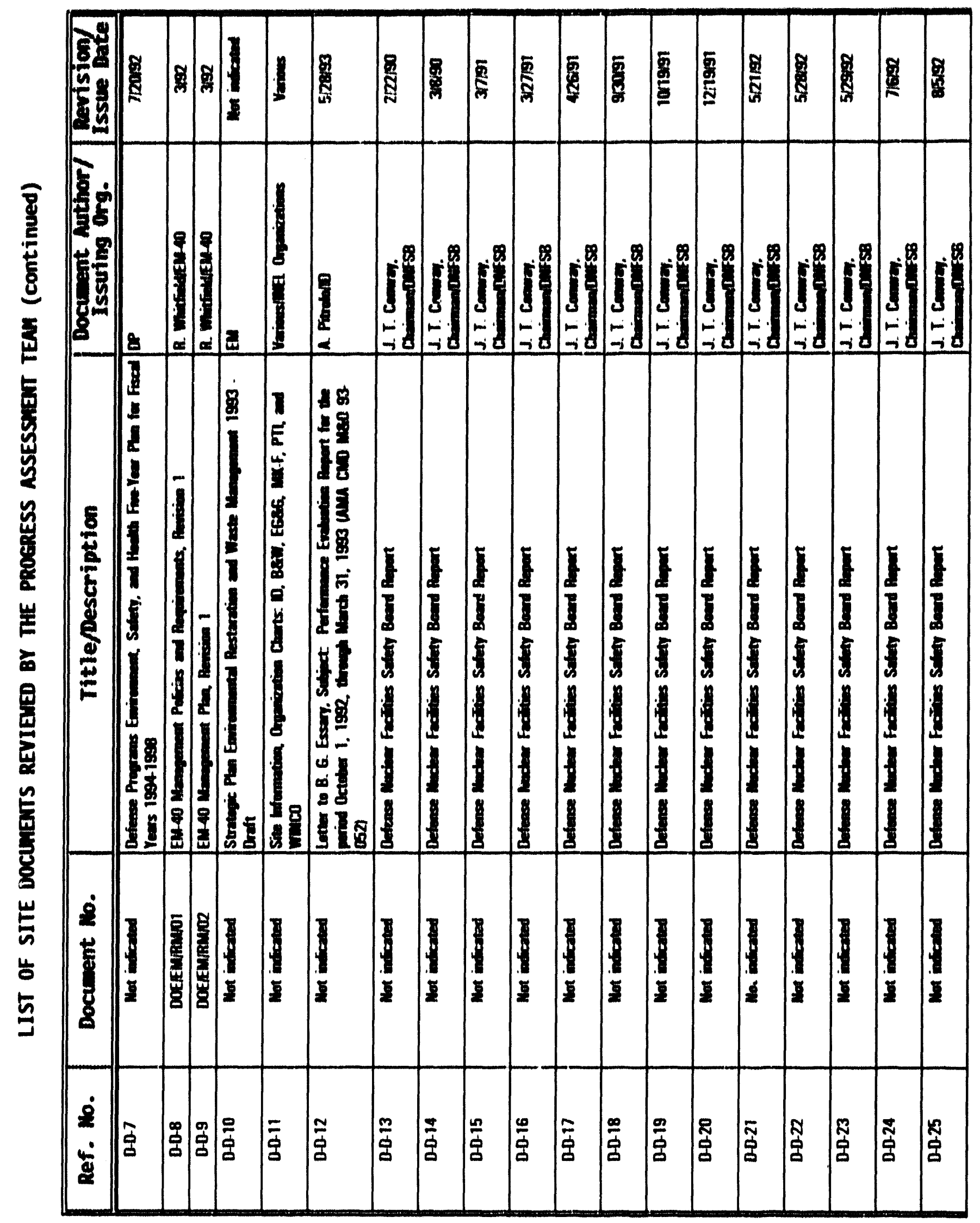




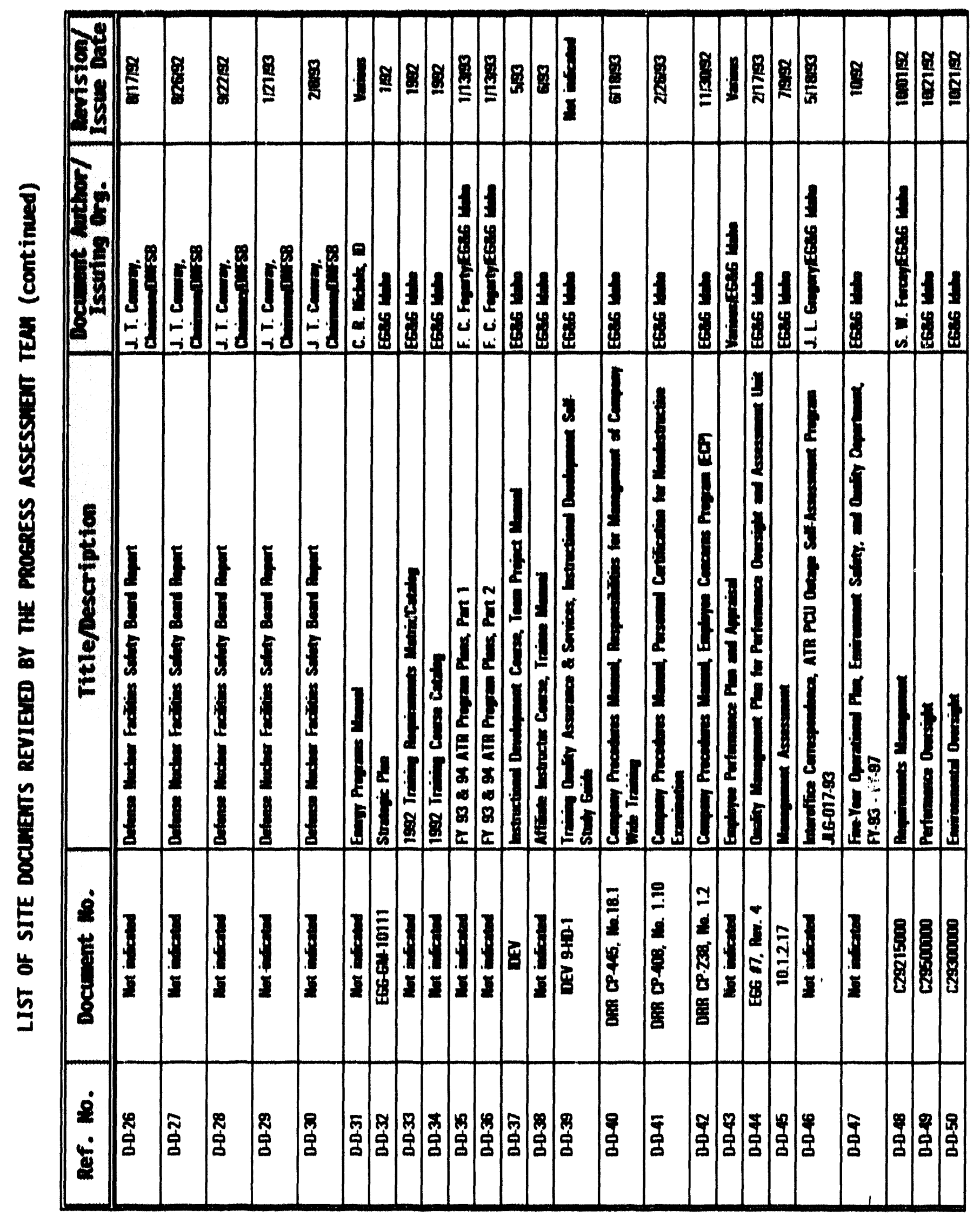




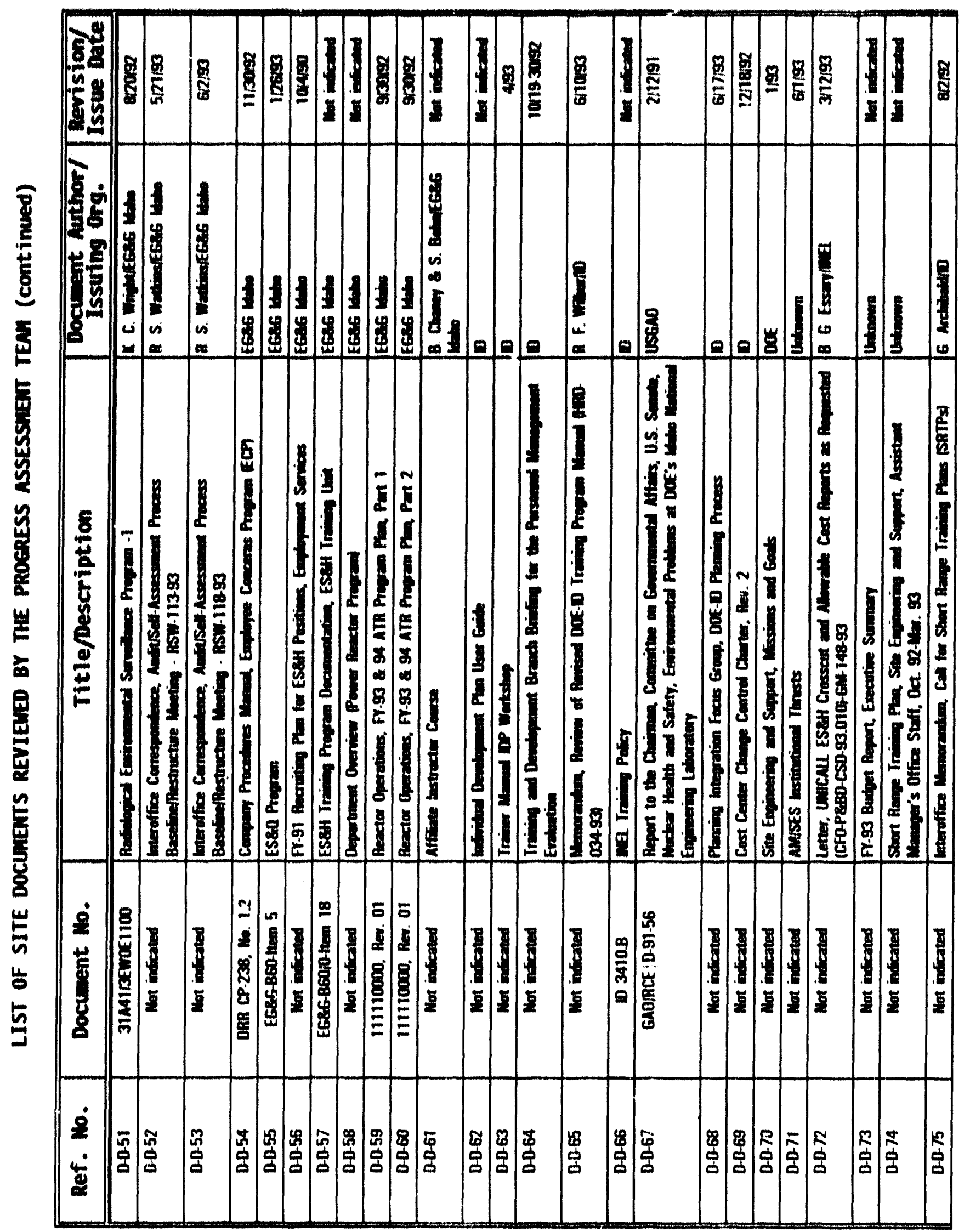




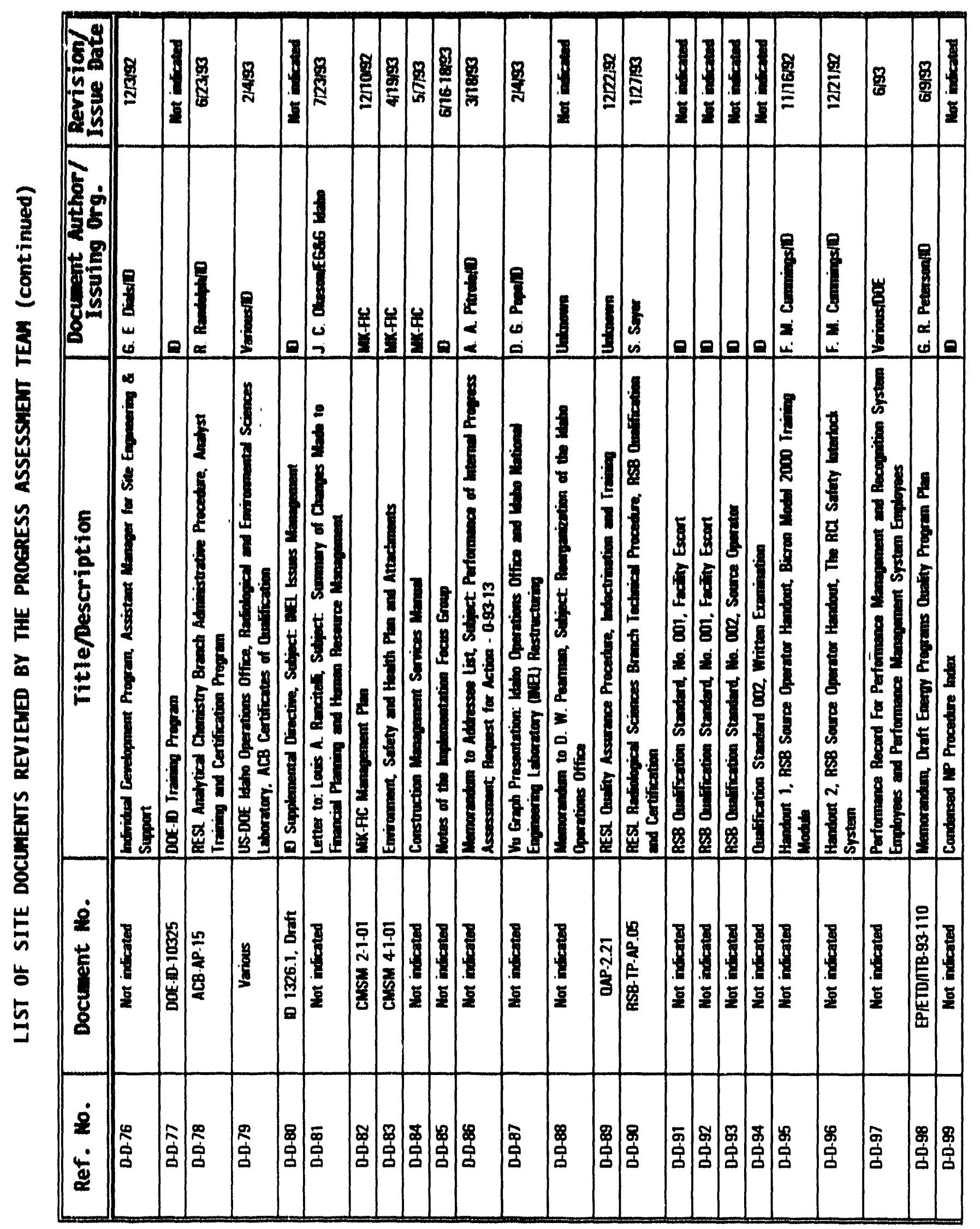




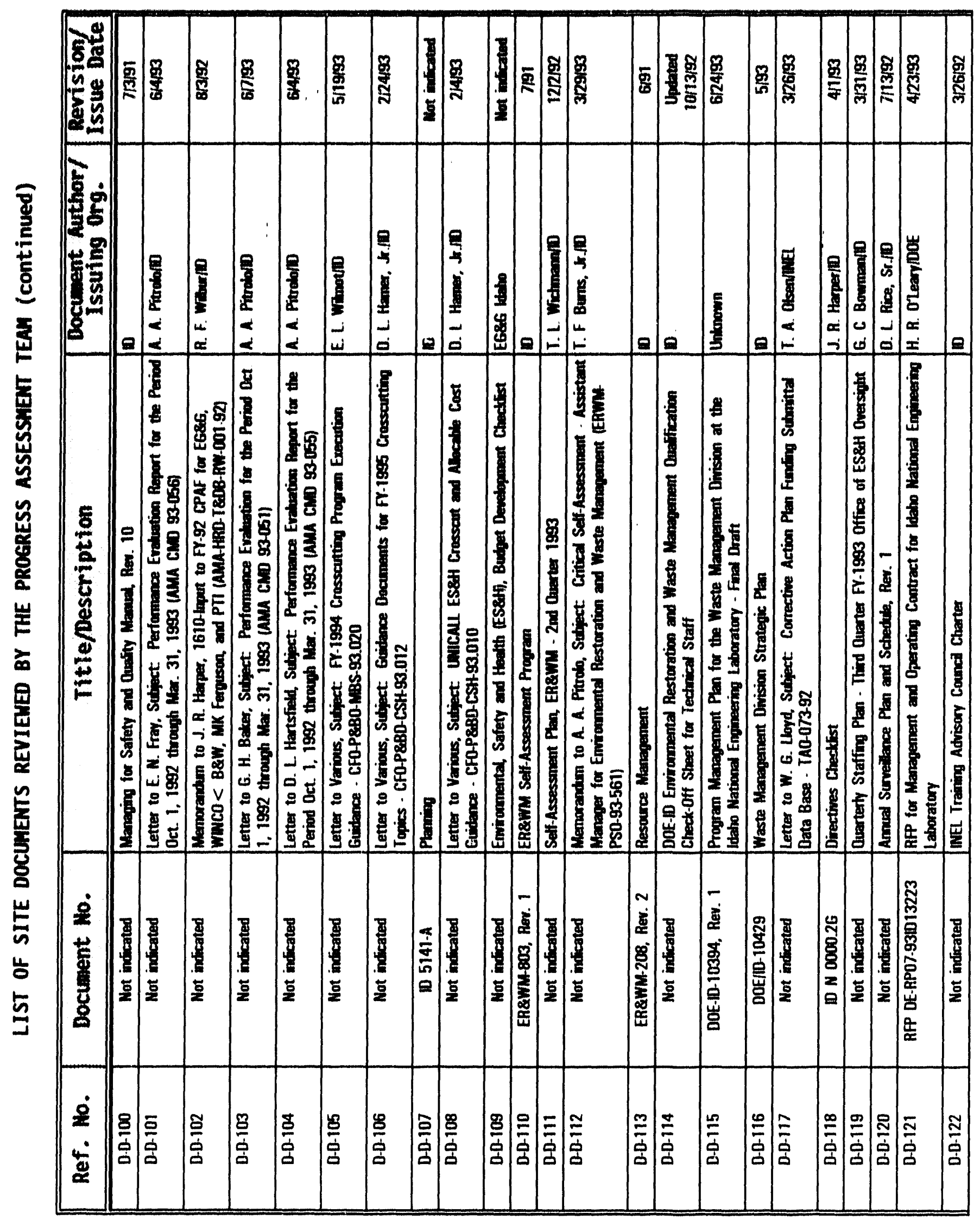




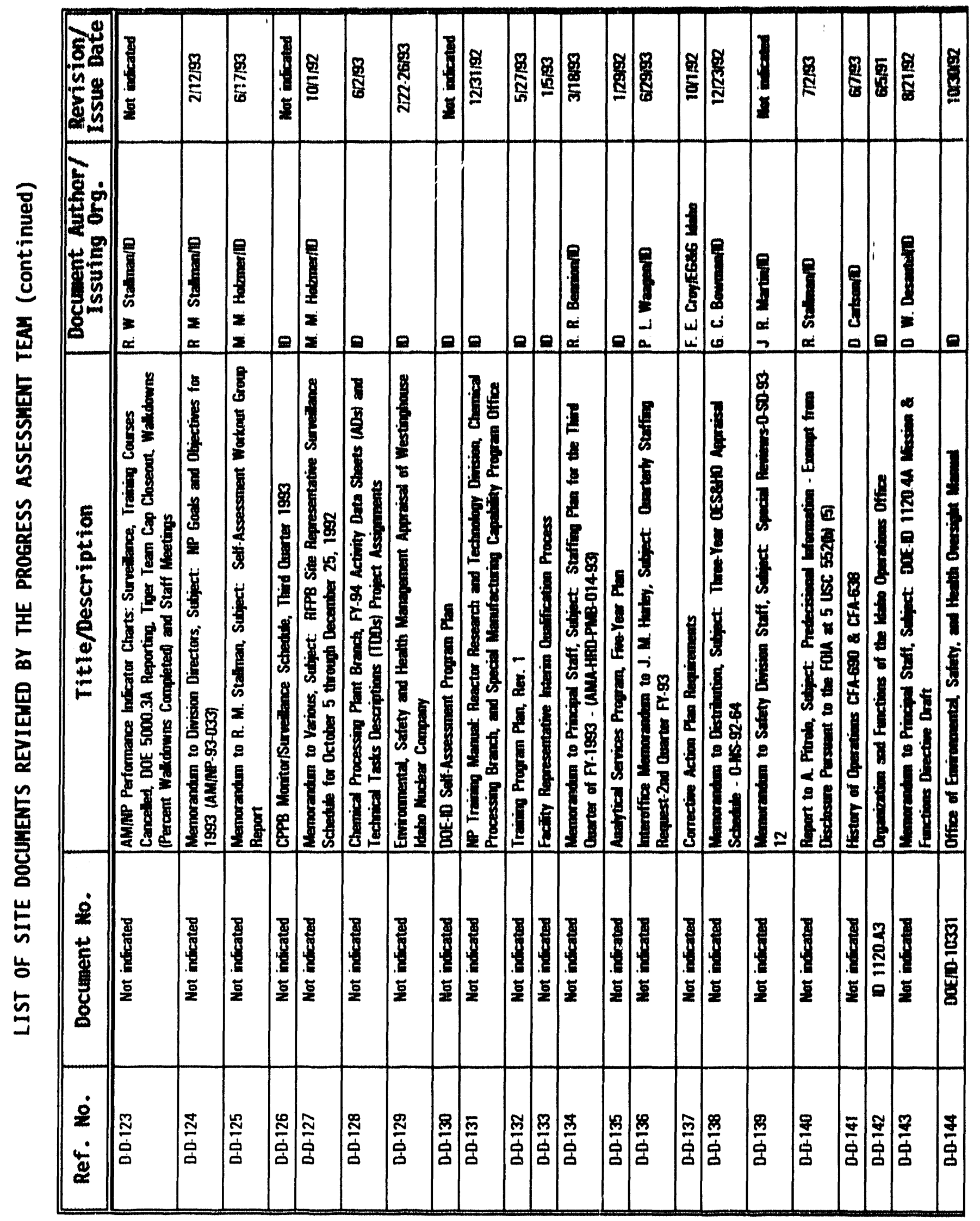




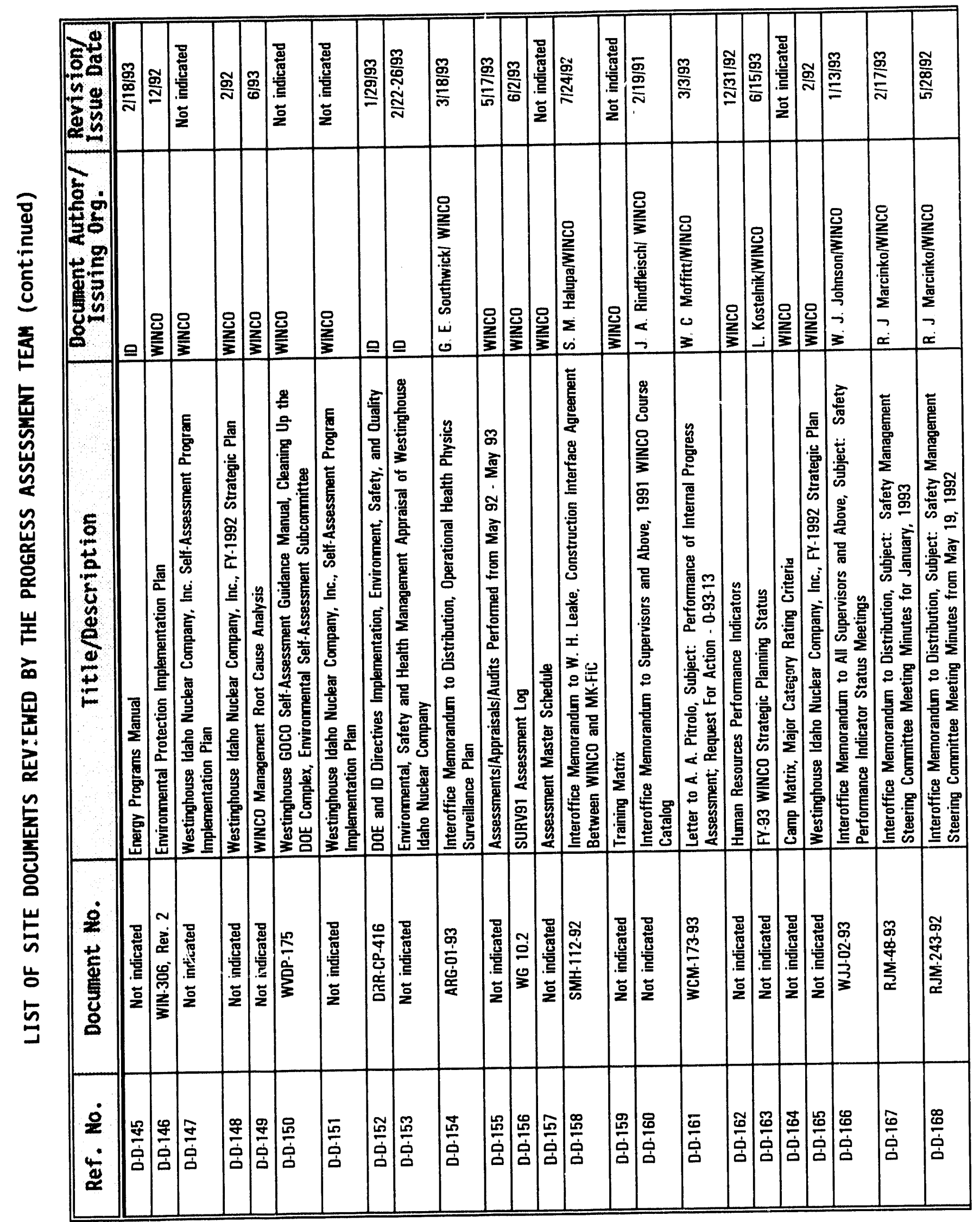




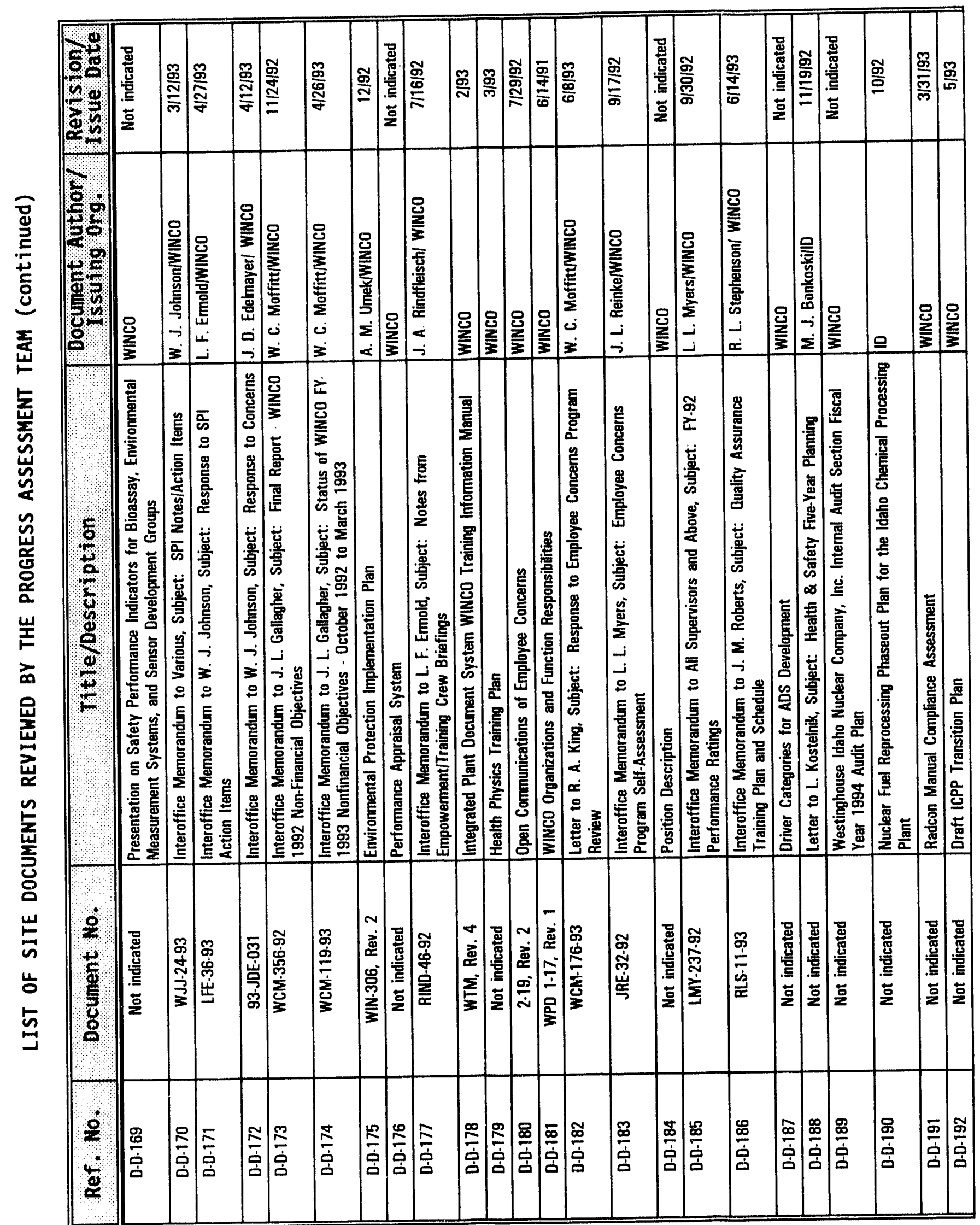




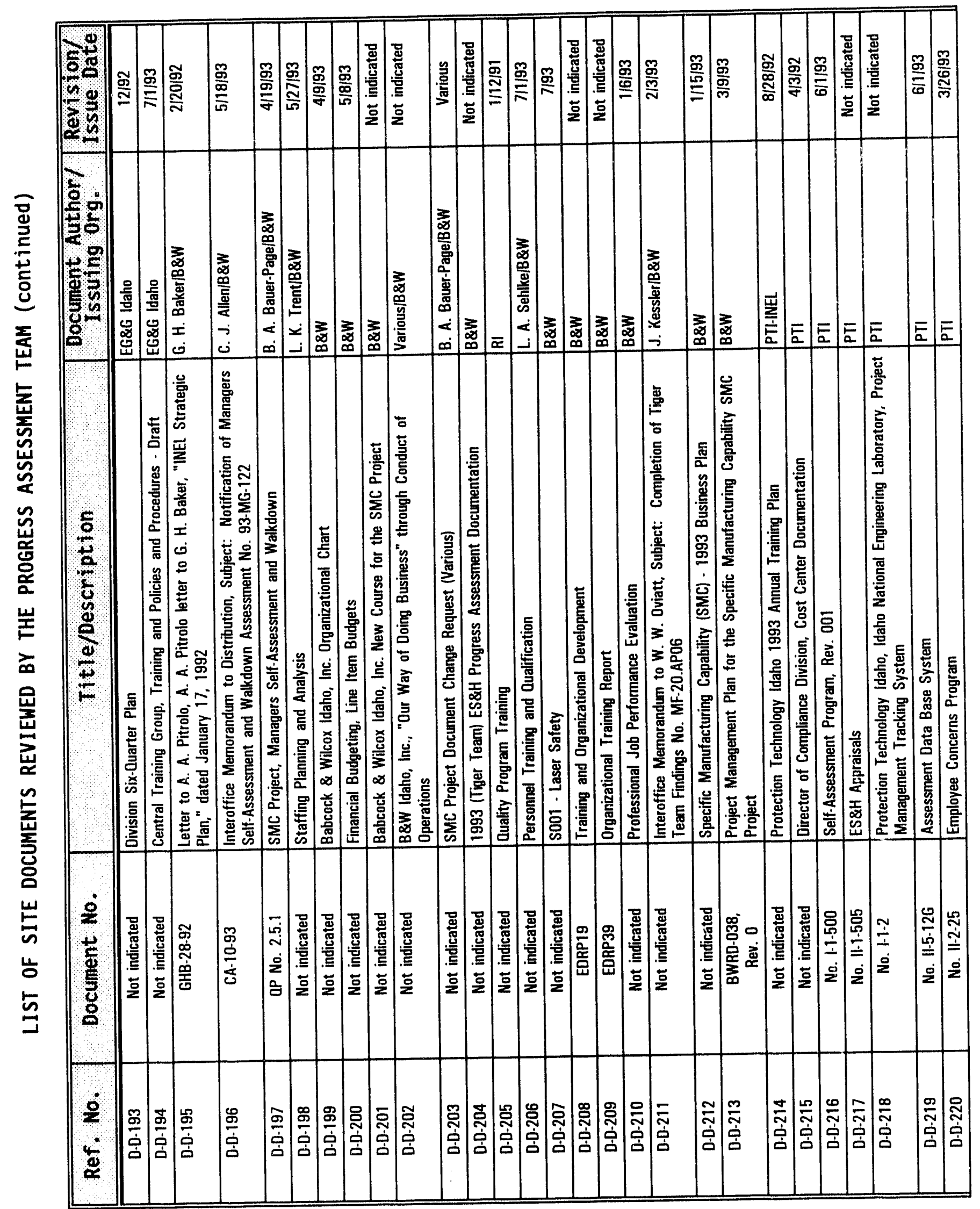




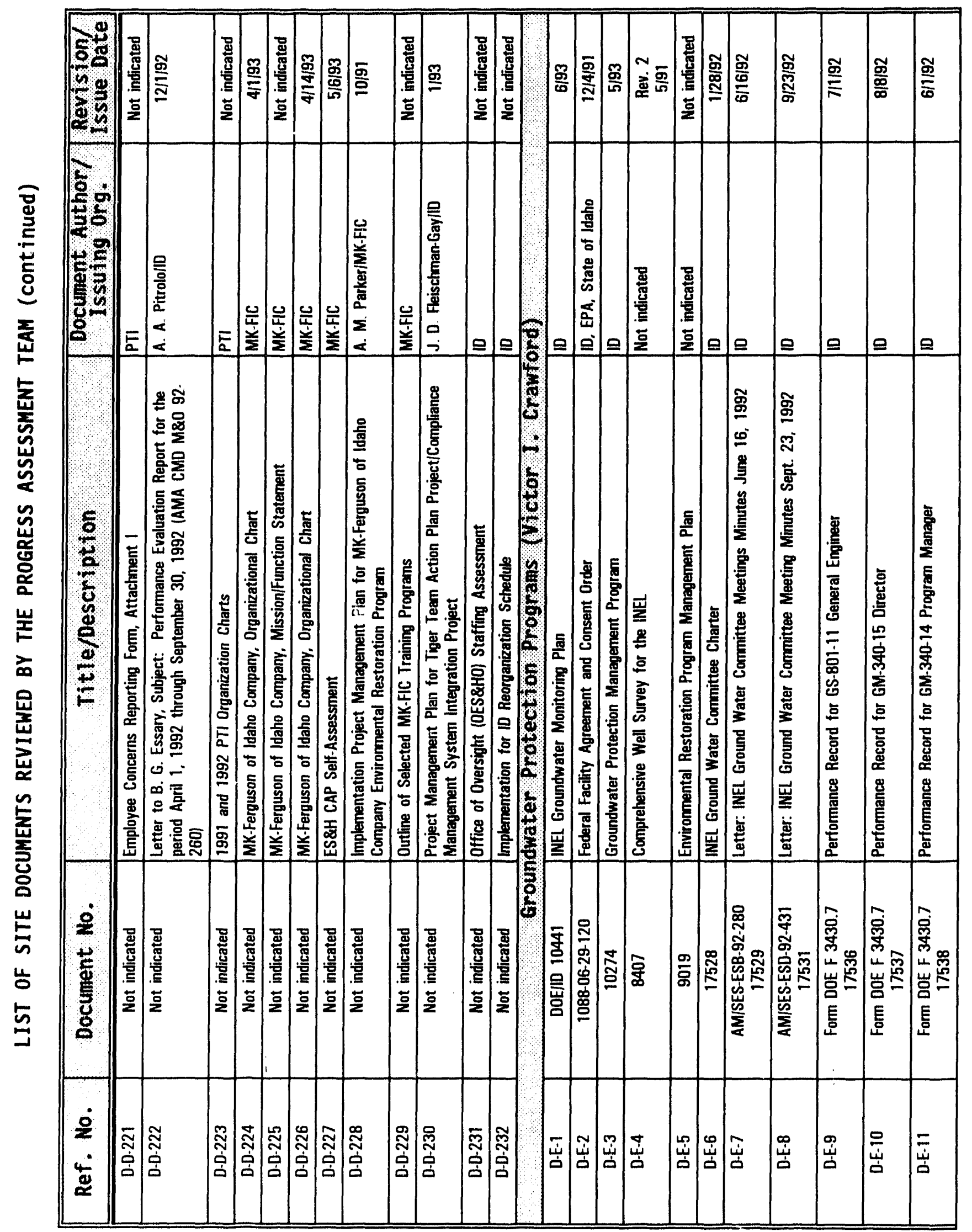




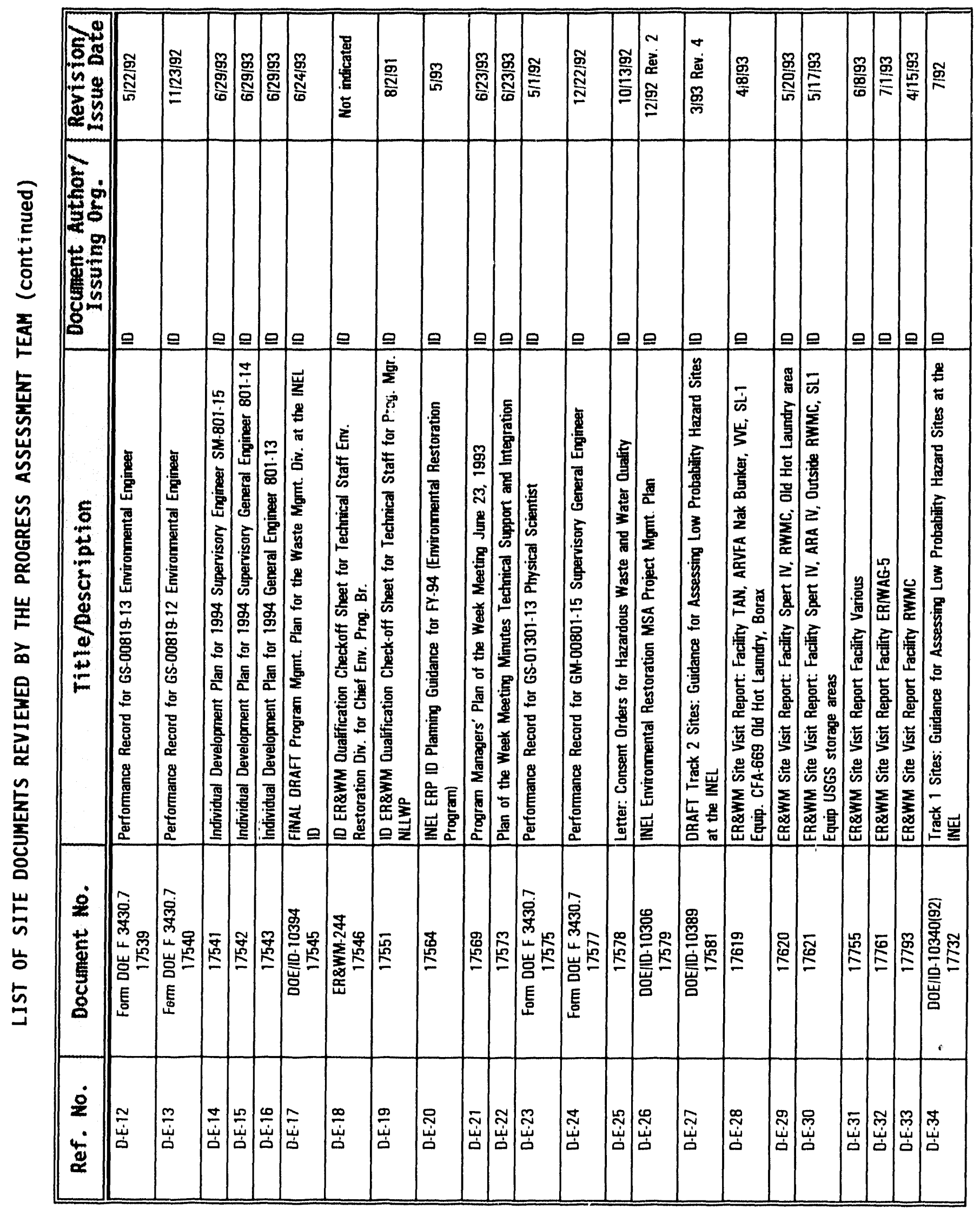




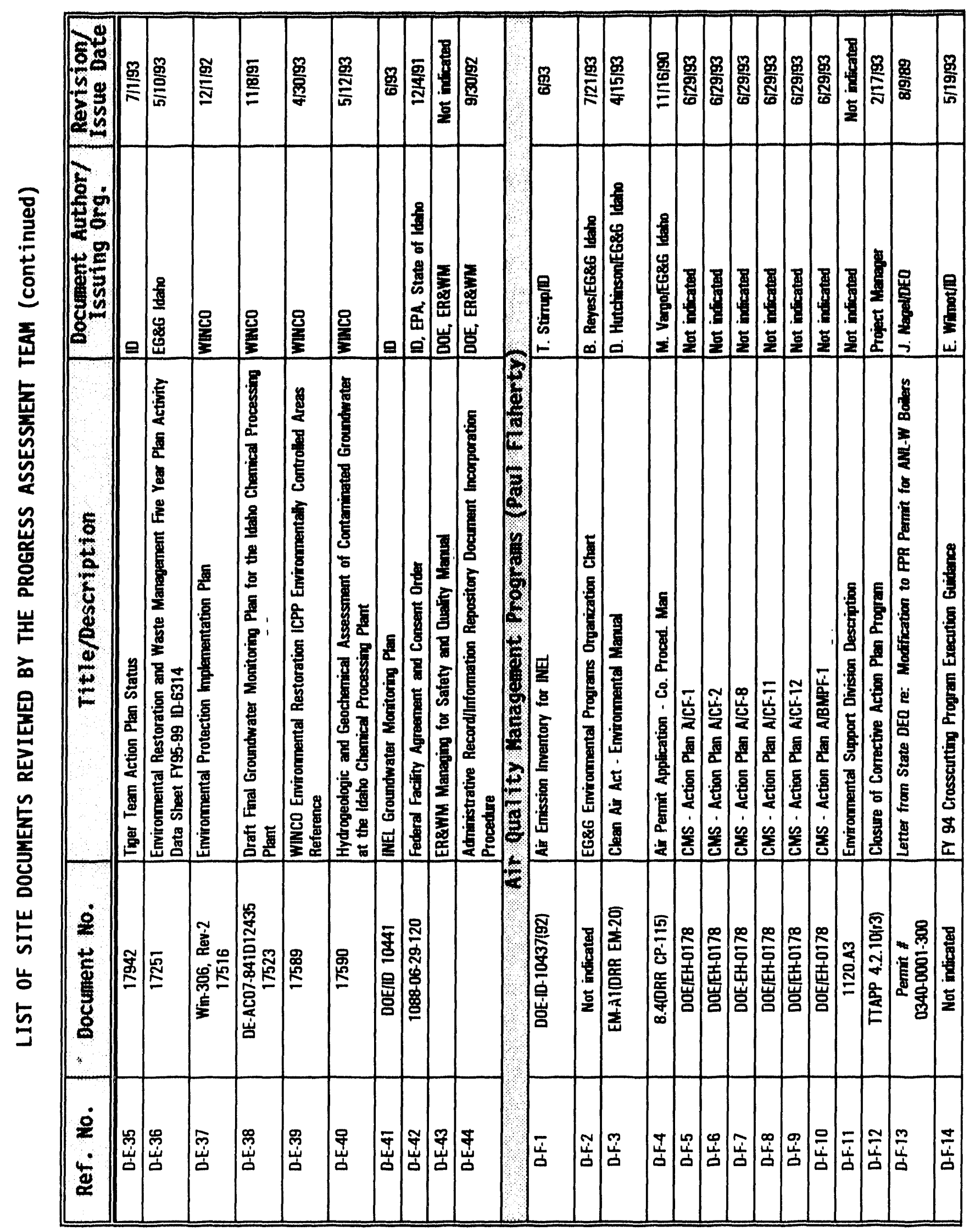




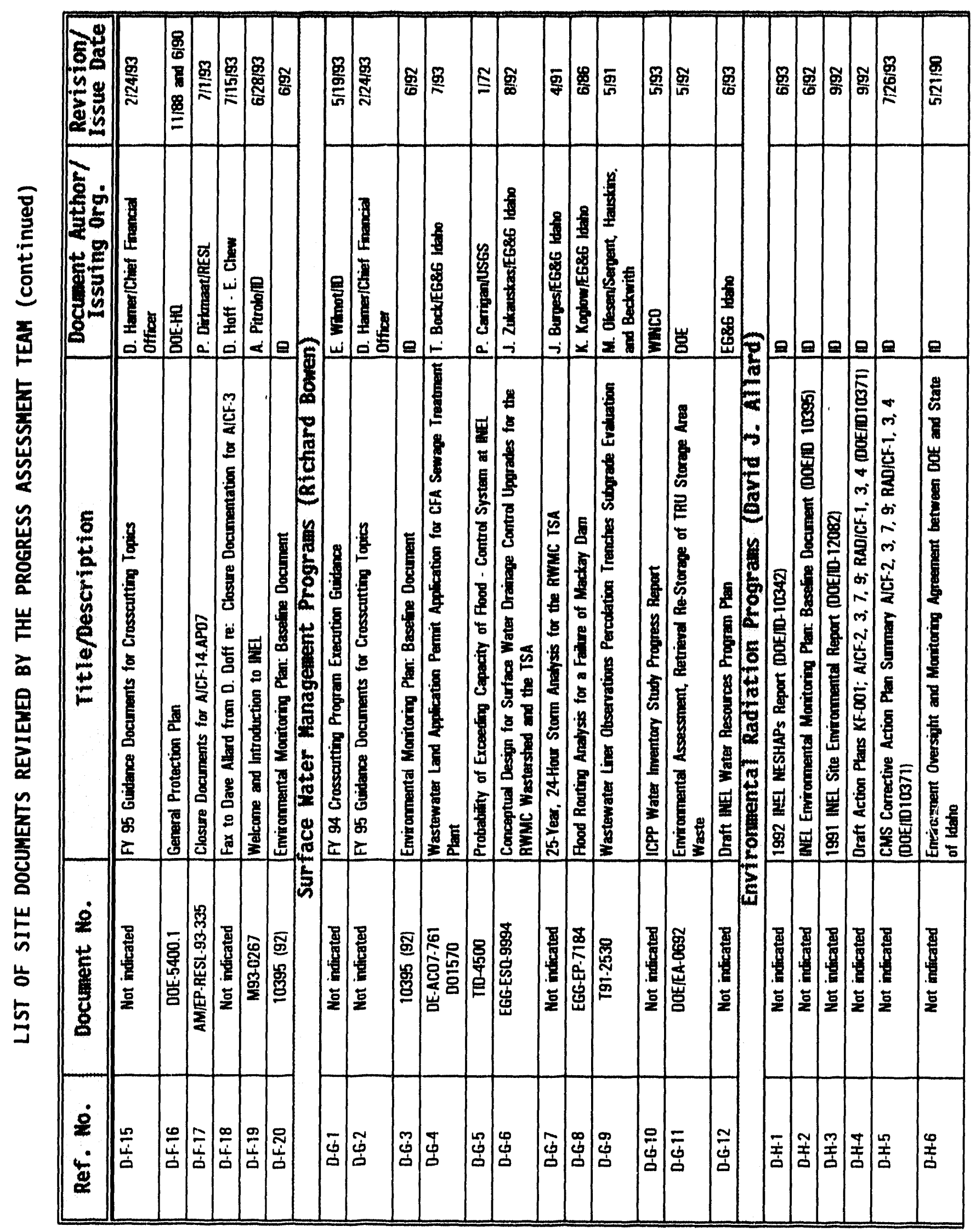




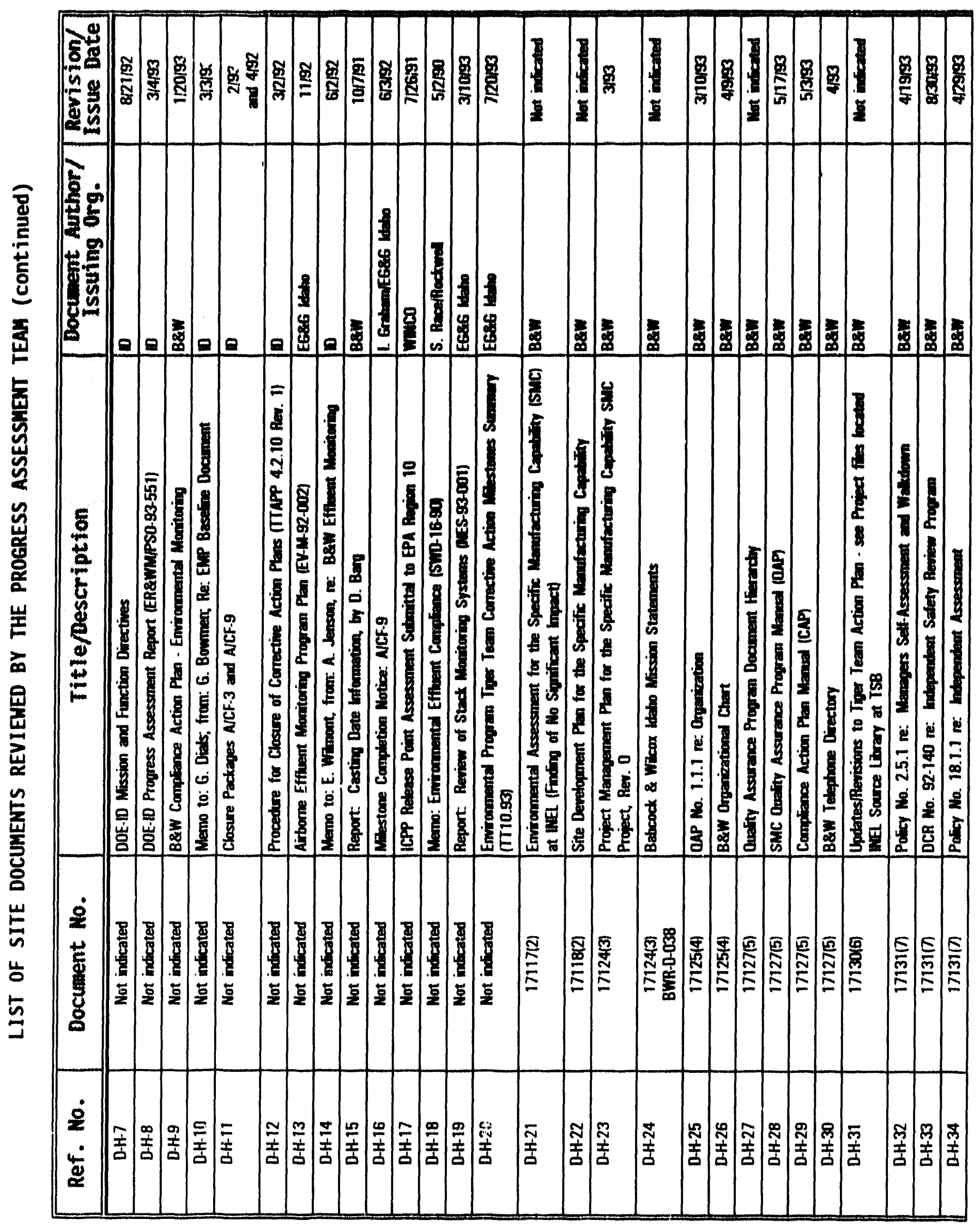




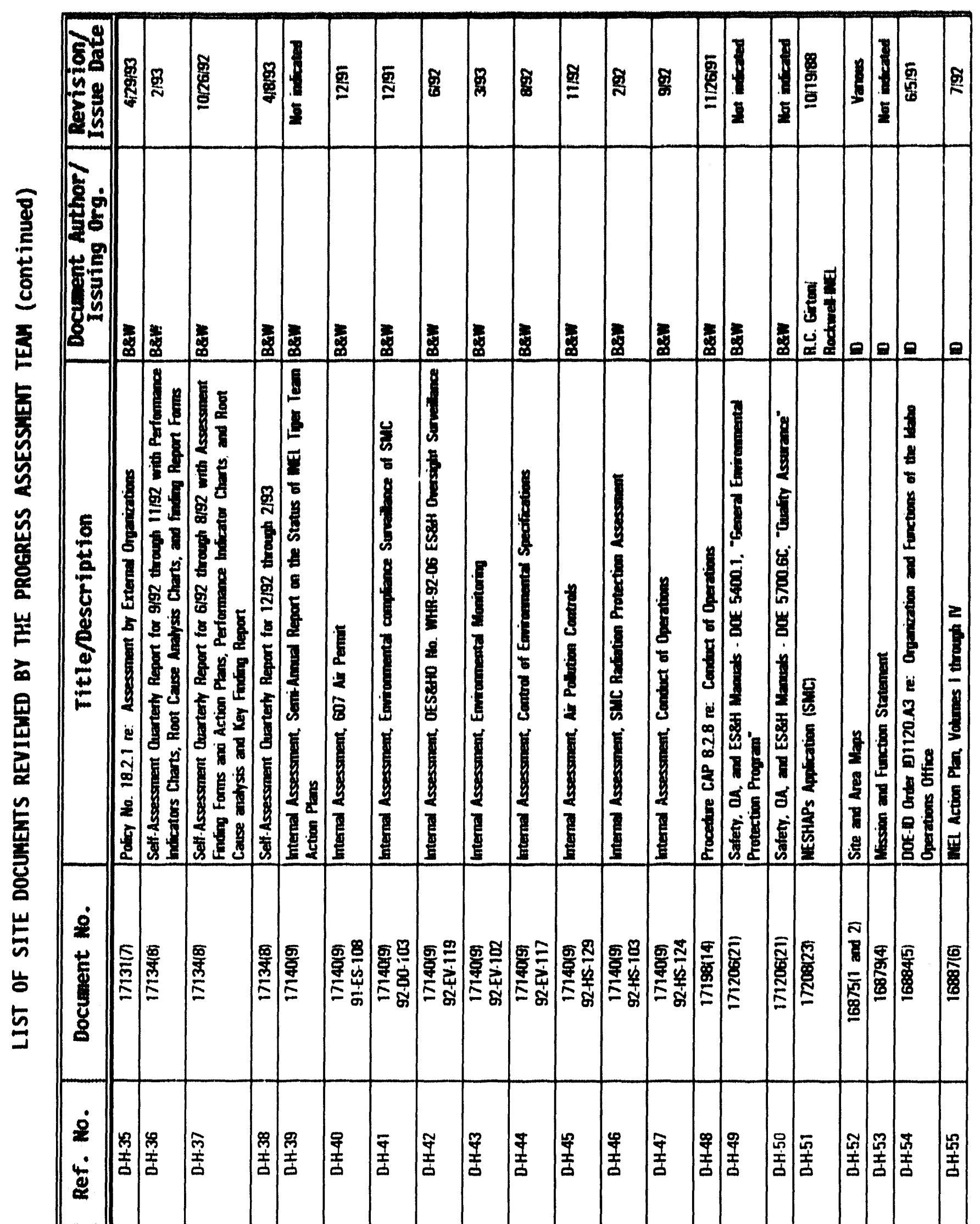




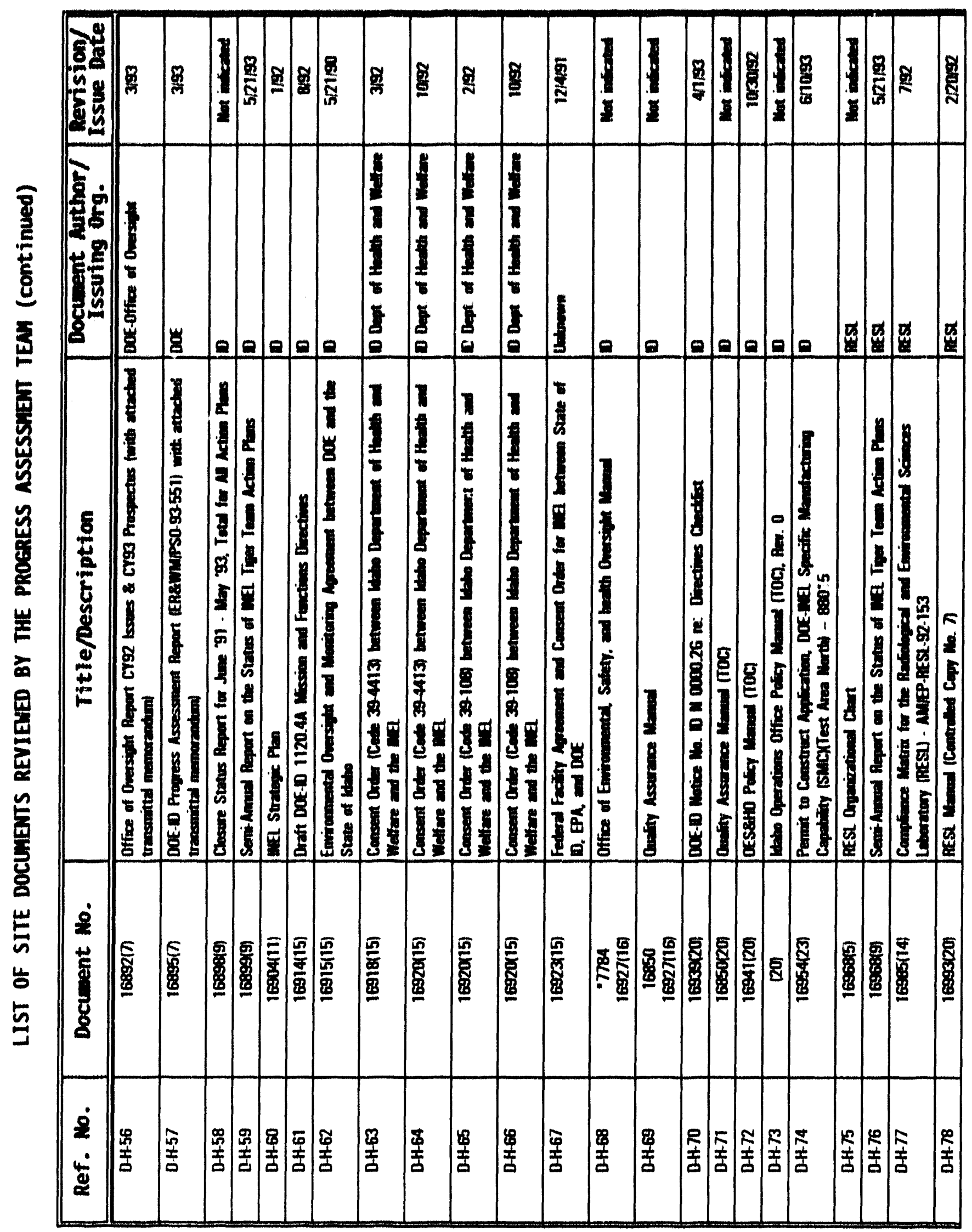




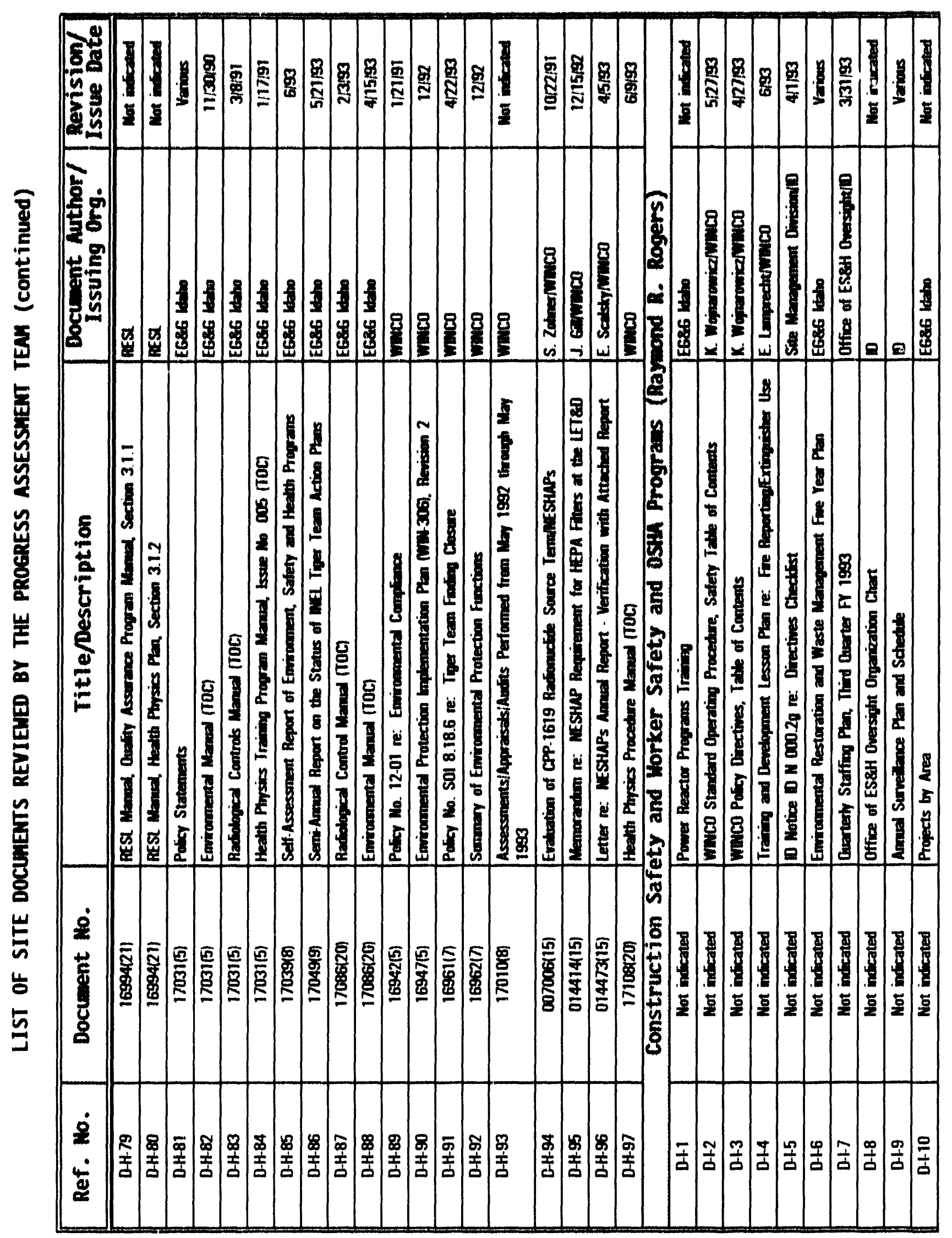




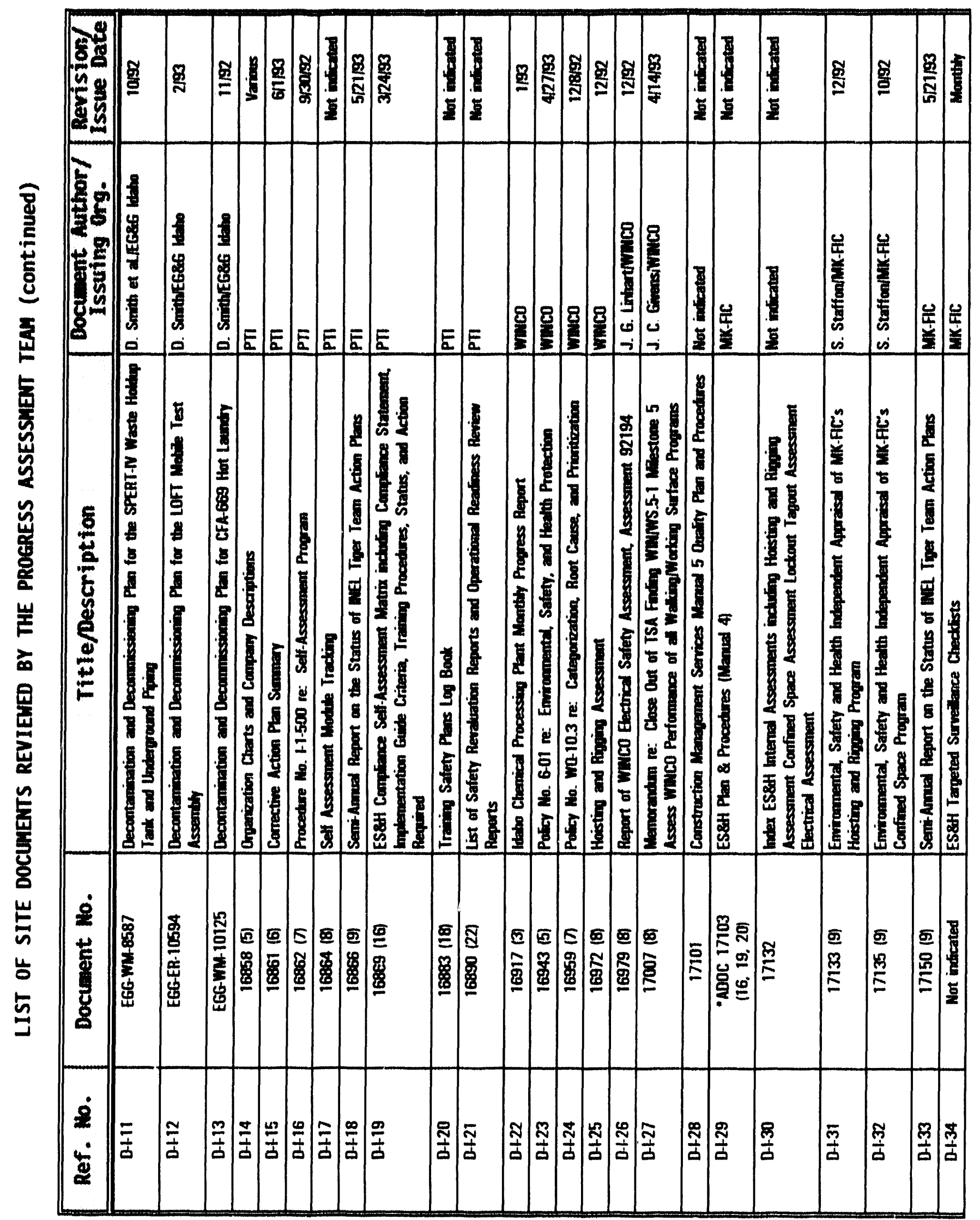




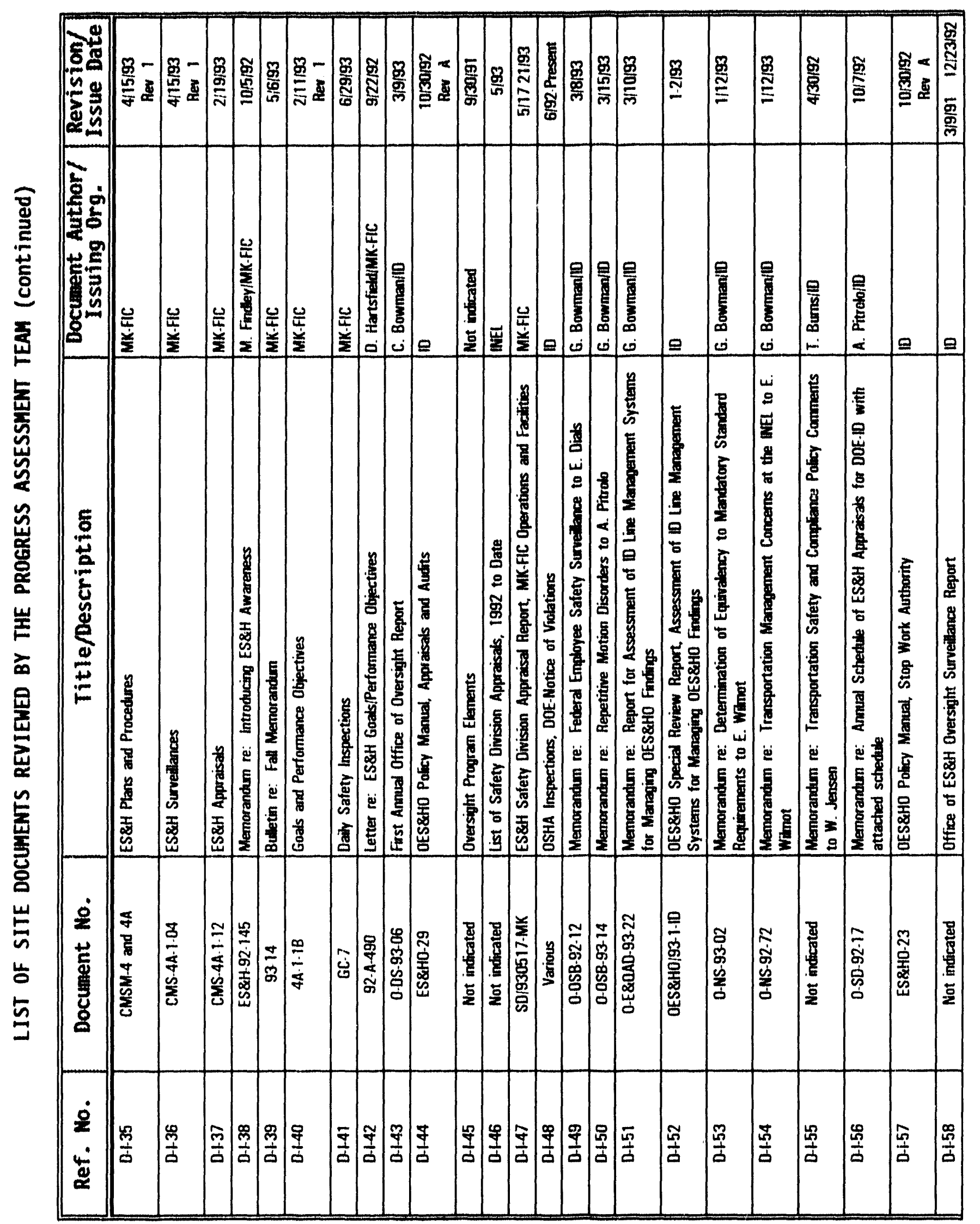




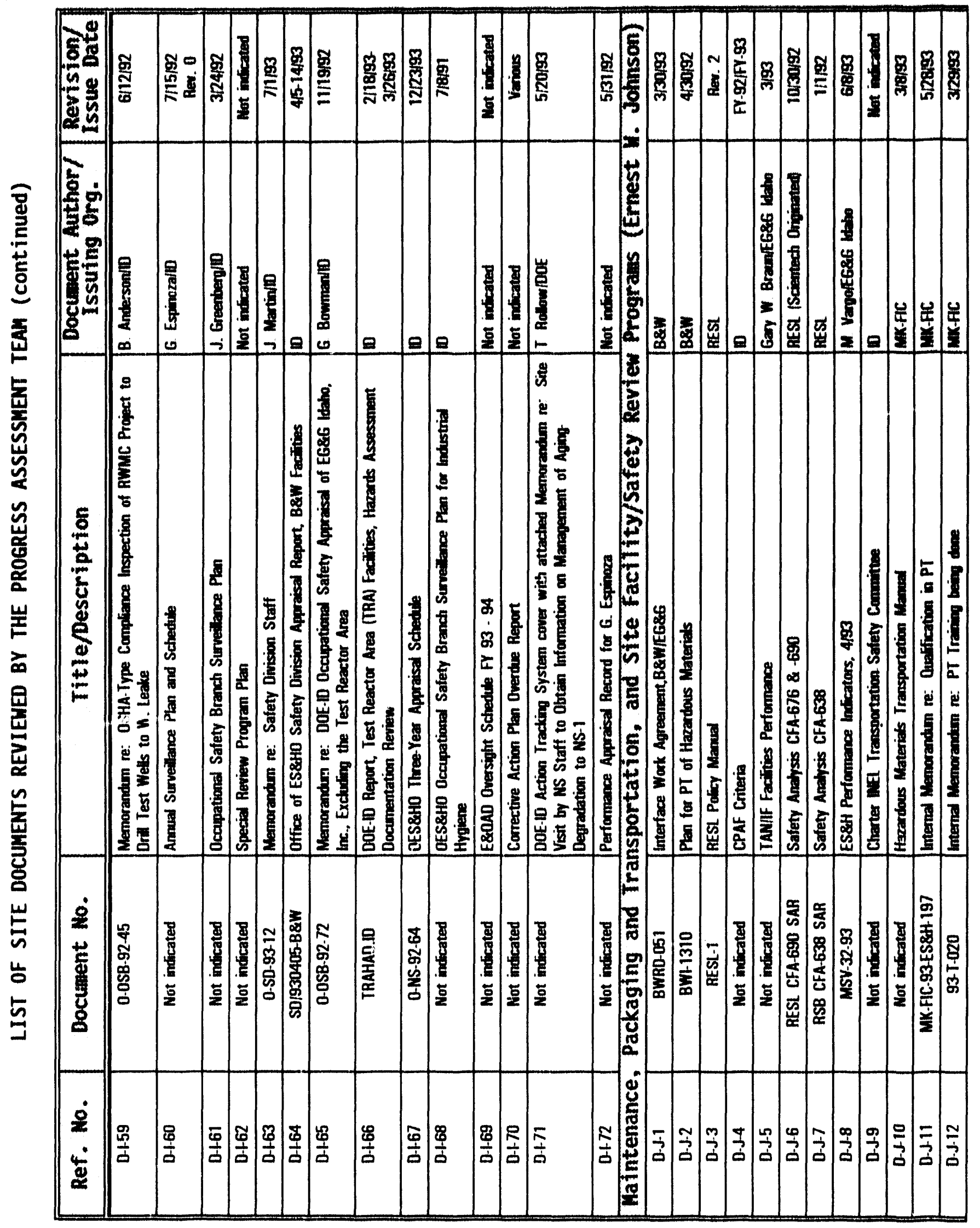




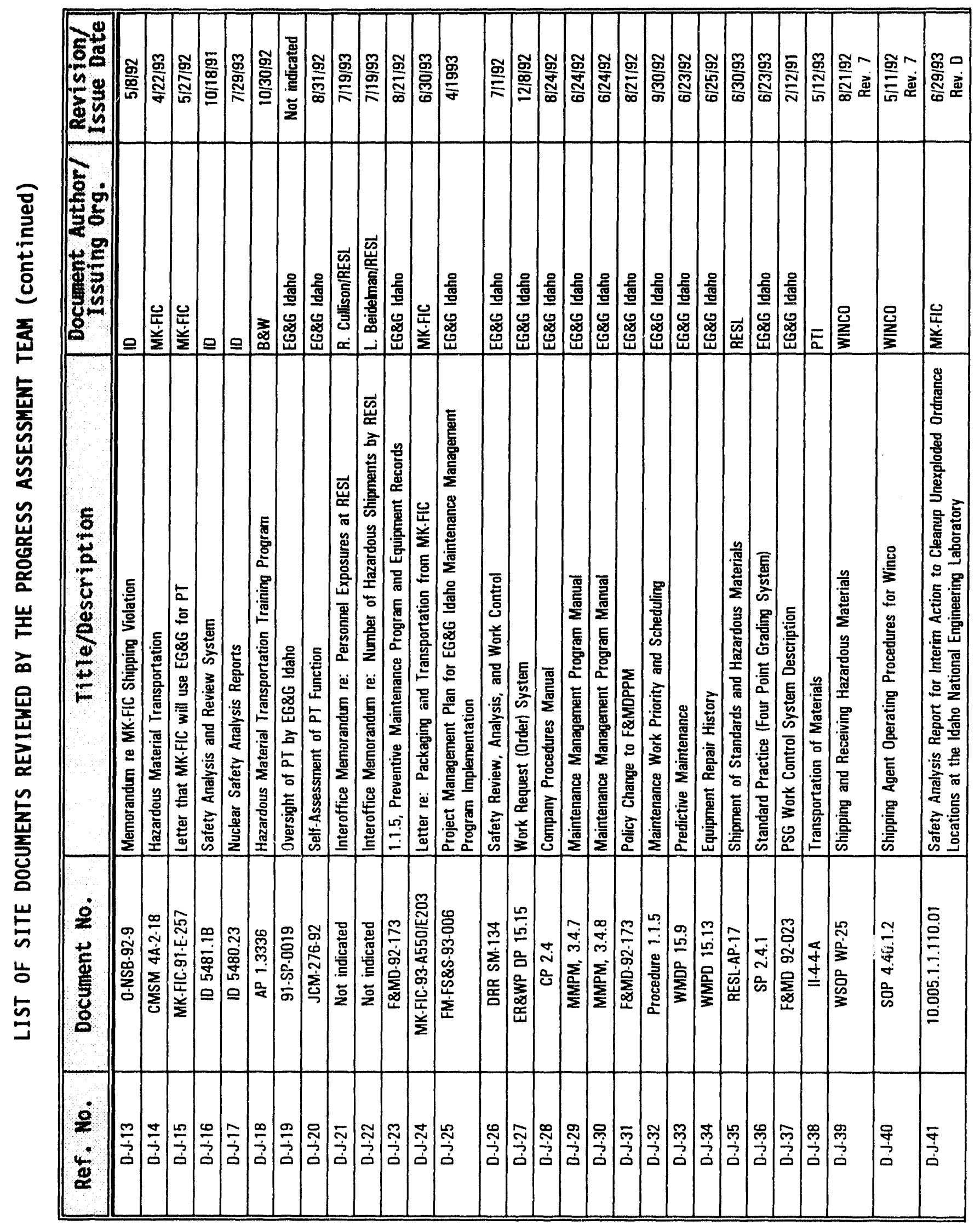




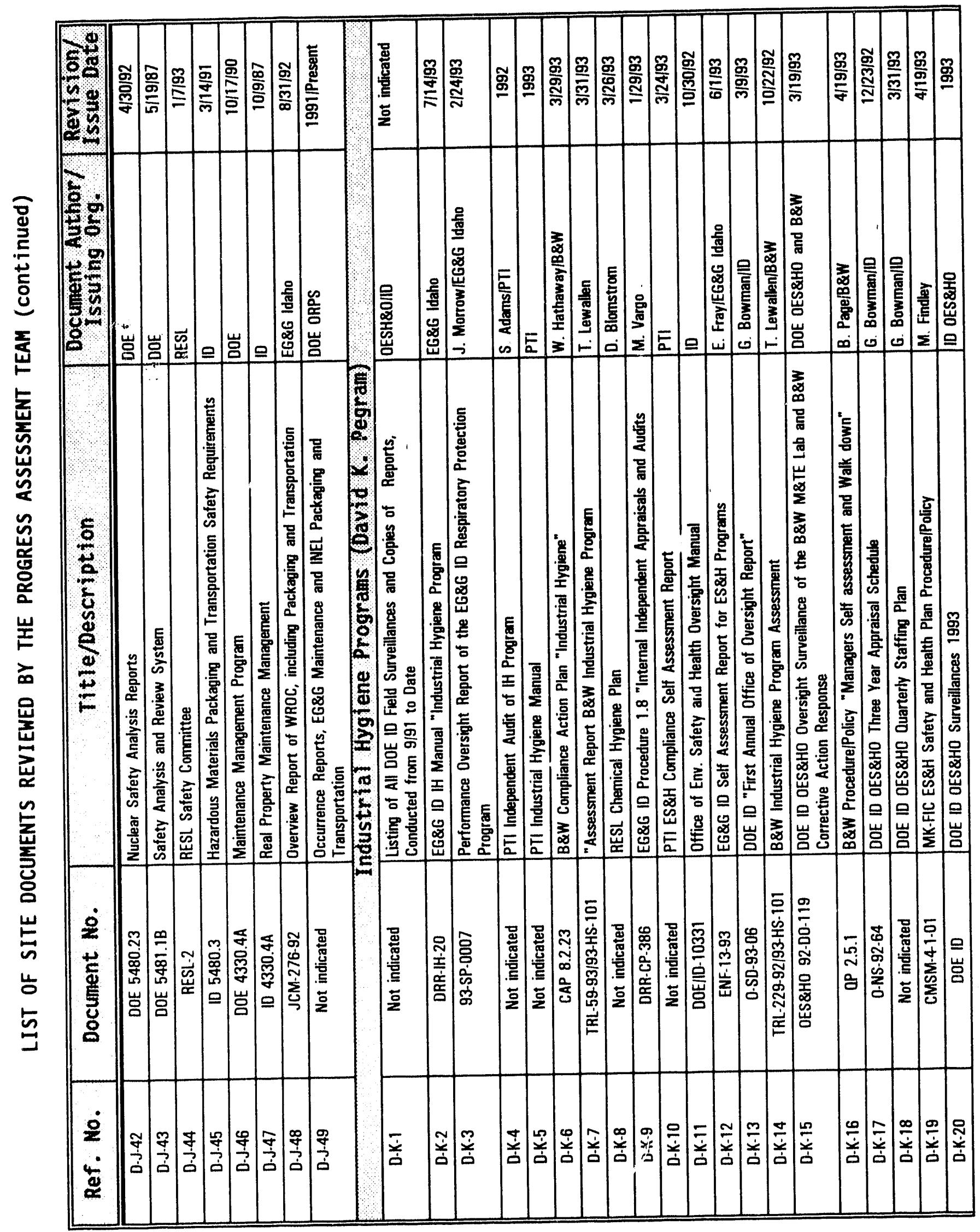




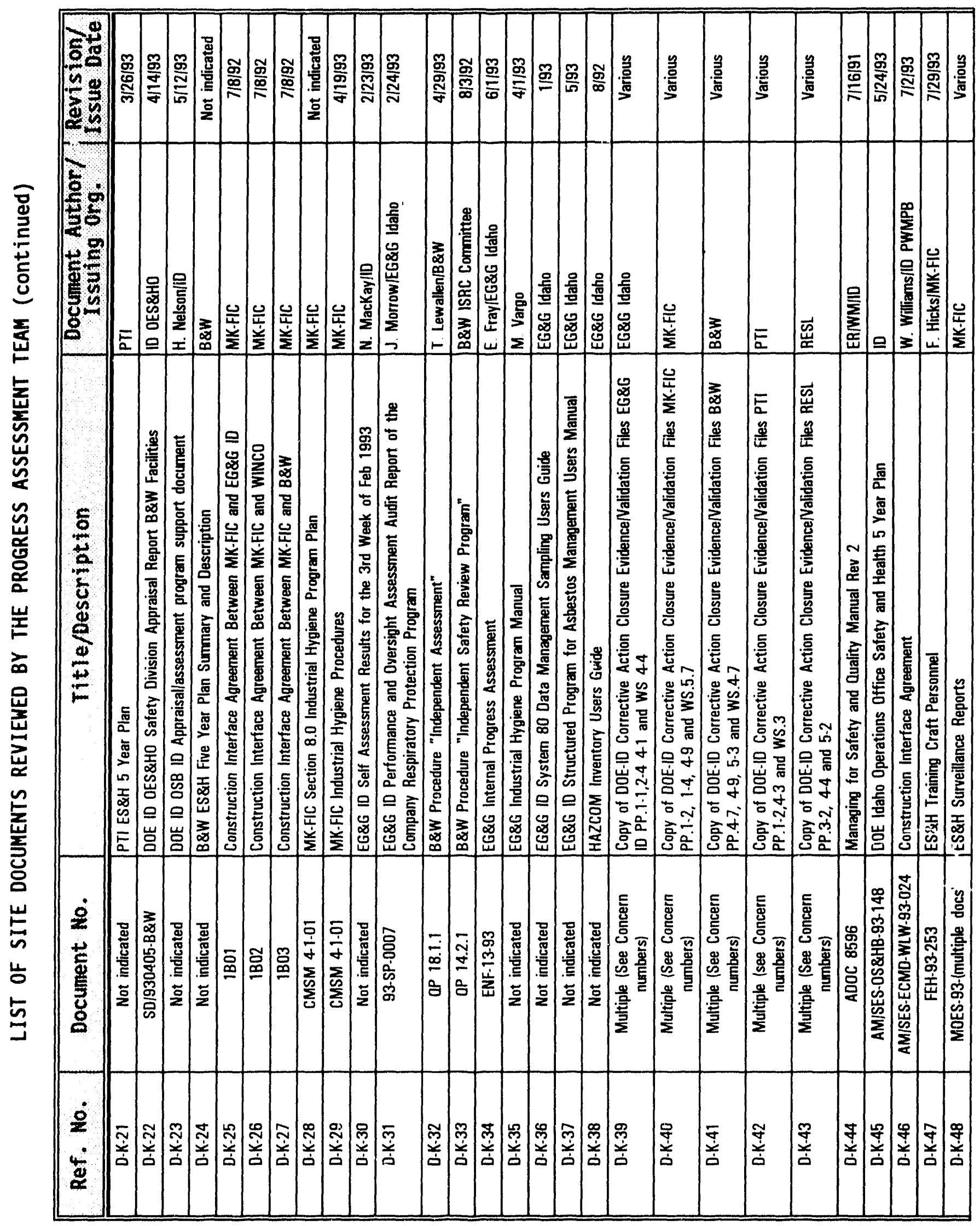




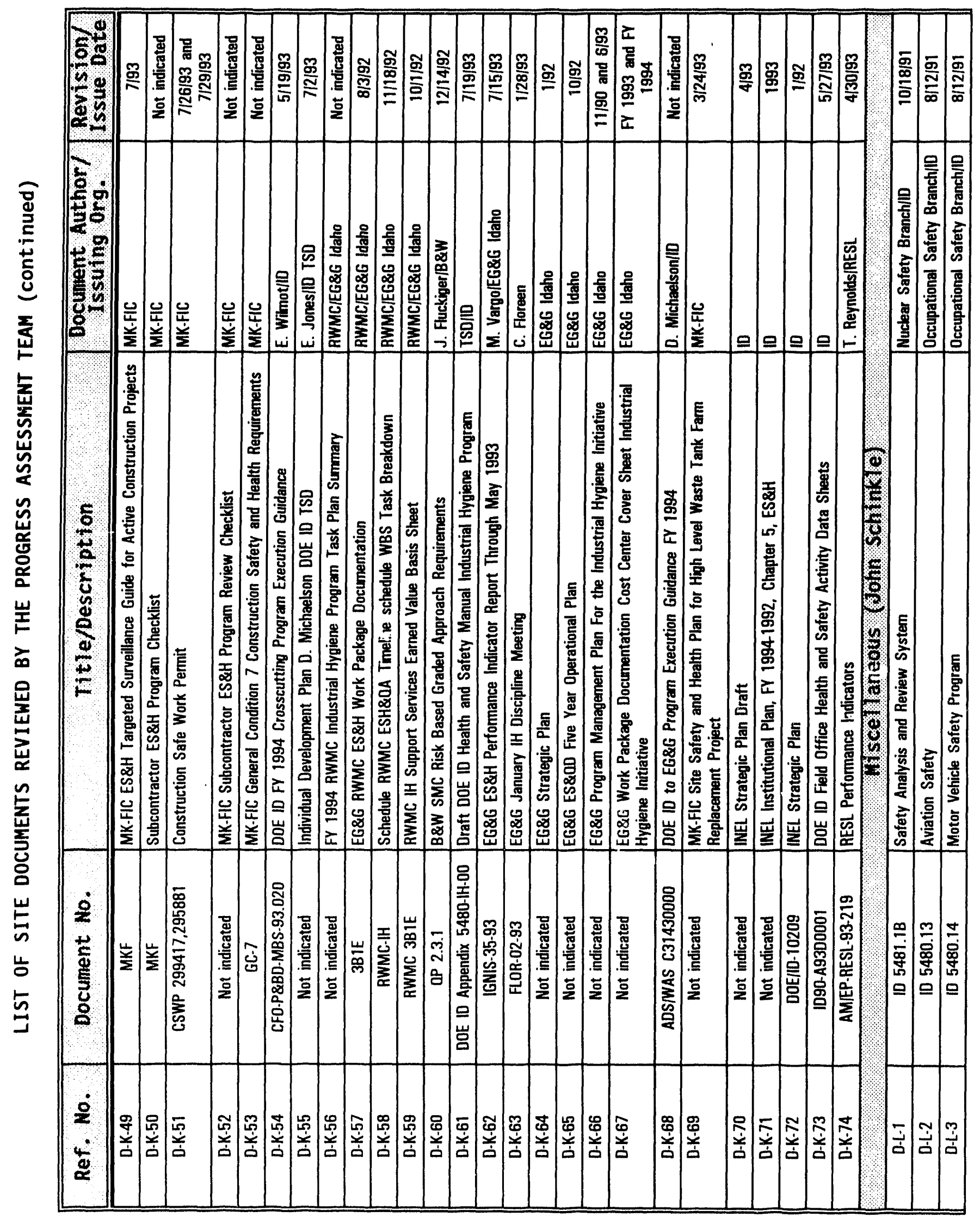




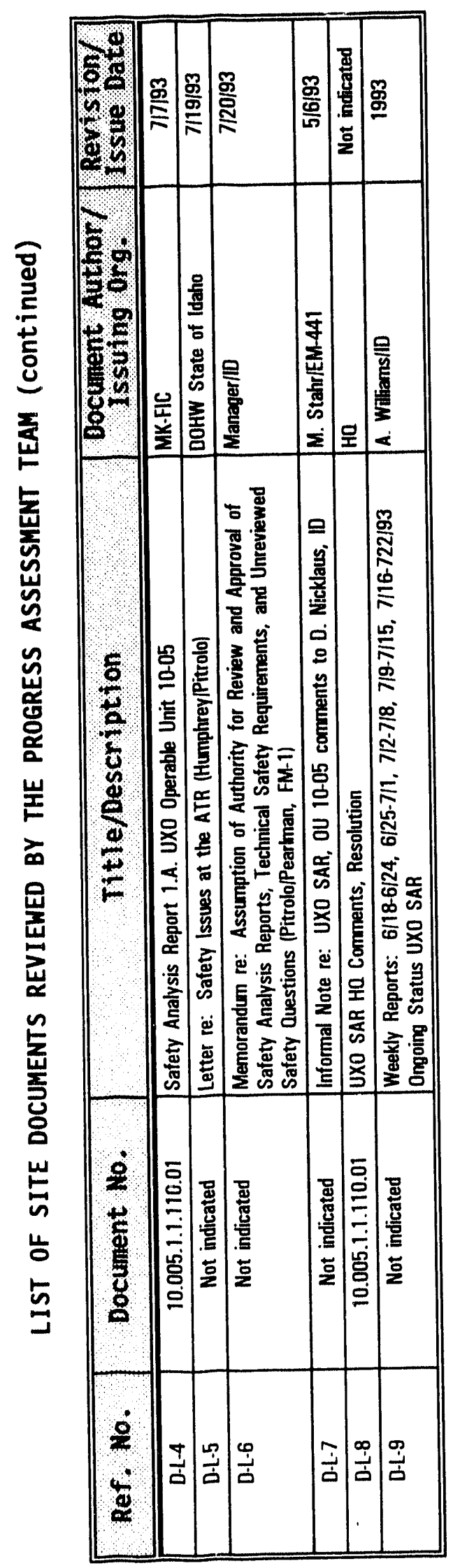


Appendix $\mathrm{H}$

List of Acronyms 


\section{LIST OF ACRONYMS}

\begin{tabular}{||l|l||}
\hline $\begin{array}{l}\text { Acronym/ } \\
\text { Abbreviation }\end{array}$ & \\
\hline AM & Assistant Manager \\
\hline AMA & Assistant Manager for Administration \\
\hline ATP & Airline Transport Pilot \\
\hline B\&W & Babcock and Wilcox Idaho \\
\hline CAP & Corrective Action Plan \\
\hline CFA & Central Facility Area \\
\hline CMS & Compliance Management System \\
\hline CPAF & Cost Plus Award Fee \\
\hline CY & Calendar Year \\
\hline DOE & Department of Energy \\
\hline EG\&G Idaho & EG\&G Idaho, Inc. \\
\hline EH & $\begin{array}{l}\text { Office of the Assistant Secretary for Environment, Safety } \\
\text { and Health }\end{array}$ \\
\hline EM & Office of Environmental Restoration and Waste Management \\
\hline EMP & Environmental Monitoring Plan \\
\hline EP & Energy Programs \\
\hline EPA & U.S. Environmental Protection Agency \\
\hline ES\&H & Environment, Safety and Health \\
\hline ES\&Q & Environment, Safety and Quality \\
\hline ESD & Environmental Support Division \\
\hline FR & Facility Representative \\
\hline FY & Fiscal Year \\
\hline HRM & Human Resource Management \\
\hline ICPP & Idaho Chemical Processing Plant \\
\hline ID & Department of Energy Operations Office, Idaho \\
\hline IDAQB & Idaho Air Quality Board \\
\hline IDPS & Individual Development Plans \\
\hline INEL & Idaho National Engineering Laboratory \\
\hline$M \& O$ & Management and Operations \\
\hline MK-FIC & MK-Ferguson of Idaho Co. \\
\hline
\end{tabular}




\section{LIST OF ACRONYMS (Continued)}

\begin{tabular}{||l|l|}
\hline $\begin{array}{l}\text { Acronym/ } \\
\text { Abbreviation }\end{array}$ & \\
\hline NE & Office of Nuclear Energy \\
\hline NESHAPS & National Emission Standards for Hazardous Air Polilutants \\
\hline NRF & Naval Reactor Factlity \\
\hline NS & Office of Nuclear Safety \\
\hline OES\&HO & Office of Environmental Safety and Health Oversight \\
\hline ORE & Operational Readiness Evaluation \\
\hline OSHA & Occupational Safety and Health Act \\
\hline PSO & Program Secretarial Officer \\
\hline PTI & Protection Technology of Idaho, Inc. \\
\hline QA & Quality Assurance \\
\hline RCRA & Resource Conservation and Recovery Act \\
\hline RESL & Radiological and Environmental Sciences Laboratory \\
\hline SAR & Safety Analysis Report \\
\hline SEN & Secretary of Energy Notice \\
\hline SES & Site Engineering Support \\
\hline TAN & Test Area North \\
\hline TDB & Training and Development Branch \\
\hline TSA & Technical Safety Appraisal \\
\hline TTAPP & Tiger Team Action Plan Project \\
\hline UXO & Unexploded Ordinance \\
\hline WINCO & Westinghouse Idaho Nuclear Company \\
\hline
\end{tabular}



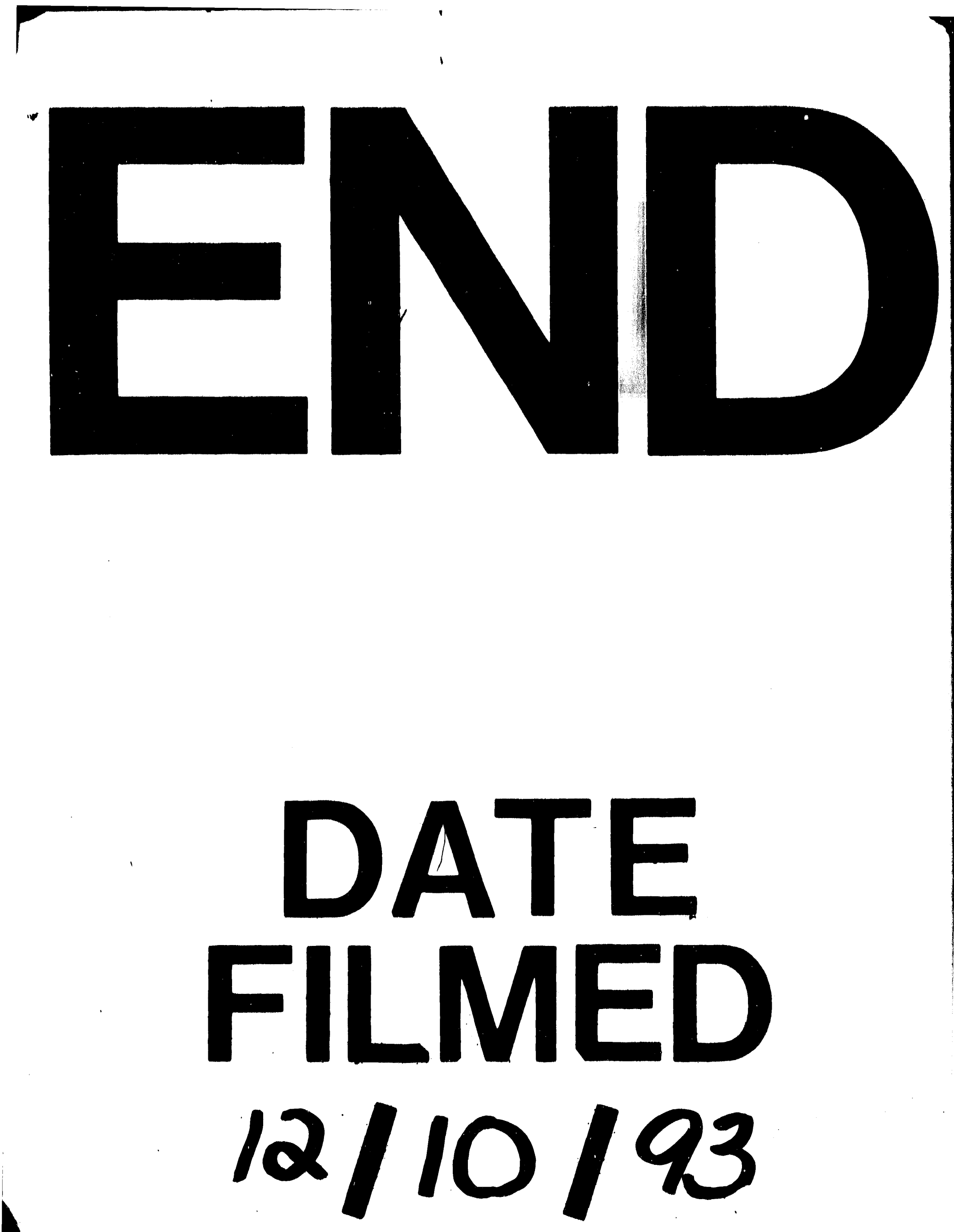


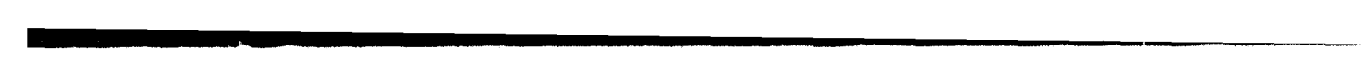

